UNIVERSIDADE DE BRASÍLIA

FACULDADE DE TECNOLOGIA

DEPARTAMENTO DE ENGENHARIA MECÂNICA

DISSERTAÇÃO DE MESTRADO EM CIÊNCIAS

MECÂNICAS

\title{
FATOR DE INTENSIDADE DE TENSÃO EM TRINCAS DE FRETTING
}

MARCELO AVELAR ANTUNES

ORIENTADOR: COSME ROBERTO MOREIRA DA SILVA

Brasília, março de 2017. 


\section{DISSERTAÇÃO DE MESTRADO EM CIÊNCIAS MECÂNICAS}

\section{FATOR DE INTENSIDADE DE TENSÃO EM TRINCAS DE FRETTING}

\section{MARCELO AVELAR ANTUNES}

DISSERTAÇÃO DE MESTRADO SUBMETIDA AO DEPARTAMENTO DE ENGENHARIA MECÂNICA DA FACULDADE DE TECNOLOGIA DA UNIVERSIDADE DE BRASÍLIA COMO PARTE DOS REQUISITOS PARA A OBTENÇÃO DO GRAU DE MESTRE.

APROVADA POR:

Prof. Cosme Roberto Moreira da Silva, PhD.

(Orientador)

Prof. Jorge Luiz de Almeida Ferreira, DSc.

(Examinador Interno)

Prof. Antonio Carlos de Oliveira Miranda, DSc.

(Examinador Externo)

PUBLICAÇÃO ENM.DM - 254/2017

Brasília, março de 2017. 


\section{FICHA CATALOGRÁFICA}

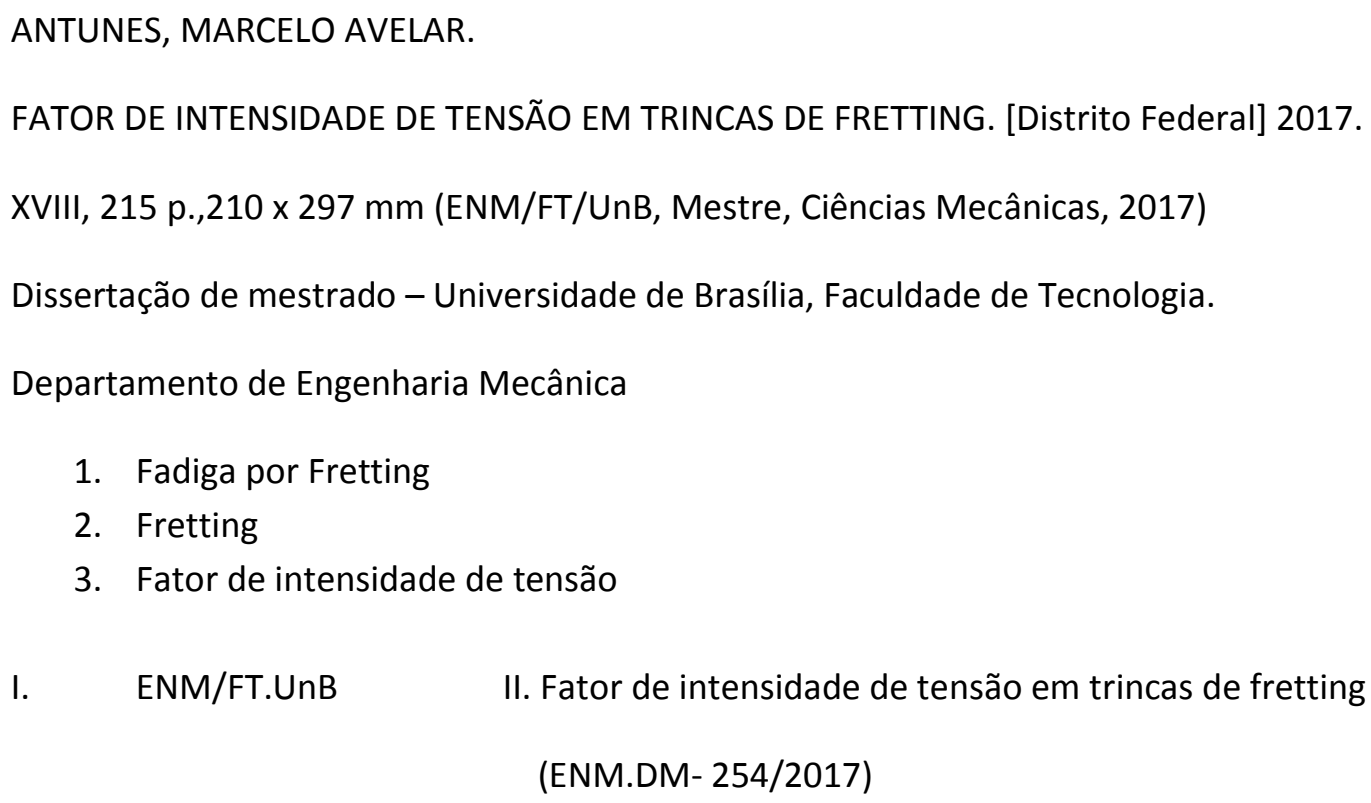

1. Fadiga por Fretting

2. Fretting

3. Fator de intensidade de tensão

I. ENM/FT.UnB II. Fator de intensidade de tensão em trincas de fretting (ENM.DM- 254/2017)

\section{REFÊNCIA BIBLIOGRÁFICA}

ANTUNES, M. A. (2017). Fator de intensidade de tensão em trincas de fretting. Dissertação de mestrado, Departamento de Engenharia Mecânica, Universidade de Brasília, Brasília, DF. 215 p.

\section{CESSÃO DE DIREITOS}

AUTOR: Marcelo Avelar Antunes

\section{TÍTULO: FATOR DE INTENSIDADE DE TENSÃO EM TRINCAS DE FRETTING}

\section{GRAU: Mestre $\quad$ ANO: 2017}

É concedida à Universidade de Brasília permissão para reproduzir cópias desta dissertação de mestrado e para emprestar ou vender tais cópias somente para propósitos acadêmicos e científicos. O autor reserva outros direitos de publicação e nenhuma parte desta dissertação de mestrado pode ser reproduzida sem autorização por escrito do autor.

Marcelo Avelar Antunes

Correio eletrônico: Marcelo.avelar.antunes@gmail.com 


\section{AGRADECIMENTOS}

Agradeço aos professores Cosme e Jorge pela oportunidade concedida,

ao Professor Miranda, pelo apoio e pela atenção despendida,

ao colega Eduardo, cuja ajuda foi primordial,

à Alline, pela ajuda e pelo companheirismo e

ao Professor Bergmann e aos membros do Conselho de Pós-Graduação, pela imprescindível contribuição à Universidade de Brasília,

Marcelo Avelar Antunes 


\section{RESUMO}

Este trabalho propõe soluções para fadiga por fretting utilizando fatores concentradores de tensão modificados $K_{p}$ para ligas de aço, alumínio e titânio, os quais são utilizados para se obter fatores de intensidade de tensão na análise com base na Mecânica da Fratura Baseada em Deformação. Primeiramente, um modelo numérico bidimensional com consideração de material elástico, isotrópico e homogêneo foi criado através do método dos elementos finitos. Assumiu-se que a nucleação da trinca ocorreu no ponto de máxima tensão normal na direção da carga remota de fadiga, seguindo uma trajetória retilínea sob tal ponto, da qual se extraíram os campos de tensões atuantes. Uma grande quantidade de campos de tensão foi gerada modificando-se, um de cada vez, parâmetros importantes no estudo de fretting, a saber: o coeficiente de atrito, a carga remota de fadiga, o raio do pad e o material. Todos os modelos propostos seguiram o regime de deslizamento parcial, com bons resultados sido obtidos quando comparados com as soluções analíticas. Através de funções de peso, fatores de intensidade de tensão elásticos sob o modo I foram obtidos, os quais foram então usados para se computar $K_{p}$. Uma análise do comportamento de $K_{p}$ é então apresentada, seguida de sugestões de seu uso para se levarem em conta efeitos de plasticidade, conhecidamente presentes em no fenômeno de fretting.

\section{ABSTRACT}

This study presents modified stress concentration factor $K_{p}$ solutions for steel, aluminum and titanium materials under fretting fatigue conditions. $K_{p}$ solutions are used to obtain stress intensity factors in strain-base fracture mechanic analysis. At first, 2D numerical models with elastic, isotropic and homogeneous materials were created using finite element method. It was assumed that under the maximum tangential load in the bulk stress direction, a straight-line crack path was formed and all stress fields in such path were extracted. A vast number of stress fields were obtained by changing - one at a time - important fretting parameters, namely: coefficient of friction, bulk stress intensity, pad radius and material. All configurations respected a partial slip contact condition and the results obtained showed good agreement with the ones obtained analytically. Weight functions were used to obtain stress intensity factors under mode I, which were then used to compute $K_{p}$. An analysis of $K_{p}$ behavior is then presented and 
discussed, followed by suggestions of its use taking into account plasticity, knowingly involved in fretting fatigue. 


\section{SUMÁRIO}

1 INTRODUÇÃO

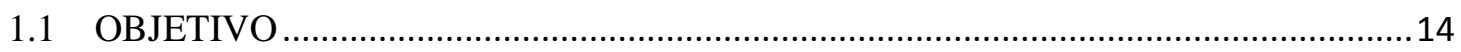

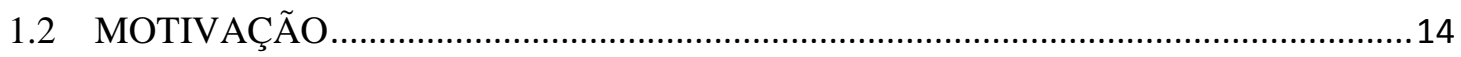

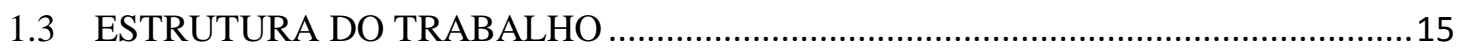

2 REVISÃO BIBLIOGRÁFICA ..................................................................................16

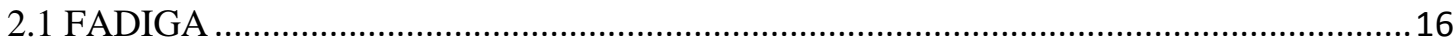

2.1.1 RESUMO HISTÓRICO ....................................................................................

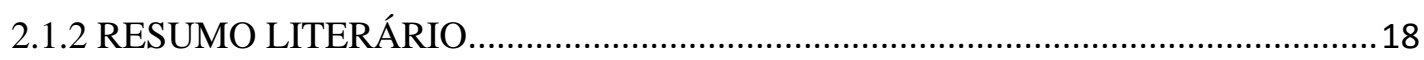

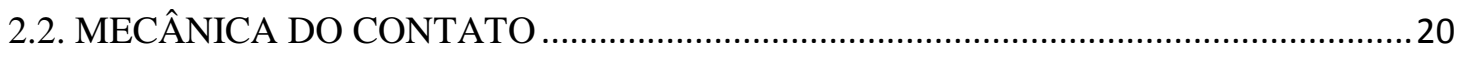

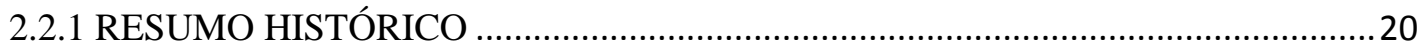

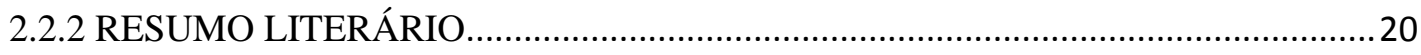

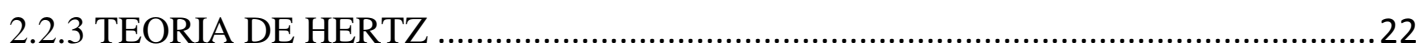

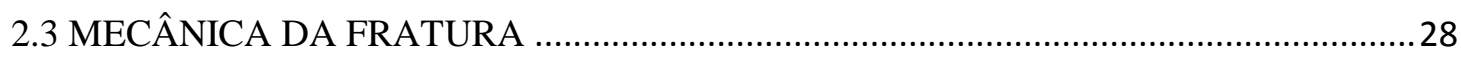

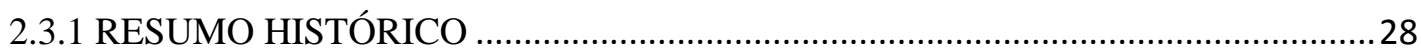

2.3.2 RESUMO LITERÁRIO........................................................................................

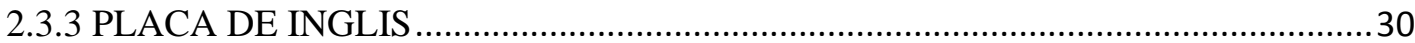

2.3.4 INSPEÇÃO E TOLERÂNCIA A DEFEITOS ……………………………………......31

2.3.5 MODOS DE FRATURA …………………………………………………….....

2.3.6 BALANÇO DE ENERGIA DE GRIFFITH ............................................................33

2.3.7 FATOR DE INTENSIDADE DE TENSÃO …………………………………….......35

2.3.8 MECÂNICA DA FRATURA BASEADA EM DEFORMAÇÃO (MFBD) ......................37

2.3.9 FUNÇÃO DE PESO .............................................................................................

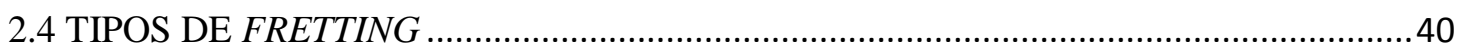

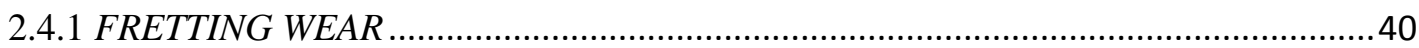

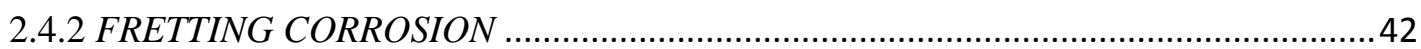

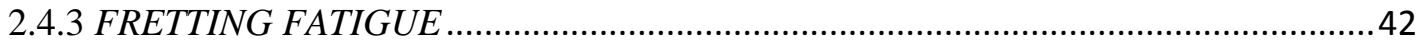

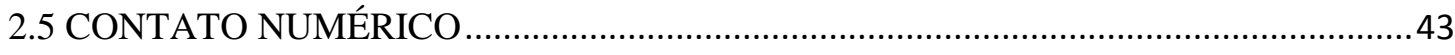

2.5.1 CONTATO NO ANSYS ……………………………………………………...4

2.5.2 FORMULAÇÃO DE CONTATO PELO MÉTODO DE LAGRANGE EXPANDIDO 49

2.5.3 REGIÃO DE PINBALL .....................................................................................

2.5.4 COMPORTAMENTOS ASSIMÉTRICO E SIMÉTRICO DO CONTATO ...............50 
2.5.5 ESTADO PLANO DE TENSÃO/DEFORMAÇÃO ................................................. 51

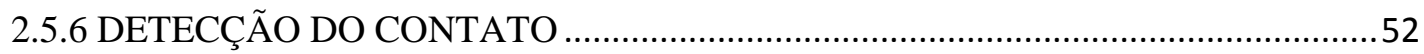

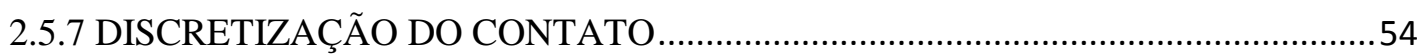

2.5.8 RESOLUÇÃO DE NÃO LINEARIDADE NO ANSYS .............................................55

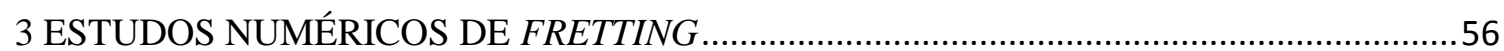

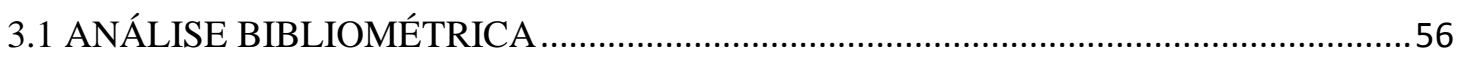

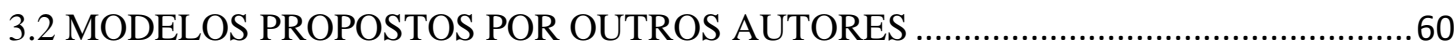

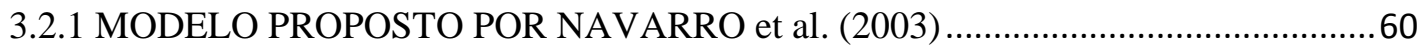

3.2.2 MODELO PROPOSTO POR DING et al. (2014).....................................................66

3.2.3 MODELO PROPOSTO POR BAIETTO et al., (2013)................................................69

3.2.4 MODELO PROPOSTO POR RAMMOHAN et al. (2012) ………………..............76

3.2.5 MODELO PROPOSTO POR PIERRES et al. (2010).................................................... 80

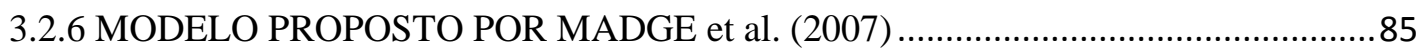

3.2.7 MODELO PROPOSTO POR KIM et al. (2011) ........................................................93

3.2.8 MODELO PROPOSTO POR BENHAMENA et al. (2012) .......................................103

3.2.9 MODELO PROPOSTO POR LUKE et al. (2016) …...............................................109

3.2.10 MODELO PROPOSTO POR LIU et al. (2014) ….................................................116

3.2.11 MODELO PROPOSTO POR NIGRO et al. (2014) ...............................................124

3.2.12 MODELO PROPOSTO POR FERJAOUI et al. (2015) ............................................129

3.2.13 MODELO PROPOSTO POR TALEMI et al. (2011)............................................138

3.2.14 MODELO PROPOSTO POR MUTOH et al. (2010) ................................................. 145

3.2.15 MODELO PROPOSTO POR GINER et al. (2011) ..................................................150

3.2.16 MODELO PROPOSTO POR LÉVESQUE et al. (2011) .........................................156

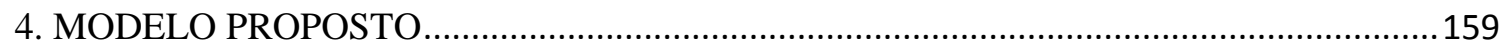

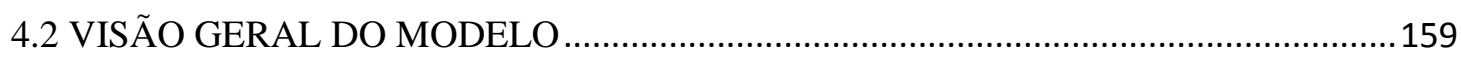

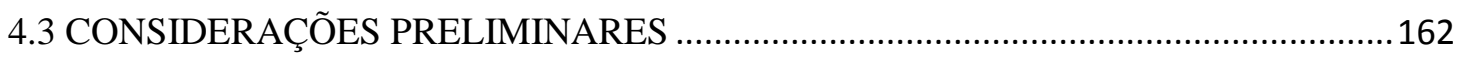

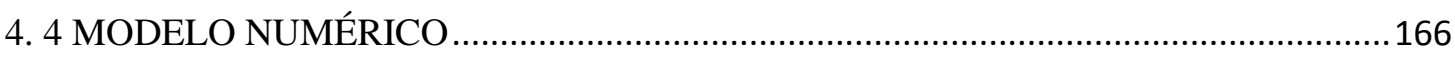

4.4.1 GEOMETRIA, CONDIÇÕES DE CONTORNO E DE CARREGAMENTO...........166

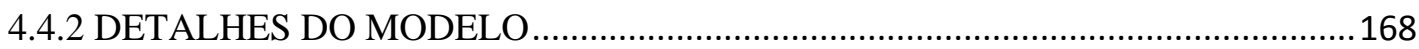

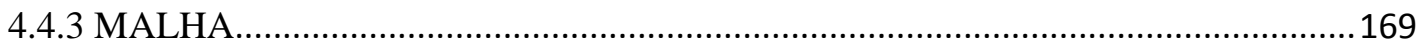

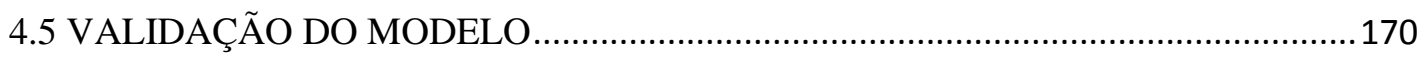

4.6 COMPORTAMENTO DOS CAMPOS DE TENSÕES...................................................172

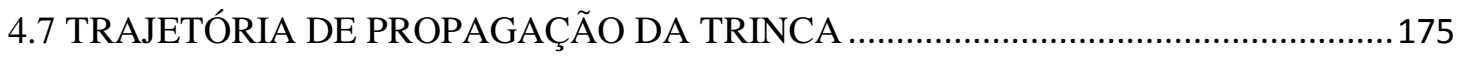

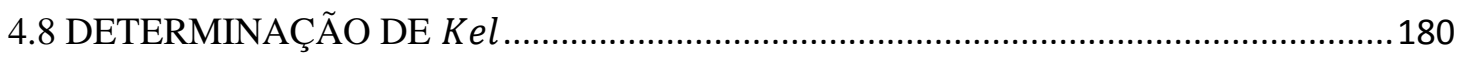




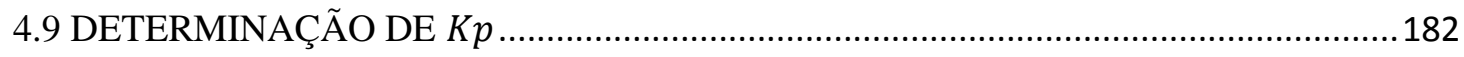

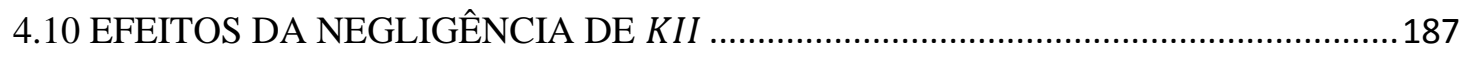

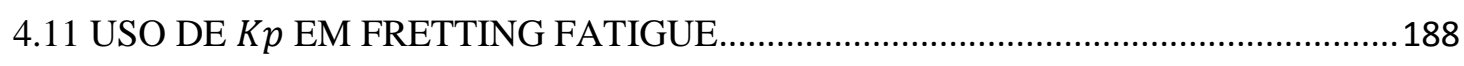

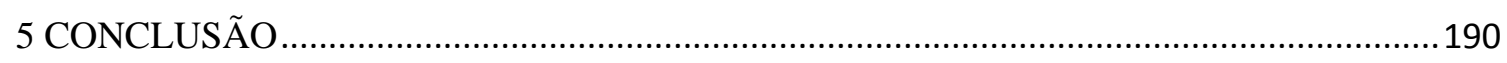

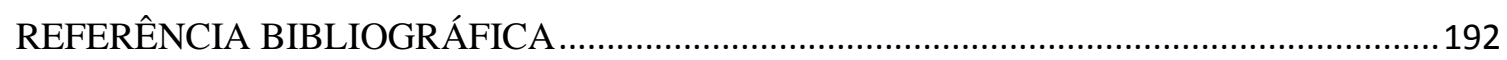




\section{LISTA DE FIGURAS}

Figura 1 - Tipos de fretting (Fonte: QI, 2013)

Figura 2 - (a) Linhas de transmissão (Fonte: QI, 2013), (b) falha por fretting em um cabo (Fonte: FADEL, 2010), (c) Situação de fretting em prótese médica (Fonte: HIN, 2004) e (d) Falha na face de um rotor de turbina (Fonte: SURESH, 1998) .............................................................13

Figura 3 - Resumo esquemático da estrutura da dissertação..................................................... 15

Figura 4 - Caracterização do contato (a) Incompleto não conforme, (b) completo, (c) incompleto com singularidade, (d) incompleto e conforme (e) retrocedente (Fonte: HILLS et al., 1994) .....21

Figura 5 - Contato entre cilindros com eixos paralelos (Fonte: ESTARLE, 2014) .......................23

Figura 6 - Regiões de escorregamento para contato entre cilindros ............................................24

Figura 7 - Carga oscilatória em função do tempo......................................................................24

Figura 8 - Variação das tensões cisalhantes na superfície de contato ao longo do tempo (Fonte:

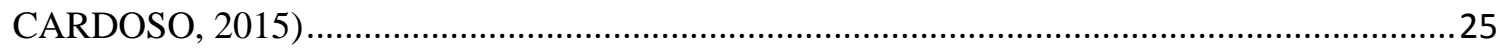

Figura 9 - Perfil de distribuição de tensões normais e cisalhantes (Fonte: CARDOSO, 2015)....25

Figura 10 - Distribuição de tensão cisalhante para diferentes cargas tangenciais sob bulk stress

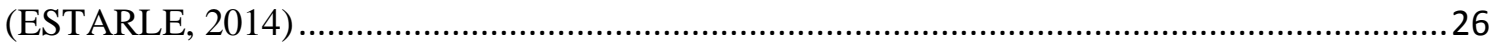

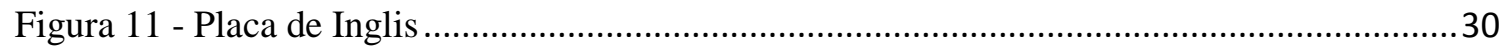

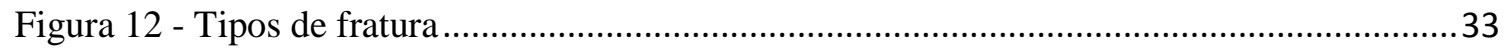

Figura 13 - Sistema de coordenadas para uma trinca ............................................................. 36

Figura 14 - Função peso para trinca unidimensional, (a), (b) e (c) (Fonte: WANG; GLINKA,

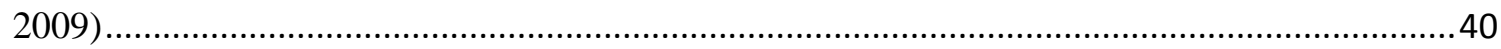

Figura 15 - Variação do coeficiente de fricção em função do número de ciclos de fretting ........41 Figura 16 - Redução da vida à fadiga por fretting para a liga T7375 (Fonte: FOULQUIER, 1988)

42

Figura 17 - Definição de contato - Importância da não interpenetração entre superfícies (Fonte:

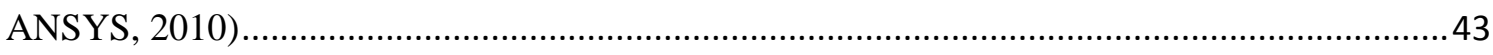

Figura 18 - Esquema geométrico da formulação por pura penalidade (Fonte: ANSYS, 2010) ... 44

Figura 19 - Geometria do contato - Formulação de Lagrange (Fonte: ANSYS, 2010) ...............45

Figura 20 - Estado do contato para o método de Lagrange (esq.) e baseado em penalidades (dir.)

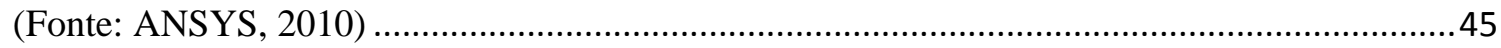

Figura 21 - Geometria do contato - Formulação MPC (Fonte: ANSYS, 2010)............................46

Figura 22 -Formulação geométrica MPC (Fonte: ANSYS, 2010) .............................................46

Figura 23 - Métodos de detecção por integração de pontos (esq.) e nodais (dir.) (Fonte: ANSYS, 2010)

Figura 24 - Efeitos de solavanco entre as superfícies em decorrência de alta rigidez de contato (Fonte: ANSYS, 2010)

Figura 25 - Contato estabelecido corretamente (esq.) e contato com excesso de penetração (dir.)

(Fonte: ANSYS, 2010) . .51

Figura 26 - Penetração por conta de comportamento assimétrico do contato (Fonte: ANSYS,

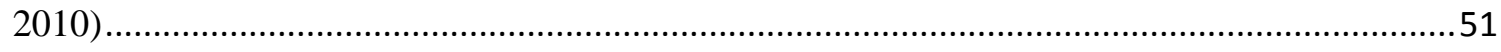

Figura 27 - Condições de contorno para EPT (Fonte: YASTREBOV, 2010) ............................. 52

Figura 28 - - Condições de contorno para EPD (Fonte: YASTREBOV, 2010).............................52

Figura 29 - Detecção do contato pelo ANSYS (Fonte: ANSYS, 2010) ......................................5

Figura 30 - Problema na detecção do contato por conta de projeção inadequada dos elementos

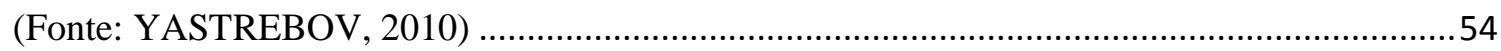


Figura 31 - Discretização de contato tipo nó-nó antes de aplicação de esforços (esq.) e depois

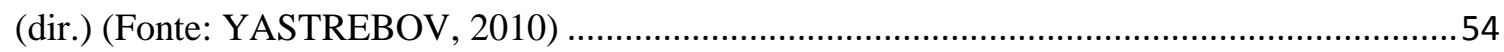

Figura 32 - Discretização de contato tipo nó-segmento (Fonte: YASTREBOV, 2010) .................55

Figura 33 - Discretização de contato tipo segmento-segmento (Fonte: YASTREBOV, 2010) ...55

Figura 34 - Quantidade de artigos publicados por ano ............................................................5

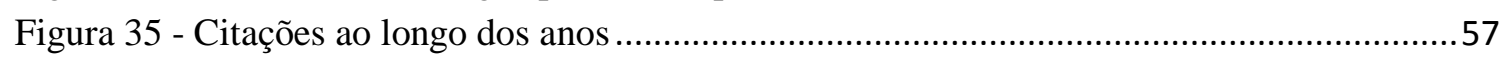

Figura 36 - Rede mostrando as citações e interconexões entre os diversos estudos......................58

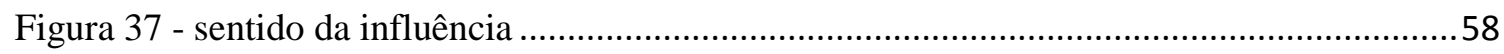

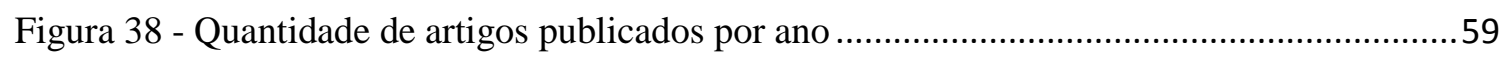

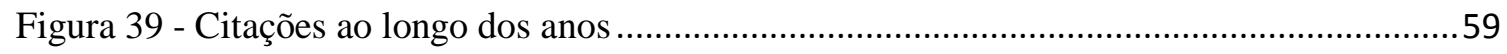

Figura 40 - Obtenção do dano da trinca por iniciação fonte (NAVARRO et al. 2003).................61

Figura 41 - Obtenção do dano por trinca por propagação (Fonte: NAVARRO et al., 2003) .......61

Figura 42 - Iniciação de propagação do dano por trinca (Fonte: Navarro et al., 2003) ................62

Figura 43 - Iniciação, propagação e vida total estimadas (Fonte: NAVARRO et al., 2003)........62

Figura 44 - Seções transversais das trincas (Fonte: NAVARRO et al., 2003) ...............................63

Figura 45 - Diferentes leis de propagação para o Al 7075 (Fonte: NAVARRO et al., 2003) .....64

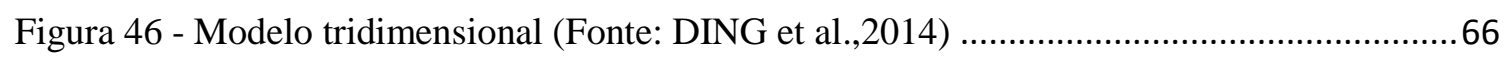

Figura 47 - Modelo bidimensional (Fonte: DING et al.,2014) ....................................................67

Figura 48 - Resultados simulados e experimentais para curvas de tensão-deformação para tensões monotônicas (Fonte: DING et al.,2014)

Figura 49 - Resultados experimentais e simulados para amplitudes de tensões vs. número de ciclos sob testes uniaxiais com deformação controlada para uma amplitude de tensão de $\pm 0.7 \%$

(Fonte: DING et.

Figura 50 - Resultados experimentais e simulados para ratchetting uniaxial (Fonte: DING et al.,2014)..... 68

Figura 51 - Trinca em uma malha bidimensional de X-FEM. Os círculos são para incrementos descontínuos e os quadrados para incrementos assimptóticos (Fonte: BAIETTO et al. 2013) ....70 Figura 52 - Modelagem do formato da trinca com dois ajustes de nível (Fonte: BAIETTO et al. 2013)

Figura 53 - Distribuição de tração para quatro carregamentos (Fonte: BAIETTO et al. 2013) ...72 Figura 54 - Domínio retangular com a malha local refinida. $h \mathrm{~min}=5 \mu \mathrm{m} \mathrm{hmaxhmin}=550$

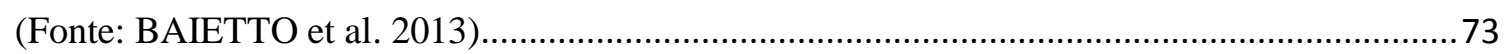

Figura 55 - Risco de surgimento de trinca de acordo com o critério de Dang Van (Fonte:

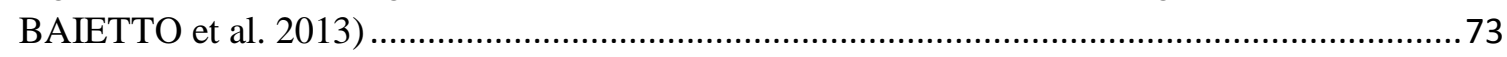

Figura 56 - Lei de crescimento da trinca em modo misto (Fonte: BAIETTO et al. 2013) ............74

Figura 57 - Conformidade entre os resultados para o critério $\Delta k 1 M a x *(\theta, t)$ (Fonte:

BAIETTO et al. 2013)

Figura 58 - Ajustes de nível $\varphi o$ e $\Psi 0$ utilizados para a representação das trincas, baseadas em reconstruções post-mortem (Fonte: BAIETTO et al. 2013) .....................................................75

Figura 59 - Taxa de liberação de energia potencial (Fonte: BAIETTO et al. 2013) .....................75

Figura 60 - Detalhes geométricos das configurações adotadas (Fonte: RAMMOHAN et al. 2012)

Figura 61 - Vistas aérea e frontal da malha para o bloco cilíndrico em contato com a superfície plana (Fonte: RAMMOHAN et al. 2012).

Figura 62 - Etapas de carregamento e condições de contorno (Fonte: RAMMOHAN et al. 2012) 
Figura 63 - Variações dos coeficientes de fricção versus pressão normal e cisalhamento ao longo da superfície de contato para diferentes profundidades em (a) 2-D (b) 3-D (Fonte:

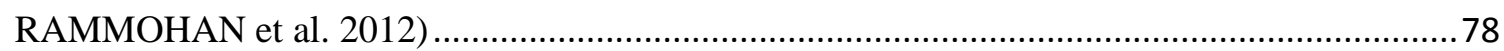

Figura 64 - Esquema experimental do teste de fretting (Fonte: PIERRES et al. 2010).................80

Figura 65 - (a) superfície de contato trincada (b) reconstrução tridimensional da trinca (c) projeção da trinca no plano x-z e (d) projeção da trinca no plano y-z (Fonte: PIERRES et al.

2010)......

Figura 66 - Esquema e notações para os problemas global e local de fratura (Fonte: PIERRES et al. 2010).

Figura 67 - (a) Geometria da trinca nas condições de contorno e (b) geometria tridimensional definida com ajustes de nível (Fonte: PIERRES et al. 2010)

Figura 68 - Definição das formas das trincas e forças normais para as trincas 1 e 2, utilizando os

ajustes de nível $\Psi$ e $\varphi$ (Fonte: PIERRES et al. 2010)

Figura 69 - Representações amplificadas dos campos de deslocamento U, de deslocamentos normais relativos WN e dos deslocamentos tangenciais WT e de tração T para os intervalos de tempo 0,4,8, 12 e 16 (Fonte: PIERRES et al. 2010)

Figura 70 - Efeito de amplitude de deslizamento em (a) vida à fadiga por fretting fatigue e (b)

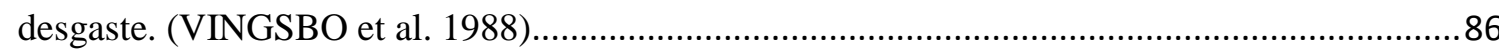

Figura 71 - Esquemática da região de contato parcial (Fonte: MADGE et al. 2007) ....................86

Figura 72 - Malhas da análise de elementos finitos para (a) deslizamento parcial e (b) deslizamento abrupto (Fonte: MADGE et al. 2007).

Figura 73 - Relação entre deslocamento aplicado, máximo deslocamento pré-determinado $\delta a p p$ e deslocamento devido às deformações $\delta \varepsilon$ (Fonte: MADGE et al. 2007) .....

Figura 74 - Tensão normal, deslocamento tangencial e tensão cíclica implementados (Fonte:

MADGE et al. 2007)

Figura 75 - Comparação da previsão por FE e das soluções teóricas de Hills e Nowell para (a) deslizamento parcial e (b) tensões de cisalhamento sub-superfíciais para deslizamento abrupto (Fonte: MADGE et al. 2007)

Figura 76 - Previsão de vida à fadiga em função da amplitude de deslizamento por modelo SWT baseado em FE, negligenciando os efeitos de remoção de material (Fonte: MADGE et al. 2007)

Figura 77 - Efeitos previstos na distribuição de forças cisalhantes por amplitudes de deslizamento (Fonte: MADGE et al. 2007). 90

Figura 78 - Previsão da distribuição de pressão de contato com desgaste para deslizamentos abruptos (Fonte: MADGE et al. 2007) .

Figura 79 - Previsão da distribuição de contato para deslizamento parcial (Fonte: MADGE et al. 2007).....

Figura 80 - Danos acumulados para o caso de (a) deslizamento parcial com 25.000 ciclos e de (b) deslizamento abrupto com 150.000 ciclos (Fonte: MADGE et al. 2007).

Figura 81 - Comparação das previsões do modelo de elementos finitos com os encontrados experimentalmente em outro estudo (Fonte: MADGE et al. 2007) ............................................92

Figura 82 - Desenho esquemático do teste fretting fatigue (Fonte: KIM et al. 2011) ...................94

Figura 83 - Detalhes dos submodelos (Fonte: KIM et al. 2011) ..................................................95

Figura 84 - Configuração da malha para o modelo bidimensional (Fonte: KIM et al. 2011).......96 Figura 85 - Desenho esquemático da distribuição de tração na superfície de contato (Fonte: KIM et al. 2011). 
Figura 86 - Impressão do contorno da pressão de contato e micrografia típica da cicatriz do espécime submetido a fretting (Fonte: KIM et al. 2011).....

Figura 87 - Comparação entre tensões normais no cento e na borda do espécime (Fonte: KIM et al. 2011).

Figura 88 - Comparação da tensão de cisalhamento e deslocamento relativos para o centro e as bordas do espécime (Fonte: KIM et al. 2011)

Figura 89 - Resultados de ambos os modelos no centro do contato (Fonte: KIM et al. 2011) .....99

Figura 90 - Resultados dos modelos na borda do contato (Fonte: KIM et al. 2011) ...................100

Figura 91 - Comparação das tensões no centro (Fonte: KIM et al. 2011) ....................................101

Figura 92 - Comparação dos modelos nas bordas (Fonte: KIM et al. 2011) ...............................101

Figura 93 - Configuração de fretting e desenho esquemático da parte central do espécime

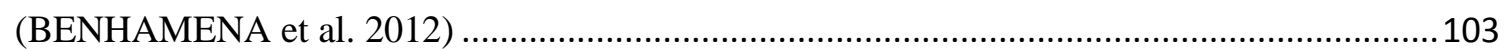

Figura 94 - Fretting pad e localização dos strain gauges (BENHAMENA et al. 2012) ...............104

Figura 95 - Evolução da vida à fretting fatigue com a força de contato (BENHAMENA et al. 2012)

Figura 96 - Evolução da morfologia da superfície em relação às forças de aperto para diferentes áreas de contato (BENHAMENA et al. 2012). 106

Figura 97 - (a) Desenho esquemático das zonas de iniciação de trinca e (b) iniciação de trincas para diferentes forças de prensamento (BENHAMENA et al. 2012).

Figura 98 - (a) Geometria e malha da placa parafusada (b) modelagem da superfície de contato

(c) modelagem da força de prensamento (BENHAMENA et al. 2012) .

Figura 99 - (a) Deslocamentos relativos na direção do carregamento cíclico; (b) Tensões na direção do carregamento cíclico; (c) Tensões de contato nas bordas de ambos os buracos (BENHAMENA et al. 2012)

Figura 100 - Exemplo de teste de fadiga para eixos (a) e trincas presentes no mesmo (b) (Fonte:

LUKE et al. 2016) 109

Figura 101 - Representação esquemática dos conceitos de fretting fatigue (esq.) e o teste adotado neste estudo (dir.) (Fonte: LUKE et al. 2016) ....

Figura 102 - Modelo em EF, mostrando espécime e PAD (a) e detalhes do contato inicial (b) (Fonte: LUKE et al. 2016).

Figura 103 - Detalhes dos três elementos utilizados na avaliação da evolução da tensão em respeito a (a) zona de contato inicial e (b) zona plástica sob carregamento máximo (Fonte:

LUKE et al. 2016)

Figura 104 - Curvas de histerese para várias amplitudes usando a aproximação de Lemaitre-

Chaboche e material EA4T (Fonte: LUKE et al. 2016)

Figura 105 - Tensões de von Mises equivalentes para a máxima carga aplicada sob diferentes condições de aperto: (a) Q=1,5 kN (b) Q=2 kN (c) Q=3 kN (d) Q=3 kN com pad elástico (Fonte: LUKE et al. 2016)

Figura 106 - Deslizamento de contato para diferentes tensões máximas aplicas e diferentes cargas de aperto (a) $\mathrm{Q}=1.5 \mathrm{kN}$ (b) $\mathrm{Q}=2 \mathrm{kN}$ (c) $\mathrm{Q}=3 \mathrm{kN}$ (Fonte: LUKE et al. 2016)...

Figura 107 - Deslizamento de contato para diferentes tensões máximas aplicadas e carga de aperto $\mathrm{Q}=1,5 \mathrm{kN}$ (Fonte: LUKE et al. 2016)

Figura 108 - Parâmetros de dano à fadiga Pswt e Pfs em função da tensão aplicada e de diferentes cargas de aperto (Fonte: LUKE et al. 2016)

Figura 109 - Variações entre as curvas de Tensão-Deformação para diferentes carregamentos (Fonte: LUKE et al. 2016) 
Figura 110 - Modelo de elemento finito proposto (Fonte: LIU et al. 2014)

Figura 111 - Evolução das curvas de torque friccional versus ciclos de vida (Fonte: LIU et al.

2014).

Figura 112 - Curva de torque angular versus deslocamento angular em $\theta=0,1$ (Fonte: LIU et al.

2014).

Figura 113 - Curva de torque angular versus deslocamento angular em $\theta=0,5$ (Fonte: LIU et al.

2014)

Figura 114 - Curvas de torque versus deslocamentos angulares para $\theta=3$ no (a) primeiro ciclo (b) décimo ciclo (Fonte: LIU et al. 2014)

Figura 115 - Curvas de torque versus deslocamentos angulares para $\theta=5$ no (a) primeiro ciclo (b) décimo ciclo (Fonte: LIU et al. 2014)

Figura 116 - Esboço da camada branca de fretting (Fonte: LIU et al. 2014)

120

Figura 117 - Deformações plásticas para diferentes regimes de deslizamento (a) parcial (b) misto (c) total (Fonte: LIU et al. 2014)

Figura 118 - Tensão cisalhante friccional e marcas de desgaste (a) Deslizamento parcial (b)

Deslizamento mixto (c) Deslizamento total (Fonte: LIU et al. 2014)

Figura 119 - Típica relação entre vida à fadiga e taxa de desgaste em função da amplitude de deslizamento (Fonte: LIU et al. 2014)

Figura 120 - Simulação da propagação de trinca na microestrutura de uma ligada de titânio. À esquerda, a geometria do teste. À direita, o local de iniciação de trinca (Fonte: NIGRO et al. 2014).

Figura 121 - Esquemática da simulação da metodologia grão a grão (Fonte: NIGRO et al. 2014)

Figura 122 - Detalhes da malha e dos grãos gerados (Fonte: NIGRO et al. 2014)...

Figura 123 - Condições de contorno e de carregamento (Fonte: NIGRO et al. 2014) 126

Figura 124 - Comparações dos resultados teóricos e computados para o critério de Crossland (Fonte: NIGRO et al. 2014).

Figura 125 - Evolução do CTSD em função do tamanho da trinca para os dois casos (Fonte:

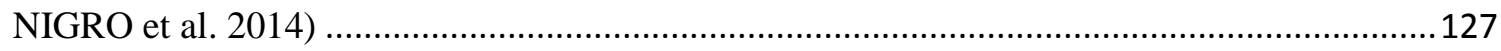

Figura 126 - Propagação de trincas para dois casos (Fonte: NIGRO et al. 2014) .......................127

Figura 127 - Visão superior do espécime, em milímetros (Fonte: FERJAOUI et al. 2015) .......129

Figura 128 - Visão lateral do espécime, em milímetros (Fonte: FERJAOUI et al. 2015) ...........129

Figura 129 - Espécime no aparato experimental (Fonte: FERJAOUI et al. 2015) ......................130

Figura 130 - Modelo em elementos finitos com cargas (Fonte: FERJAOUI et al. 2015) ...........130

Figura 131 - Modelo em elementos finitos com malha (Fonte: FERJAOUI et al. 2015) ............131

Figura 132 - Cicatriz de fretting na placa lateral (Fonte: FERJAOUI et al. 2015) ......................131

Figura 133 - Cicatriz de fretting no centro da placa $\sigma=125 \mathrm{MPa}$ (Fonte: FERJAOUI et al. 2015)

Figura 134 - Cicatriz de fretting no centro da placa $\sigma=112,5 \mathrm{MPa}$ (Fonte: FERJAOUI et al. 2015)

Figura 135 - Contornos de von Mises obtidos (Fonte: FERJAOUI et al. 2015) …….................133

Figura 136 - Contornos de von Mises obtidos (Fonte: FERJAOUI et al. 2015) .........................133

Figura 137 - Tensão principal máxima (esquerda) e tensão cisalhante (direita) na superfície de

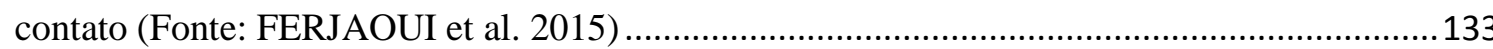

Figura 138 - Variação da superfície de contato de acordo com a força de aperto (Fonte:

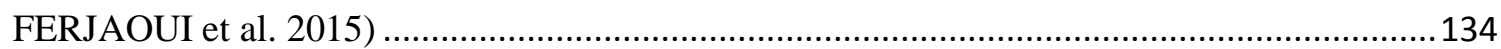


Figura 139 - Variação da superfície de contato sob diferentes tensões atuantes (Fonte:

FERJAOUI et al. 2015)

Figura 140 - Variações das tensões cisalhantes normalizadas para as diferentes cargas aplicadas

(Fonte: FERJAOUI et al. 2015).....

Figura 141 - Variação da amplitude de deslizamento normalizada em função da linha de contato normalizada, para diferentes cargas (Fonte: FERJAOUI et al. 2015)

Figura 142 - Variação das tensões cisalhantes normalizadas (esq.) e amplitude de deslizamento (dir.) para a linha de contato normalizada de um determinado teste (Fonte: FERJAOUI et al. 2015)

Figura 143 - Variáveis normalizadas em função da distância de contato deslizada para um

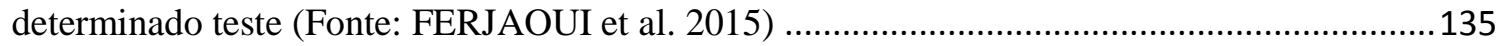

Figura 144 - Distribuição dos picos de tensão no contato (Fonte: FERJAOUI et al. 2015) .......136 Figura 145 - Zona de processo no local de nucleação da trinca (Fonte: FERJAOUI et al. 2015)

Figura 146 - Resultados computados versus resultados experimentais (Fonte: FERJAOUI et al. 2015)

Figura 147 - Visão geral do aparato (Fonte: TALEMI et al. 2011) .........................................138

Figura 148 - Aparato experimental (Fonte: TALEMI et al. 2011) …….................................... 139

Figura 149 - Diferentes geometrias de pad utilizados (Fonte: TALEMI et al. 2011)..................139

Figura 150 - Espécime plano utilizado (Fonte: TALEMI et al. 2011).......................................139

Figura 151 - Modelo numérico proposto (Fonte: TALEMI et al. 2011) ....................................140

Figura 152 - Trajetória de crescimento da trinca (Fonte: TALEMI et al. 2011) ...........................142

Figura 153 - Trinca inicial no FRANC2D/L (Fonte: TALEMI et al. 2011) ...............................142

Figura 154 - Comparação entre os crescimentos da trinca experimental e numérico (Fonte:

TALEMI et al. 2011)

Figura 155 - Efeito da dimensão do pad na propagação da trinca (Fonte: TALEMI et al. 2011)

Figura 156 - Modelo numérico proposto (Fonte: MUTOH et al. 2010). 145

Figura 157 - Relação entre tensão tangencial na borda do contato e tamanho da malha (Fonte:

MUTOH et al. 2010) 145

Figura 158 - Efeitos da rigidez do pad no coeficiente de força tangencial (Fonte: MUTOH et al. 2010).

Figura 159 - Efeito da altura do pé do pad sobre a tensão tangencial no contato (Fonte: MUTOH et al. 2010)

Figura 160 - Efeito da altura do pé do pad na tensão compressiva na borda do contato (Fonte:

MUTOH et al. 2010)

Figura 161 - Efeito da altura do pé do pad na amplitude de deslizamento parcial na borda do contato (Fonte: MUTOH et al. 2010)

Figura 162 - Tensão tangecial versus tensão compressiva na borda do contato (Fonte: MUTOH et al. 2010)

Figura 163 - Estimativa de v ida total e definição do tamanho de trinca inicial (Fonte: GINER et al. 2011)

Figura 164 - Geometria dos modelos numéricos (Fonte: GINER et al. 2011) 151

Figura 165 - Fator de intensidade de tensão normalizado para a superfície do teste 7 (Fonte: GINER et al. 2011).... 152

Figura 166 - Contorno de von Mises para o teste 1 (Fonte: GINER et al. 2011) 152 
Figura 167 - Valores de Ki versus tamanho da trinca para o (a) teste 7 e (b) teste 4 (Fonte: GINER et al. 2011)

Figura 168 - Correlação entre valores estimados e experimentais para o teste S\&F (Fonte:

GINER et al. 2011)....

Figura 169 - Correlação entre valores estimados e experimentais para o teste A\&N (Fonte:

GINER et al. 2011).

Figura 170 - Modelo geométrico global (a) e submodelo (b) (Fonte: LÉVESQUE et al. 2011)

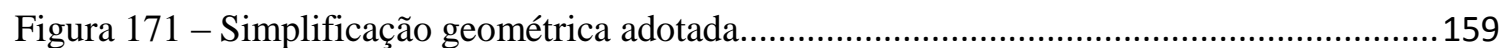

Figura 172 - Resumo esquemático dos parâmetros de entrada para a simulação numérica ........160

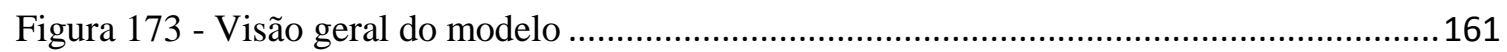

Figura 174 - Alumínio, $\sigma$ bulk $=100 \mathrm{MPa}, \mu=0,90$ curvas Kt e Kp .......................................162

Figura 175 - Comportamento das tensões cisalhantes para deslizamentos parcial (esq.) e abrupto

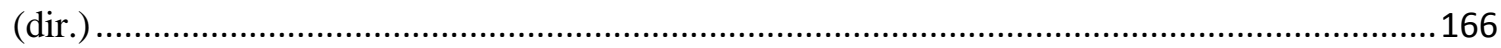

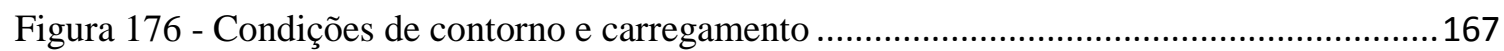

Figura 177 - Região de contato na malha para cada material ......................................................169

Figura 178 - Malha discretizada total (esq.) e zoom do contato (dir.).....................................170

Figura 179 - Tensão normal - comparação entre resultado numérico e teórico..............................171

Figura 180 - Tensão cisalhante - comparação entre resultado numérico e teórico ........................171

Figura 181 - Comparação entre os coeficientes de Lagrange ...................................................172

Figura 182 - Campos de tensão $\sigma x$ para o ensaio de aço $\sigma b u l k=100 \mathrm{MPa}$ e $\mu=0.9 \ldots \ldots \ldots . . .173$

Figura 183 - Campos de tensão $\sigma y$ para o ensaio de aço $\sigma b u l k=100 \mathrm{MPa}$ e $\mu=0.9 \ldots \ldots \ldots . . .173$

Figura 184 - Campos de tensão $\tau x y$ para o ensaio de aço $\sigma b u l k=100 \mathrm{MPa}$ e $\mu=0.9 \ldots \ldots \ldots . .173$

Figura 185 - Evolução das tensões máximas ao longo do tempo - Aço $\sigma b u l k=100 \mathrm{MPa}$ e $\mu=$ 0.9

Figura 186 - Evolução das tensões máximas ao longo da profundidade - Aço $\sigma b u l k=100 \mathrm{MPa}$

e $\mu=0.9$

Figura 187 - Evolução das tensões máximas ao longo do tempo - Aço $\sigma b u l k=80 \mathrm{MPa}$ e $\mu=$

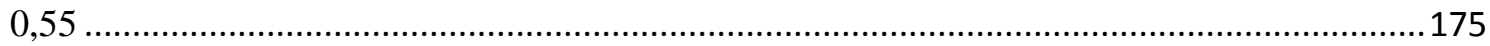

Figura 188 - Caminho da trinca sob fretting (Fonte: PENG et al., 2014) ..................................176

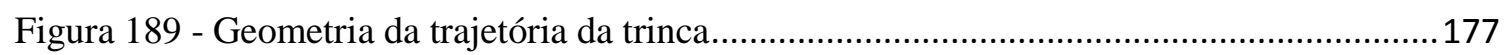

Figura 190 - Convergência do contato em relação à profundidade para o aço (REMOTA 60

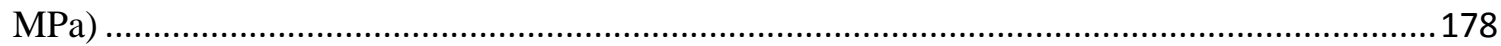

Figura 191 - Valores de KI obtidos por função de peso (WF) e com trinca inclinada inicialmente $\left(60^{\circ}\right)$ Fonte: (RÊGO, 2017).

Figura 192 - Modelo numérico com trinca para validação da função de peso (Fonte: Rêgo, 2017)

Figura 193 - Comparação entre a função de peso (WF) e o modelo numérico (Fonte: RÊGO,

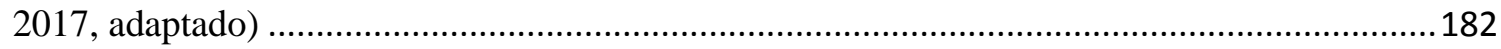

Figura 194 - Aço - Curvas de Kp e seus respectivos ajustes para $\sigma$ bulk=100 MPa variando $\mu 183$ Figura 195 - Aço - Curvas de Kp e seus respectivos ajustes para $\mu=0,9$ variando as cargas remotas de fadiga

Figura 196 - Ligas de titânio, aço e alumínio - Curvas de Kp e seus respectivos ajustes para $\mu=$

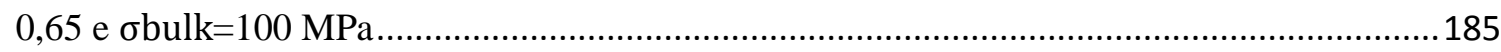

Figura 197 - Aço - Curvas de Kp para $\sigma b u l k=100 \mathrm{MPa}$ e $\mu 0.75$ variando o raio do pad .......186 
Figura 198 - Conformidade entre os resultados numéricos e pela função de peso para o modo II -

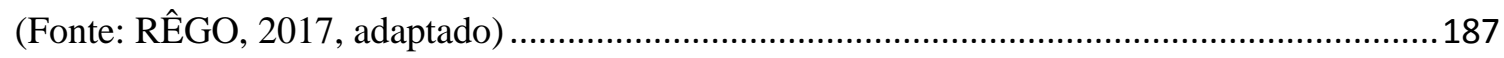

Figura 199 - Comparação entre os FIT no modo misto e modo I..............................................188

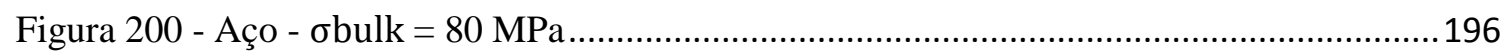

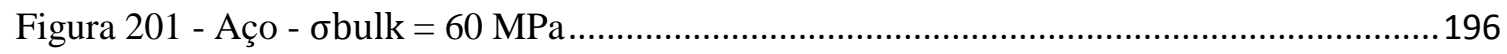

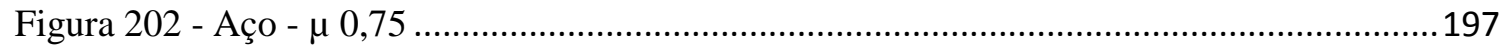

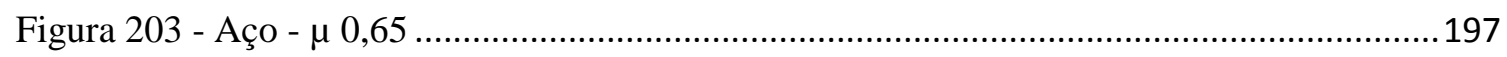

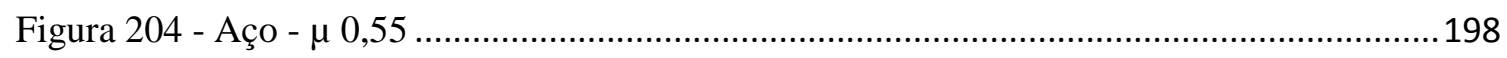

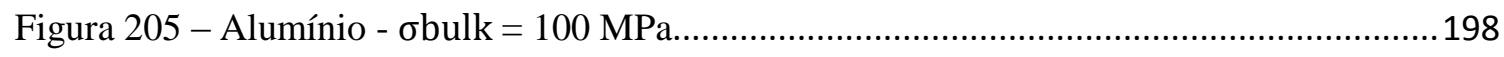

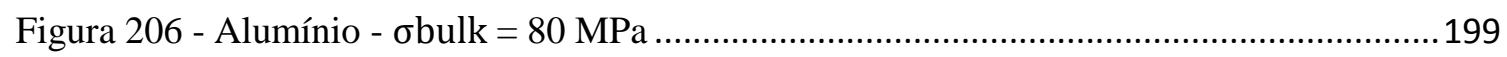

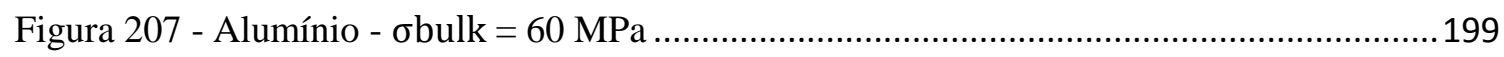

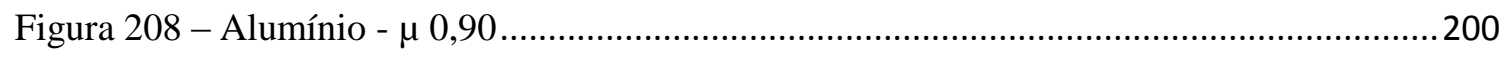

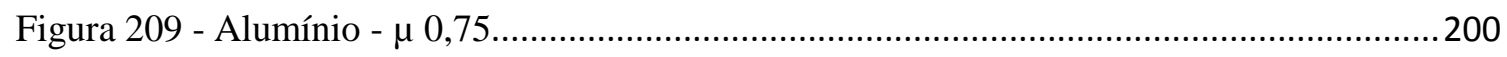

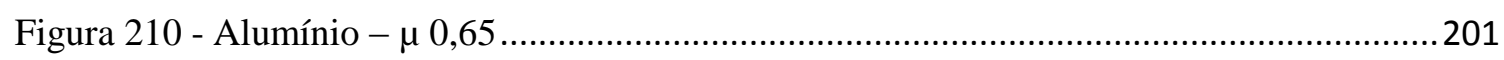

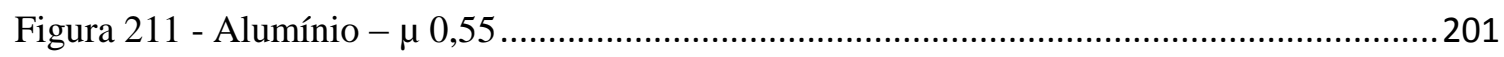

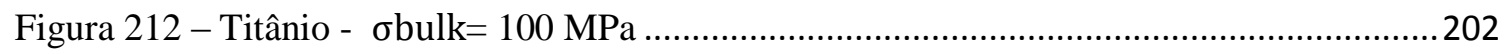

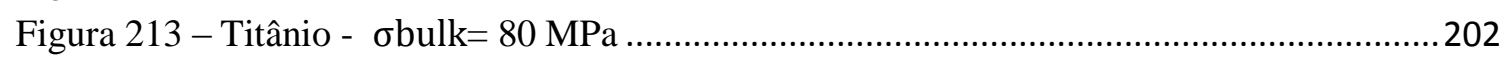

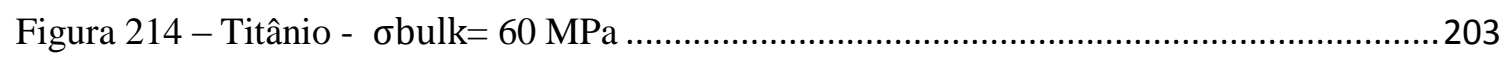

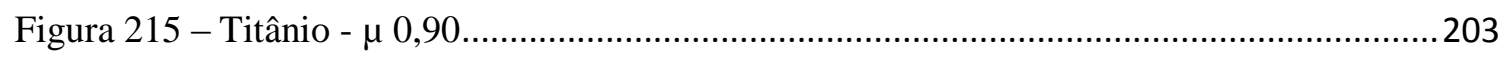

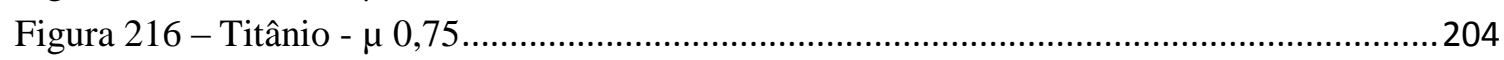

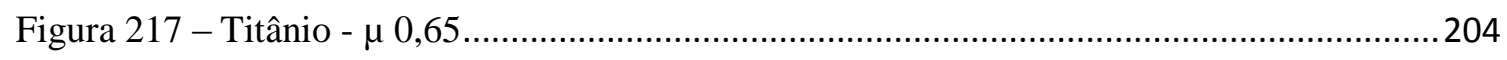

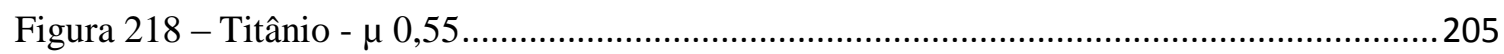




\section{LISTA DE SÍMBOLOS E ABREVIAÇÕES}

EPD - Estado plano de deformação

EPT - Estado plano de tensão

$\mathrm{CP}$ - Corpo de prova

MFLE - Mecânica da Fratura Linear Elástica

MFBD - Mecânica da Fratura Baseada em deformação

MPC - Multipoint Constraints

FIT - Fator de intensidade de tensões

Sin - Seno

Cos - Cosseno

zp - Zona de perturbação

SWT - Modelo de Smith-Watson-Topper

FEA - Análise por elementos finitos

FEM - Método dos elementos finitos

X-FEM - Método dos elementos finitos expandidos

FE - Elementos finitos

MPM - Material point mesh

CDM - Mecânica dos danos contínuos

DBJL - Junta de dois parafusos sobrepostos.

$K_{p}-$ Fator concentrador de tensão modificado

$K_{e l}-$ Fator de intensidade de tensão elástico

$K_{\text {ref }}-$ Fator de intensidade de tensão de referência

$K_{t}-$ Fator concentrador de tensão

$K_{I}-$ Fator de Intensidade de tensão sob modo I

$\sigma_{n}-$ Tensão nominal

$\sigma_{\max }-$ Tensão nominal máxima 
$\sigma_{b u l k}$ - Carga remota de fadiga

r - Raio elíptico 


\section{INTRODUÇÃO}

A falha por fadiga ocorre em componentes sujeitos a cargas dinâmicas e oscilatórias, geralmente imputada em níveis de tensão bem inferiores ao que ocorreria sob uma carga estática. Uma forma de falha ainda mais perigosa é a fadiga por fretting, a qual surgirá quando ocorrer movimento relativo entre as superfícies de dois componentes em contato submetidos a cargas oscilatórias.

O termo fretting, até o presente momento, ainda carece de definições unificadas, ocorrendo uma vasta quantidade de terminologias, como: fretting, fretting wear, fretting fatigue, fretting corrosion, rubbing fretting, impact fretting (QI, 2013). Assim sendo, é razoável adotar o termo fretting para caracterizar os aspectos gerais de todos estes fenômenos supracitados, o qual se caracteriza pelo movimento relativo entre duas superfícies de contato. Comumente, o fretting ocorre em superfícies firmemente presas e em contato que sofreram pequenos deslocamentos entre si por conta de carregamentos oscilatórios. Existem quatro formas principais de movimentos relativos que ocasionam o fretting, os quais estão ilustrados na Figura 1, são eles:

(a) Tangencial,

(b) Radial

(c) Rotacional

(d) Torsional

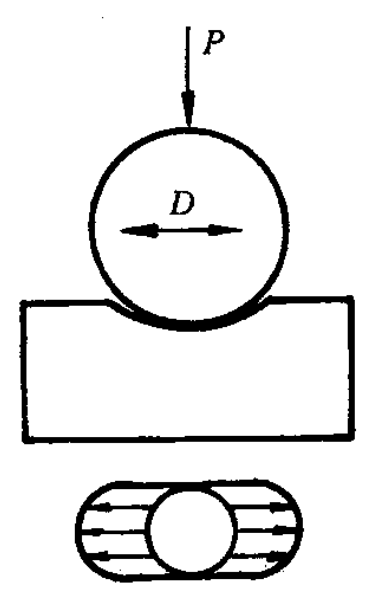

(a)

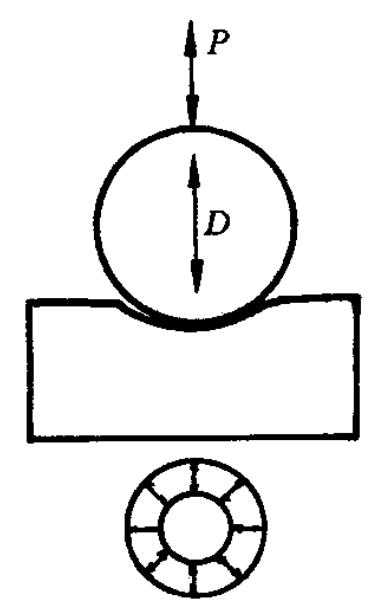

(b)

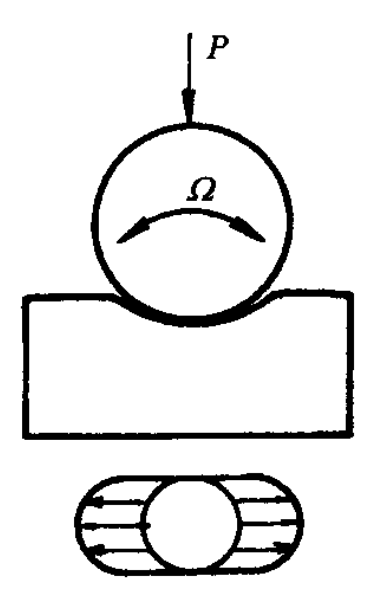

(c)

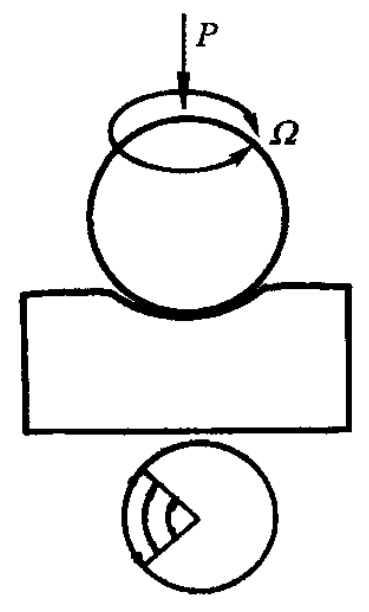

(d)

Figura 1 - Tipos de fretting (Fonte: QI, 2013) 
Embora todos os tipos de movimento relativo acima demonstrados ocorram com frequência em estruturas reais, a maioria dos estudos presentes na literatura refere-se apenas ao primeiro, o de deslocamento tangencial.

O estudo do fretting em situações normais de carregamento é uma tarefa extremamente complexa, comumente havendo uma combinação de movimentos relativos que o ocasionam. Atualmente, é sabido que o dano por fretting causa desgaste do material, diminuindo a resistência da peça. Ademais, ele também acaba contribuindo para o inicio da corrosão no local, acelerando o processo de desgaste. O fretting também está associado a significantes reduções da vida à fadiga de alto ciclo.

Justamente por reduzir consideravelmente a vida dos componentes onde se encontra presente, o fenômeno de fretting deve ser levado em conta ao se estimar a vida de determinadas estruturas. Ele está presente em diversas áreas da engenharia, como nos exemplos sumarizados na Tabela 1, extraída de SURESH (1998):

Tabela 1 - Exemplos práticos da ocorrência de fretting

\begin{tabular}{|c|c|}
\hline Tipo de estrutura & Local de ocorrência do fretting \\
\hline Turbinas a gás ou a vapor & $\begin{array}{l}\text {-Assentamento de disco de turbina no eixo } \\
\text { de acionamento de turbinas terrestres } \\
\text {-Seção de cauda ou abeto de motores a } \\
\text { jato de aviões onde a lâmina é juntada ao } \\
\text { disco } \\
\text {-A junta flangeada entre o disco/aparato } \\
\text { chanfraco e o eixo de transmissão em } \\
\text { transmissões de turbina a gás em } \\
\text { helicópteros } \\
\text {-Região de contato entre rotor-dente nas } \\
\text { vizinhanças de cunhas de lacunas de } \\
\text { compensação de rigidez em rotores de } \\
\text { turbogeradores. }\end{array}$ \\
\hline Cabos e cordas & $\begin{array}{l}\text {-Contato de interação entre os fios, por } \\
\text { conta de cargas variáveis em decorrência } \\
\text { de fluxos de ar e água } \\
\text {-Transmissão de linhas elétricas }\end{array}$ \\
\hline
\end{tabular}




\begin{tabular}{|c|l|}
\hline \multirow{2}{*}{ Juntas } & $\begin{array}{l}\text {-Cordas utilizadas em bondes } \\
\text {-Amarrações em ambiente marítimo }\end{array}$ \\
\hline & $\begin{array}{l}\text {-Rebites em estruturas aeronáuticas } \\
\text {-Chavetas em eixos de acoplamento } \\
\text {-Componentes ajustados por encolhimento }\end{array}$ \\
\hline Implantes médicos & $\begin{array}{l}\text {-Fraturas abaixo da superfície da cabeça } \\
\text { de parafuso e do escareador no placa base } \\
\text { conectada a ossos. } \\
\text {-Haste femoral em implantes totais de } \\
\text { quadril onde o trocômetro é amarrado a } \\
\text { haste do componente femoral. }\end{array}$ \\
\hline
\end{tabular}

Alguns dos exemplos da Tabela 1 são ilustrados na Figura 2:

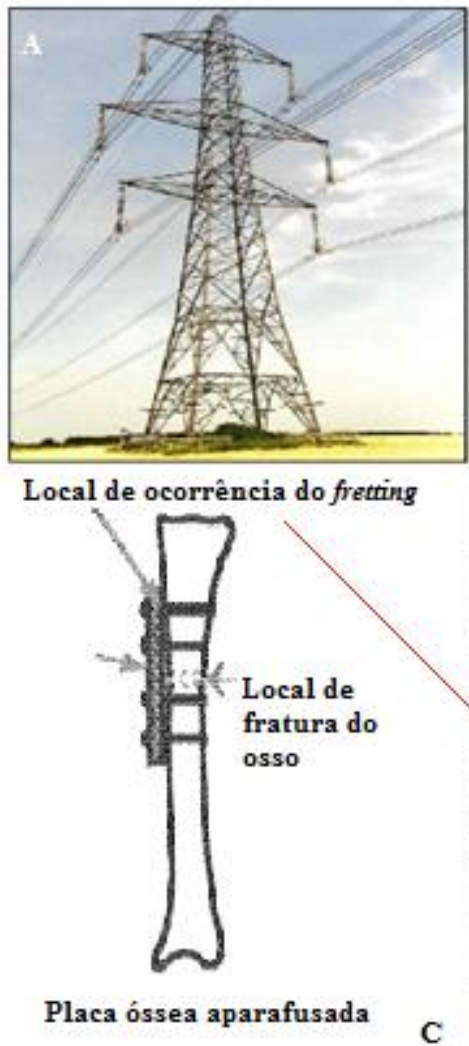

B
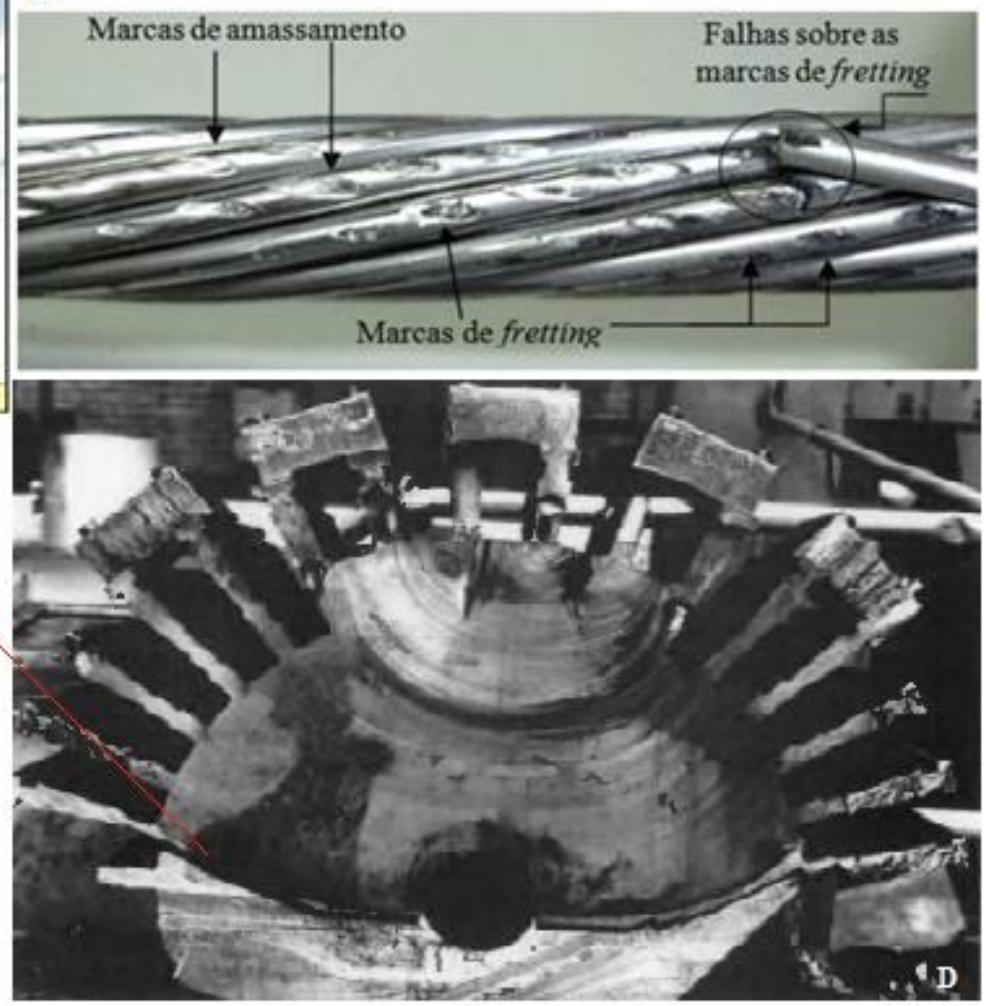

Figura 2 - (a) Linhas de transmissão (Fonte: QI, 2013), (b) falha por fretting em um cabo (Fonte: FADEL, 2010), (c) Situação de fretting em prótese médica (Fonte: HIN, 2004) e (d) Falha na face de um rotor de turbina (Fonte: SURESH, 1998)

Diversas variáveis são significativas no dimensionamento de fretting, como a amplitude de deslizamento entre as superfícies, o coeficiente de fricção, a carga de aperto, a carga remota de fadiga, dimensões, entre outras. Ademais, o fenômeno 
geralmente está associado a outros fenômenos, como desgaste e corrosão. Assim, vários modelos foram propostos com o intuito de entender como cada elemento envolvido afeta a vida à fadiga dos materiais, sobretudo após o desenvolvimento tecnológico que facilitou e aprimorou o uso de métodos computacionais. Contudo, o fretting ainda encontra-se longe de ser completamente entendido (CIGRE, 2006), sendo necessários estudos e modelos complementares que o modelem de forma adequada.

\subsection{OBJETIVO}

Este trabalho objetiva apresentar uma abordagem do conceito de fatores concentradores de tensão modificados $K_{p}$ para dimensionamento de fadiga por fretting. Também almeja discursar sobre os comportamentos de tais fatores concentradores de tensão de acordo com a variação de alguns parâmetros reconhecidamente importantes envolvidos no fenômeno: propriedades dos materiais, dimensão do pad, carga remota de fadiga e coeficiente de atrito entre as superfícies.

É também objetivo deste trabalho apresentar revisões bibliométrica e bibliográfica extensas, capazes, em conjunto, de demonstrar a originalidade da ideia e sua relevância, assim como propiciar ao leitor um resumo de como o tema vem sido abordado por outros pesquisadores.

O objetivo final é de apresentar como o conceito proposto pode ser utilizado na estimativa de vida ao fretting.

\subsection{MOTIVAÇÃO}

A despeito de contar com relativa extensa literatura, o fenômeno de fretting ainda não é completamente compreendido (CIGRE, 2006). Embora existam diversos estudos demonstrando a relação entre suas variáveis e seus efeitos na vida do componente, a simples mudança em pequenos detalhes muitas vezes ocasiona diferenças significativas nos resultados. Portanto, ainda existe a necessidade de criar-se um modelo que matematicamente represente o fenômeno, possibilitando a estimativa de vida à fadiga de forma confiável. A maioria dos modelos propostos com sucesso infelizmente representa um problema específico, onde a mudança dos parâmetros invalida sua utilização.

O estímulo para o desenvolvimento deste trabalho deu-se nesta necessidade de encontrar um modelo genérico de baixo custo para se utilizar em fadiga por fretting. 


\subsection{ESTRUTURA DO TRABALHO}

A dissertação apresenta primeiramente uma revisão teórica acerca dos diversos temas que englobam o fenômeno de fretting. Em seguida, os resultados da análise bibliométrica elaborada sobre o tema é apresentado, seguido por resumos de diversos modelos numéricos recentes propostos para se entender o fenômeno. Por fim, o método proposto é apresentado e discutido. A Figura 3 ilustra esquematicamente a estrutura do trabalho.

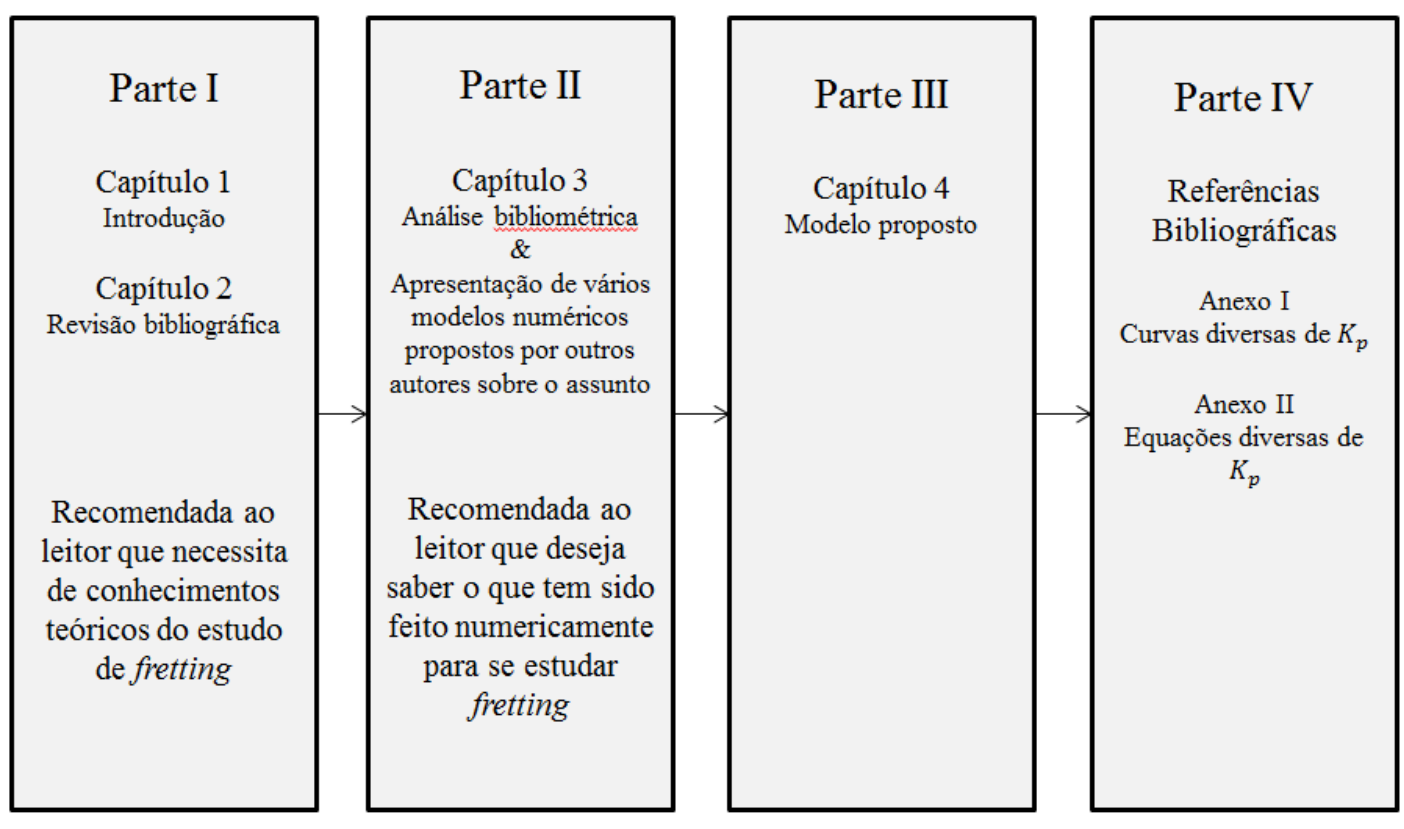

Figura 3 - Resumo esquemático da estrutura da dissertação 


\section{REVISÃO BIBLIOGRÁFICA}

\subsection{FADIGA}

\subsubsection{RESUMO HISTÓRICO}

Os estudos de fadiga dos materiais iniciaram-se no século XIX, tendo como motivação a percepção de que, mesmo sob cargas aplicadas abaixo das cargas de serviço projetadas, ocorriam grandes danos nas estruturas. Era evidente que o fenômeno de resistência dos materiais era algo mais complexo, especialmente sob cargas cíclicas, variação de temperatura, efeitos corrosivos, entre outros, mas faltava explica-lo e dimensiona-lo.

Pioneiros dos estudos de fadiga, como August Wöhler, passaram, então, entre 1850 e 1870, a conduzir experimentos para estabelecer faixas seguras de tensões alternadas abaixo das quais não ocorreriam falhas (BANNANTINE et al., 1989). Seguiram-se, principalmente na Alemanha, diversos estudos experimentais com modelos em tamanho real e escalonados para laboratórios a fim de se estabelecer um limite de resistência seguro para projetos, onde não ocorressem falhas por fadiga.

Entre 1850 e 1860, Wöhler realizou diversos testes e pôde então propor uma relação entre tensão e vida (curvas S-N). Com os diagramas montados por estas curvas, o autor estabeleceu um critério de como a vida à fadiga diminuía em virtude das amplitudes de tensão, assim como mostrava que abaixo de uma certa amplitude, não havia dano por fadiga. Wöhler também constatou que a amplitude de tensão era predominante na falha por fadiga frente à tensão máxima (STEPHENS et al. 2001). Aos trabalhos de Wöhler, diversos outros pesquisadores fizeram importantes contribuições, como Gerber e Goodman nos anos 80's e 90's do século em questão, respectivamente, cujos modelos até hoje são usados.

Dentre os trabalhos mais importantes, destaca-se criado por Bauschinger em 1885 através de um extensômetro espelhado capaz de medir um micrômetro. Estudando as relações entre pequenas deformações inelásticas e cargas seguras de fadiga, o pesquisador propôs que havia um limite natural elástico para o qual a fadiga não ocorreria. O fenômeno é hoje reconhecido como a diferença entre a resistência de escoamento monotônica e ao escoamento cíclico (BANNANTINE et al., 1989). 
Em seguida, utilizando-se de microscopia, (EWING \& HUMPHREY, 1903) constataram que: "Ao primeiro exame, feito após várias alternâncias de tensão, ocorreram deslizamentos de algumas linhas de cristais, similares ao que ocorreria se fosse aplicada uma tensão acima do limite elástico do material. Após diversas alternâncias, as linhas transformaram-se em uma banda larga com bordas definidas. Ao continuar o processo, algumas superfícies passaram a mostrar-se quase que enegrecidas. Quando este ponto foi atingido, perceberam-se as quebras de alguns cristais, as quais foram encontradas nas bandas de deslizamentos". Também puderam constatar que a propagação das quebras tornava-se um fenômeno local, confinada às proximidades dos primeiros cristais quebrados. Estava finalmente explicada a causa microscópica da fadiga, a qual, posteriormente, através de microscopia eletrônica e diversas outras ferramentas poderosas, recebeu novas contribuições, explicando-se melhor a nucleação da trinca como um resultado entre as variações no carregamento e nas deformações.

Na década de 20 do século XX, Gough, junto de outros pesquisadores, contribuíram de forma significativa para o entendimento da fadiga, a qual passou a ser entendida como uma mistura de tensão e torção (Fadiga multiaxial). Desde então, diversos modelos, como os de Moore, Matake e Findley, Smith-Watson-Topper foram propostos, cada qual com sua vantagem. 


\subsubsection{RESUMO LITERÁRIO}

A fadiga é uma forma de falha que ocorre em estruturas submetidas a tensões dinâmicas e oscilantes, situação na qual a falha ocorrerá mesmo estando sob um nível tensão bem abaixo do limite de escoamento ou do limite de resistência à tração do material. A origem do termo, conforme descreve (CALLISTER JR., 2000), decorre do típico longo período de tensão repetitiva ou de ciclo de deformação para que a falha se concretize. O autor ainda afirma que cerca de $90 \%$ de todas as falhas metálicas são desta natureza, estendendo-se ainda a polímeros e a compósitos, exceto vidros. Sendo assim, torna-se imprescindível estudar-se o fenômeno de fadiga para o correto dimensionamento e previsão de durabilidade dos projetos de engenharia, principalmente porque suas falhas costumam ser de difícil detecção e repentinas, o que aumenta a chance da ocorrência de catástrofes.

Ao contrário das falhas estruturais, ou mecânicas, onde as cargas de serviço na peça são a origem do problema, as falhas por fadigas podem ser consideradas localizadas, progressivas e cumulativas. "Logo, a modelagem do trincamento por fadiga pode (e deve) ser tratada como um problema local, que pouco depende das tensões na peça como um todo" (CASTRO \& MEGGIOLARO, 2009a).

O estudo da fadiga é tipicamente dividido em duas partes: A nucleação da trinca e a sua propagação. A distinção da transição de um processo para o outro é uma árdua tarefa, pois a nucleação da trinca deve levar em consideração a geometria, o material, os históricos de tensões e de deformações e do ponto crítico da peça. Autores como (BANNANTINE et al., 1989) adotam a simplificação de que a iniciação é a parte de desenvolvimento da trinca até que atinja a ordem de uma polegada, enquanto propagação corresponderia ao restante da vida em fadiga. A propagação da trinca é paulatina e estável, dependendo da história dos fatores de intensidade de tensões de serviço. No entanto, a fratura final pode ocorrer de forma brusca.

A modelagem da vida à fadiga é, portanto, ao mesmo tempo complexa e necessária. É importante que a mesma seja prática, precisa e confiável, de modo que engenheiros consigam elaborar projetos seguros e ao mesmo tempo economicamente satisfatórios. Uma vez que se trata de uma falha local, o trincamento costuma estar restrito ao ponto crítico da peça, a qual comumente está contida em um objeto ainda maior, o que torna a falha, normalmente brusca, inesperada. Sendo assim, em projetos 
onde falhas não são toleradas, como em certos componentes de aviões, é imprescindível que exista um plano de garantia de segurança que inclua inspeções periódicas e de avaliação do acumulo de dano.

As falhas por fadiga começam pela nucleação no ponto mais solicitado, geralmente devido a um concentrador de tensão. Se a faixa de tensões cíclicas solicitantes for pequena em relação à resistência do material, considera-se que há uma lenta iniciação de trinca, grandemente influenciada por:

(i) As propriedades mecânicas do material.

(ii) $\mathrm{O}$ acabamento superficial da peça.

(iii) O gradiente das tensões atuantes.

(iv) As tensões residuais (se for compressiva, aumentará a vida).

Quando as cargas atuantes são altas o suficiente para induzir o escoamento cíclico, os detalhes do ponto crítico passam a ter menor importância. A vida de iniciação de trinca passa a ser curta, sofrendo maior influência da ductilidade do material.

Existem três formas tradicionais de dividir a metodologia de estudo da vida à fadiga:

(1) Método SN, ou curvas de Wöhler: Por meio de corpos-de-prova devidamente condicionados e testados sob certas cargas, permite estimar o inicio da nucleação de trinca para determinadas tensões, supondo que as tensões de serviço no ponto crítico sejam lineares e elásticas. Deve ser utilizado apenas para evitar o trincamento ou prever vidas longas associadas a cargas elásticas.

(2) Método $\varepsilon \mathrm{N}$, ou de Coffin-Manson: Através de testes de corpos-de-prova devidamente condicionados submetidos a cargas similares às de serviço, permite a correlação destes com as deformações elastoplásticas do ponto crítico da peça, supondo que ocorram deformações elastoplásticas no ponto crítico. Pode ser utilizado para prever qualquer vida de iniciação, mas é de implementação mais difícil que o método SN.

(3) Método da/dN, ou de Paris: Baseia-se na Mecânica da Fratura Elástica e é utilizado para modelar e prever propagações de trincas, assim como quando ocorrerá o faturamento final da peça. 


\subsection{MECÂNICA DO CONTATO}

\subsubsection{RESUMO HISTÓRICO}

Os estudos em mecânica do contato são inicializados por Heinrich Hertz em 1882 em seu clássico artigo "Über die Berührung fester elastischer Körper" (Sobre o contato de sólidos elásticos). Trabalhando como pesquisador assistente em Berlim, sua motivação foi o questionamento se as deformações elásticas em lentes por conta de endentação influenciavam de forma significativa nos padrões de franjas (JOHNSON, 1985). A hipótese era que uma área de contato elíptica poderia incitar alterações nas observações de franjas. Com seu conhecimento de potencial eletrostático, Hertz provou que uma distribuição de contato produzia deslocamentos elásticos em dois corpos com área de contato elíptica.

A teoria de Hertz, entretanto, não abrange força de atrito e abrange apenas sólidos perfeitamente elásticos. Progressos posteriores, feitos principalmente a partir da metade do século XX, permitiram estender a teoria inicial de Hertz para superfícies de contato com deslizamento e rolamento, tornando o estudo da mecânica do contato mais próximo da realidade. Enquanto isso, houve avanços em teorias de plasticidade e viscoelasticidade, o que permitiu que a inelasticidade dos corpos na zona de contato fosse examinada adequadamente.

\subsubsection{RESUMO LITERÁRIO}

Há uma enorme complexidade envolvida em problemas de fadiga que envolvam corpos em contato. Não só a geometria, mas imperfeições superficiais, o histórico dos carregamentos e diversos outros fatores influenciam no problema real. Na prática da engenharia, torna-se necessário fazer simplificações da realidade, sendo modelagens numéricas a forma mais viável de aplica-las e obter bons resultados. Destas técnicas, a mais popular é por elementos finitos e é a que será utilizada neste trabalho.

Se o problema de elementos finitos for bem modelado e executado, ocorrerá convergência e todas as desigualdades serão satisfeitas, então obter-se-á: O completo estado das tensões na vizinhança do contato, a distribuição de tração na superfície, o deslocamento tangencial relativo em pontos de contato dentro da região de deslizamento (HILLS \& NOWELL, 1994). 
Os diversos contatos podem ser devidamente classificados para melhor elucidação nas teorias de contato. Comumente, a classificação baseia-se em dois quesitos:

(i) Completude

(ii) Conformidade

Em relação à completude, diz-se que o contato é completo quando a carga aplicada não influencia na extensão do contato, conforme mostrado na Figura 4.1 (b). Nos demais casos ilustrados na mesma figura, percebe-se que uma aplicação de carga alterará a extensão do contato, sendo então chamados de incompletos.

Quanto à conformidade, diz que um contato é não conforme quando a meia largura $\mathbf{b}$ é insignificante em relação ao raio $\mathbf{R}$ do cilindro, conforme visto na Figura 4 (a). Nos casos 4.1 (b,d), fica evidente que a dimensão ' $b$ ' é significativa, logo haverá conformidade entre os corpos quando houver aplicação da carga, classificados como conformes.

O caso da Figura 4 (e) é um caso particular onde ocorre um recuo da superfície de contato.

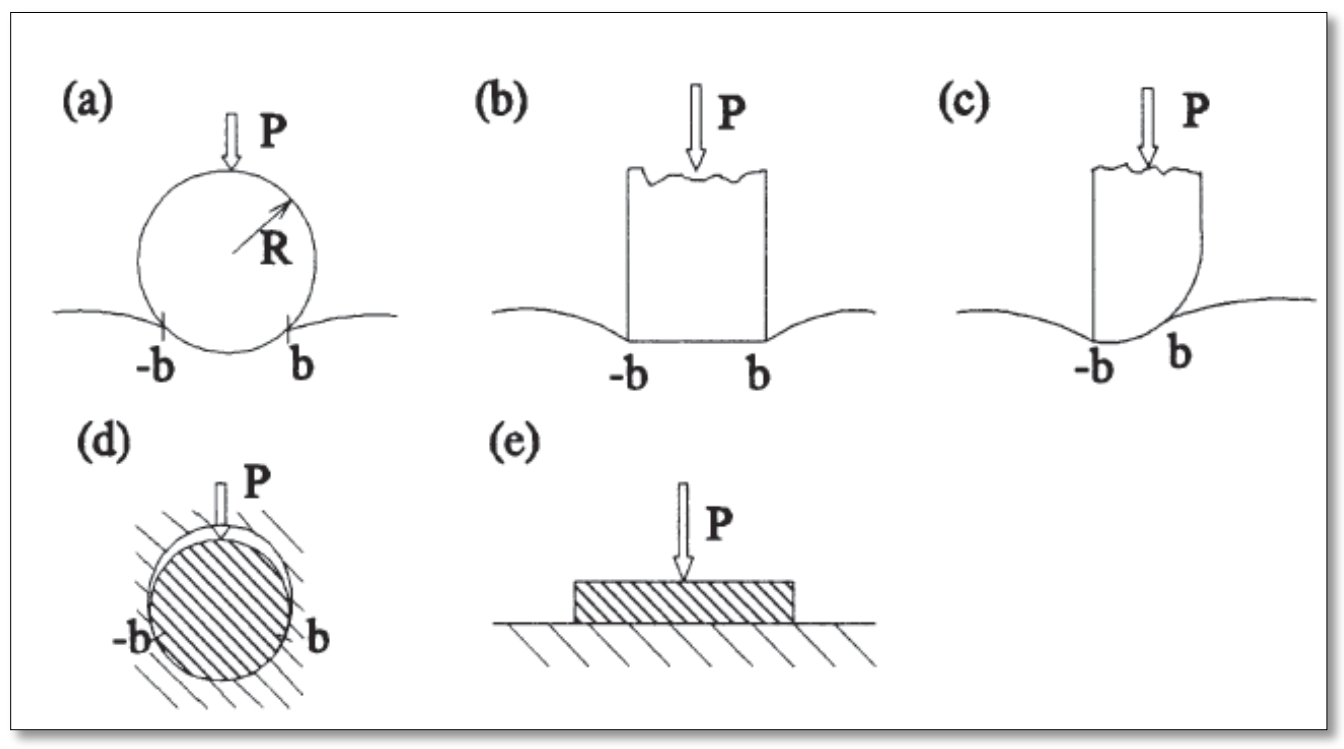

Figura 4 - Caracterização do contato (a) Incompleto não conforme, (b) completo, (c) incompleto com singularidade, (d) incompleto e conforme (e) retrocedente (Fonte: HILLS et al., 1994) 


\subsubsection{TEORIA DE HERTZ}

Quando dois corpos não conformes entram em contato, há um ponto único entre eles. Se ocorrer um carregamento, por menor que seja, haverá deformação de uma pequena área na vizinhança do ponto de contato, mas ainda assim pequena em relação às dimensões dos corpos. Através da teoria do contato, pode-se prever tanto o formato da área de contato, como o quanto ela cresce com o aumento do carregamento. Conforme descreve (JOHNSON, 1985), algumas considerações foram feitas para satisfazer a teoria de Hertz:

(i) As superfícies são continuas e não conformes.

(ii) As deformações são pequenas.

(iii) Cada sólido é considerado como um meio-espaço elástico.

(iv) Não há atrito entre as superfícies.

A solução das iterações na zona do contato se dará pela Equação 1:

$y_{1}+y_{2}=\delta-\mathrm{Z} \mathrm{x}^{2}-\mathrm{Hz}^{2}$

onde $y_{1}$ e $y_{2}$ são os deslocamentos verticais das superfícies em relação ao eixo dos cilindros 1 e 2 , respectivamente, $\delta$ é a soma dos deslocamentos de pontos pertencentes ao eixo $\mathrm{z}$ distantes da zona de contato e $\mathrm{Z}$ e $\mathrm{H}$ correspondem às constantes reais que denotam o perfil elíptico da zona de contato, que devem satisfazer o sistema:

$$
\left\{\begin{array}{c}
(Z+H)=\frac{1}{2}\left(\frac{1}{R_{1}^{\prime}}+\frac{1}{R_{1}^{\prime \prime}}+\frac{1}{R_{2}^{\prime}}+\frac{1}{R_{2}^{\prime \prime}}\right) \\
(-Z+H)=\frac{1}{2}\left[\left(\frac{1}{R_{1}^{\prime}}-\frac{1}{R_{1}^{\prime \prime}}\right)^{2}+\left(\frac{1}{R_{2}^{\prime}}-\frac{1}{R_{2}^{\prime \prime}}\right)^{2}+2\left[\left(\frac{1}{R_{1}^{\prime}}-\frac{1}{R_{1}^{\prime \prime}}\right)+\left(\frac{1}{R_{2}^{\prime}}-\frac{1}{R_{2}^{\prime \prime}}\right) \cos (2 \propto)\right]^{\frac{1}{2}}\right.
\end{array}\right.
$$

onde $R_{i}^{\prime}$ e $R_{i}^{\prime \prime}$ são os raios de curvatura da superfície do corpo i em relação ao eixo x e ao eixo $z$, respectivamente, com $\alpha$ sendo o ângulo de inclinação relativo aos eixos principais entre os dois sólidos (ESTARLE, 2014). 


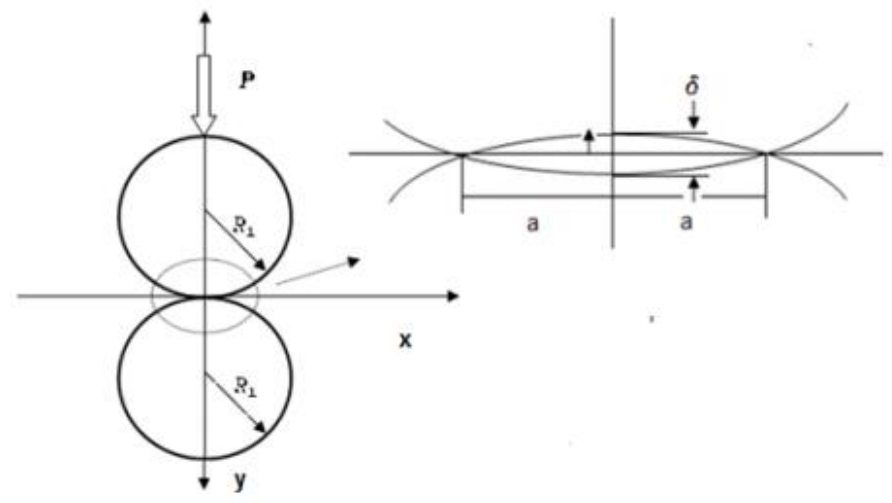

Figura 5 - Contato entre cilindros com eixos paralelos (Fonte: ESTARLE, 2014)

No caso de cilindros de raios iguais com eixos paralelos ao eixo $\mathrm{x}$, como na Figura 5, os termos $R_{1}^{\prime}=R_{2}^{\prime}=R_{S}$ e $R_{1}^{\prime \prime}=R_{2}^{\prime \prime}=\infty$. Isto permite chegar, através das equações supracitadas, à Equação (3):

$2 \frac{d}{a}=\frac{a}{R_{S}}$

onde 2 a é a largura do contato, $R_{S}$ é o raio da superfície de contato d é a deformação de contato, dada por:

$\mathrm{d}=y_{1}(0)-y_{1}(a)$

Para uma faixa estreita, o deslocamento normal entre pontos correspondentes dos corpos em contato, h(x), é dado pela Equação (5):

$\frac{1}{A} \frac{\partial h}{\partial x}=\frac{1}{\pi} \int_{-a}^{a} \frac{P(\varepsilon)}{x-\varepsilon} d \varepsilon$

onde A é uma constante do material, dada pela Equação (6), $\varepsilon$ é a variável de integração do carregamento $\mathrm{P}$ ao longo da zona de contato.

$A=\frac{4(1-v)}{E}$

Da mesma forma, o deslocamento tangencial relativo entre dois pontos correspondentes em contato, $\mathrm{g}(\mathrm{x})$, é função da carga tangencial $\mathrm{Q}(\mathrm{x})$ :

$\frac{1}{A} \frac{\partial g}{\partial x}=\frac{1}{\pi} \int_{-a}^{a} \frac{Q(\varepsilon)}{x-\varepsilon} d \varepsilon$

Com a devida manipulação algébrica das Equações (6-7), é possível chegar às Equações (8-12): 
$\mathrm{a}=\sqrt{\mathrm{P} \frac{2 \mathrm{~A}}{\pi\left(\frac{1}{\mathrm{R}_{\mathrm{S} 1}}+\frac{1}{\mathrm{R}_{\mathrm{S} 2}}\right)}}=\sqrt{\frac{4 \mathrm{R}^{*}}{\pi \mathrm{E}^{*}}}$

Eq. (8)

$E^{*}=\left(\frac{1-v_{1}^{2}}{E_{1}}+\frac{1-v_{2}^{2}}{E_{2}}\right)^{-1}$

Eq. (9)

$\mathrm{R}^{*}=\left(\frac{1}{\mathrm{R}_{1}}+\frac{1}{\mathrm{R}_{2}}\right)^{-1}$

Eq. (10)

$\mathrm{p}_{0}=\frac{2 \mathrm{P}}{\pi \mathrm{a}}$

Eq. (11)

$\mathrm{p}(\mathrm{x})=\mathrm{p}_{0} \sqrt{1-\left(\frac{\mathrm{x}}{\mathrm{a}}\right)^{2}}$

Eq. (12)

Em situações de fretting, muitos estudos confirmam a ocorrência de escorregamento parcial entre o espécime e o pad. Tal fenômeno pode ser dividido em escorregamento total, onde $c<|x| \leq a$, e zona de adesão, onde $|x| \leq c$, sendo 2c o tamanho da zona de adesão, como é demonstrado na Figura 6.

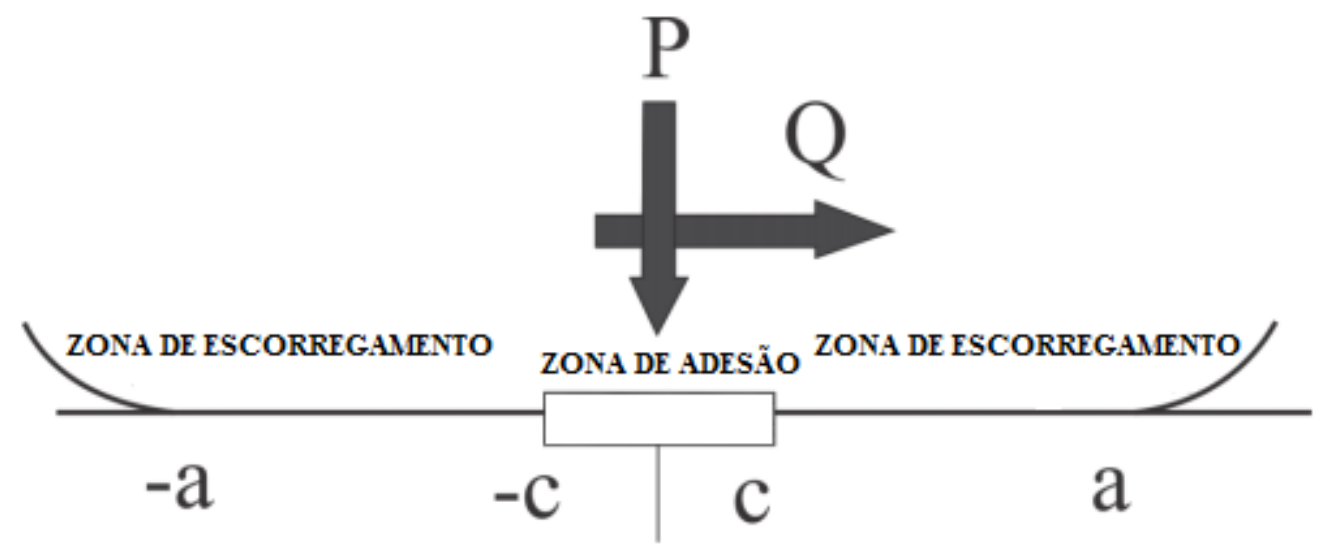

Figura 6 - Regiões de escorregamento para contato entre cilindros

Ademais, o fenômeno de fretting envolve carregamentos cíclicos, como o que ilustra a Figura 7.

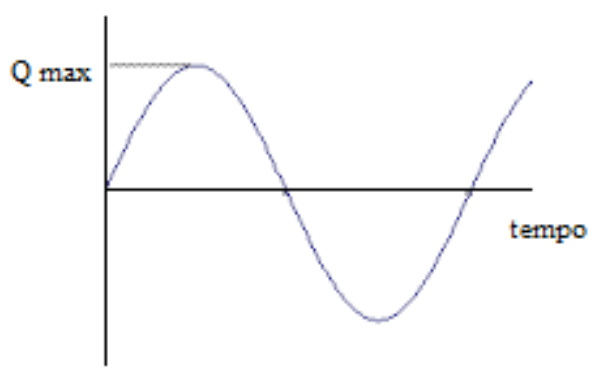

Figura 7 - Carga oscilatória em função do tempo 
O escorregamento supramencionado ocorre pela mudança da direção das partículas de contato por conta da alteração da direção do carregamento. O tamanho da zona de adesão, 2c, para um coeficiente de atrito f, é dado pela Equação (13):

$c(t)^{\prime}=a \sqrt{1-\frac{Q \max -Q(t)}{2 f P}}$

A variação das tensões cisalhantes na superfície de contato ao longo do tempo para o carregamento cíclico é ilustrada na Figura 8.

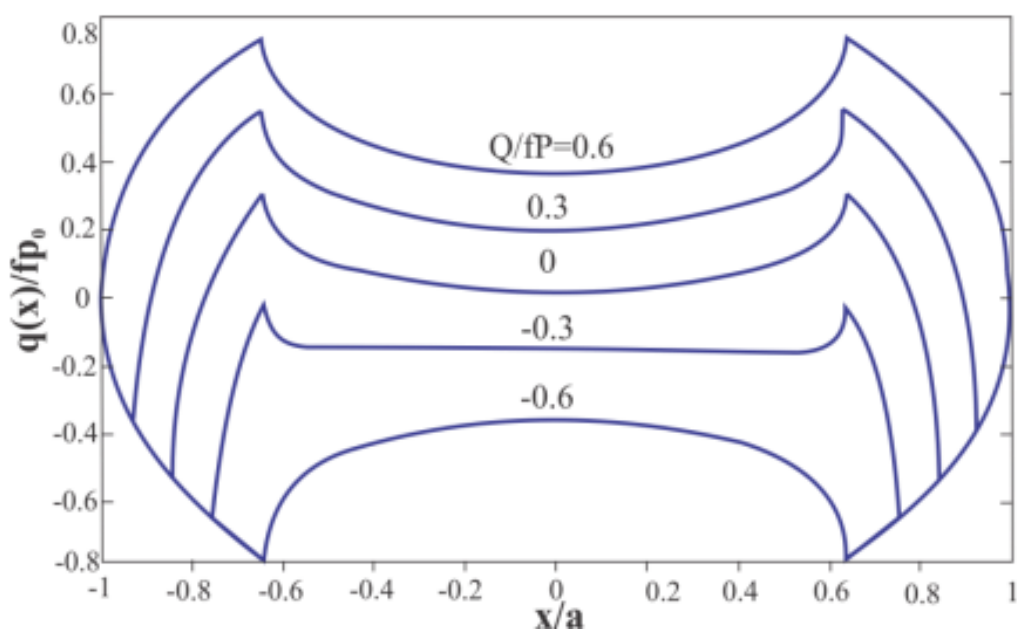

Figura 8 - Variação das tensões cisalhantes na superfície de contato ao longo do tempo (Fonte: CARDOSO, 2015)

Os formatos das curvas típicas de carregamento possuem tal forma, conforme cita (CARDOSO, 2015), por conta do desconto da razão $\mathrm{p}(\mathrm{x}) / p_{o}$ da perturbação q'(x) na zona de adesão (Figura 9).

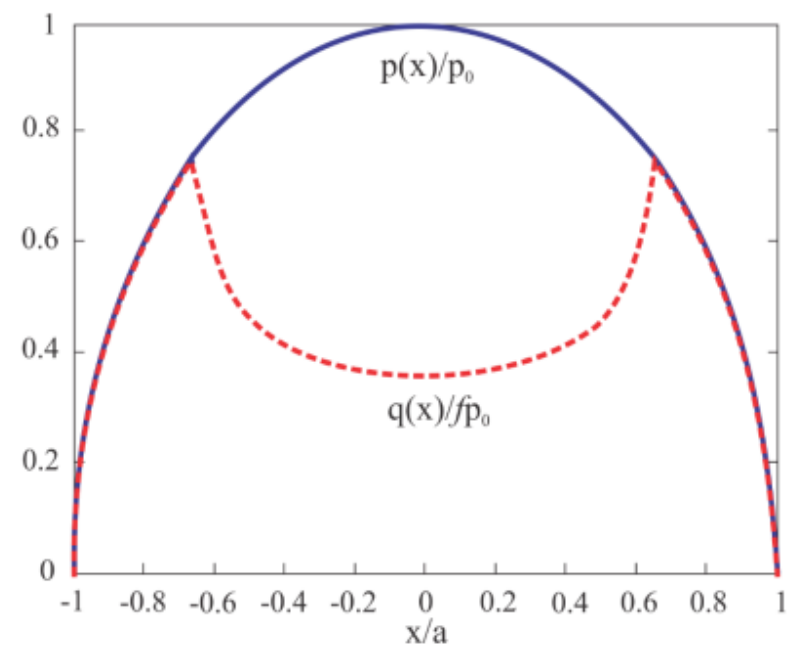

Figura 9 - Perfil de distribuição de tensões normais e cisalhantes (Fonte: CARDOSO, 2015) 
Portanto, conforme podem ser visualizadas na Figura 9, as distribuições de tensões cisalhantes são iguais em módulos para as cargas máximas e mínimas, porém com sinais opostos. É importante notar que a ausência de carga não implica em tensão cisalhante nula, mas em equilíbrio. Logo, a distribuição de tensões ao longo do tempo não é linear e depende da história do carregamento.

É comum que durante a ocorrência do fenômeno de fretting, cargas longitudinais variáveis, também conhecidas por cargas remotas de fadiga e bulk stress, ocorram. A carga remota de fadiga, $\sigma_{b}$, costuma ocorrer em fase com a carga tangencial. Isto provoca o deslocamento da zona de adesão durante os picos e vales de carregamento. Consequentemente, as curvas típicas da Figura 9 deformam-se como mostrado na Figura 10.

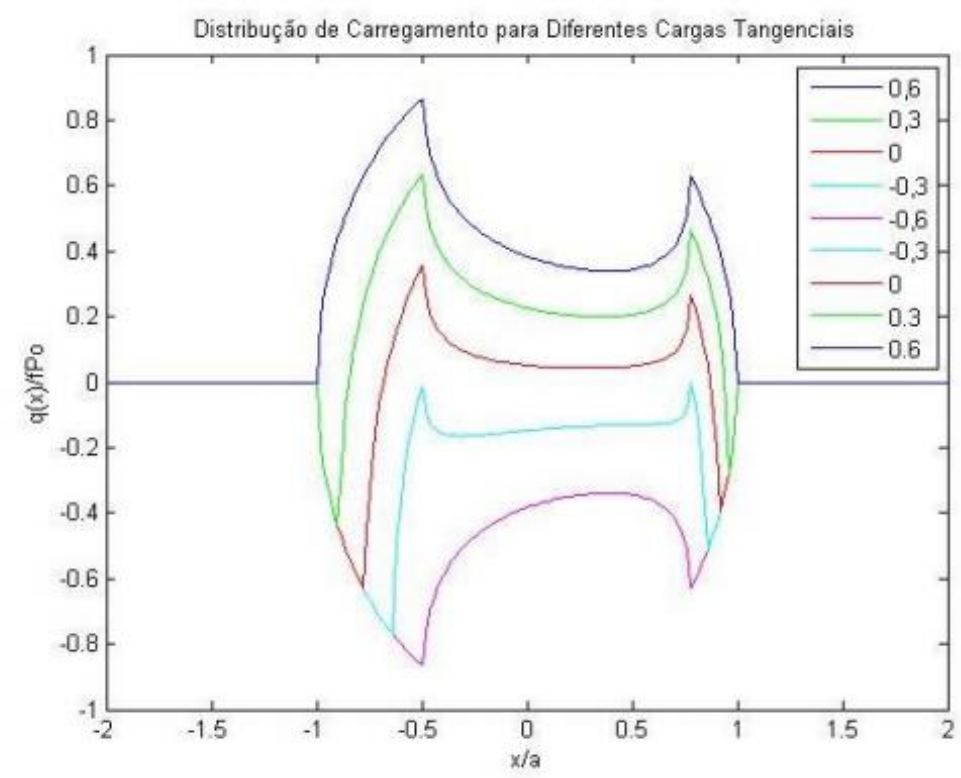

Figura 10 - Distribuição de tensão cisalhante para diferentes cargas tangenciais sob bulk stress (ESTARLE, 2014)

Sob o regime elástico, o campo de tensões pode ser obtido pela superposição dos campos de tensão provocados pelas cargas normal e tangencial para um mesmo período de tempo.

As demais equações (14-17) que representam o fenômeno do contato hertziano quando há carga remota de fadiga foram descritas por NOWELL \& HILLS (1987): 


$$
\begin{gathered}
q(x)=-f p(x)+q^{\prime}(x)=-f p_{0} \sqrt{1-\left(\frac{x}{a}\right)^{2}}+q^{\prime}(x) \\
q(x)=-f p_{0} \sqrt{1-\left(\frac{x}{a}\right)^{2}}+\frac{c}{a} f p_{0} \sqrt{1-\left(\frac{x-e}{c}\right)^{2}} \\
q^{\prime}(x)=0,|x-e|>c \\
\frac{e}{a}=\frac{\sigma}{4 f p o}
\end{gathered}
$$




\subsection{MECÂNICA DA FRATURA}

\subsubsection{RESUMO HISTÓRICO}

Embora o interesse humano pela mecânica da fratura surja provavelmente com a origem das civilizações, os primeiros estudos sobre resistência à fratura foram encontrados nos registros de Leonardo da Vinci sobre cabos de ferro imperfeitos. (ROSSMANITH, 1982). O inventor, embora com uma forte determinação para descobrir a resistência à fratura dos cabos e que tenha desenvolvido alguns aparatos para a determinação desta propriedade, encontrava-se mais interessado em proporcionar um transporte seguro para suas grandes obras do que na mecânica da fratura em si.

Existem registros históricos de outros estudos relacionados à mecânica da fratura, como o elaborado pelo Corpo Real de Engenheiros, encomendado por Louis XIV em 1650 para examinar deformações em fontes do palácio de Versalhes. Em todos esses estudos, no entanto, o foco ainda não era a mecânica da fratura, mas como resolver problemas decorrentes da mesma, o que acabava por gerar conhecimentos de usos bem específicos.

Foi somente no século XX que a mecânica da fratura moderna teve sua base fomentada. O britânico Charles Inglis publicou, em 1913, um importante estudo sobre tensões em placas devido à presença de trincas e de entalhe. E, somente em 1920, o também britânico, Alan Arnold Griffith, publicou "The phenomena of Rupture and Flow in Solids", trabalho considerado como a base dessa ciência.

A partir da década de 1930, com a militarização advinda da ascensão de grupos extremistas, foram feitas cada vez mais investigações na área a fim de melhorar a blindagem e principalmente reduzir o peso das unidades blindadas. Embora falhas em unidades de artilharia, metralhadoras e outros equipamentos militares tivessem sido observadas durante a primeira grande guerra, tratava-se ainda de um conflito relativamente estático, com tanques e aviões extremamente lentos. Na América, a marinha americana inicializou por volta de 1937 pesquisas relacionadas a trincas na Universidade de North Carolina. Já na Europa, Weibull publicou em 1939 sua teoria de falhas utilizando conceitos estatísticos. Trabalhos de cunho similar foram desenvolvidos na mesma época no Japão (ROSSMANITH, 1982). 
Durante a Segunda Guerra, a Blitzkrieg alemã deu origem à guerra de mobilidade. Os grandes avanços tecnológicos durante esta época deram outra velocidade e potência a unidades blindadas, submarinos, navios, aviões e até foguetes. Com estes avanços, aumentavam-se tensões e amplitudes de frequências aplicadas, levando as peças a esforços antes inimagináveis. Naturalmente, assustadores acúmulos de falhas por fratura foram contabilizados, o que aumentava grandemente o interesse de pesquisadores pela mecânica da fratura. Através de pesquisas neste período e no pós-guerra, surgiram diversos trabalhos importantes, como os do americano George Rankin Irwin, considerado por muitos o pai da mecânica da fratura.

O desenvolvimento da ciência da fratura tem, desde então, acompanhado os avanços tecnológicos, principalmente ligados aos novos recursos computacionais.

\subsubsection{RESUMO LITERÁRIO}

A Mecânica da fratura trata do estudo de propagação da trinca e de sua ruptura final. As trincas, também comumente conhecidas por fissuras, fendas, frestas ou rachaduras, podem ter origens de fabricação ou devido ao serviço da peça. As estruturas dúcteis que não falham por sobrecarga ou corrosão generalizada despendem suas vidas úteis para gerar ou propagar trincas de uma forma estável e paulatina (CASTRO \& MEGGIOLARO, 2009b). É possível distinguir os diversos processos físicos associados ao crescimento da trinca em:

(i) Fraturamento: quando a fratura é instável.

(ii) Rasgamento: quando a fratura é semi-estável, ou seja, requer cargas crescentes para progredir em tempos curtos.

(iii) Trincamento: quando há propagação estável e paulatina. 


\subsubsection{PLACA DE INGLIS}

Trabalhos como o de INGLIS (1913) demonstraram que o furo elíptico, conforme apresentado na Figura 11, pode simular entalhes em geral e onde um fator de concentração de tensão $K_{t}$ cresce à medida que o raio $\rho$ da ponta do furo diminui.

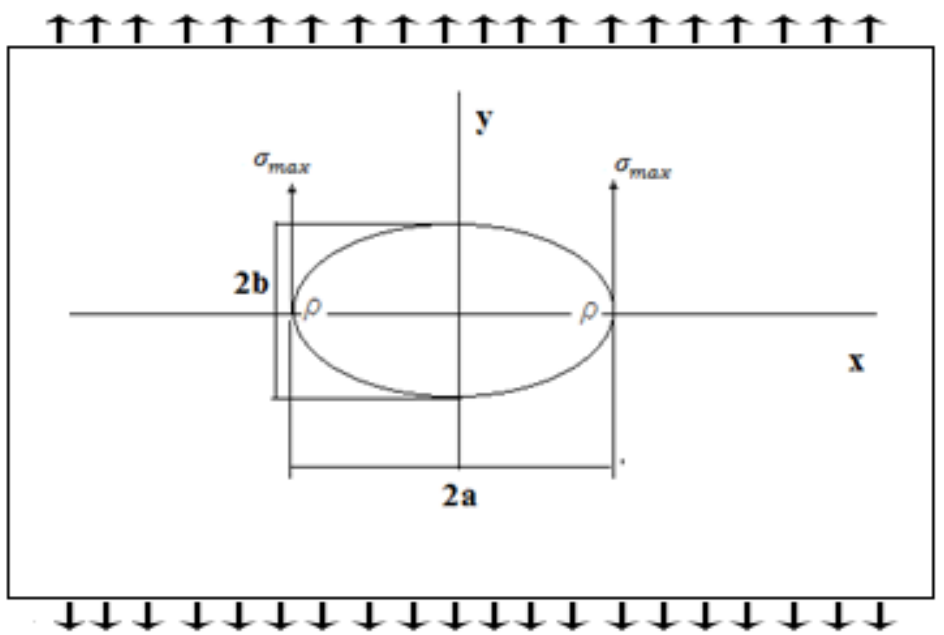

Figura 11 - Placa de Inglis

Da Geometria, sendo a e b os semi-eixos da elipse da Figura 11, $\sigma_{n}$ a tensão nominal aplicada à placa de Inglis em uma direção perpendicular ao semi-eixo $a>b$, $\sigma_{\max }$ a maior tensão que atua na borda do furo nos extremos do maior eixo da elipse, tem-se da Equações (18) e (19):

$\rho=b^{2} / a$

$K_{t}=\frac{\sigma_{\max }}{\sigma_{n}}=1+2 \frac{a}{b}=1+2 \sqrt{\frac{a}{\rho}}$

Visto que as trincas podem ser aproximadas pelos entalhes elípticos ou semielípticos que as envolvem, e como os raios das trincas ideias são tão pequenos que se aproximam de zero, $K_{t}$ se aproxima do infinito. (CASTRO \& MEGGIOLARO, 2009b). Logo, as tensões lineares elásticas são singulares nas pontas, permitindo que para qualquer tensão normal maior que zero a tensão máxima assuma qualquer valor. Este fator torna as trincas especialmente perigosas. 


\subsubsection{INSPEÇÃO E TOLERÂNCIA A DEFEITOS}

Uma estrutura é considerada segura quando, sob determinadas cargas previsíveis e repetitivas, tolere trincas não detectadas durante a última inspeção. Este conceito, denominado projeto tolerante a defeitos, foi desenvolvido no último quarto do século $\mathrm{XX}$, principalmente após a queda de um avião F-111.

Mesmo tendo sido inspecionado por pelo menos três inspetores altamente qualificados, de companhias diferentes, ter sido fabricada com a mais alta tecnologia disponível, sem restrição de custos, um pino, que era uma peça crítica atrelada à asa do avião, falhou após 104 horas de vôo. Perícias após o acidente indicaram uma pequena falha de fabricação de $23,3 \times 5,7 \mathrm{~mm}$, a qual cresceu apenas $0,44 \mathrm{~mm}$ até sua fratura (CASTRO \& MEGGIOLARO, 2009a).

A U.S. Air Force concluiu então que era necessário adotar uma metodologia que supunha que as estruturas não possuíam defeitos maiores do que o limiar de detecção, cujo valor é estabelecido de acordo com o método de inspeção. A partir de 1974, tornouse compulsório pela USAF que todos seus aviões fossem projetados para resistir a possíveis defeitos que poderiam passar despercebidos, sendo, os piores possíveis, as trincas.

Logo, a segurança estrutural é garantida sob esta metodologia se for garantido que qualquer defeito não detectado em uma determinada inspeção não possa atingir seu tamanho crítico até a seguinte. O período entre as inspeções é determinado pelos modelos de fadiga, os quais calcularão o tempo e a dimensão da propagação de trinca para uma determinada carga de serviço.

Existem diversas formas para se detectar as trincas, a numerar algumas de natureza não destrutiva:

(i) Inspeção visual

(ii) Líquido penetrante

(iii) Partículas magnéticas

(iv) Correntes parasitas

(v) Ultrassom

(vi) Radiografia 
Cada uma dessas técnicas possui um grau de precisão, um custo e uma praticidade associados. Naturalmente, o método de inspeção será escolhido conforme várias características, sendo a mais importante o risco de morte em caso de falha do objeto. Outra forma de inspeção é o teste de sobrecarga, o qual possivelmente ocasionará a falha da peça, mas, como no caso de aeronaves, impede a perda total da mesma e também salva a vida dos tripulantes.

A probabilidade de detecção de trincas utilizando métodos não destrutivos possui alta probabilidade de detecção quando o tamanho das mesmas está na ordem de $10 \mathrm{~mm}$. Para valores da ordem de $1 \mathrm{~mm}$, todos poderiam não detectar as trincas. Abaixo de 0.1 $\mathrm{mm}$, nenhum deles faria a detecção de forma confiável (CASTRO \& MEGGIOLARO, 2009a).

\subsubsection{MODOS DE FRATURA}

A introdução de uma trinca, entalhe ou qualquer outro concentrador de tensão fará que haja uma redistribuição das tensões na peça, o que pode ser analisado por métodos lineares elásticos. Deve-se priorizar o estudo do aumento de pressão na vizinhança da ponta da trinca, a qual, conforme descrevem (TADA, PARIS, \& IRWIN, 2000), acaba sendo acompanha por uma zona de plasticidade e outros efeitos não lineares. De toda forma, a mecânica da fratura linear elástica (MFLE) é a base da análise de fraturas, ao menos quando há uma escala pequena de escoamento da peça, pois, neste caso, os efeitos de não linearidade se limitam a zona descrita.

É possível, conforme sugerem TADA et al. (2000), classificar os modos de fratura em três, conforme exemplificado na Figura 12. 


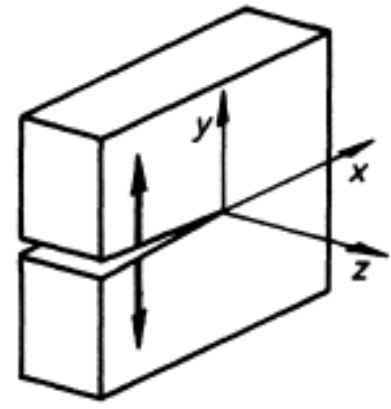

Tipo I

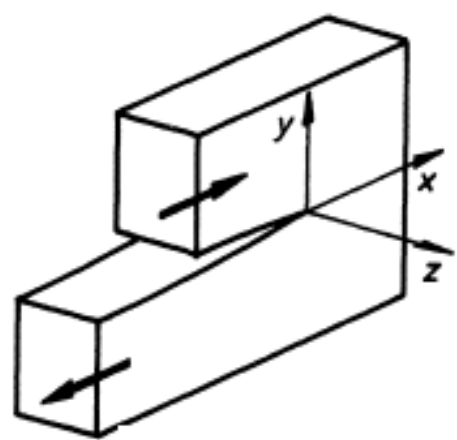

Tipo II

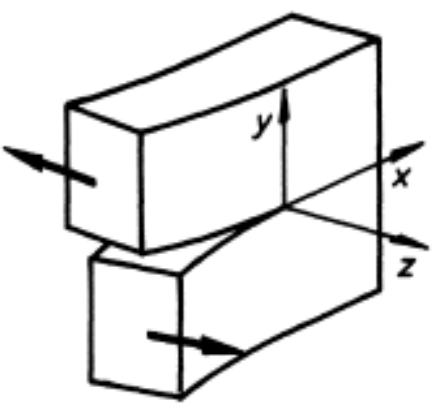

Tipo III

Figura 12 - Tipos de fratura

No Tipo I, existe clara predominância de tensões trativas, onde as superfícies da trinca movem-se uma longe da outra. No segundo tipo, há predominância de forças cisalhantes, onde as superfícies deslizam-se uma sobre a outra. Já no Tipo III, ocorre uma espécie de rasgamento, onde as superfícies também deslizam-se uma sobre a outra, havendo predominâncias de tensões de cisalhamento. A sobreposição destes tipos de fratura é suficiente para a descrição da maioria dos casos relacionados à mecânica da fratura linear elástica.

\subsubsection{BALANÇO DE ENERGIA DE GRIFFITH}

O trabalho matemático de Inglis em 1913 demonstrava os efeitos de concentradores de tensão em placas com furos elípticos, mas não conseguia explicar o motivo pelo qual as peças trincadas não quebravam sob carregamento.

A fim de explicar os efeitos de ranhuras e sulcos em superfícies na resistência das peças, (GRIFFITH, 1921) propôs uma abordagem levando-se em conta o Teorema de Energia Mínima.

O autor provou que, uma vez que deve ocorrer conservação de energia, uma trinca só poderia crescer, se lhe fosse fornecida energia na forma de trabalho. Desta afirmação, obtemos a Equação (20):

$\delta W \geq \delta E_{D}+\tau \delta A$

onde $\delta E_{D}$ é a variação da energia de deformação, $\delta W$ é o incremento de trabalho fornecido, $\tau$ é a tenacidade e $\delta \mathrm{A}$ é o aumento da área da trinca. 
A variação de energia $\delta E_{D}$ é calculada em função da densidade da energia de deformação, U, conforme a Equação (21):

$\delta E_{D}=\iiint U d x d y d z$

Onde a Equação 22 é a densidade U de energia de deformação:

$U=\frac{\left(\sigma_{x}^{2}+\sigma_{y}^{2}+\sigma_{z}^{2}\right)}{2 E}-\frac{\sigma_{x} \sigma_{y}+\sigma_{x} \sigma_{z}+\sigma_{y} \sigma_{z}}{\frac{E}{v}}+\frac{\tau_{x y}^{2}+\tau_{x z}^{2}+\tau_{y z}^{2}}{2 G}$

Conforme descrevem CASTRO \& MEGGIOLARO (2009a), o aumento da trinca tende a crescer a quantidade de material da peça descarregado, pois as tensões trativas não podem ser transmitidas através das faces das trincas. Assim, o aumento da trinca implica em um alívio da energia de deformação armazenada na peça, expresso pela Equação (23):

$E_{p}=E_{d}-W$

onde W é o trabalho realizado pelos esforços atuantes na peça trincada quando a mesma se mexe. A variação desta energia potencial em relação à variação de área da trinca é definida como taxa de alívio da energia potencial elástica, dada pela Equação (24):

$\mathscr{G}=-\partial E_{p} / \partial A$

A letra Ğ é uma homenagem a Griffith. É provado que esta taxa independe da forma da carga, podendo ser medida pela variação da flexibilidade $\mathrm{dC} / \mathrm{da}$ da peça à medida que a trinca aumenta. A variação de tal flexibilidade é, inclusive, uma técnica popular para medição de tamanhos de trincas através de corpos de prova.

É possível fazer a divisão das taxas de alívio de energia de acordo com os modos (ou tipos) de trincas descritos na seção anterior: $\mathscr{L}_{1}=\mathscr{G}_{i}+\mathscr{G}_{i i}+\mathscr{G}_{i i i}$. Como as trincas normalmente propagam em modo I, este é o crítico e mais relevante para a engenharia estrutural.

Para o caso em que a tenacidade $\tau$ do material independa do tamanho da trinca a e do seu incremento $\Delta \mathrm{a}$, a trinca gasta Ġic para que sua área $\mathrm{A}$ cresça uma unidade do incremento em modo I. Então, por conservação de energia chega-se à Equação (25): 
$-\frac{\partial E_{p}}{\partial A}=\mathcal{G}_{i} \geq \tau=\mathcal{G}_{i c}$

Eq. (25)

Portanto, a trinca permanecerá estável sempre que $\mathcal{L g}_{i} \leq \tau=\mathcal{G}_{i c \text {. }}$ "Desta forma, Ġic pode ser usada para medir a resistência à propagação da trinca, ou seja, a tenacidade do material em modo I sob condições predominantemente elásticas. Isto ocorre porque os materiais quase idealmente elásticos são muito frágeis, pois praticamente toda energia Ġic ${ }^{*}$ dA necessária para propagar a trinca é despendida para formar suas novas superfícies. Aliás, por isto que Griffith, que sabia estimar a energia potencial do vidro, usou pequenas fibras deste material (extremamente frágil) para comprovar a sua teoria experimentalmente" (CASTRO \& MEGGIOLARO, 2009a).

\subsubsection{FATOR DE INTENSIDADE DE TENSÃO}

É necessária a análise global das tensões e deformações em todos os pontos de uma peça, a fim de que se calcule analiticamente a energia elástica armazenada na mesma. Naturalmente, trata-se uma tarefa extremamente trabalhosa, o que limita o uso prático da taxa de alívio determinar por Griffith. Como descrevem (CASTRO \& MEGGIOLARO, 2009a), a utilidade da taxa de alívio de Griffith é maior na análise de trincas por elementos finitos, devido à relativa facilidade em se calcular o produto $\sigma{ }^{*} \varepsilon$ em toda a peça.

Em 1957, Williams em "On the stress distribution at the base of a stationary crack" e Irwin em "Analysis of stresses and strains near the end of a crack transversing a plate" introduziram o conceito de fator de intensidade de tensões para quantificar o campo de tensões em torno de uma trinca em uma peça predominantemente linear elástica. Os trabalhos, embora tenham chegado ao mesmo resultado, foram feitos de formas independentes e diferentes. Irwin baseou-se no trabalho de Westergaard, enquanto Williams propôs seu trabalho em função de uma série infinita.

Este trabalho tratará apenas do conceito de Irwin, onde a expressão completa do campo de tensões em torno de qualquer trinca, para qualquer material linear, elástico, isotrópico e homogêneo, em modo I é:

$$
\left(\begin{array}{c}
\sigma_{x} \\
\sigma_{y} \\
\tau_{x y}
\end{array}\right)=\frac{K_{I}}{\sqrt{2 \pi r}} \cos \left(\frac{\theta}{2}\right) *\left\{\begin{array}{c}
1-\sin \left(\frac{\theta}{2}\right) * \sin \left(\frac{3 \theta}{2}\right) \\
1+\sin \left(\frac{\theta}{2}\right) * \sin \left(\frac{3 \theta}{2}\right) \\
\sin \left(\frac{\theta}{2}\right) * \cos \left(\frac{3 \theta}{2}\right)
\end{array}\right.
$$


Para o modo II, a expressão é a seguinte:

$$
\left(\begin{array}{c}
\sigma_{x} \\
\sigma_{y} \\
\tau_{x y}
\end{array}\right)=\frac{K_{I I}}{\sqrt{2 \pi r}} \cos \left(\frac{\theta}{2}\right) *\left\{\begin{array}{c}
-\sin \left(\frac{\theta}{2}\right)\left[2+\cos \left(\frac{\theta}{2}\right) * \cos \left(\frac{3 \theta}{2}\right)\right. \\
\sin \left(\frac{\theta}{2}\right) * \cos \left(\frac{\theta}{2}\right) * \cos \left(\frac{3 \theta}{2}\right) \\
\cos \left(\frac{\theta}{2}\right) *\left[1-\sin \left(\frac{\theta}{2}\right) * \sin \left(\frac{3 \theta}{2}\right)\right.
\end{array}\right.
$$

E por fim, para o modo III:

$$
\left(\begin{array}{c}
\tau_{x z} \\
\tau_{y z}
\end{array}\right)=\frac{K_{I I I}}{\sqrt{2 \pi r}} *\left(\begin{array}{c}
-\sin \left(\frac{\theta}{2}\right) \\
\cos \left(\frac{\theta}{2}\right)
\end{array}\right)
$$

O sistema de coordenadas tem a ponta da trinca como origem, conforme pode ser visto na Figura 13.

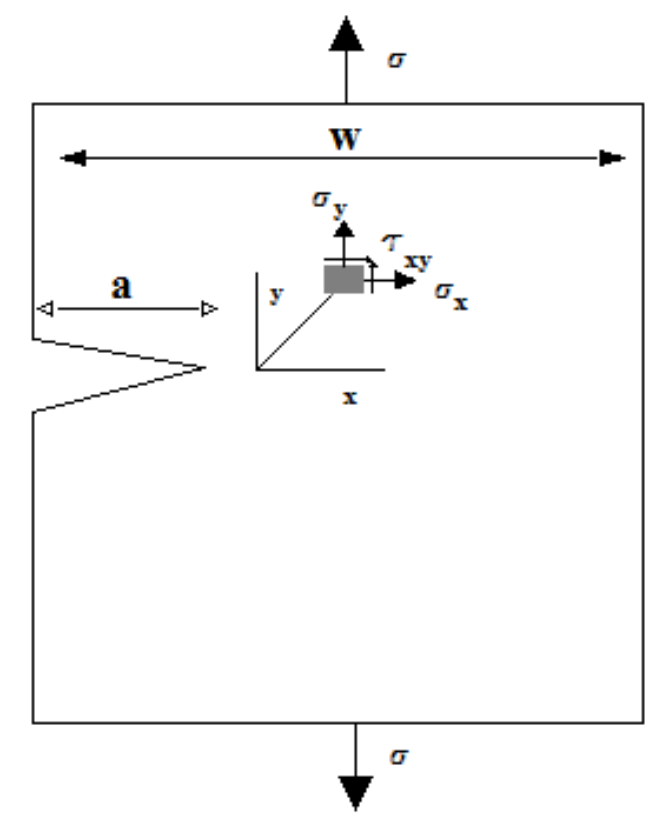

Figura 13 - Sistema de coordenadas para uma trinca

É importante notar que, uma vez estabelecido o fator de intensidade de tensão K da peça, o mesmo pode ser tabelado para uma mesma geometria. As Equações (26-28) levavam em consideração que $\rho=0$, ou seja, as tensões tenderiam ao infinito na ponta da trinca. Naturalmente, esta análise linear elástica não pode descrever as tensões na ponta da trinca. Contudo, materiais reais não são lineares nem elásticos sob tensões altas. Deste modo, assume-se que exista uma região não linear em torno das pontas das trincas 
e que, desde que esta região seja diminuta suficiente, a peça terá comportamento linear elástico.

Portanto, a validação do fator de intensidade de tensões de Irwin depende do tamanho da zona de perturbação em relação ao tamanho da peça. Caso tal perturbação seja demasiadamente grande, não haverá previsão efetiva dos efeitos das trincas pelo FIT.

A zona de perturbação zp pode ser calculada para $\theta=0$. Para o modo I, por exemplo, ter-se-á a Equação 29:

$z p=\frac{1}{2 \pi} *\left(\frac{K_{I}^{2}}{S_{E}^{2}}\right)$

Para Meggiolaro (2009), nas estruturas reais, quando zp $<<(\mathrm{a}, \mathrm{w}-\mathrm{a}, \mathrm{h})$, onde a é o tamanho da trinca, w-a é o ligamento residual (a parte não trincada à frente da ponta da trinca) e $\mathbf{h}$ é a menor distância da fronteira da peça à ponta da trinca, K controlará as tensões, valendo a MFLE.

\subsubsection{MECÂNICA DA FRATURA BASEADA EM DEFORMAÇÃO (MFBD)}

Embora a mecânica da fratura linear elástica tenha boa aplicabilidade para estudos de fadiga, ela se mostra incapaz de prever os efeitos de não linearidade dos materiais. A fim de considerar estes efeitos, utiliza-se o método da mecânica da fratura baseada em deformação (MFBD), a qual é uma adaptação da MFLE.

Como descrevem GHAREMANI et al. (2016), a MFBD é capaz de prever os mecanismos de aceleração de crescimento de duas trincas, como o do efeito de relaxamento de tensões compressivas atuantes grandes o suficiente para causar efeitos não-lineares. Ademais, a MFBD não necessita de duas fases para a modelagem da vida à fadiga e foi originalmente desenvolvida para modelar o comportamento de trincas pequenas em entalhes, fora dos domínios da MFLE. No entanto, os resultados obtidos pela MFBD convergem para os da MFLE nos casos de trincas maiores.

O número de ciclos até à falha $(\mathrm{N})$ neste método é calculado aplicando-se as constantes de taxa de crescimento da trinca $(\mathrm{C}$ e $\mathrm{m}$ ) para um intervalo de profundidade da trinca, $\left[a_{i n i}, a_{c}\right.$ ], onde $a_{i n i}$ corresponde à profundidade inicial da trinca e $a_{c}$ à profundidade crítica. O cálculo é efetuado pela integração da Equação 30: 
$\frac{\mathrm{da}}{\mathrm{dN}}=\mathrm{C}\left(\Delta \mathrm{K}_{\mathrm{eff}}^{\mathrm{m}}-\Delta \mathrm{K}_{\mathrm{th}}^{\mathrm{m}}\right)$

A Equação 30 é uma modificação da lei de Paris-Erdogan para se considerar os efeitos de fechamento da trinca, que são levados em conta pelo cálculo da Equação 31:

$\Delta \mathrm{K}_{\mathrm{eff}}=\mathrm{K}_{\mathrm{max}}-\max \left(\mathrm{K}_{\mathrm{op}}, \mathrm{K}_{\mathrm{min}}\right)$

Onde $K_{\max }$ e $K_{\min }$ são os FIT correspondentes aos níveis de tensão máxima e mínima para cada ciclo de carregamento e $K_{o p}$ corresponde ao nível de tensão para abrir a trinca para uma essa carga cíclica. Cada FIT é computado pela Equação 32:

$\mathrm{K}=\mathrm{FE} \varepsilon \sqrt{\pi \mathrm{a}}$

Onde $\mathrm{F}$ é o fator de correção para o formato da trinca, a espessura finita da placa e a superfície livre em um lado da trinca, E é o módulo de elasticidade do material, a é a profundidade da trinca abaixo da superfície e $\varepsilon$ é a deformação local para uma determinada profundidade.

O modelo de material sob carga cíclica proposto por Ramberg-Osgood é então utilizado para se calcular tensões e deformações para cada ciclo de carregamento e a regra de Neuber é utilizada para se calcular a história de deformações para diferentes profundidades abaixo da superfície.

O FIT elástico que considera a distribuição de tensão não uniforme ao longo do caminho da trinca pode ser calculado por funções de peso, como as propostas por SHEN \& GLINKA (1991):

$\mathrm{K}_{\mathrm{el}}=\int_{0}^{\mathrm{a}} \mathrm{k}(\mathrm{x}) \mathrm{m}(\mathrm{x}, \mathrm{a})$

Onde $\mathrm{k}(\mathrm{x})$ é o fator concentrador de tensão para uma profundidade $\mathrm{x}$ da trinca e $\mathrm{m}(\mathrm{x}, \mathrm{a})$ é a função de peso.

DEBAYEH et al. (1998) propuseram um fator de concentração de tensão modificado $K_{p}$ que considera a presença da trinca na zona crítica para se determinar as tensões locais elásticas.

$\mathrm{k}_{\mathrm{p}}=\frac{\mathrm{K}_{\mathrm{el}}}{\mathrm{F} \sigma \sqrt{\pi \mathrm{a}}}$ 
As tensões elásticas locais $\left(\sigma_{e l}\right)$ correspondentes às tensões nominais $\mathbf{S}$ podem então ser calculadas usando a Eq. (35)

$$
\sigma_{\mathrm{el}}=\mathrm{k}_{\mathrm{p}} \mathrm{S}
$$

\subsubsection{FUNÇÃO DE PESO}

A análise bibliométrica, apresentada no capítulo seguinte, permite afirmar que o Método da função de peso (WF) é amplamente utilizado para se determinar o fator de intensidade de tensão (FIT). A vantagem em tal escolha esta na possibilidade de separação do carregamento e a geometria na simulação (WANG \& GLINKA, 2009).

A mudança de geometria devido ao surgimento e propagação da trinca torna o custo computacional elevado para se determinar o fator de intensidade de tensão para análises de fadiga exclusivamente por elementos finitos. Há necessidade de se recriar a malha para cada situação, o que torna o tempo despedindo excessivo. Algumas alternativas, como o método dos elementos finitos expandidos, mostram-se soluções interessantes para evitar tal problema. As WF utilizam o campo de tensões em um corpo sem trincas, não sendo necessárias atualizações no campo de tensões com o progresso da trinca. O FIT pode ser determinado pela mesma função de peso e é proporcional à carga aplicada (GLINKA \& REINHARDT, 2000), o que o torna eficiente.

A Figura 14 mostra esquematicamente a determinação do FIT, obtida analiticamente através da Equação 36.

$K=\int_{0}^{a} \sigma(x) m(x, a) d x$

Para um corpo com trinca (Figura 11 a), sujeito a uma carga externa S, o FIT é imutável para a mesma geometria, mesmo que um campo de tensão seja aplicado ao corpo (Figura $11 \mathrm{c}$ ). $\mathrm{O}$ campo de tensão local induzido pela carga $\mathrm{S}$ é determinado para um corpo sem trinca (Figura 11b). Assim, o FIT unidimensional é obtido multiplicandose a função de peso $\mathrm{m}(\mathrm{x}, \mathrm{a})$ e a distribuição de tensão $\sigma(\mathrm{x})$ no plano da trinca $\mathrm{e}$ integrando-se o resultado em relação a posição x. 


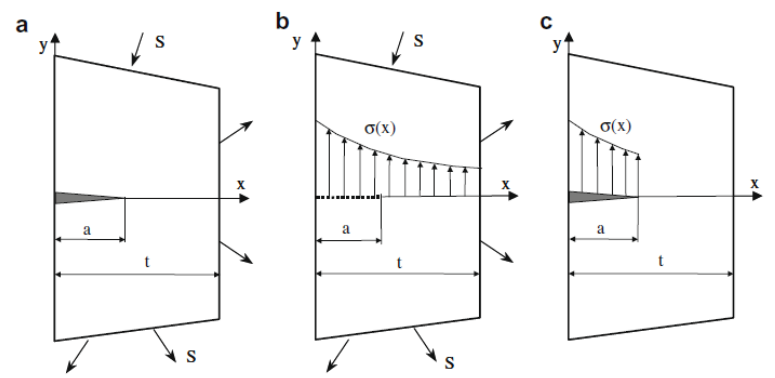

Figura 14 - Função peso para trinca unidimensional, (a), (b) e (c) (Fonte: WANG; GLINKA, 2009)

Uma expressão geral para a função de peso unidimensional foi proposta por GLINKA \& SHEN (1991), onde os parâmetros Mi já foram determinados para diversas geometrias.

$m(x, a)=\frac{2 F}{\sqrt{2 \pi(a-x)}}\left[1+M_{1}\left(1-\frac{x}{a}\right)^{1 / 2}+M_{2}\left(1-\frac{x}{a}\right)^{1}+M_{3}\left(1-\frac{x}{a}\right)^{3 / 2}\right]$

Os resultados obtidos com a expressão da Equação 29 foram validados por GLINKA et al. (2000) com diversos resultados presentes na literatura, com erros não acima de $5 \%$.

Para a análise bidimensional, a Equação 33 toma a forma da Equação 38:

$K=\iint_{\Omega} \sigma(x, y) m_{A}(x, y, F) d x d y$

Eq. (38)

\subsection{TIPOS DE FRETTING}

\subsubsection{FRETTING WEAR}

A diferença mais significativa entre este conceito e os demais é que o fretting wear sempre ocorrerá em superfícies de contato que deveriam estar fixas uma relação à outra, mas onde ocorre o movimento relativo.

O processo deste tipo de dano foi sumarizado por HURRICKS (1970), o qual o dividiu em três etapas: A adesão e transferência do contato das superfícies, a formação de detritos e suas oxidações e a etapa estável. Em 2002, HOEPPNER propôs considerar o fretting wear em cinco aspectos: influência dos filmes de superfície, aderência das superfícies de contato, deformação plástica e esfregaço, transferência de material de uma superfície para a outra e formação do óxido. No entanto, essas teorias não explicavam como o mecanismo de fretting estava presente em materiais como o diamante, onde não havia oxidação. Em 1988, GODET propôs um modelo onde havia um mecanismo da velocidade de acomodação das interfaces de contato, a fim de explicar as propriedades 
de fricção e o movimento relativo. Esta teoria também dividia o mecanismo de fretting wear em três processos:

(a) Estágio do contato entre dois corpos

(b) Estágio de transição

(c) Estágio de contato entre três corpos

Segundo esta teoria, há um coeficiente de fricção que varia de acordo com a quantidade de ciclos de fretting. No início do ciclo, tal coeficiente possui valor baixo, explicado pela influência dos filmes de contato das superfícies, os quais as protegem antes de suas remoções. Depois disto, há um aumento súbito devido ao aumento das interações de contato, adesão, deformação plástica e esfregaço. Tudo isso gera acúmulo de detritos entre as duas superfícies, os quais são considerados o terceiro corpo, ocorrendo então a transformação do contato entre dois corpos para o de contato entre três corpos. $\mathrm{O}$ mecanismo finalmente atinge um ponto de equilíbrio dinâmico, onde o coeficiente de fricção mantém-se finalmente estável, também dando uma característica estável ao dano por fretting wear. Este mecanismo é ilustrado na Figura 15.

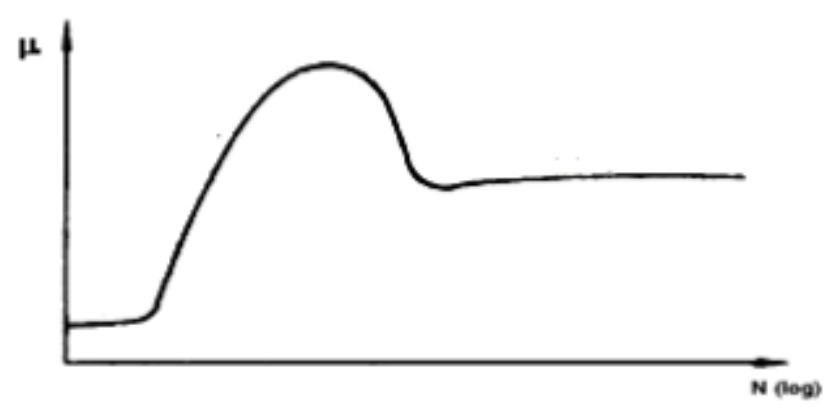

Figura 15 - Variação do coeficiente de fricção em função do número de ciclos de fretting

Alguns dos principais parâmetros que influenciam o fretting wear são: a amplitude de deslocamento, a tensão normal, a carga residual, a frequência das cargas tangenciais, deformação plástica local da peça, o coeficiente de rigidez tangencial, o modo do contato, a qualidade da superfície de contato, a temperatura, os efeitos de geometria e as propriedades do material. 


\subsubsection{FRETTING CORROSION}

O conceito de Fretting Corrosion está comumente associado ao de Fretting Wear, diferenciando-se que para ser considerado Fretting Corrosion, as condições do estudo devem estar sob ambientes agressivos, onde a corrosão seria facilitada.

\subsubsection{FRETTING FATIGUE}

A terceira forma de fretting, uma das mais comuns e danosas existentes, é a de dano por fretting fatigue. Os estudos de FOULQUIER (1988) demonstram que para uma liga de alumínio T7375 houve uma redução de 50\% da vida em fadiga por conta dos efeitos de fretting fatigue. A Figura 16 ilustra a redução prevista pelo autor.

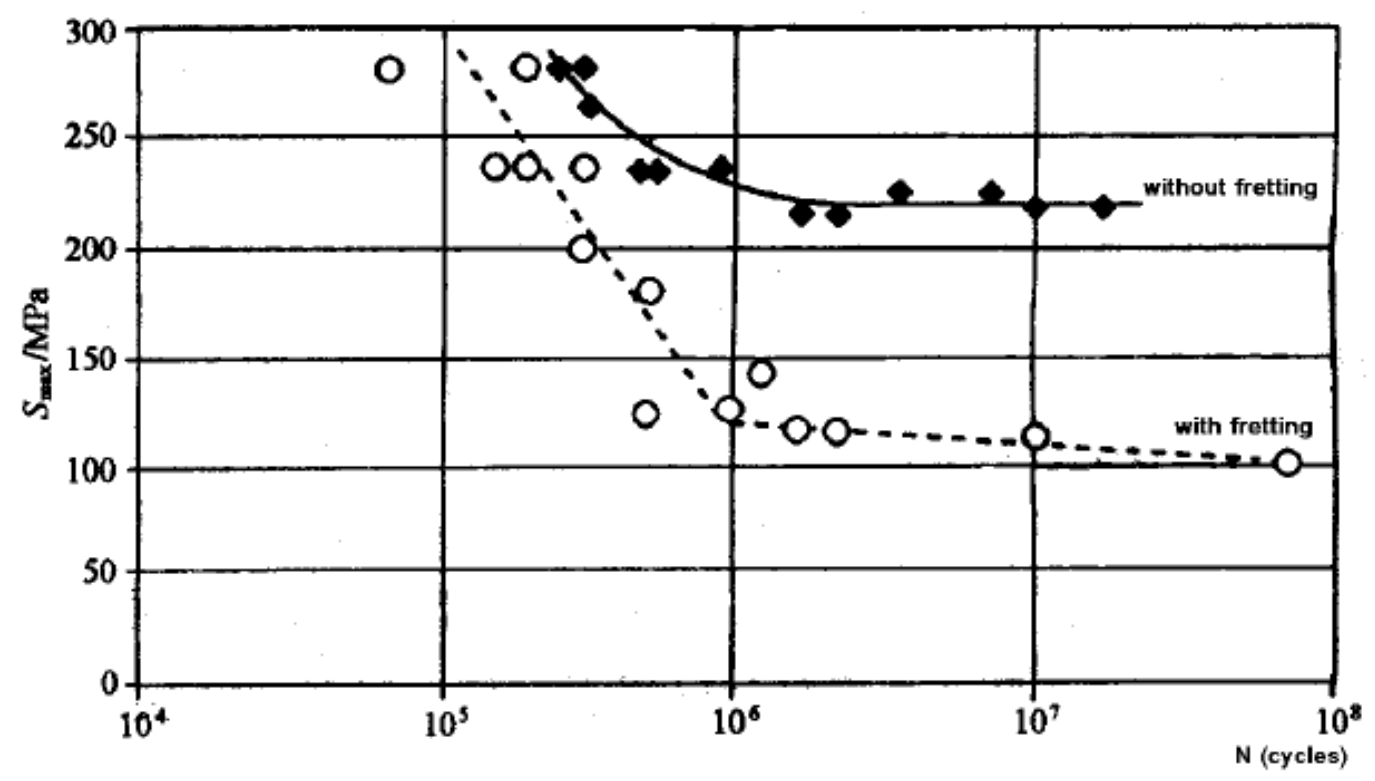

Figura 16 - Redução da vida à fadiga por fretting para a liga T7375 (Fonte: FOULQUIER, 1988)

O conceito de fretting fatigue está atrelado ao complexo fenômeno tribológico, sendo às vezes denominado também por fadiga de contato. No entanto, devido aos deslizamentos parciais da superfície de contato, a fricção por fretting torna o seu estudo muito mais complexo do que meras análises de fricção por deslizamento, visto que ocorrem plasticidades nas pontas das áreas de contato entre as superfícies originais e a de detritos formados pelo desgaste. Geralmente, associa-se o estudo deste tipo de fretting com a análise de fadiga por alto ciclo, sendo o estudo atrelado a parâmetros como: Amplitude de deslizamento, tensão normal, tensão de cisalhamento, plasticidade, carga residual, frequência de carregamento tangencial, rigidez do contato tangencial, modo de contato, qualidade da superfície de contato, propriedades dos materiais, temperatura 
elevada, presença de oxidação, presença de detritos por desgaste, efeitos do campo de tensões e efeitos geométricos (QI, 2013).

\subsection{CONTATO NUMÉRICO}

\subsubsection{CONTATO NO ANSYS}

Quando duas superfícies separadas tornam-se mutualmente tangentes, elas são consideradas em contato, possuindo as seguintes características:

1- Elas não se interpenetram;

2- Elas podem transmitir forças normais compressivas e tangenciais oriundas de resistência à fricção;

3- Normalmente elas não transmitem forças longitudinais, isto é, elas estão livres para se separar e mover-se uma da outra.

O contato por si só é uma mudança de estado de não linearidade. Isto é, a rigidez do sistema depende do estado do contato, se as partes estão em contato ou separadas. $\mathrm{O}$ ANSYS utiliza o método iterativo de Newton-Raphson para a resolução de problemas não lineares. Usando incrementos de força, o programa considera que o equilíbrio foi atingido quando o resíduo é menor que uma tolerância pré-definida.

Uma vez que os corpos em contato não podem penetrar uns aos outros, o programa é obrigado a estabelecer uma relação entre as duas superfícies em contato para prevenir que uma atravesse a outra durante a simulação. A esta condição, ilustrada na Figura 17, é dado o nome de Imposição de Compatibilidade de Contato, sendo que as formulações oferecidas pelo ANSYS para que isto ocorra são: Métodos de Lagrange, de Lagrange expandido, de Penalidade Pura e MPC (Multi-points constraints).

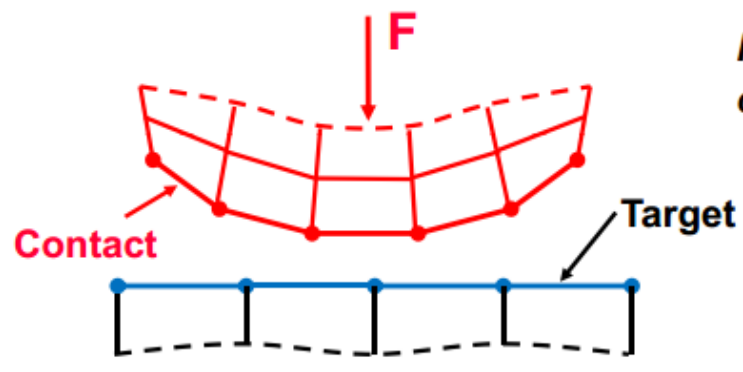

\section{Penetration occurs when contact compatibility is not enforced.}

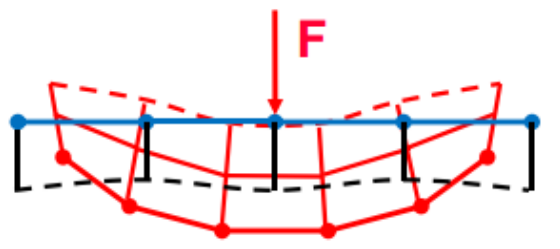

Figura 17 - Definição de contato - Importância da não interpenetração entre superfícies (Fonte: ANSYS, 2010) 
Para contatos não lineares de corpos rígidos, as formulações de penalidade pura ou de Lagrange expandido podem ser utilizadas, ambas sendo baseadas em formulações de penalidade, cuja formulação matemática é dada pela Equação 39 e sua ilustração é apresentada na Figura 18.

$F_{\text {normal }}=K_{\text {normal }} X_{\text {penetração }}$

Nestas formulações, para uma força de contato finita, quanto maior a rigidez do contato, menor será a penetração permitida. Idealmente, a rigidez deveria aproximar-se de um valor tão alto quanto próximo de infinito, tornando a penetração nula. Contudo, isto não é possível numericamente, mas conquanto o valor da penetração é pequeno ou insignificativo, as soluções serão confiáveis.

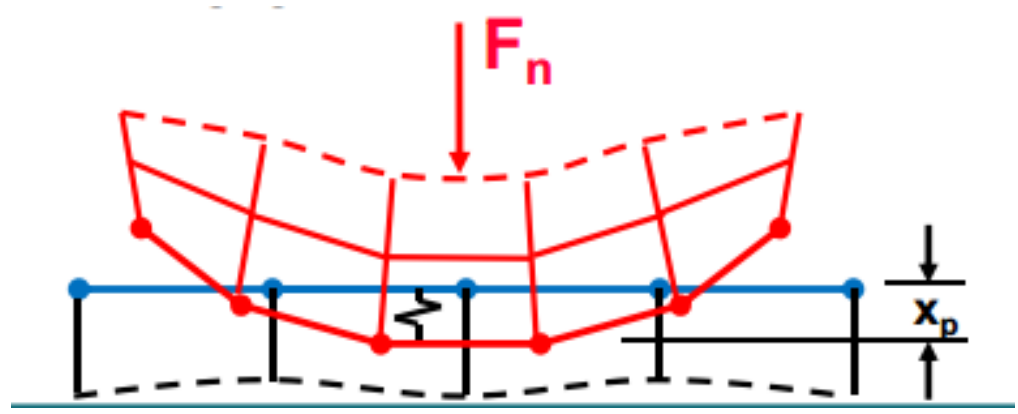

Figura 18 - Esquema geométrico da formulação por pura penalidade (Fonte: ANSYS, 2010)

A diferença principal entre os dois métodos é que, para o caso de Lagrange expandido, é adicionado um termo extra com o intuito de se reduzir a sensibilidade à magnitude da rigidez do contato, como é dado na Equação 40.

$F_{\text {normal }}=K_{\text {normal }} X_{\text {penetração }}+\lambda$

Outro opção oferecida pelo ANSYS é a formulação do multiplicador de Lagrange, o qual adiciona um grau de liberdade (pressão de contato) para satisfazer a compatibilidade do contato. Portanto, ao invés de resolver a força de contato por rigidez e penetração, esta formulação a resolve por grau de liberdade, como na Equação 41.

$F_{\text {normal }}=G L$

Consequentemente, há imposição de penetração nula ou quase nula com o novo grau de liberdade. Também não há necessidade de se estabelecer uma rigidez para o contato (não há, portanto, deslizamento elástico). No entanto, é necessário utilizar 
métodos de resolução direta, computacionalmente mais caras. A Figura 19 ilustra o método.

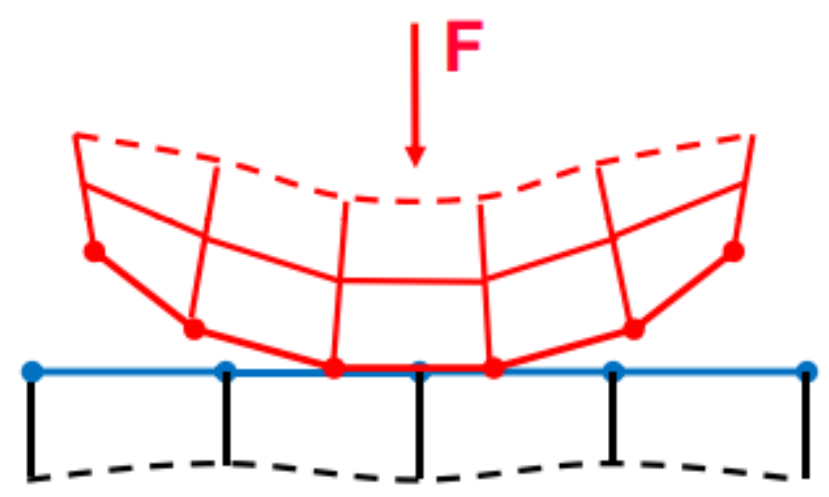

Figura 19 - Geometria do contato - Formulação de Lagrange (Fonte: ANSYS, 2010)

Problemas de chattering ocorrem com frequência no método de Lagrange, pois como nenhuma penetração é permitida, o estado do contato encontra-se sempre aberto ou fechado. A convergência pode oscilar entre ambos os status, ocorrendo o chattering. Se alguma penetração é permitida, como nos métodos de penalidade, a convergência é atingida mais facilmente, pois o contato não é mais um passo onde o contato deve estar obrigatoriamente fechado ou aberto. A comparação entre os estados de contato para os métodos baseados em penalidade e o método de Lagrange é apresentado na Figura 20.

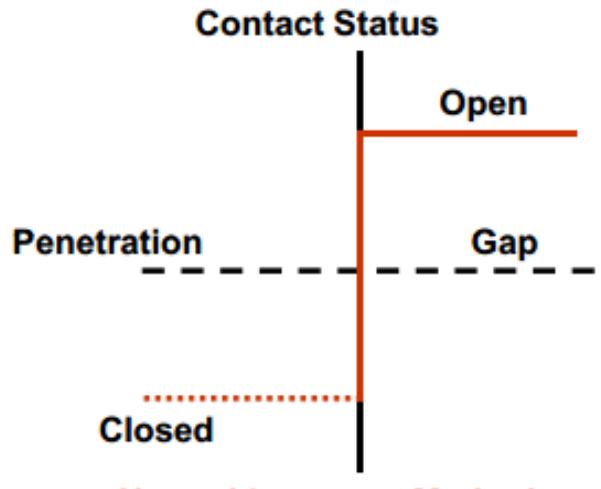

Normal Lagrange Method

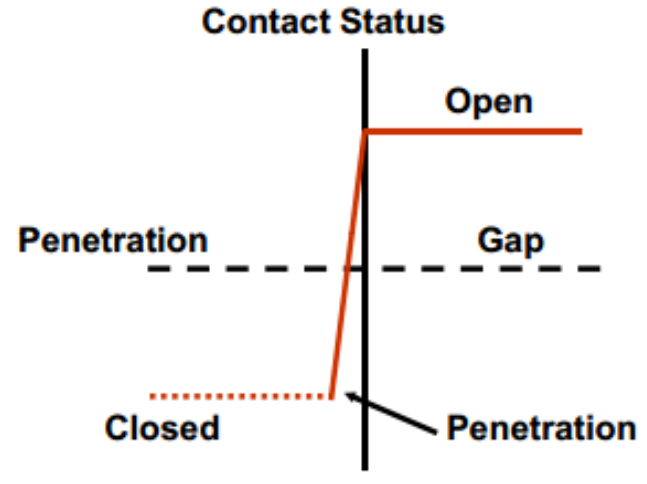

Penalty-Based Method

Figura 20 - Estado do contato para o método de Lagrange (esq.) e baseado em penalidades (dir.) (Fonte: ANSYS, 2010)

Para o caso específico de contatos da forma "Aderente" e "Sem separação", existe a formulação de Restrição Multipontos (MPC), ilustrada na Figura 21. 
A MPC adiciona internamente equações de restrição para unir os deslocamentos entre as superfícies de contato. A formulação não se baseia em métodos de penalidade ou de multiplicadores de Lagrange, sendo uma forma direta e eficiente de relacionar as superfícies de contato unidas. Uma vantagem desta formulação é que ela suporta grandes efeitos de deformação.

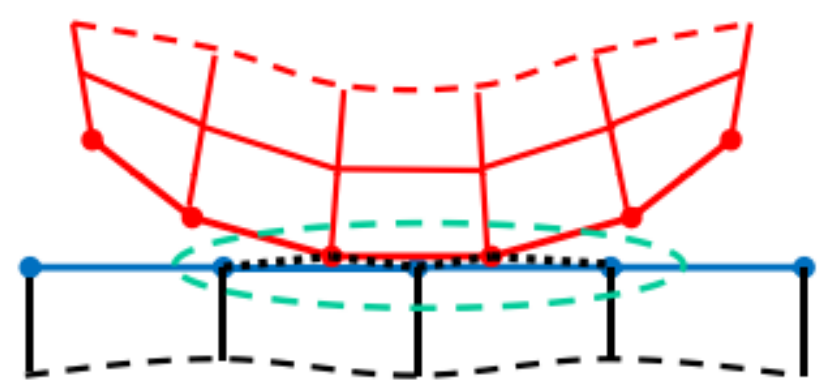

Figura 21 - Geometria do contato - Formulação MPC (Fonte: ANSYS, 2010)

A ilustração da Figura 22 demonstra como é feito o cálculo pelo MPC, regido pela Equação 42:
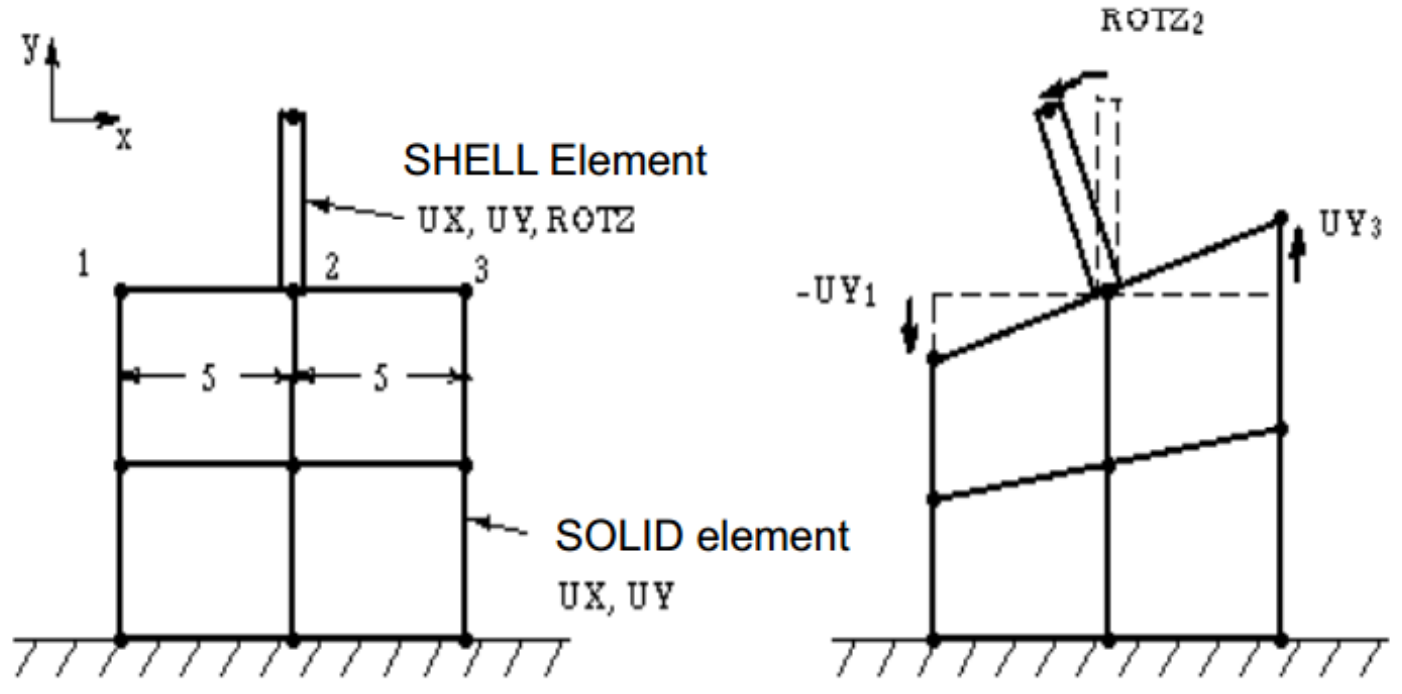

Figura 22 -Formulação geométrica MPC (Fonte: ANSYS, 2010)

$0=U Y_{3}-U Y_{1}-10 R O T Z_{2}$

O programa detecta o contato de forma diferente, a depender da formulação utilizada: para os casos de formulação por penalidade pura ou de Lagrange expandido, a detecção é feita por integração de ponto, o que resultado em uma quantidade maior de pontos de detecção. Já no caso do método de Lagrange e MPC, a detecção é feita por 
nós, resultado em uma quantidade menor de pontos de detecção. Isto é ilustrado na Figura 23. Enquanto a detecção nodal trabalha ligeiramente melhor em arestas, uma malha fina e localizada alivia o prejuízo da detecção por integração de pontos.
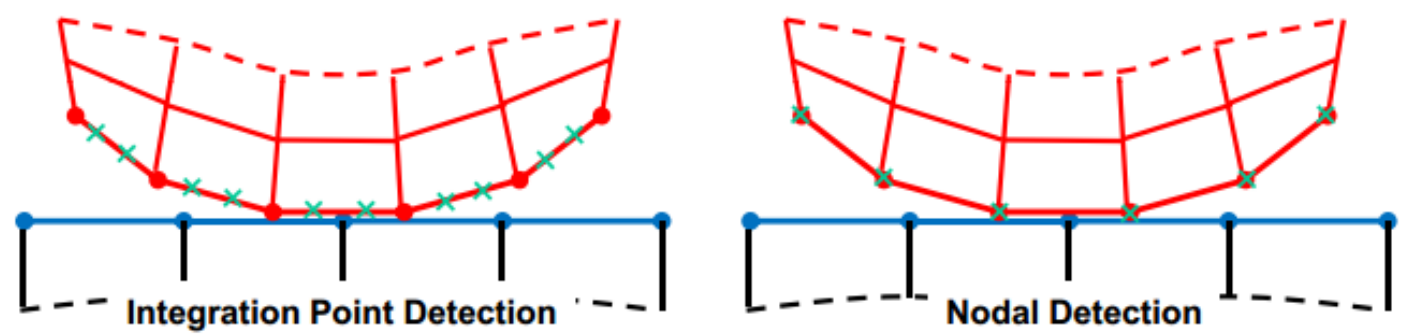

Figura 23 - Métodos de detecção por integração de pontos (esq.) e nodais (dir.) (Fonte: ANSYS, 2010)

As condições até aqui descritas são de contato na direção normal às superfícies. Se houver fricção entre as mesmas, condições similares na direção tangencial são impostas, descritas pela Equação 43. No entanto, é sempre usado o método de penalidade pura, onde agora a força tangencial será regida pela rigidez tangencial e o deslocamento de deslizamento. A única exceção a esta condição é na formulação por MPC, a qual continua valendo para o caso tangencial.

$F_{\text {normal }}=K_{\text {tangencial }}{ }^{*} X_{\text {deslizamento }}$

*Não é fornecida como input pelo usuário

A Tabela 2 resume os possíveis métodos a serem utilizados no programa:

Tabela 2- Resumo das formulações de contato no ANSYS (Fonte: ANSYS, 2010)

\begin{tabular}{|c|c|l|c|c|c|}
\hline Formulação & Normal & Tangencial & $\begin{array}{c}\text { Rigidez } \\
\text { normal }\end{array}$ & $\begin{array}{c}\text { Rigidez } \\
\text { Tangencial }\end{array}$ & $\begin{array}{c}\text { Tipo de } \\
\text { contato }\end{array}$ \\
\hline $\begin{array}{c}\text { Lagrange } \\
\text { Expandido }\end{array}$ & $\begin{array}{c}\text { Lagrange } \\
\text { Expandido }\end{array}$ & Penalidade & Sim & Sim & Qualquer \\
\hline $\begin{array}{c}\text { Penalidade } \\
\text { Pura }\end{array}$ & $\begin{array}{c}\text { Penalidade } \\
\text { Pura }\end{array}$ & Penalidade & Sim & Sim & Qualquer \\
\hline MPC & MPC & MPC & - & - & $\begin{array}{c}\text { Colado, sem } \\
\text { separação }\end{array}$ \\
\hline Lagrange & Lagrange & Penalidade & - & Sim & Qualquer \\
\hline
\end{tabular}

As vantagens e desvantagens de cada formulação são sumarizadas na Tabela 3: 
Tabela 3 - Resumo das vantagens (+) e desvantagens (-) de cada formulação de contato (Fonte: ANSYS, 2010)

\begin{tabular}{|c|c|c|c|c|c|c|c|}
\hline \multicolumn{2}{|r|}{ Penalidade Pura } & \multicolumn{2}{|c|}{ Lagrange Expandido } & \multicolumn{2}{|r|}{ Lagrange Normal } & \multicolumn{2}{|r|}{ MPC } \\
\hline+ & $\begin{array}{c}\text { Bom } \\
\text { comportamento } \\
\text { de convergência }\end{array}$ & - & $\begin{array}{l}\text { Pode necessitar de } \\
\text { iterações extras de } \\
\text { equilíbrio se a } \\
\text { penetração for } \\
\text { muito grande }\end{array}$ & - & $\begin{array}{l}\text { Pode necessitar de } \\
\text { iterações extras de } \\
\text { equilíbrio se } \\
\text { houver chattering }\end{array}$ & + & $\begin{array}{c}\text { Boa } \\
\text { convergência }\end{array}$ \\
\hline- & $\begin{array}{l}\text { Sensível a seleção } \\
\text { da rigidez normal } \\
\text { de contato }\end{array}$ & & $\begin{array}{l}\text { Menos sensível a } \\
\text { rigidez normal de } \\
\text { contato }\end{array}$ & + & $\begin{array}{l}\text { Não necessita de } \\
\text { rigidez de contato }\end{array}$ & + & $\begin{array}{l}\text { Não necessita de } \\
\text { rigidez de } \\
\text { contato }\end{array}$ \\
\hline- & $\begin{array}{c}\text { Há penetração de } \\
\text { contato } \\
\text { incontrolável }\end{array}$ & & $\begin{array}{l}\text { Há penetração de } \\
\text { contato, mas } \\
\text { controlável até } \\
\text { certo ponto }\end{array}$ & + & $\begin{array}{l}\text { Praticamente não } \\
\text { há penetração }\end{array}$ & + & $\begin{array}{c}\text { Não há } \\
\text { penetração }\end{array}$ \\
\hline+ & $\begin{array}{l}\text { Útil para qualquer } \\
\text { tipo de contato }\end{array}$ & + & $\begin{array}{l}\text { Útil para qualquer } \\
\text { tipo de contato }\end{array}$ & + & $\begin{array}{l}\text { Útil para qualquer } \\
\text { tipo de contato }\end{array}$ & - & $\begin{array}{l}\text { Somente útil } \\
\text { para contato } \\
\text { sem separação }\end{array}$ \\
\hline+ & $\begin{array}{c}\text { Podem ser usados } \\
\text { métodos iterativos } \\
\text { ou diretos }\end{array}$ & + & $\begin{array}{l}\text { Podem ser usados } \\
\text { métodos iterativos } \\
\text { ou diretos }\end{array}$ & - & $\begin{array}{l}\text { Apenas métodos } \\
\text { diretos podem ser } \\
\text { usados }\end{array}$ & + & $\begin{array}{c}\text { Podem ser } \\
\text { usados métodos } \\
\text { iterativos ou } \\
\text { diretos }\end{array}$ \\
\hline+ & $\begin{array}{l}\text { Contatos } \\
\text { simétricos e } \\
\text { assimétricos são } \\
\text { permitidos }\end{array}$ & + & $\begin{array}{c}\text { Contatos } \\
\text { simétricos e } \\
\text { assimétricos são } \\
\text { permitidos }\end{array}$ & & $\begin{array}{l}\text { Apenas contatos } \\
\text { assimétricos são } \\
\text { permitidos }\end{array}$ & & $\begin{array}{l}\text { Apenas contatos } \\
\text { assimétricos são } \\
\text { permitidos }\end{array}$ \\
\hline+ & $\begin{array}{c}\text { Detecção de } \\
\text { contato por } \\
\text { pontos integrados }\end{array}$ & + & $\begin{array}{c}\text { Detecção de } \\
\text { contato por pontos } \\
\text { integrados }\end{array}$ & & $\begin{array}{l}\text { Detecção de } \\
\text { contato nodal }\end{array}$ & & $\begin{array}{l}\text { Detecção de } \\
\text { contato nodal }\end{array}$ \\
\hline
\end{tabular}

O método padrão utilizado no programa é o de Pura Penalidade. No entanto, a empresa sugere que seja utilizado o método de Lagrange expandido sempre que ocorrer contato sem fricção ou contato friccional com grandes deformações. Este último caso é o 
que se acredita que ocorre nas simulações envolvidas neste trabalho e, por este mesmo motivo, ele é detalhado adiante na seção 2.5.2.

\subsubsection{FORMULAÇÃO DE CONTATO PELO MÉTODO DE LAGRANGE EXPANDIDO}

A rigidez normal de contato é o parâmetro mais importante que afeta a precisão e o comportamento de convergência dos resultados numéricos. Ele é dado no programa em valores relativos, onde recomenda-se 1 para deformações dominadas por cargas remotas e valores menores, próximos de 0.1 para casos de flexão, as quais sugeridas em casos de problema de convergência.

Quanto maior a rigidez normal utilizada, maior será a precisão obtida, porém maior será a dificuldade de convergência do método. Outro problema em decorrência de valores de rigidez de contato muito elevados é que pode ocorrer oscilação do modelo, com ocorrência de solavancos entre as superfícies. A Figura 24 ilustra este possível efeito.

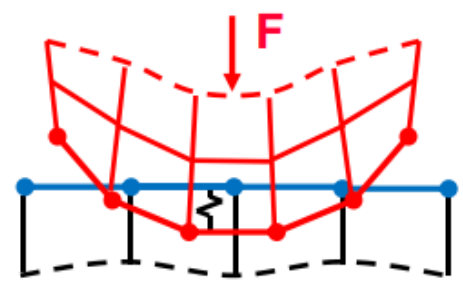

Iteration $n$

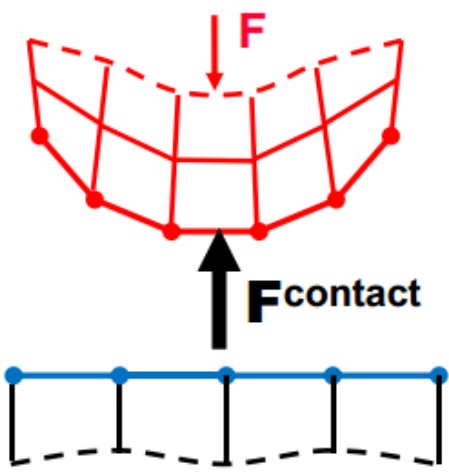

Iteration $n+1$

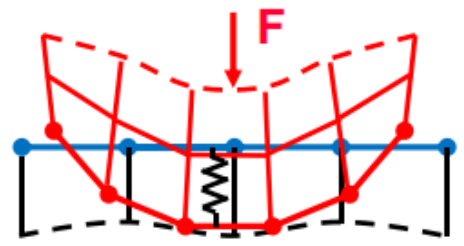

Iteration $n+2$

Figura 24 - Efeitos de solavanco entre as superfícies em decorrência de alta rigidez de contato (Fonte: ANSYS, 2010)

A rigidez normal padrão é automaticamente detectada pelo programa. É possível que o usuário altere este valor caso o deseje, sendo o valor padrão para a rigidez igual a 10 para casos de superfícies grudadas, sem separação e rigidez igual a 1 para os demais comportamentos. A rigidez também pode ser automaticamente reajustada pelo programa, bastando que isto seja especificado pelo usuário em suas opções. 


\subsubsection{REGIÃO DE PINBALL}

A região de pinball é um parâmetro de contato que diferencia estados de contato abertos longínquos dos pertos. Ela pode ser percebida como um contorno esférico circundando cada ponto de detecção. Se um nó dentro da superfície alvo está dentro desta esfera, o programa considera que esta superfície está próxima ao contato e monitorará a relação entre este ponto e o contato.

São diversas as utilidades da utilização da região de pinball dentro do contato:

1- Aumenta a eficiência computacional dos cálculos de contato ao diferenciar as regiões próximas das longes do contato.

2- Determina o espaçamento máximo para contatos aderentes.

3- Determina a profundidade para a qual a penetração inicial será resolvida se presente.

O tamanho da região de pinball pode ser definido manualmente pelo usuário, mas por padrão é calculada automaticamente pelo programa de acordo com o tipo de elemento e os tamanhos dos mesmos.

\subsubsection{COMPORTAMENTOS ASSIMÉTRICO E SIMÉTRICO DO CONTATO}

O usuário deve escolher no programa qual a superfície de contato escrava e qual a superfície alvo (mestre). O ANSYS adota como padrão o comportamento simétrico, no qual ambas as superfícies não poderão se interpenetrar.

Contudo, é possível escolher a condição assimétrica de contato, na qual apenas a superfície de contato escrava não poderá penetrar a superfície alvo. Se a opção de assimetria automática é escolhida, a designação de qual superfície é a alvo é designada automaticamente pelo programa, podendo ter seu status revertido pelo programa durante a simulação.

É importante atentar-se às designações das superfícies e as condição de simetria escolhida. A Figura 25 demonstra como a má definição poderia ocasionar erros decorrentes de penetrações excessivas. 


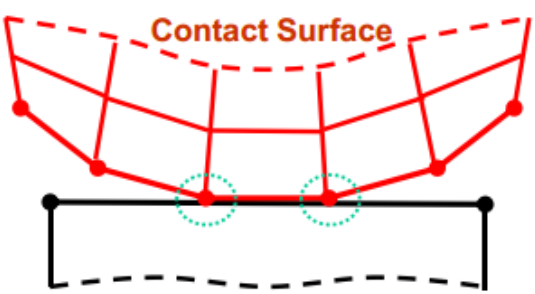

Target Surface

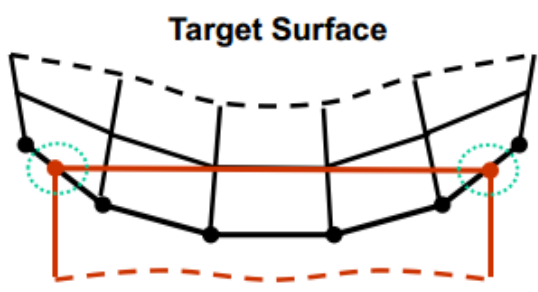

Contact Surface

Figura 25 - Contato estabelecido corretamente (esq.) e contato com excesso de penetração (dir.) (Fonte: ANSYS, 2010)

Para o comportamento assimétrico, a detecção por integração de pontos permite alguma penetração nas arestas por conta da localização das detecções dos pontos. A Figura 26 demonstra esta ocorrência:

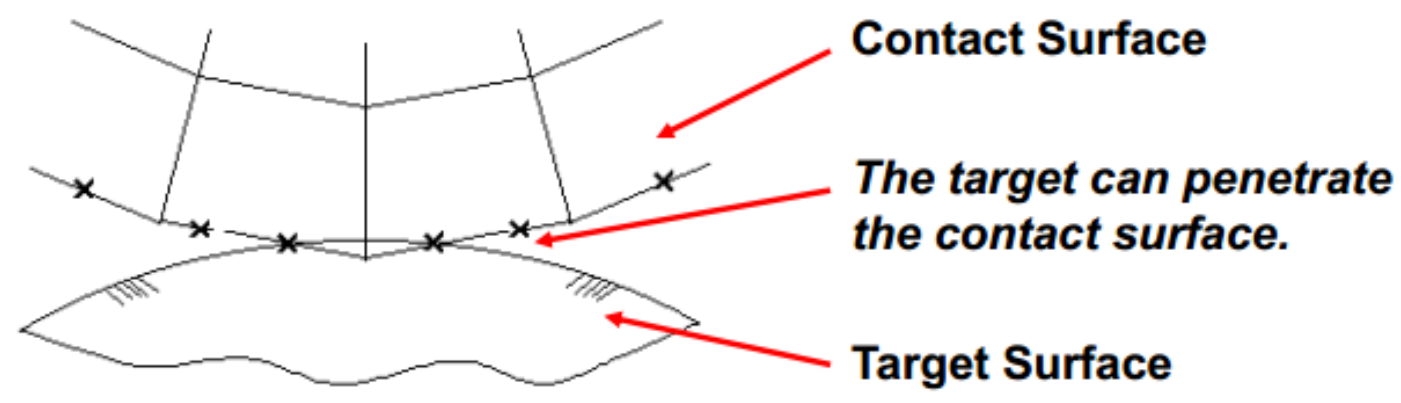

Figura 26 - Penetração por conta de comportamento assimétrico do contato (Fonte: ANSYS, 2010)

Por outro lado, o método de detecção por integração possui uma maior quantidade de pontos para estabelecer o contato. Logo, há vantagem e desvantagem em seu uso.

\subsubsection{ESTADO PLANO DE TENSÃO/DEFORMAÇÃO}

Diversos problemas elásticos podem ser tratados satisfatoriamente bidimensionalmente. Pode-se dizer que há duas formas principais de se analisar estes tipos de problema: O estado plano de tensão e o estado plano de deformação.

O estado plano de tensão (EPT) pode ser definido como um estado de tensão no qual a tensão normal $\sigma_{z}$ e as tensões cisalhantes $\tau_{x z}$ e $\tau_{y z}$ são assumidas como zero. Uma situação típica de análise do estado plano de tensão é demonstrado na Figura 27, na qual a carga é aplicada em uma estrutura delgada. 


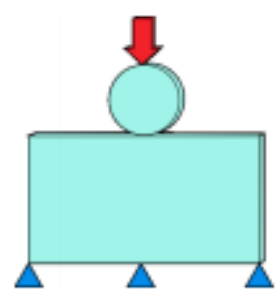

Figura 27 - Condições de contorno para EPT (Fonte: YASTREBOV, 2010)

Já o estado plano de deformação (EPD) pode ser entendido como um estado no qual a deformação normal ao plano x-y, $\varepsilon_{z}$, e as deformações $\gamma_{x z}$ e $\gamma_{y z}$ são presumidamente nulas. Uma situação típica de análise do estado plano de tensão é demonstrada na Figura 29, na qual a carga é aplicada em uma estrutura cuja uma dimensão é consideravelmente superior às outras duas.

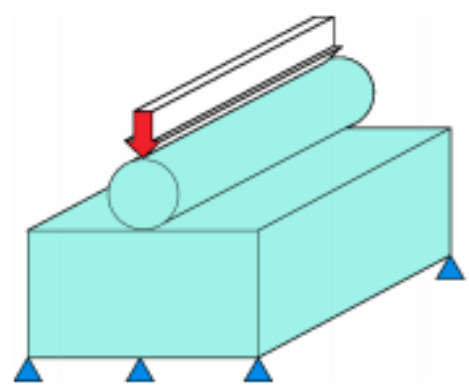

Figura 28 - - Condições de contorno para EPD (Fonte: YASTREBOV, 2010)

\subsubsection{DETECÇÃO DO CONTATO}

É importante que o programa utilizado para a simulação numérica seja capaz de detectar a ocorrência do contato antes que ocorram penetrações de uma superfície na outra. Dentre as inúmeras técnicas de detecção disponíveis, o ANSYS utiliza o ponto de integração de Gauss para formulações pelo método de Lagrange expandido, como mostrado na Figura 29. 


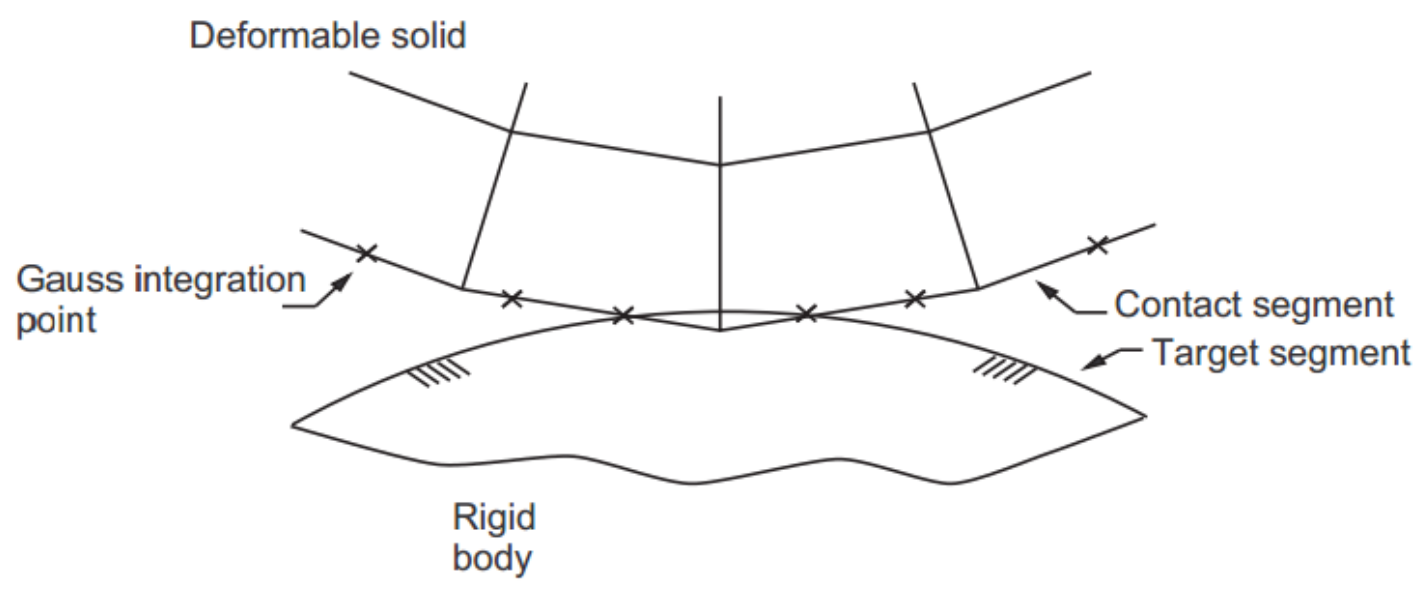

Figura 29 - Detecção do contato pelo ANSYS (Fonte: ANSYS, 2010)

A detecção do contato pode ocorrer no começo de cada incremento (passo de carga) ou no começo de cada iteração (passo de convergência). No primeiro caso, as vantagens são a rápida velocidade, a boa convergência e a estabilidade da detecção, a qual terá a desvantagem de não ser tão precisa. Por outro lado, o outro caso oferece melhor precisão, mas é mais lenta, pode cair em um loop infinito e se apresentar instável.

Ao se elaborar o modelo numérico, é importante que o usuário atente-se a questões que possam levar a não convergência das soluções. Além da já discutida primordial decisão de se escolher corretamente qual superfície é a mestre e qual é a escrava, é importante que as projeções dos nós da superfície escrava não se encontrem em zonas cegas das projeções (de distância mais próxima) dos pontos de detecção da superfície mestre. Quanto menos suave forem as superfícies envolvidas no estudo, mais crítica será esta situação, podendo ocorrer situações onde sequer ocorre a projeção na superfície escrava ou ocorrem múltiplos pontos de projeção na mesma (e, consequentemente, não haverá solução única, o que é, naturalmente, um problema). A Figura 30 ilustra as situações descritas. 


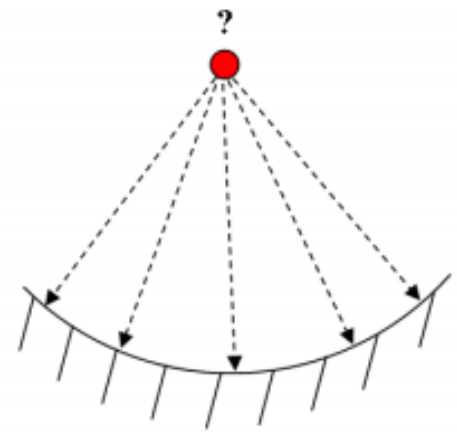

Projection of $\mathrm{is}$ not unique

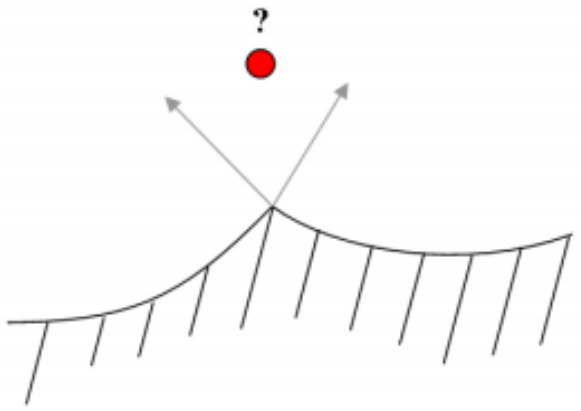

No projection of

Figura 30 - Problema na detecção do contato por conta de projeção inadequada dos elementos (Fonte: YASTREBOV, 2010)

\subsubsection{DISCRETIZAÇÃO DO CONTATO}

A fim de se obter unidades elementares responsáveis pela correta transmissão dos esforços envolvidos no contato de uma superfície para a outra com precisão adequada, é necessária a discretização da malha.

A primeira forma de discretização do contato é a nó-nó, ilustrada na Figura 31. Nesta discretização, ocorrerá apenas contato direto entre nós, sendo ela uma forma simples de discretização que só pode ser utilizada para pequenas deformações e deslizamentos, requerendo também que a malha de ambas as superfícies em contato sejam conformes, ou seja, os nós de ambas as superfícies são alinhados em um mesmo eixo.

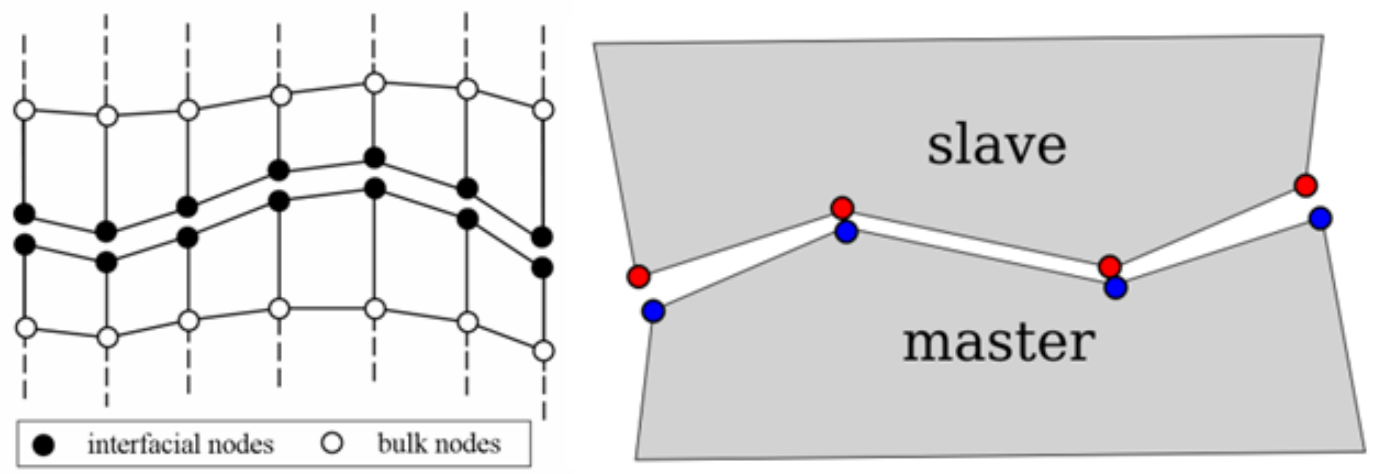

Figura 31 - Discretização de contato tipo nó-nó antes de aplicação de esforços (esq.) e depois (dir.) (Fonte: YASTREBOV, 2010)

Outra forma de discretização utilizada é a nó-segmento, demonstrada na Figura 32. Neste caso, ocorrerá o contato do nó da superfície escrava em um segmento da superfície mestre. Ela possui a vantagem de ainda ser de simples formulação, permitir 
grandes deformações e deslizamentos e que não há necessidade de conformidade entre as malhas das superfícies.

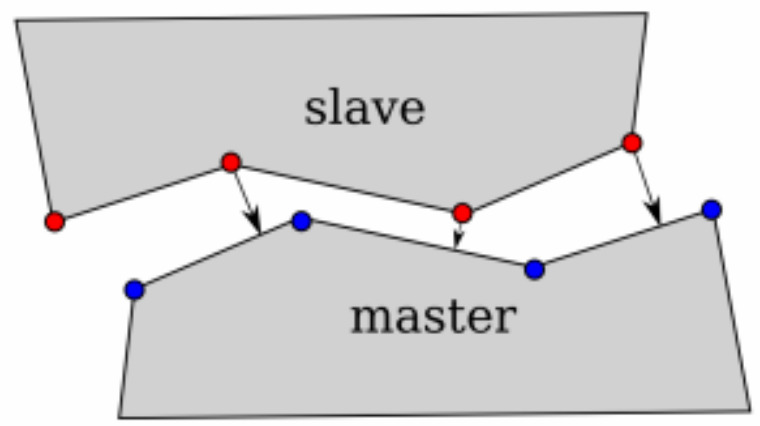

Figura 32 - Discretização de contato tipo nó-segmento (Fonte: YASTREBOV, 2010)

Uma terceira forma de discretização usual é a segmento-segmento, ilustrada na Figura 33. O contato desta discretização é formulado pela projeção dos nós de uma superfície na outra. Ela evita problemas de forma encontrados na discretização nósegmento, também permite grandes deformações e deslizamentos e não requer conformidade entre as malhas. No entanto, sua formulação é mais complicada e há pressão de contato constante para um mesmo segmento.

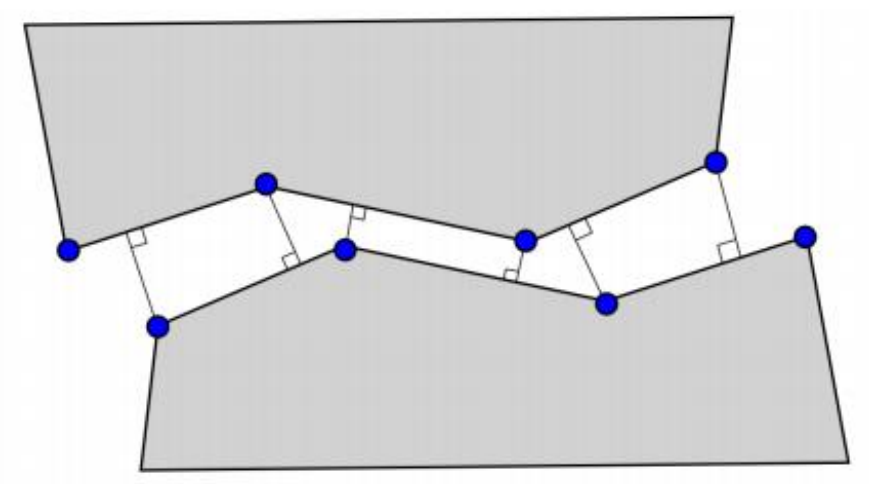

Figura 33 - Discretização de contato tipo segmento-segmento (Fonte: YASTREBOV, 2010)

\subsubsection{RESOLUÇÃO DE NÃO LINEARIDADE NO ANSYS}

O ANSYS utiliza o método numérico de Newton-Raphson para a resolução de problemas não lineares em suas simulações. Trata-se de um método iterativo e, para o caso em questão, utilizam-se incrementos de força para cada iteração até que se atinja a tolerância definida, situação para a qual considera-se que o equilíbrio foi atingido. 


\section{ESTUDOS NUMÉRICOS DE FRETTING}

\subsection{ANÁLISE BIBLIOMÉTRICA}

A bibliometria diz respeito às manifestações estatisticamente significantes de informação contidas no material utilizado por um determinado estudo, independentemente da área do conhecimento.

Antes de se utilizar uma metodologia eficiente ou de se propor uma nova, é interessante que se realize uma análise bibliométrica. Esta demonstrará quais abordagens de análise de fretting têm sido utilizadas, qual a relevância de cada artigo para o meio acadêmico, quais autores têm produzido trabalhos mais citados, etc.

A primeira etapa deu-se pela escolha da base de dados a ser utilizada e das palavras-chaves que melhor descrevessem os temas neste trabalho estudados. A base utilizada foi a da ISI Web of Science, devido à grande quantidade de material disponível no mesmo.

Para o período de 1997 a 2016, com busca utilizando as palavras-chaves FRETTING FATIGUE ou FRETTING WEAR ou FRETTING e NUMERICAL ANALYSIS, foram encontrados 99 artigos obedecendo este critério. Nenhum artigo contendo tais palavras foi encontrado antes do ano de 1997.

Os 99 artigos encontrados receberam um total de 1154 citações desde suas criações, com uma média de citação por artigo igual a 11,66.

A Figura 34 demonstra a quantidade de artigos criados dentro dos critérios pesquisados, tendo sido omitidos os anos sem citações.

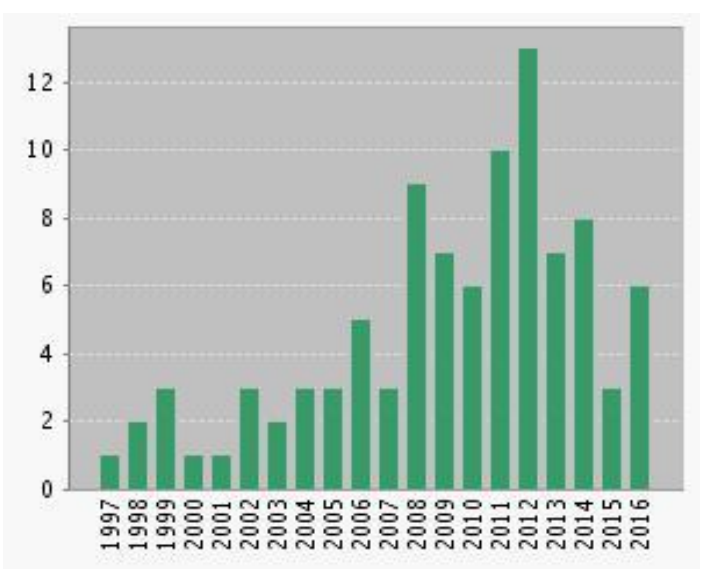

Figura 34 - Quantidade de artigos publicados por ano 
Nota-se pela Figura 34 que há um aumento médio significativo de artigos relacionados à análise numérica de fretting ao longo dos anos, tanto pela importância do tema, quanto pelo avanço computacional que permite análises numéricas mais avançadas. Vale ressaltar, que o período referente ao ano de 2016 ainda sofrerá acrescimentos, visto que o ano ainda não se acabou.

A Figura 35 refere-se às citações que os artigos receberam ao longo dos anos.

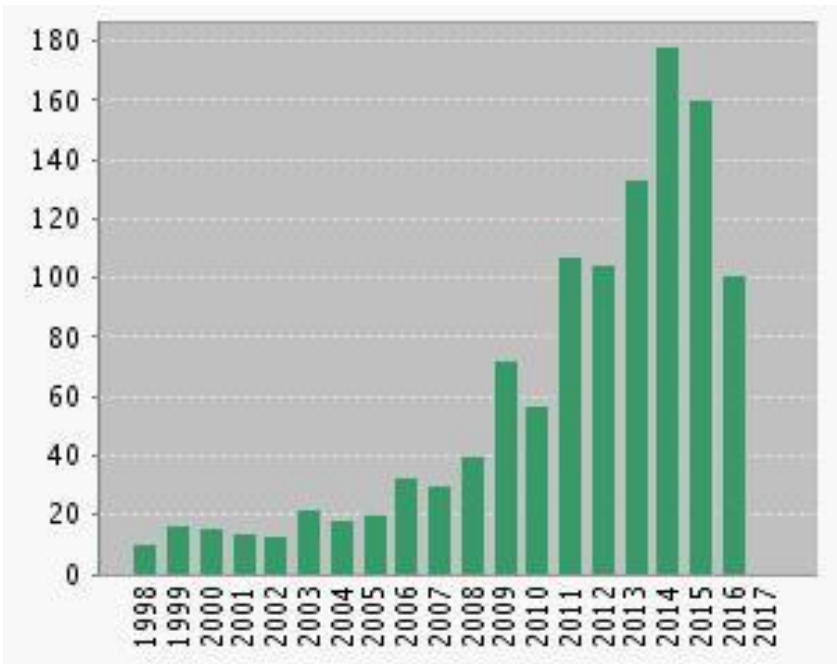

Figura 35 - Citações ao longo dos anos

Mais uma vez, é visível a crescente relevância do tema. É possível criar as redes de influência de cada artigo, como a ilustrada na Figura 36. O programa transforma as informações emitidas pelo servidor da ISI Web of Science e cria pontos contendo cada um dos artigos citados dentro dos 99 artigos obtidos. Pontos maiores significam uma maior relevância daquele artigo, o qual foi citado mais vezes. 


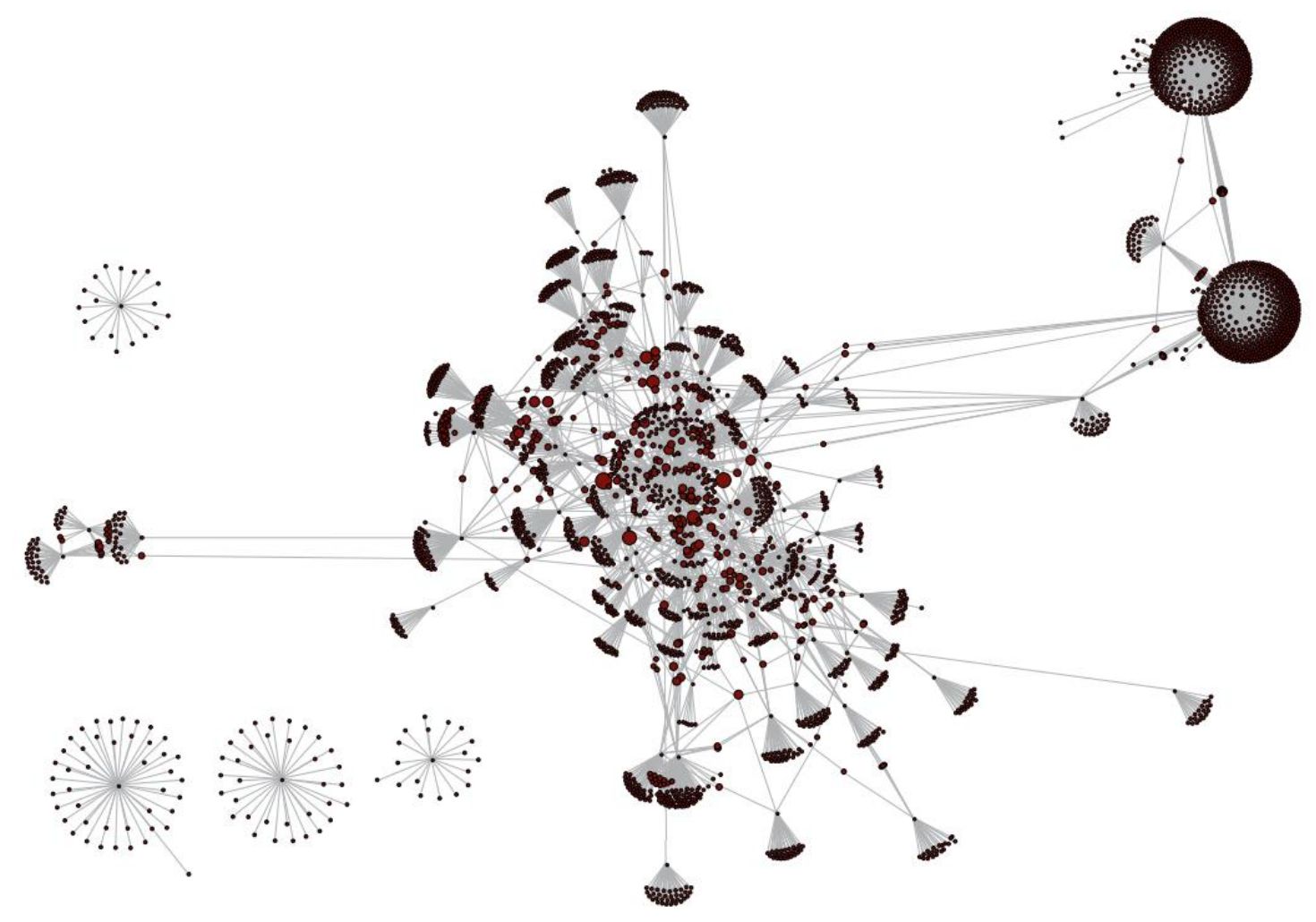

Figura 36 - Rede mostrando as citações e interconexões entre os diversos estudos

As linhas que interconectam os pontos mostram que existe uma ligação entre os diferentes artigos. Se o artigo não possui ligação direta com outro ponto, não haverá linha que os conecte. No caso de estarem em redes diferentes, os artigos não possuem qualquer ligação por meio de citações, nem sequer indireta. Um zoom na Figura 36, conforme é ilustrado na Figura 37, permite ver quem citou quem.

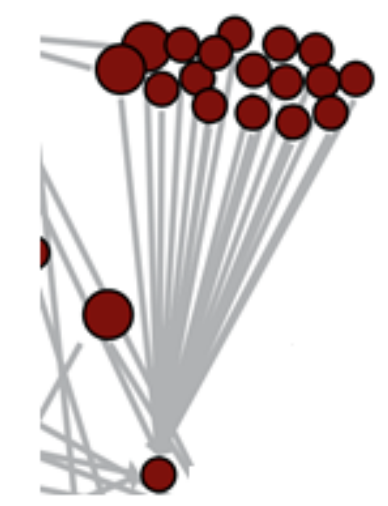

Figura 37 - sentido da influência 
Dentro dos temas relevantes, destacam-se o uso de função de peso ligado ao fator de intensidade de tensão. Usando a mesma base de dados da primeira análise bibliométrica, com o mesmo critério de tempo de 1997 a 2016, foram encontrados 71 artigos que possuíam as palavras-chaves WEIGHT FUNCTION e STRESS INTENSITY FACTOR E NUMERICAL ANALYSIS. A figura 38 ilustra o número de citações destes artigos ao longo dos anos.

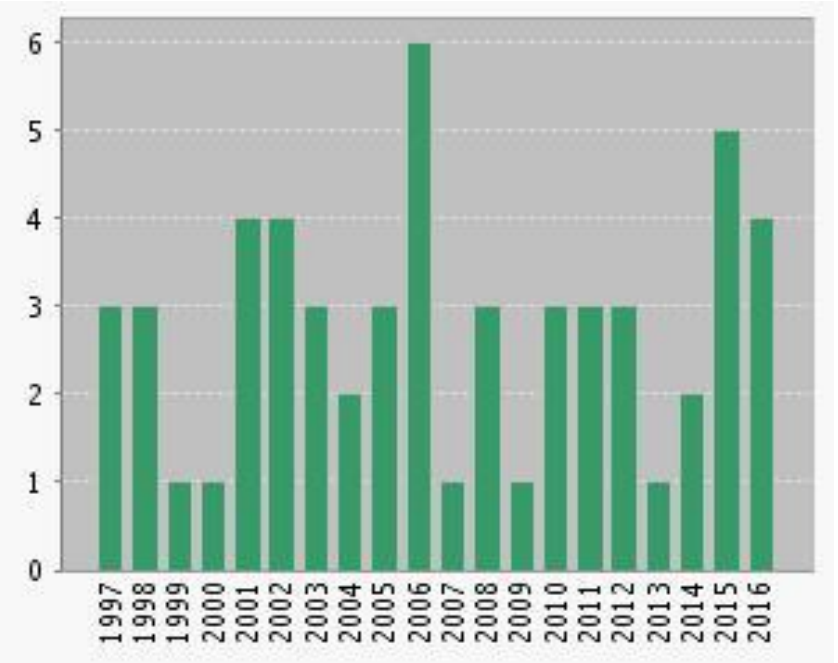

Figura 38 - Quantidade de artigos publicados por ano

Os artigos receberam, no total, 844 citações, com uma média de citação por artigo igual a 11,89. Percebe-se que a abordagem pesquisada foi e continua a ser estudada desde a propagação do uso da análise numérica. $\mathrm{O}$ ano de 2016 provavelmente sofrerá acréscimos, visto que o mesmo não foi finalizado na data da pesquisa.

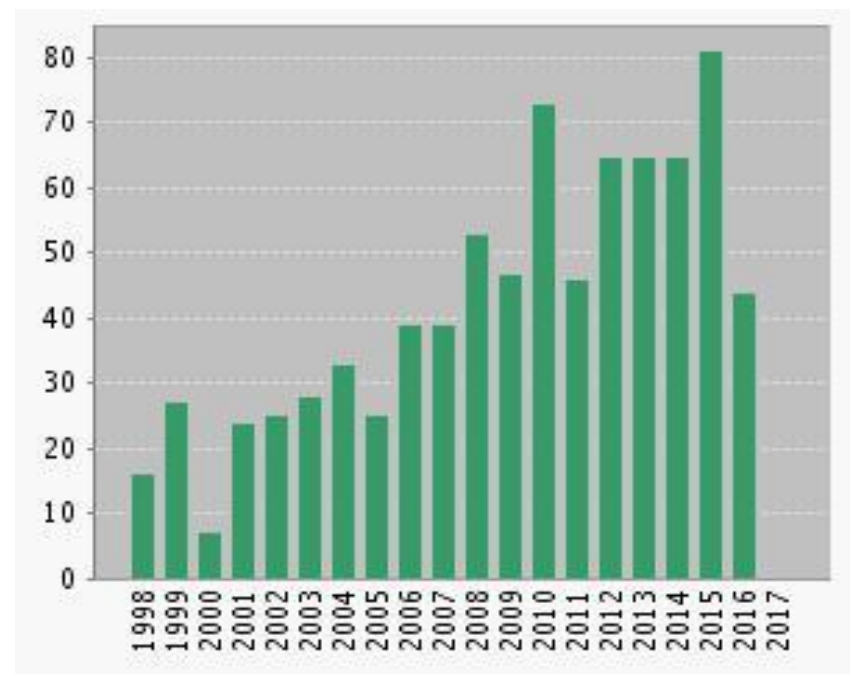

Figura 39 - Citações ao longo dos anos 
A Figura 39 permite concluir que a relevância dos artigos elaborados está em ascensão. Também é possível perceber que a relevância do tema é significativa, visto que os artigos sob os critérios pesquisados apresentam boas médias de citação.

Baseado nos resultados da análise bibliométrica realizada, diversos modelos propostos para se estimar numericamente a vida à fretting fatigue são resumidos neste trabalho e apresentados na seção 3.2, com o intuito de demonstrar o que tem sido apresentado no tema e justificar a inovação do método proposto neste trabalho.

\subsection{MODELOS PROPOSTOS POR OUTROS AUTORES}

\subsubsection{MODELO PROPOSTO POR NAVARRO et al. (2003)}

Neste estudo, os autores propuseram um método para se estimar a vida à fretting fatigue como uma combinação das fases de nucleação e de propagação da trinca. Ao invés de se determinar um valor para o tamanho da trinca inicial, os autores o definiram como sendo uma função do estado de tensão no local de nucleação e de leis de iniciação e propagação de trincas. O método proposto foi similar ao de Socie para corpos-de-prova entalhados sob carregamento uniaxial, mas estendido para englobar o fenômeno de fretting fatigue sob carregamento multiaxial.

Baseadas no método supracitado de Socie, duas curvas foram calculadas para se levar em conta ambos os fenômenos de nucleação e propagação. A primeira foi obtida através de conceitos de crescimento de trincas para fadigas de baixo ciclo, (da/DN $l_{i}-\mathrm{a}$ ), enquanto a segunda, (da/DN $l_{p^{-}}$a), refere-se à taxa de dano durante a propagação da trinca, baseada nos conceitos de mecânica da fratura linear elástica (LEFM).

A primeira taxa é obtida calculando-se os números de ciclos necessários para se iniciar a trinca, para cada ponto, e, posteriormente, derivando-os. O número de ciclos é obtido calculando-se as tensões ao longo do caminho da trinca e aplicando-se critérios de fadiga multiaxial. A curva de tensão-vida é utilizada para se obter o número de ciclos para uma determinada tensão equivalente.

A segunda curva é calculada usando-se a curva experimental (da/DN $\left.l_{p}-\Delta \mathrm{K}\right)$ do material e a curva ( $\Delta \mathrm{K}$-a) (Figura 40$)$. Esta, por sua vez, é obtida através de vários tipos de métodos (Funções de peso, métodos dos elementos finitos), sendo necessário para a sua determinação calcular-se previamente as tensões no local. 


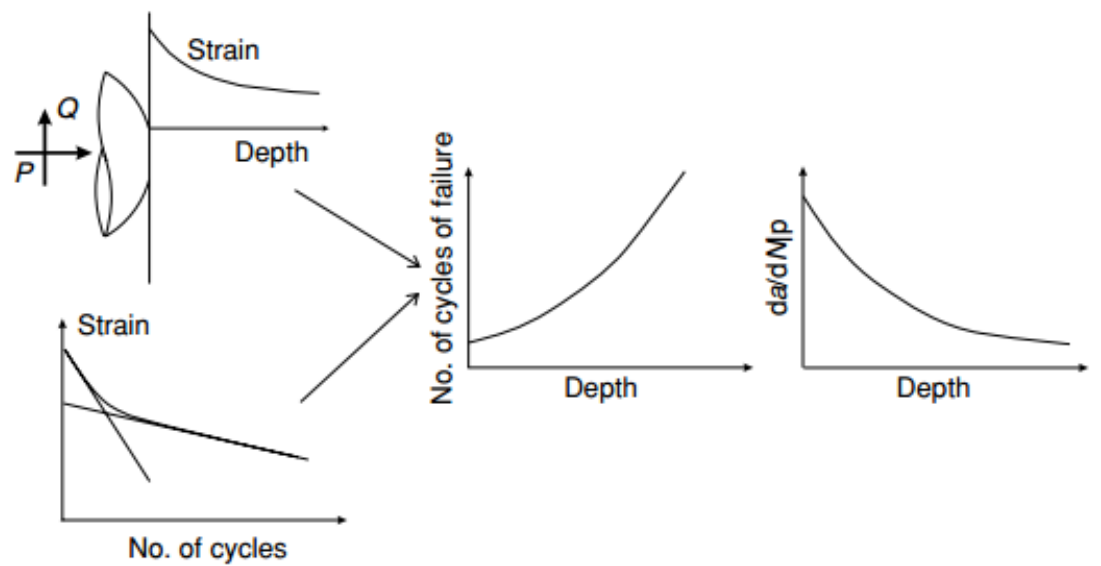

Figura 40 - Obtenção do dano da trinca por iniciação fonte (NAVARRO et al. 2003)
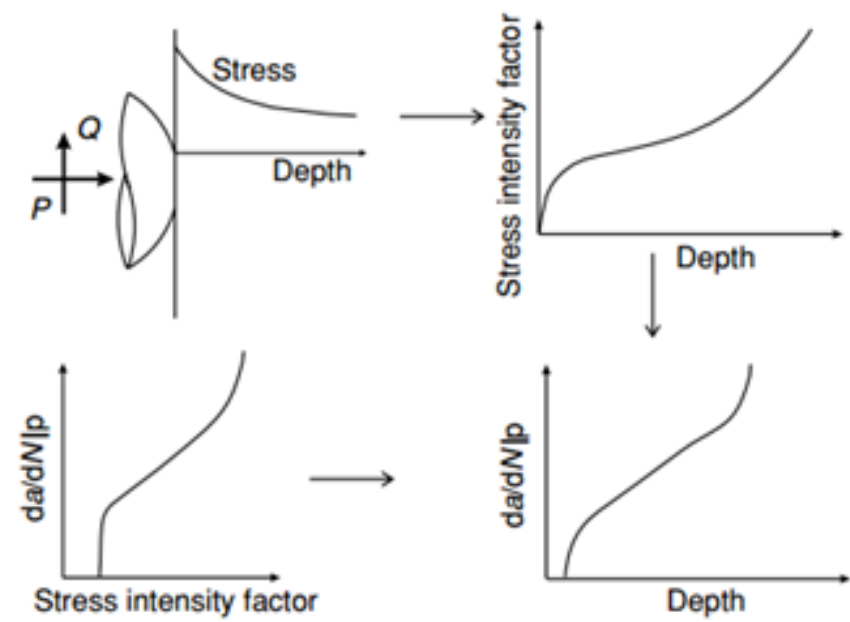

Figura 41 - Obtenção do dano por trinca por propagação (Fonte: NAVARRO et al., 2003)

O método de Socie define o tamanho da nucleação da trinca como sendo o ponto de interseção das duas curvas, conforme mostrado na Figura 42. 


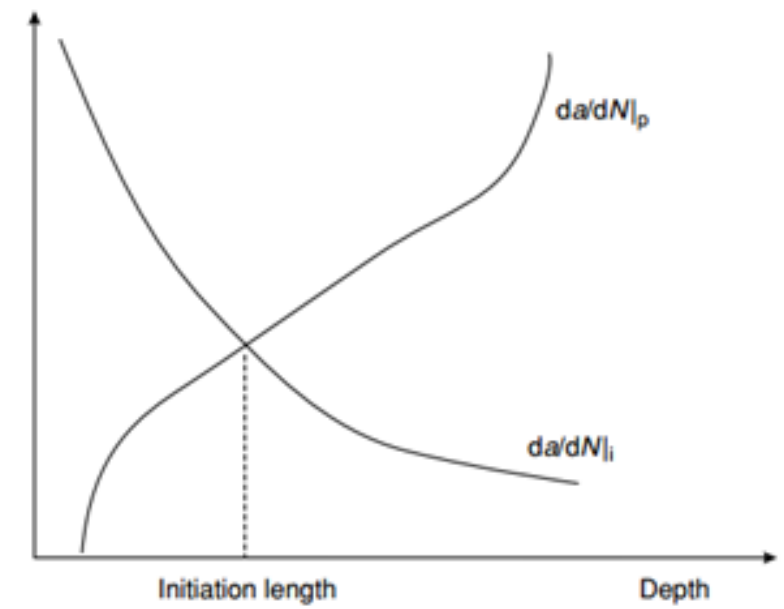

Figura 42 - Iniciação de propagação do dano por trinca (Fonte: Navarro et al., 2003)

Contudo, NAVARRO et al (2003) calcularam a vida à fadiga em cada ponto baseado em fadiga de baixo ciclo, Ni, sem calcular a derivada. Baseando-se nas leis da LEFM para se determinar a vida de propagação, eles explicam a necessidade de calcular a curva $(\Delta \mathrm{K}-\mathrm{a})$ e então integrar (da/DN $\left.l_{p^{-}} \Delta \mathrm{K}\right)$ para cada ponto até que a falha ocorra. Naturalmente, a soma das fases de nucleação e propagação da trinca, Ni e Np, respectivamente, dá a vida total à fadiga do espécime, Nt. Logo, onde Nt é mínimo, obtém-se a vida do espécime, conforme ilustrado na Figura 43.

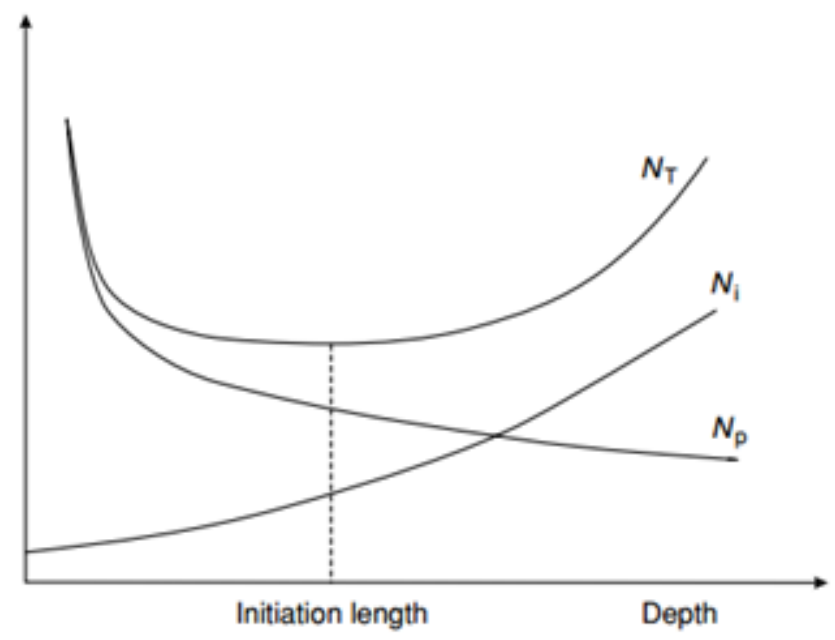

Figura 43 - Iniciação, propagação e vida total estimadas (Fonte: NAVARRO et al., 2003)

Os autores usaram as expressões explícitas encontradas em HAMILTON (1983) para que pudessem obter os resultados analíticos do caso estudado, com contato esférico.

Com base em outros estudos, eles determinaram o local de nucleação e o ângulo de propagação da trinca. Após diversas análises, eles resolveram adotar um caminho da 
trinca perpendicular à superfície, pois isto se mostrava, segundo eles, uma aproximação razoável dos resultados experimentais, como os obtidos na Figura 44. O local de iniciação da trinca foi escolhido como a borda da zona de contato.

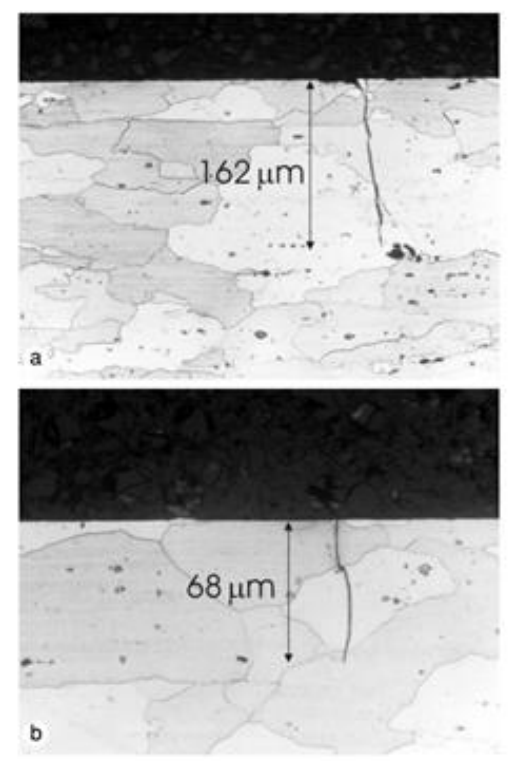

Figura 44 - Seções transversais das trincas (Fonte: NAVARRO et al., 2003)

De acordo com as considerações efetuadas, os autores então puderam computar a iniciação de trinca usando o critério de McDiarmid. Já a propagação da trinca foi calculada através de fator de intensidade tensão para o modo $K_{I}$. A função de peso utilizada foi a de Bueckner.

O tamanho da trinca foi medido em diversos testes onde o espécime não falhou, mas uma trinca foi encontrada. Encontrou-se uma razão entre os tamanhos medidos da trinca e a meia espessura do espécime de 0.5 , o que forneceu um fator de correção de 0.78 para se considerar os efeitos tridimensionais da trinca.

Os autores, no entanto, julgaram o fator de correção insuficiente, visto que pela Figura 45, a taxa de propagação versus o fator de intensidade de tensão para o modelo proposto mostrou-se abaixo dos demais modelos ilustrados. 


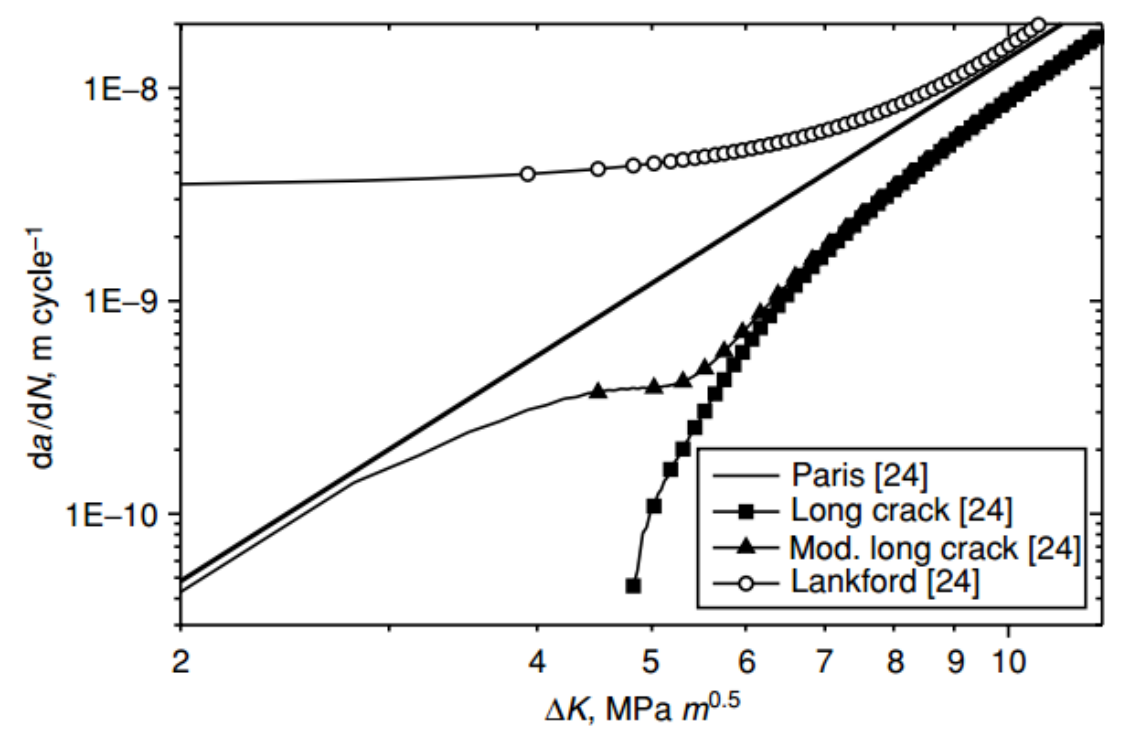

Figura 45 - Diferentes leis de propagação para o Al 7075 (Fonte: NAVARRO et al., 2003)

Todos os corpos-de-prova que não falharam foram analisados, procurando-se por trincas e as medindo, quando existentes. Os corpos-de-prova foram então cortados, moldados em plástico e polidos até que $30 \mu \mathrm{m}$ de material fossem removidos, fotografados e novamente polidos. O processo repetiu-se até que as trincas fossem estudadas por inteiro, permitindo a análise de forma, dimensão e iniciação das potenciais trincas. Tal procedimento permitiu a observação de que as trincas paravam próximas de uma vizinhança de grão, seja um pouco antes ou um pouco depois da mesma. É também possível notar que as trincas se iniciavam com um pequeno ângulo em relação à superfície. Por fim, outro fator importante é que as trincas principais se iniciavam ligeiramente dentro da zona de contato.

Portanto, NAVARRO et al. (2003) puderam concluir que para os casos de contato esférico submetido a fretting fatigue, a iniciação das trincas ocorre logo no começo quando comparada à vida total.

A comparação das estimativas calculadas para os corpos-de-prova que romperam permitiu a observação que:

I) $\mathrm{O}$ modelo de trinca longa resulta em maiores valores de vida ao fretting.

II) Uma lei de crescimento de trincas que é o limite superior para trincas curtas resulta em valores menores de vida ao fretting. 
III) O modelo de trinca longa modificado de Paris dá um resultado dentre os anteriores.

A comparação das estimativas calculadas para os corpos-de-prova que não falharam permitiu concluir:

I) O modelo de longa trinca fornece resultados de ciclos dispersos.

II) O modelo de curta trinca e o modificado de Paris subestimam o número de ciclos, provavelmente porque a região de pausa da trinca está próxima ao limite do grão.

Os autores por fim sugerem que sejam elaborados mais trabalhos para se estudar o crescimento de trincas curtas. Também ressaltam a necessidade de elaboração de futuros trabalhos no modo II. 


\subsubsection{MODELO PROPOSTO POR DING et al. (2014)}

A análise numérica realizada por estes autores partiu da construção de uma estrutura 2-D simplificada, a qual utilizou uma força normal equivalente obtida por uma modelagem numérica 3-D, como mostra a Figura 46. O programa utilizado foi o ABAQUS, tendo-se implementado uma sub-rotina do material com um modelo constitutivo de ciclo elastoplástico, a fim de se prover os efeitos de endurecimento cíclico para o aço inoxidável 316L. Para se previr o local de iniciação da trinca e a vida do material, utilizou-se o modelo de Smith-Watson-Topper (SWT). Os resultados foram então comparados com experimentos, colhendo-se bons resultados.
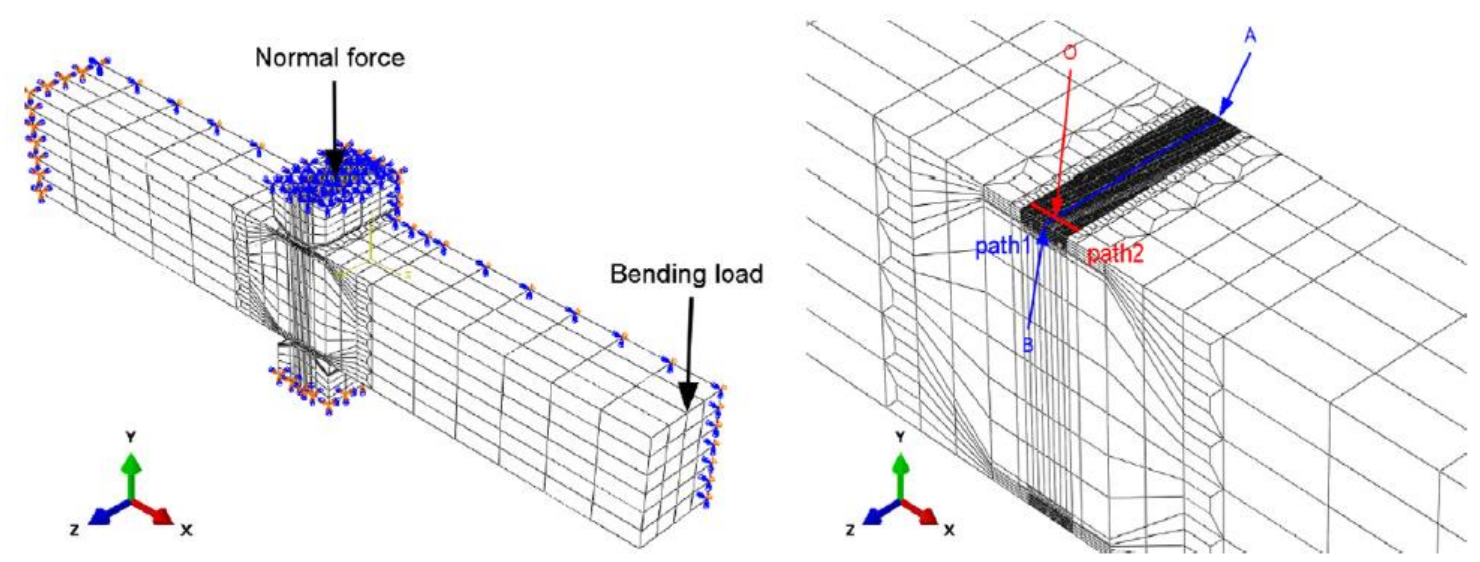

Figura 46 - Modelo tridimensional (Fonte: DING et al.,2014)

Os autores adotaram então um modelo 2-D simplificado, como ilustrado na Figura 47, por conta da quantidade diminuta de ciclos que os recursos computacionais permitiriam computar caso se prosseguisse com a modelagem tridimensional complexa. Assim, os mesmos propuseram o modelo 2-D para se analisar o processo de fretting fatigue por flexão. Entretanto, a força normal aplicada ao modelo 2-D não é apenas a média do valor normal correspondente a espessura do modelo 3-D, visto que foi observada a presença de empenamento na direção da espessura durante os experimentos. Foi considerada, portanto, uma força normal que levasse em conta tal fenômeno no modelo 3-D. 


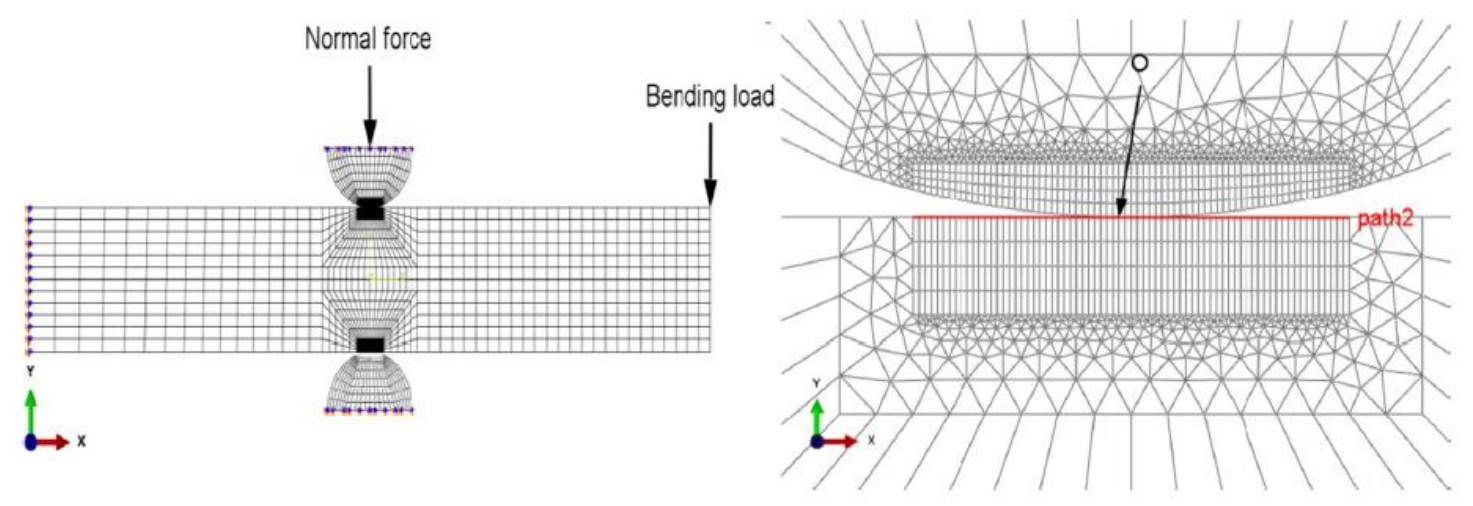

Figura 47 - Modelo bidimensional (Fonte: DING et al.,2014)

Como anteriormente mencionado, os autores utilizaram sub-rotina para melhor definição das propriedades do material. O modelo constitutivo utilizado na sub-rotina foi o de ciclos avançados elastoplásticos com a regra de endurecimento cinemático não linear propostos por Ohno-Abdel-Karim. Também implementaram uma regra de endurecimento isotrópico não linear, a fim de chegar às propriedades do aço em questão anteriormente experimentalmente testadas. As equações utilizadas, assim como as condições de contorno, são demonstradas na publicação. Os resultados da verificação do modelo constitutivo adotado são demonstrados nas Figuras 48 a 50. Percebe-se clara proximidade do modelo para com os resultados experimentais.

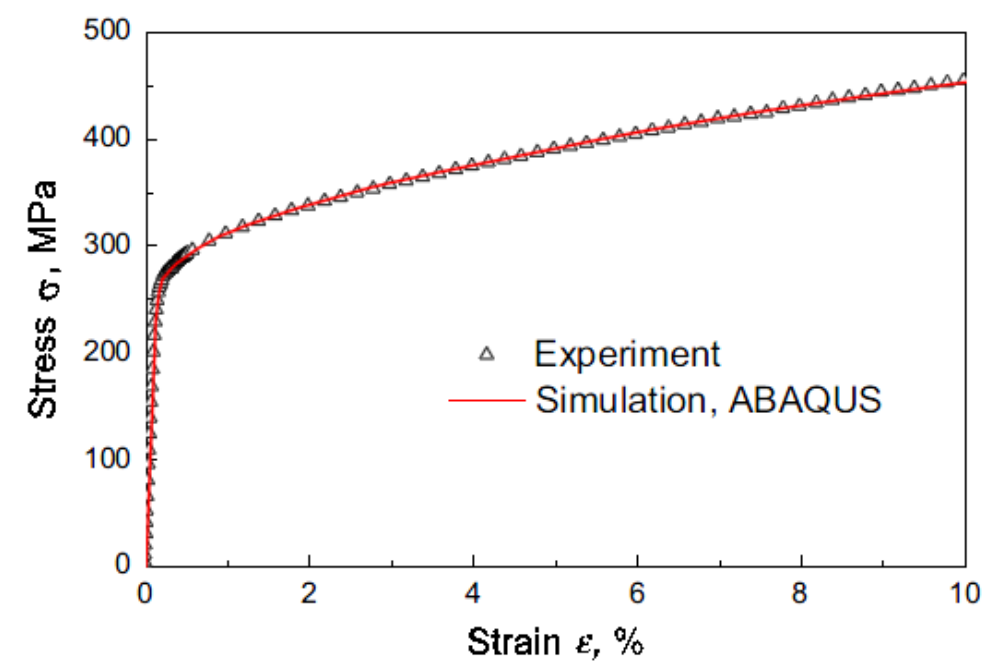

Figura 48 - Resultados simulados e experimentais para curvas de tensão-deformação para tensões monotônicas (Fonte: DING et al.,2014) 


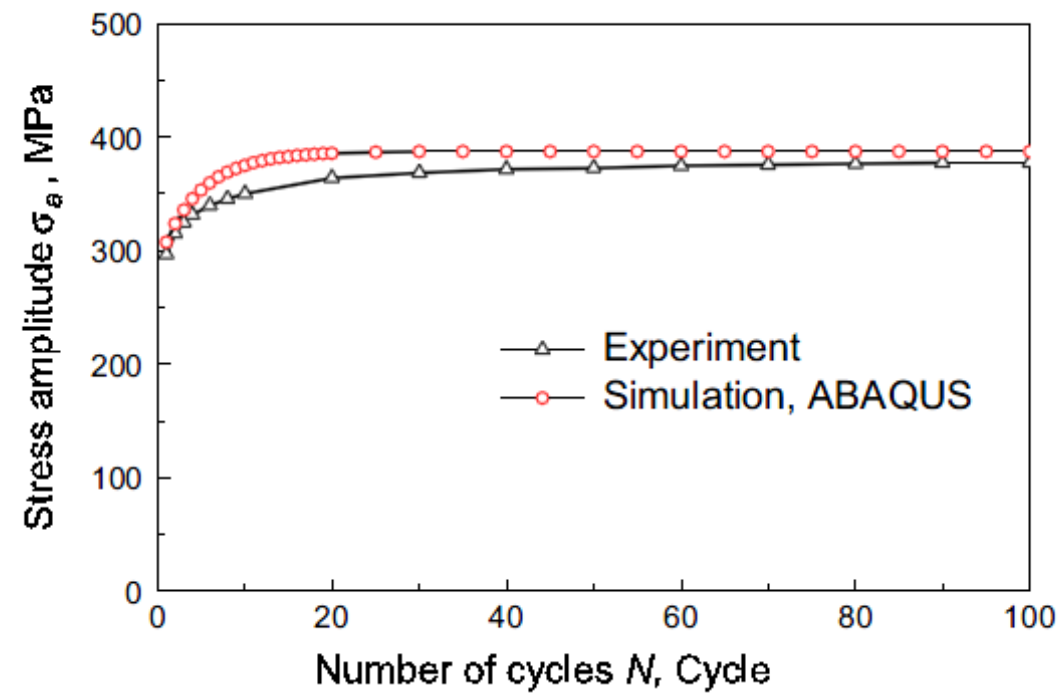

Figura 49 - Resultados experimentais e simulados para amplitudes de tensões vs. número de ciclos sob testes uniaxiais com deformação controlada para uma amplitude de tensão de $\pm \mathbf{0 . 7 \%}$ (Fonte: DING et

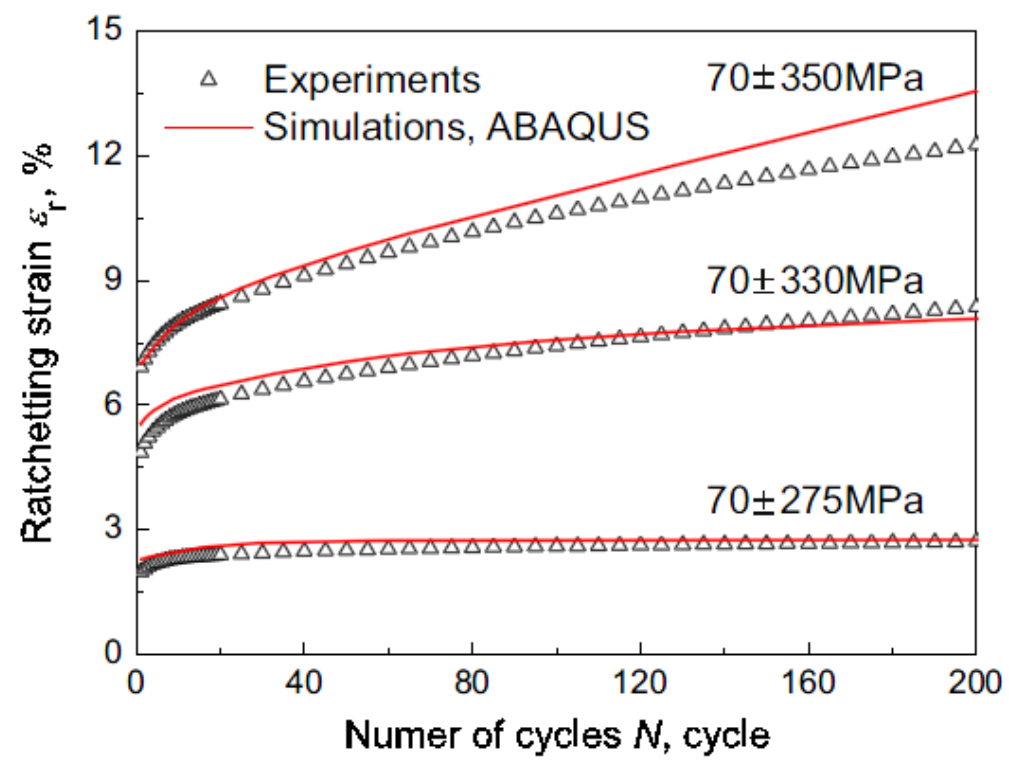

Figura 50 - Resultados experimentais e simulados para ratchetting uniaxial (Fonte: DING et al.,2014) 


\subsubsection{MODELO PROPOSTO POR BAIETTO et al., (2013)}

Os autores apresentam uma estimativa de propagação de trincas de fretting por modelagens numérica e experimental. O estudo foi feito através de:

1- Testes bi e tridimensionais, com controle cauteloso de cargas até que surgissem as trincas, através de espécimes 2-D e 3-D post-mortem de seções transversais;

2- $\quad$ Análise numérica por método dos elementos finitos expandido (X-FEM) de três campos baseada na formulação fraca para trincas friccionais 3-D não planares, por meio da reconstrução do formato da trinca, através de quantificações de fatores de intensidade de tensões, através de um modo misto da lei de Paris;

3- Uma simulação de crescimento de trincas.

Referente à simulação numérica, os autores fizeram um modelo 2-D onde simulavam o crescimento da trinca de fretting por modo misto, onde obtiveram bons resultados. Posteriormente, simularam tridimensionalmente testes de fretting a fim de se comparar com valores reais.

Conforme descrevem BAIETTO et al. (2013), a simulação do crescimento de trincas é algo que envolve o entendimento de inúmeros fenômenos como a plasticidade confinada a uma zona ou contato com fricção interfacial. Esses efeitos não lineares impactam diretamente tanto na taxa de crescimento quanto na direção da trinca. Além disso, os diminutos deslocamentos envolvidos na fadiga por fretting costumam ser bem menores que as peças ou até mesmo que as trincas de fretting envolvidas. Os autores tentaram, então, reproduzir, por meio de X-FEM, os aspectos da estrutura, dos componentes, da interface entre os dois corpos, as trincas e as não linearidades interfaciais. 


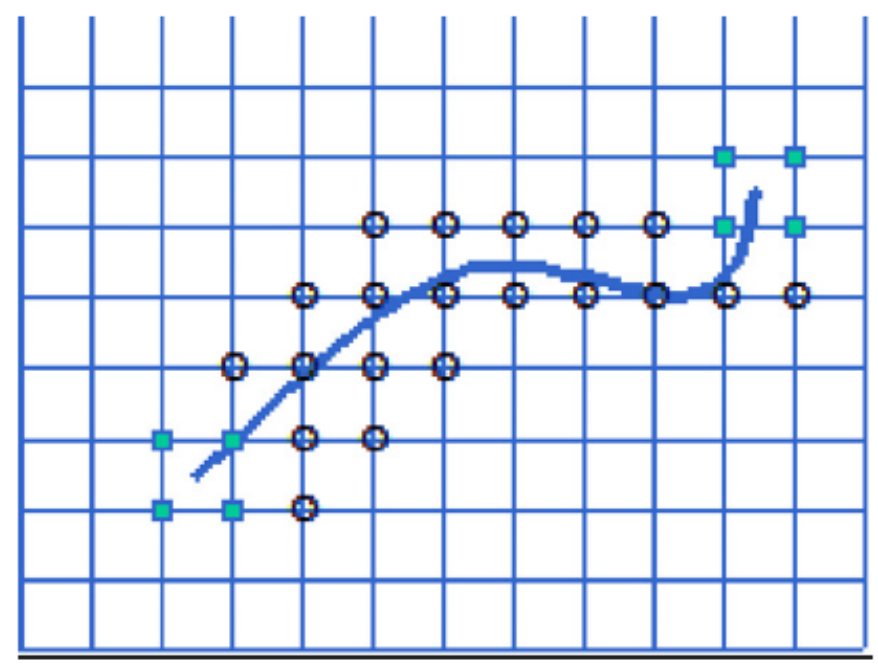

Figura 51 - Trinca em uma malha bidimensional de X-FEM. Os círculos são para incrementos descontínuos e os quadrados para incrementos assimptóticos (Fonte: BAIETTO et al. 2013)

$u(x, t) \cong$

$\sum u_{i}(t) \phi_{i}(x)+H(x) \sum_{j \in N_{\text {front }}} a_{j}(t) \phi_{j}(x)+\sum_{l=1}^{4} B_{l} \sum_{k \epsilon N_{\text {front }}} b_{l k}(t) \phi_{k}(x)$

Eq. (44)

A Equação 44 descreve matematicamente o problema da Figura 51. $u_{j}$ representa os graus de liberdade do Método dos Elementos Finitos convencional, $a_{j}$ são os graus de liberdade ligados a função de Heaviside generalizada, $\mathbf{H}$, e $\boldsymbol{b}_{\boldsymbol{l} \boldsymbol{k}}$ são os graus de liberdade associados às funções incrementais singulares $B_{l}$ no fronte da trinca. $\phi_{i}, \phi_{j}$ e $\phi_{k}$ são as funções de forma de primeira ordem. Tais incrementos evitam a dependência da malha em relação à forma inicial da trinca, eliminando a necessidade de recriação da malha e interpolação dos campos durante a possível propagação da trinca. Os autores ainda extrapolaram e modificaram o método acima para que mesmo se adequasse à modelagem tridimensional de trincas não planares.

A geometria da trinca foi modelada numericamente por duas superfícies descritas implicitamente por dois campos de distâncias escalares tridimensionais, denominados ajustes de nível $\varphi$ e $\Psi$. A primeira superfície, $\varphi_{o}$, representava a superfície da trinca, enquanto a interseção de $\varphi_{o}$ e $\Psi_{0}$ era o seu fronte. BAIETTO et al. (2013) ainda afirmam que a grande vantagem de se usar esta abordagem ao invés de se usar geometria explicita é a informação volumétrica disponível no fronte da área da trinca. Isto facilitaria a definição das funções incrementais para refinamentos futuros, como os despendidos nos cálculos dos fatores de intensidade de tensões. A Figura 52 ilustra a modelagem. 


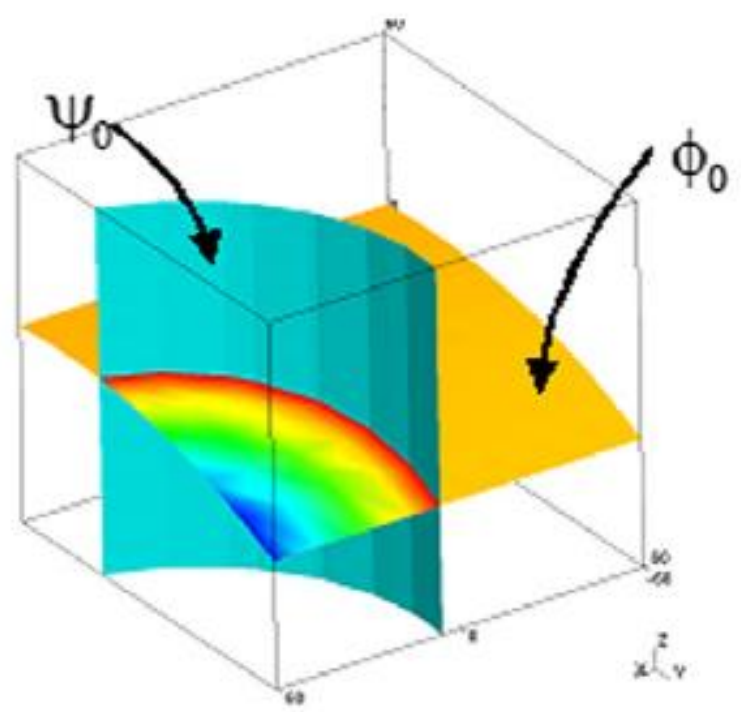

Figura 52 - Modelagem do formato da trinca com dois ajustes de nível (Fonte: BAIETTO et al. 2013)

Os pesquisadores então propuseram uma estratégia inovadora baseada na formulação fraca da mecânica da fratura a fim de se lidar de forma precisa no contato de fricção ao longo das superfícies da trinca. A interface da trinca foi vista como uma entidade autônoma, com variáveis próprias, seguindo sua própria lei constitutiva e com sua discretização adaptada à escala das condições de contato friccional ao longo da trinca. A ordem de grandeza do tamanho da interface da trinca pode ser muito inferior ao tamanho da trinca em si. Assim, a formulação fraca de três campos permite a discretização de uma interface da trinca incompatível com a malha estrutural. Os autores fizeram então um algoritmo específico para discretizar tal interface em uma escala pertinente, subdividindo o tanto quanto necessário os elementos da mesma, independentemente do refinamento da malha global. Tal ação permitiu uma redução da quantidade de elementos na ordem de 10 vezes utilizando-se o software ANSYS, mas obtendo-se uma precisão da mesma ordem.

As resoluções para os problemas de contato 3-D foram obtidas resolvendo-se problemas quasi-estáticos para a friç̧ão do contato através de iterações não lineares baseadas no método LATIN. A convergência local fica então garantida para problemas normais e tangenciais e as oscilações falsas geradas são eliminadas com um algoritmo baseados nos multiplicadores de Lagrange. Por fim, foram calculados os FIT ao longo da trinca por integração. 
Para se caracterizar o caminho da trinca, foi utilizado que assume que a direção da trinca se dará ou quando os fatores de intensidade de tensão são máximos ou na direção correspondente ao maior crescimento utilizando-se da/dN sob modo I de carregamento. No caso, uma das adaptações foi levar-se também em conta o modo de carregamento misto $\left(K_{I}\right.$ e $\left.K_{I I}\right)$ ao invés de apenas o modo I puro.

As Figuras 53 e 54 demonstram, respectivamente, as quatro distribuições de carregamentos adotadas para os ciclos tangenciais e o domínio discretizado da simulação numérica:

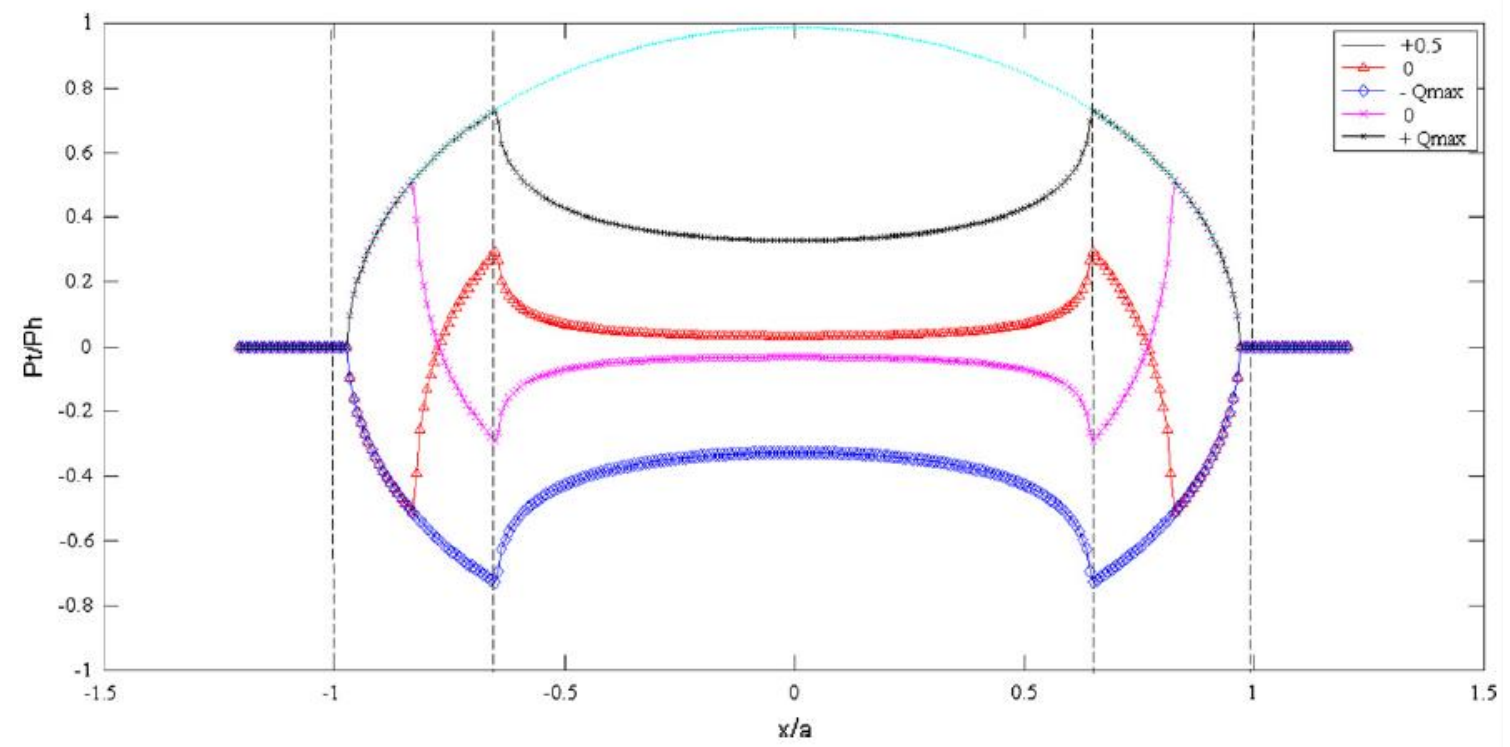

Figura 53 - Distribuição de tração para quatro carregamentos (Fonte: BAIETTO et al. 2013) 


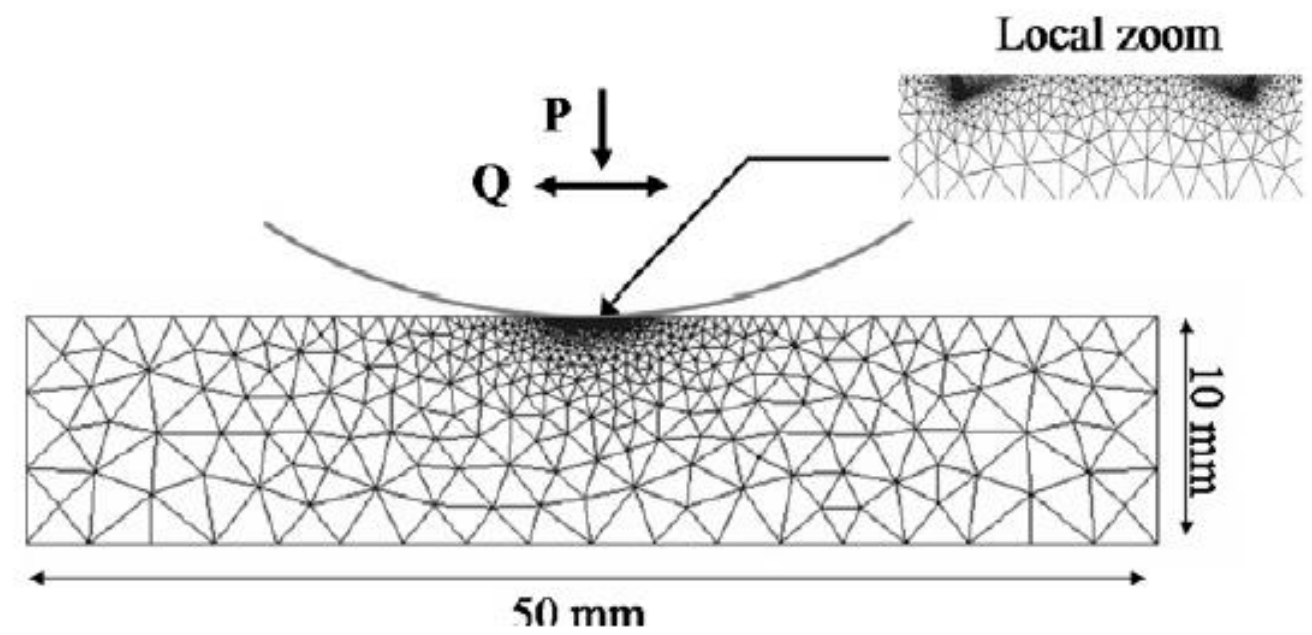

Figura 54 - Domínio retangular com a malha local refinida. $\boldsymbol{h}_{\min }=\mathbf{5} \boldsymbol{\mu} \boldsymbol{m} \frac{\boldsymbol{h}_{\max }}{\boldsymbol{h}_{\min }}=\mathbf{5 5 0}$ (Fonte: BAIETTO et al. 2013)

O risco de surgimento da trinca foi calculado pelo critério de Dang Van, com os resultados apresentados na Figura 55.

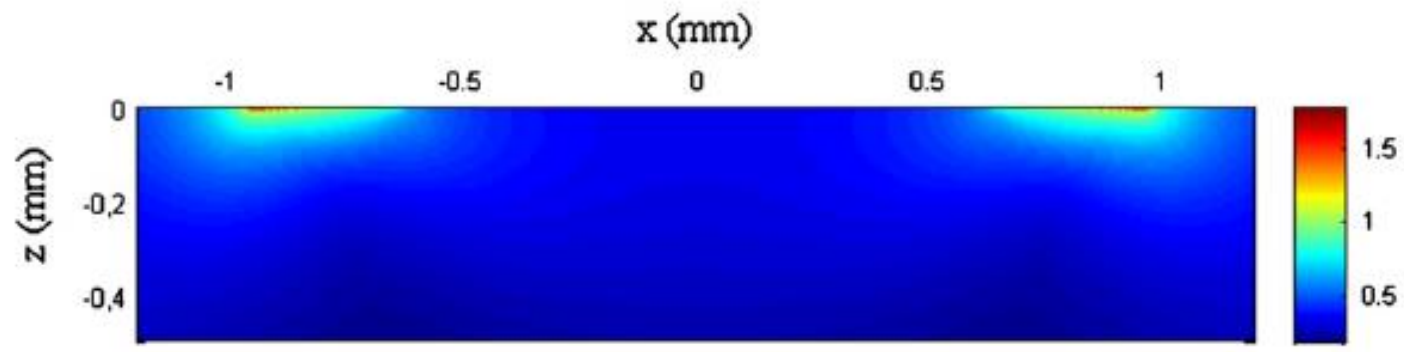

Figura 55 - Risco de surgimento de trinca de acordo com o critério de Dang Van (Fonte: BAIETTO et al. 2013)

É possível notar pela Figura 55 que o risco de surgimento da trinca é mais elevado nas proximidades das duas zonas de micro deslizamento. Utilizando dados experimentais, a constante $\mathbf{b}$ da lei de Paris foi reajustada para o cálculo de $\boldsymbol{K}_{\boldsymbol{I I}}$. Os valores da da/dN versus $\Delta \mathrm{K}$ são demonstrados na Figura 56. A título de comparação, os autores adicionaram na figura os cálculos da lei de Paris sob fadiga em modo I puro com $\mathrm{R}=0.1$. 


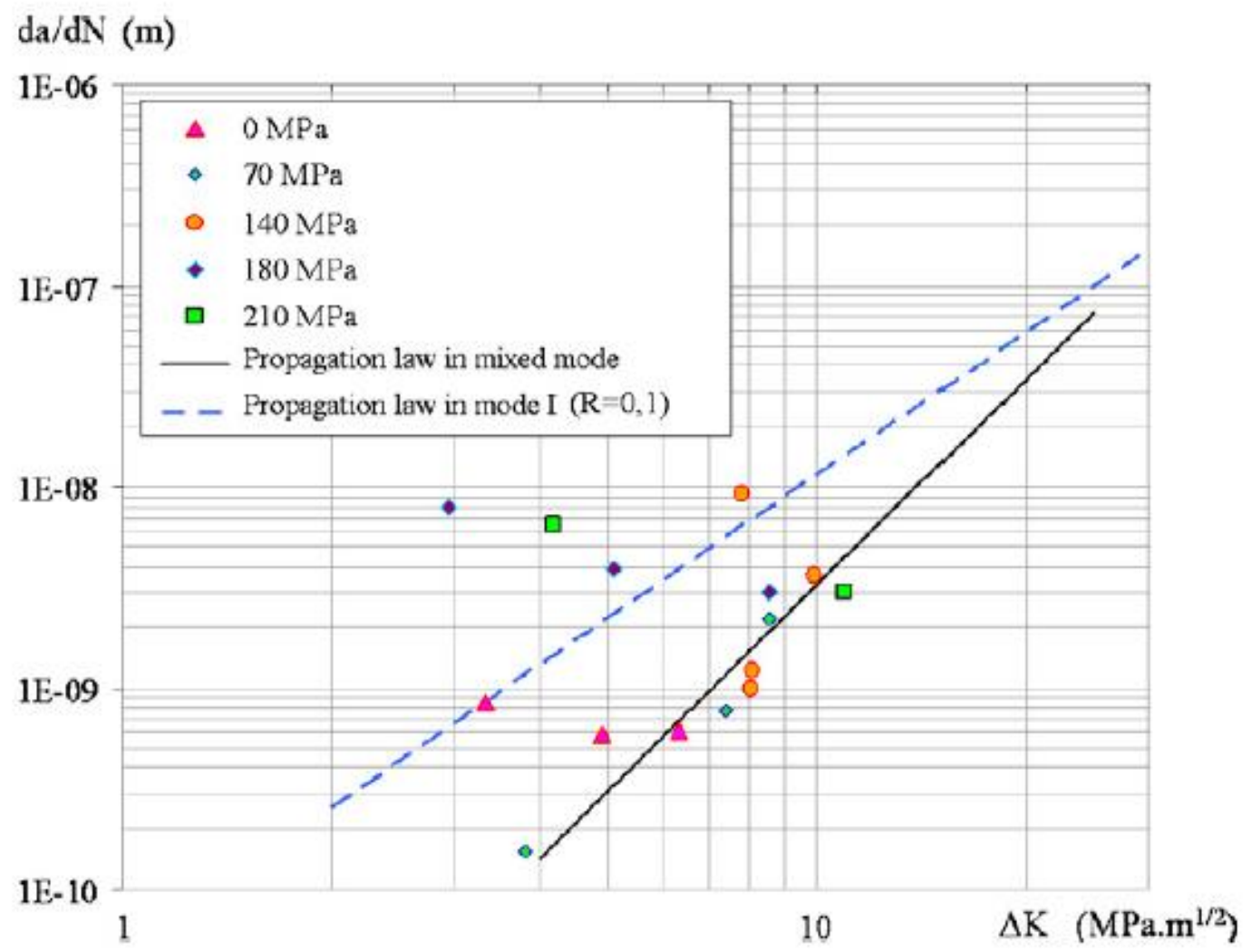

Figura 56 - Lei de crescimento da trinca em modo misto (Fonte: BAIETTO et al. 2013)

Por fim, compararam-se os valores obtidos experimentalmente com os das simulações numéricas para o caso bidimensional. Os pesquisadores então afirmam que, embora os critérios $\Delta k_{1 \text { Max }}^{*}(\theta, t)$ e $d a / d N_{\text {Max }}(\theta, t)$ tenham dado boa conformidade com os valores obtidos experimentalmente, o mesmo não aconteceu para o critério $k_{1 \text { Max }}^{*}(\theta, t)$. A Figura 57 demonstra a conformidade dos resultados.

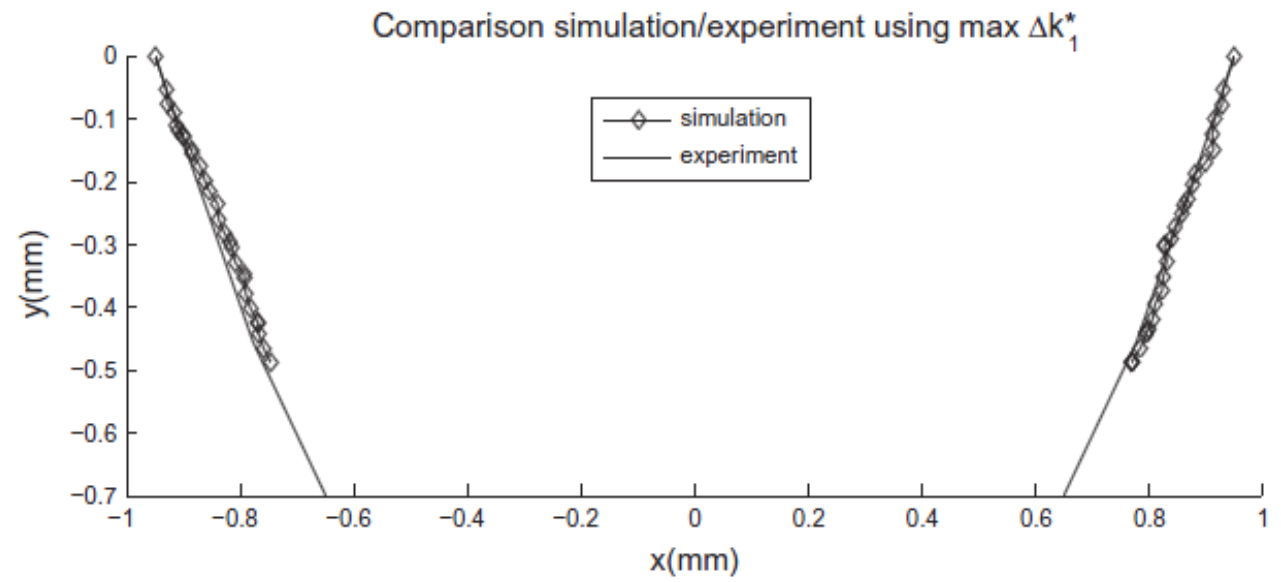

Figura 57 - Conformidade entre os resultados para o critério $\Delta \boldsymbol{k}_{\mathbf{1} \boldsymbol{M a x}}^{*}(\boldsymbol{\theta}, \boldsymbol{t})$ (Fonte: BAIETTO et al. 2013) 
Para o caso tridimensional, também foram calculados os FIT ao longo das trincas não planares. BAIETTO et al. utilizaram os ajustes de nível $\varphi_{o}$ e $\Psi_{0}$ supramencionados para a modelagem, conforme mostra a Figura 58.

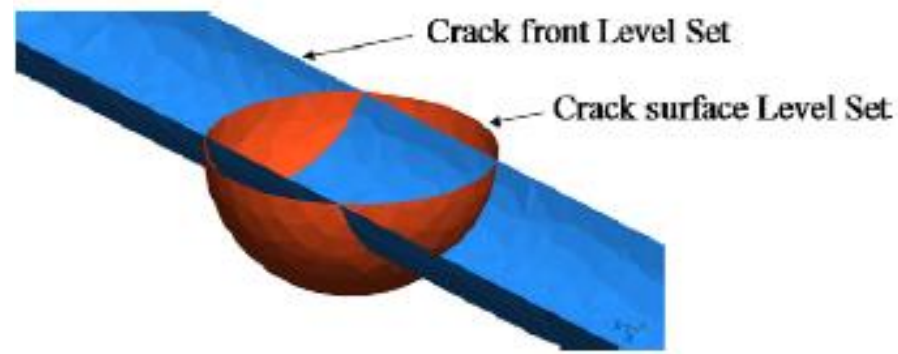

Figura 58 - Ajustes de nível $\boldsymbol{\varphi}_{\boldsymbol{o}}$ e $\boldsymbol{\Psi}_{\mathbf{0}}$ utilizados para a representação das trincas, baseadas em reconstruções post-mortem (Fonte: BAIETTO et al. 2013)

Maiores detalhes das estratégias de integração entre os dados experimentais e numéricos são encontrados na publicação e serão omitidos neste trabalho. Os autores conseguiram, após calcular os FIT, obter as taxas de liberação de energia, as quais demonstraram uma propagação potencialmente assimétrica, conforme demonstrado na Figura 59.

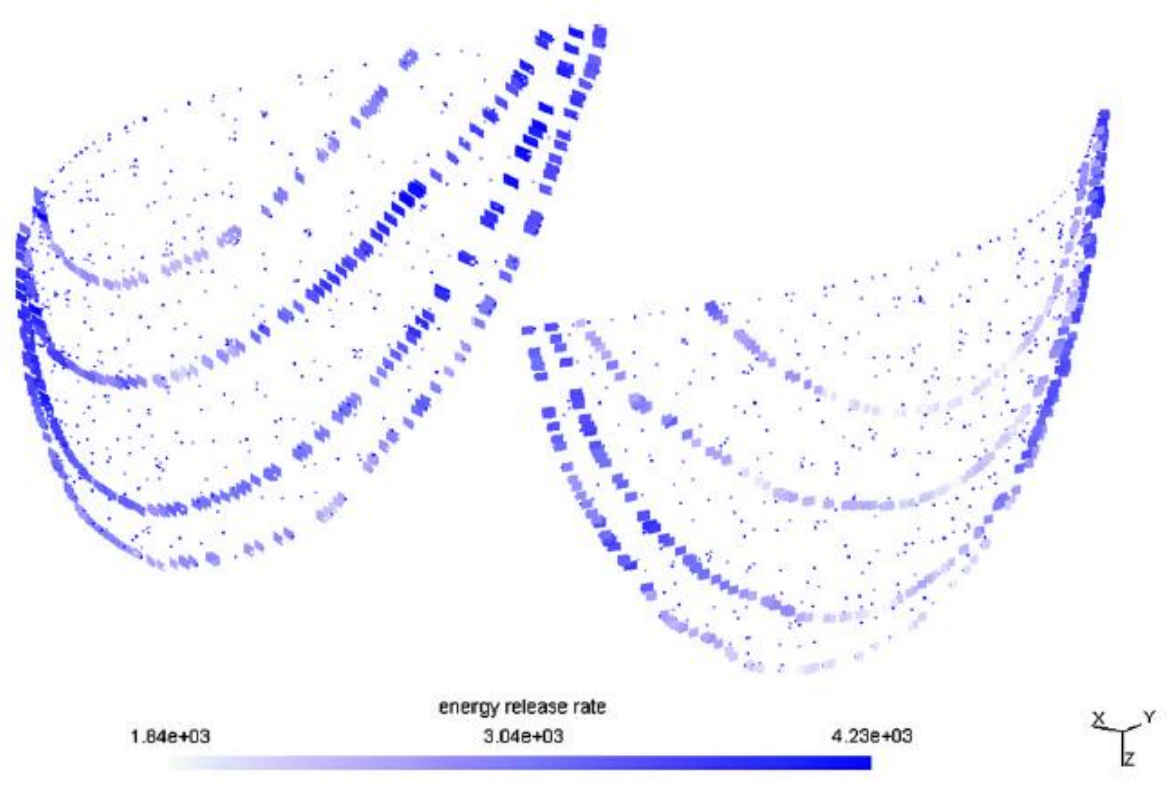

Figura 59 - Taxa de liberação de energia potencial (Fonte: BAIETTO et al. 2013) 


\subsubsection{MODELO PROPOSTO POR RAMMOHAN et al. (2012)}

Neste estudo, foi feita uma análise tridimensional por elementos finitos para se analisar os deslizamentos parciais entre as superfícies de contato e seus efeitos nas tensões atuantes. Para tal, escolheu-se como geometria cilindros com e sem fillet de borda entrando em contato com superfícies planas, tendo ambos os membros em contato as mesmas espessura e profundidade (Figura 60). As análises contaram com carregamentos normais e tangenciais nos blocos, assim como a aplicação de pressões internas nos espécimes.

Para se investigar os efeitos de fillet em trações de contato e deslizamento, RAMMOHAN et al. (2012) utilizaram blocos cilíndricos com e sem fillet de borda em contato com superfícies planas. Como em situações reais há presença de pressões internas além das tensões normais e cisalhantes, sendo elas significativas no direcionamento das trincas, as mesmas foram implementadas no modelo.

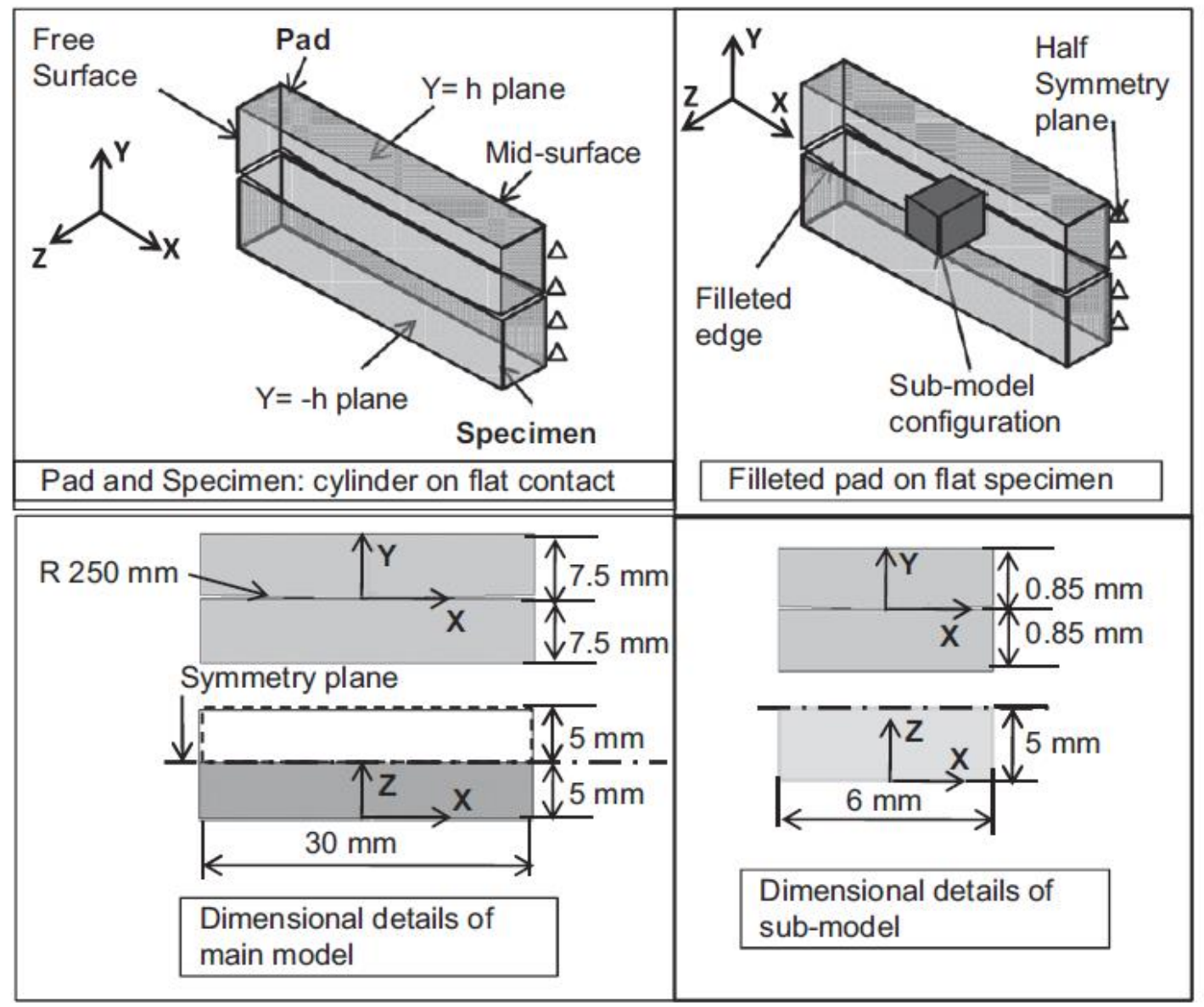

Figura 60 - Detalhes geométricos das configurações adotadas (Fonte: RAMMOHAN et al. 2012) 
Por conta das dimensões do comprimento e da altura dos espécimes serem muito superiores às do comprimento do contato, pode-se considerar que o comportamento deste seja similar ao proposto por Hertz.

O problema então teve sua malha gerada por HYPERMESH, sendo o programa utilizado para a resolução do modelo o ABAQUS. A malha foi refinada de tal forma que o tamanho dos elementos fosse mínimo na região do contato, principalmente em sua conta, onde há uma concentração dos gradientes de tensão, como pode ser visto na Figura 61.

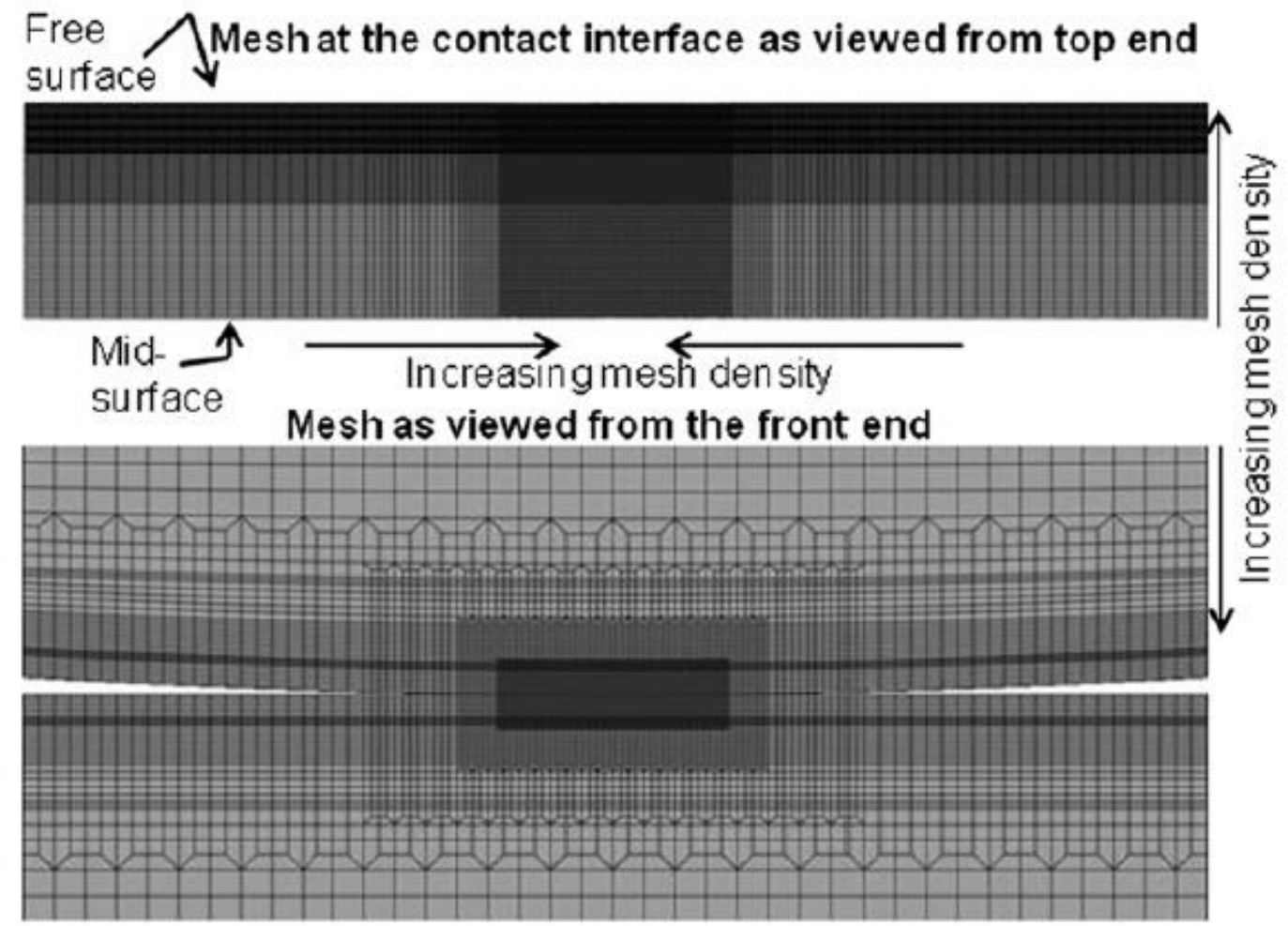

Figura 61 - Vistas aérea e frontal da malha para o bloco cilíndrico em contato com a superfície plana (Fonte: RAMMOHAN et al. 2012)

Em relação às condições de contorno e de carregamento, os autores tentaram ao máximo simular as que haviam ocorrido no experimento que tomaram como base. As etapas de carregamento e condições de contorno utilizadas são apresentadas na Figura 62. 


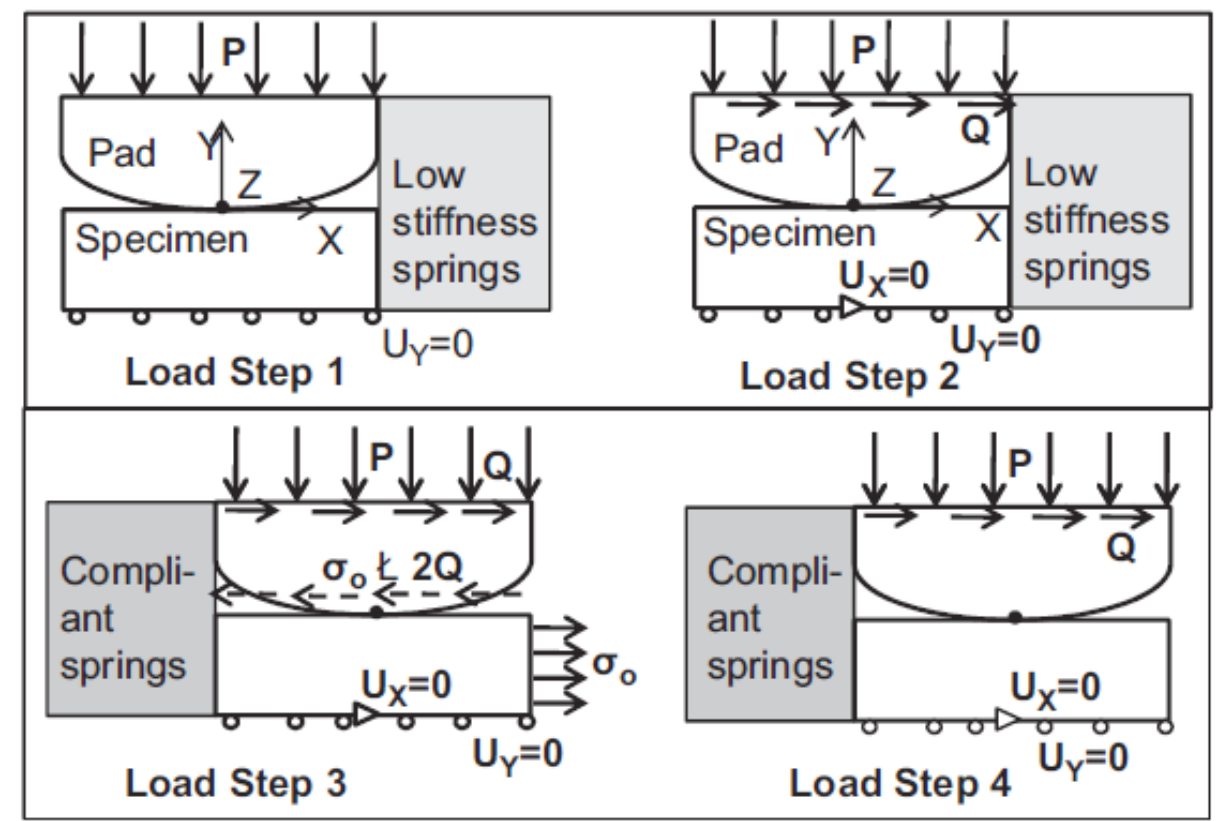

Figura 62 - Etapas de carregamento e condições de contorno (Fonte: RAMMOHAN et al. 2012)

A simulação do contato foi realizada através de elementos lineares contínuos, onde se utilizou o algoritmo já disponibilizado no ABAQUS do tipo pareamento de superfície para superfície. A superfície mestre escolhida foi a do bloco, sendo a do espécime a escrava. As restrições de contato foram impostas utilizando-se o método de Lagrange e o método das penalidades, enquanto a fricção seguiu a lei de Coulomb.
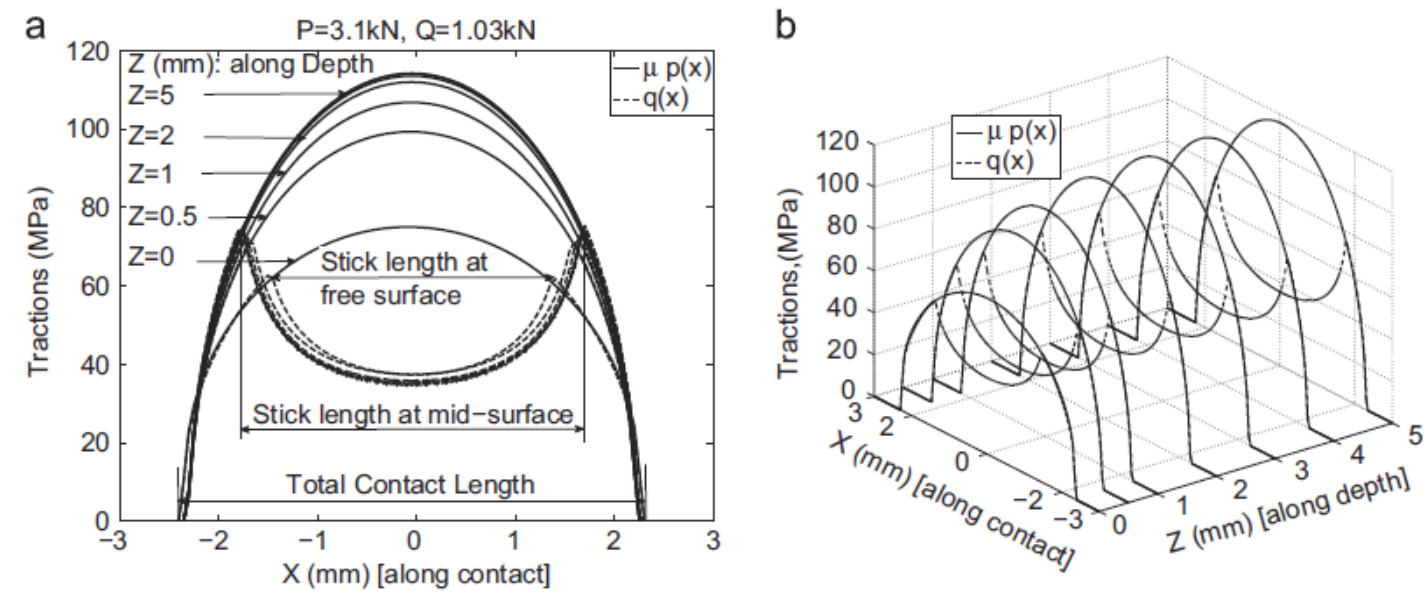

Figura 63 - Variações dos coeficientes de fricção versus pressão normal e cisalhamento ao longo da superfície de contato para diferentes profundidades em (a) 2-D (b) 3-D (Fonte: RAMMOHAN et al. 2012)

Os autores por fim calcularam o local de nucleação das trincas utilizando os conceitos de planos críticos. Valendo-se do MATLAB, plotaram onde ocorreria a nucleação da trinca em função da distância para o centro do contato. Os modelos 
utilizados para tal foram os de Findley, Smith-Watson-Topper, Fatemie-Socie-Kurath e Chu-Conle-Bonnen.

Os resultados mostraram-se satisfatórios para a caracterização de fretting tridimensional. As pressões internas mostraram significantes influências no aumento dos efeitos das tensões cisalhantes e de deslizamento. Os autores encontraram um aumento da ordem de três vezes na ordem de grandeza na magnitude dos deslizamentos levandose em conta as pressões internas. Por fim, a presença do fillet também aumentou consideravelmente o dano estimado. 


\subsubsection{MODELO PROPOSTO POR PIERRES et al. (2010)}

Com base em modelos experimentais e numéricos, o método proposto visava o melhoramento da técnica de previsão de trincas. Após realizar testes que simulavam situação de fretting, formas das trincas tridimensionais foram reconstruídas através de metalografia das seções transversais e descritas em funções de ajuste de nível. Tais trincas foram usadas como dado de entrada no modelo de elementos finitos expandido tridimensional, cujas condições de contato são descritas em maiores detalhes no trabalho.

Antes da apresentação do modelo numérico elaborado, é relevante apresentar o modelo experimental dos autores: Através de uma esfera com condições de deslizamento parcial sobre uma superfície plana, eles simularam as formações de trincas, as quais surgiam nas proximidades da zona de contato bem cedo. A Figura 64 ilustra o esquema.

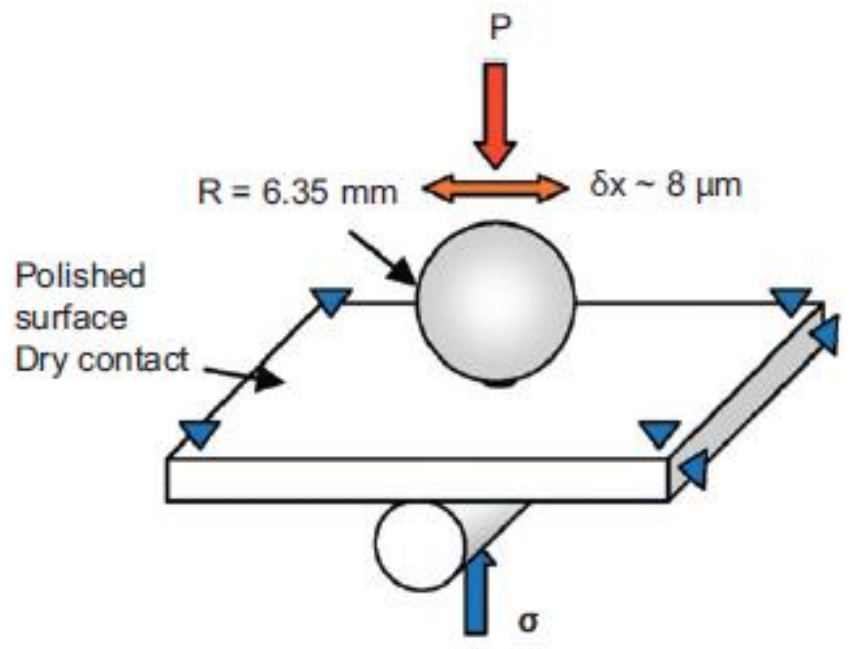

Figura 64 - Esquema experimental do teste de fretting (Fonte: PIERRES et al. 2010)

Os pesquisadores então observaram que apenas duas destas trincas geradas, usualmente simétricas em relação ao centro do contato, propagavam-se, enquanto as outras acabavam se anulando. Essas duas trincas propagavam-se perpendicularmente à direção do fretting, com forma semielíptica na superfície da configuração esfera/plano, por fim se encontrando na borda do espécime. Após um número $N$ de ciclos, inspeções post-mortem das seções transversais foram realizadas para a construção de padrões de planos das trincas. Foram feitas, no total, vinte seções transversais do volume a fim de se determinar a forma tridimensional da trinca. A Figura 65 ilustra o que foi elaborado. 
a

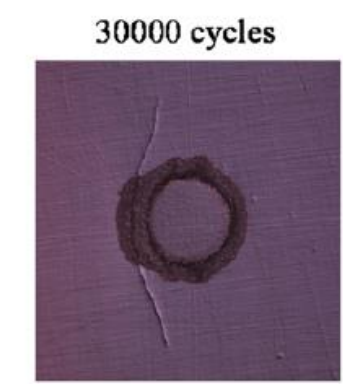

b
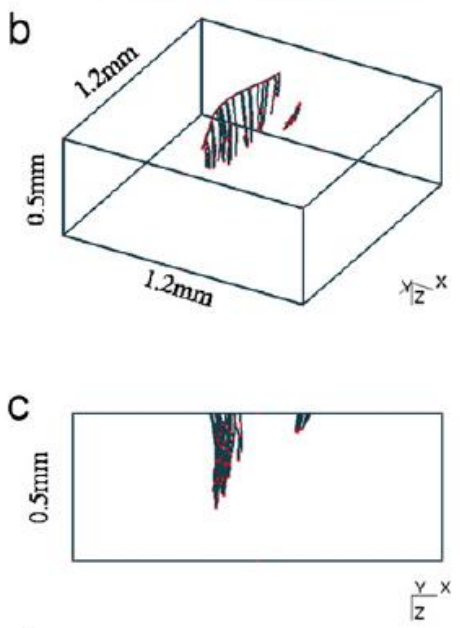

d

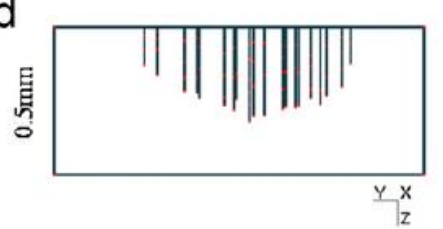

50000 cycles
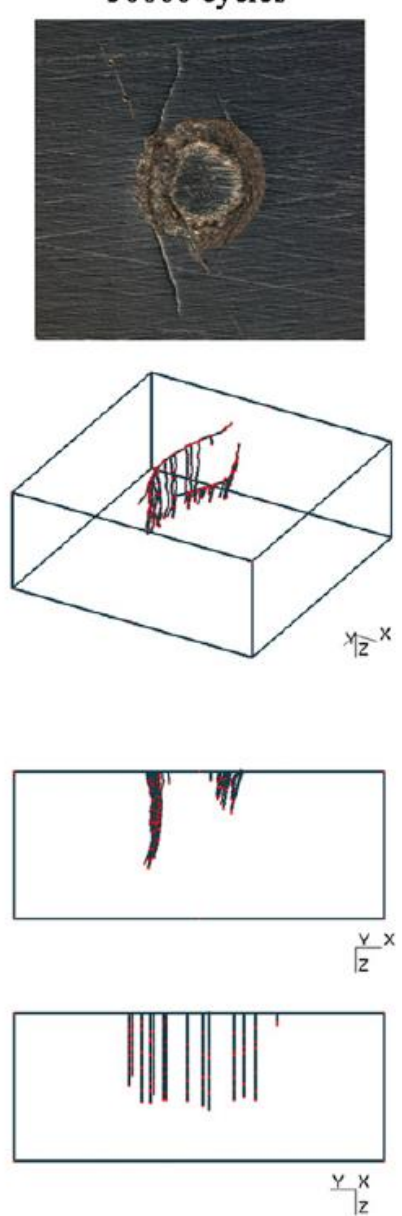

70000 cycles
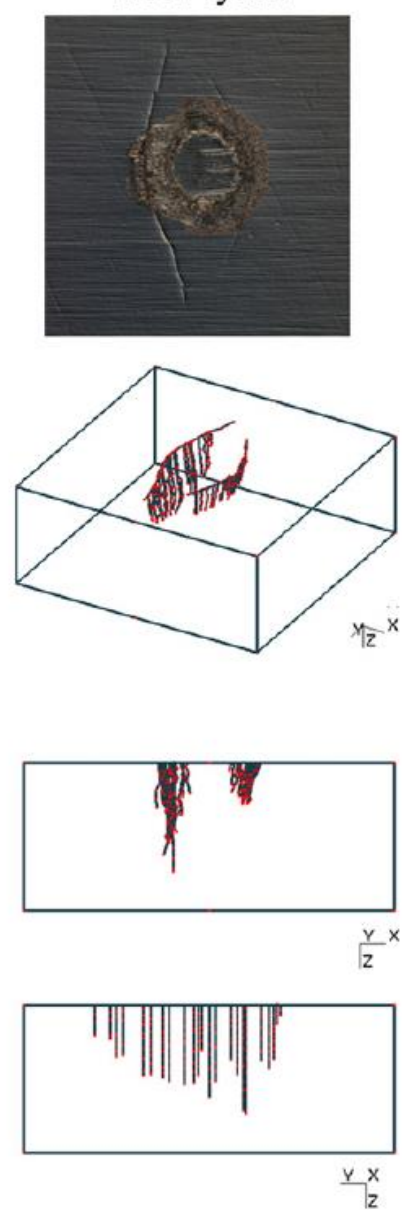

Figura 65 - (a) superfície de contato trincada (b) reconstrução tridimensional da trinca (c) projeção da trinca no plano x-z e (d) projeção da trinca no plano y-z (Fonte: PIERRES et al. 2010)

Para um corpo elástico sujeito a restrições de deslocamento e uma força cíclica externa atuando em seu limite, a lei de fricção do contado será dada por:

$w=w_{N} n_{c}+w_{T} n_{T}$

$t=t_{N} n_{c}+t_{T} n_{T}$

w e $\mathbf{t}$ são, respectivamente, os campos de interface de deslocamento e força. $n_{c}$ e $n_{t}$ a força normal e a força tangencial, respectivamente, ligadas à superfície da trinca $\Gamma_{c}$ do corpo elástico $\Omega$ em um determinado tempo. 


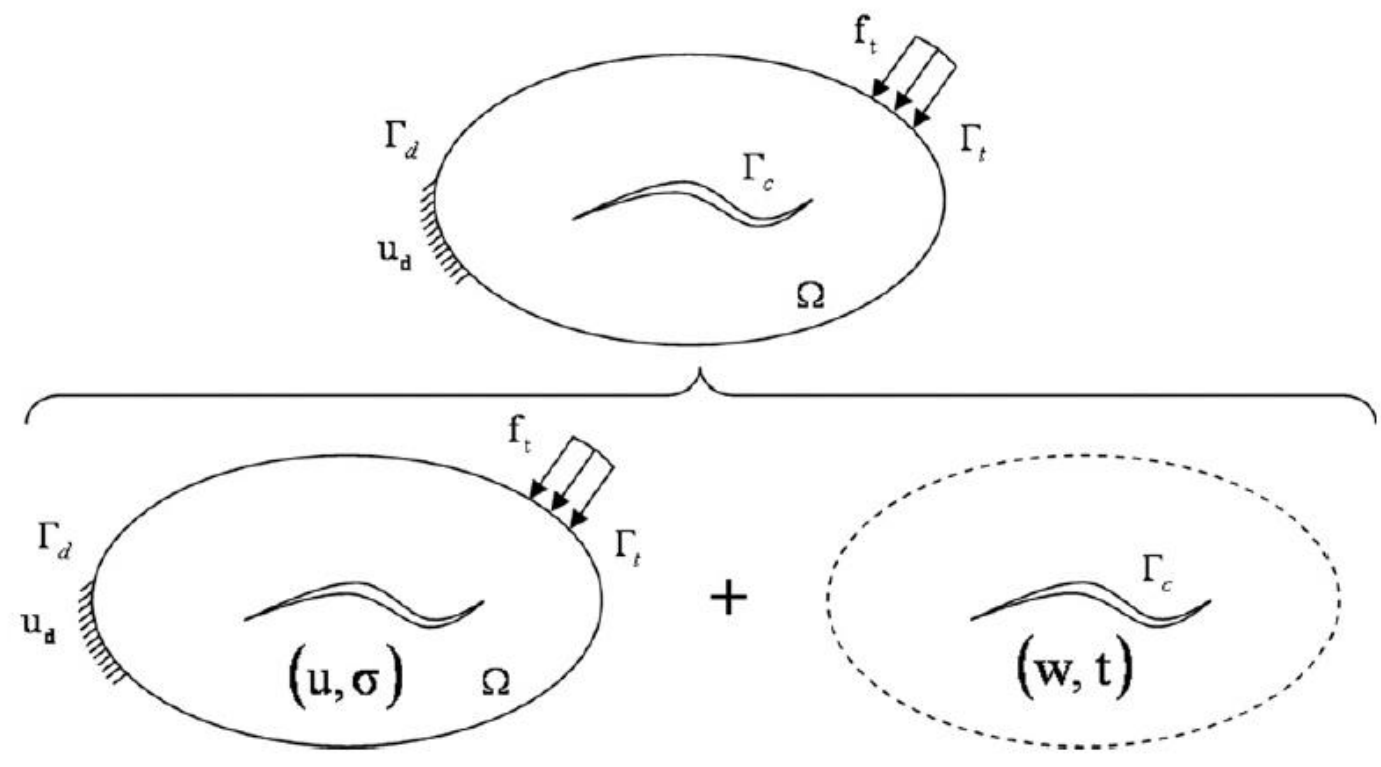

Figura 66 - Esquema e notações para os problemas global e local de fratura (Fonte: PIERRES et al. 2010)

Utilizando os dados experimentais para reconstruir os padrões elípticos das trincas, os autores utilizaram dois ajustes de nível para a modelagem dos padrões das trincas, conforme a Figura 67.

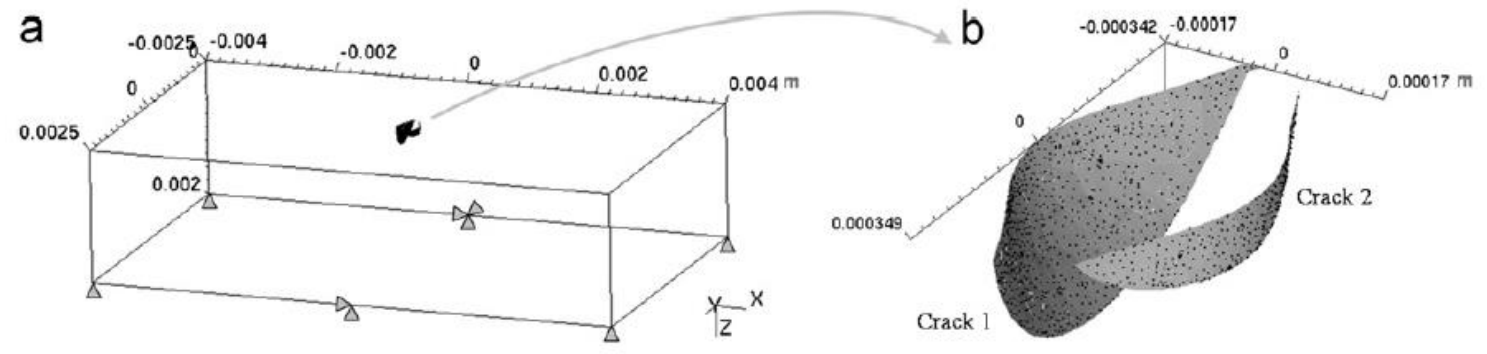

Figura 67 - (a) Geometria da trinca nas condições de contorno e (b) geometria tridimensional definida com ajustes de nível (Fonte: PIERRES et al. 2010)

A definição das duas trincas requer apenas um par de ajustes de nível, conforme mostra a Figura 68. 

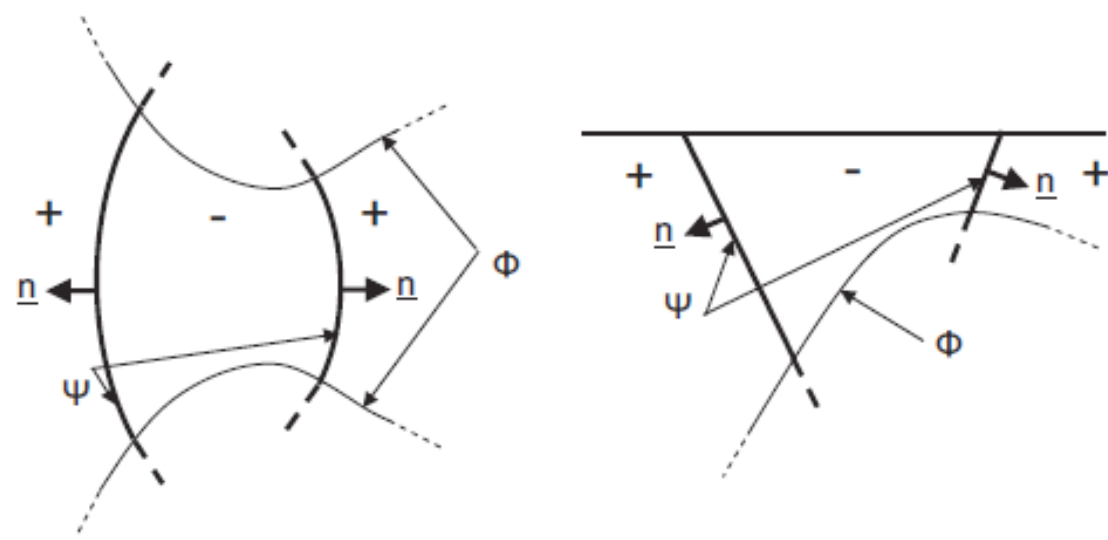

Figura 68 - Definição das formas das trincas e forças normais para as trincas 1 e 2, utilizando os ajustes de nível $\Psi$ e $\boldsymbol{\varphi}$ (Fonte: PIERRES et al. 2010)

O coeficiente de atrito entre as superfícies utilizado foi o médio obtido através de simulação no software ANSYS. O carregamento de fretting considerado foi simplificado, consistindo de uma pressão estática normal de Hertz e um carregamento cíclico tangencial.

Os autores por fim concluíram que os resultados obtidos foram satisfatórios, validados, inclusive, por outros estudos bidimensionais de modelos X-FEM. Maiores detalhes sobre a discretização da malha e as condições de contorno e carregamento utilizados podem ser encontrados na publicação. A Figura 69 resume os resultados obtidos com modelagem no ANSYS. 


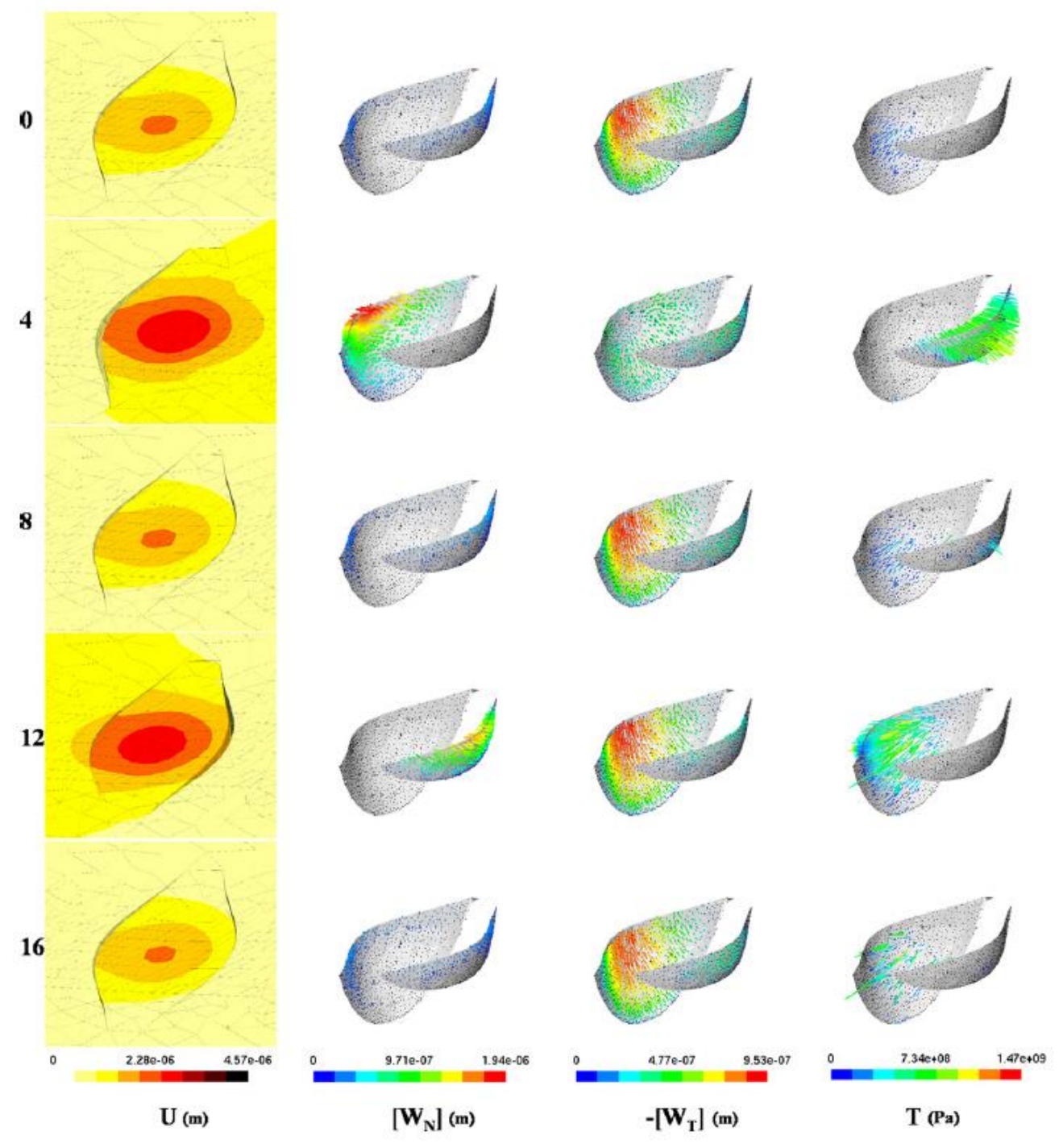

Figura 69 - Representações amplificadas dos campos de deslocamento U, de deslocamentos normais relativos $\mathbf{W}_{\mathbf{N}}$ e dos deslocamentos tangenciais $\mathbf{W}_{\mathbf{T}}$ e de tração T para os intervalos de tempo 0,4,8, 12 e 16 (Fonte: PIERRES et al. 2010) 


\subsubsection{MODELO PROPOSTO POR MADGE et al. (2007)}

O modelo de elementos finitos proposto por MADGE et al. (2007) objetivava a previsão da evolução da geometria do contato por conta de fretting wear, a estimativa das tensões no contato e a determinação de parâmetros de danos por fadiga multiaxial levando-se em conta efeitos de danos cumulativos. Para isto, foram utilizadas funções de amplitude de deslizamento e condições similares as de testes de fadiga disponíveis fartamente na literatura.

Conforme descrevem MADGE et al (2007), dentre cerca de cinquenta variáveis diferentes que já foram identificadas como fatores relevantes em fretting fatigue, são geralmente aceitas como primárias a pressão de contato, amplitude de deslizamento e coeficiente de fricção. Ainda acrescentam: "VINGSBO \& SODERBERG (1988) descobriram uma relevante redução na vida à fadiga por fretting fatigue para um determinado intervalo de amplitudes de deslizamento". As amplitudes de deslizamento comumente aceitas como sendo as mais danosas são as que causam deslizamento parcial.

Citando o trabalho de FOUVRY et al.(2004) em "fretting damage: friction wear and crack nucleation", os autores afirmam que deslizamentos abruptos estão associados a altas energias de dissipação e altos volumes de desgaste, enquanto deslizamentos parciais estão associados a baixas energias de dissipação e menores volumes de desgaste, mas que o último, entretanto, está associado a trincas, principalmente na interface do deslizamento parcial. Portanto, deslizamentos abruptos estão associados à fadiga de alto ciclo, enquanto deslizamentos parciais estão associados a fadigas de ciclos mais curtos e a falhas por trincamento (Figura 70). 


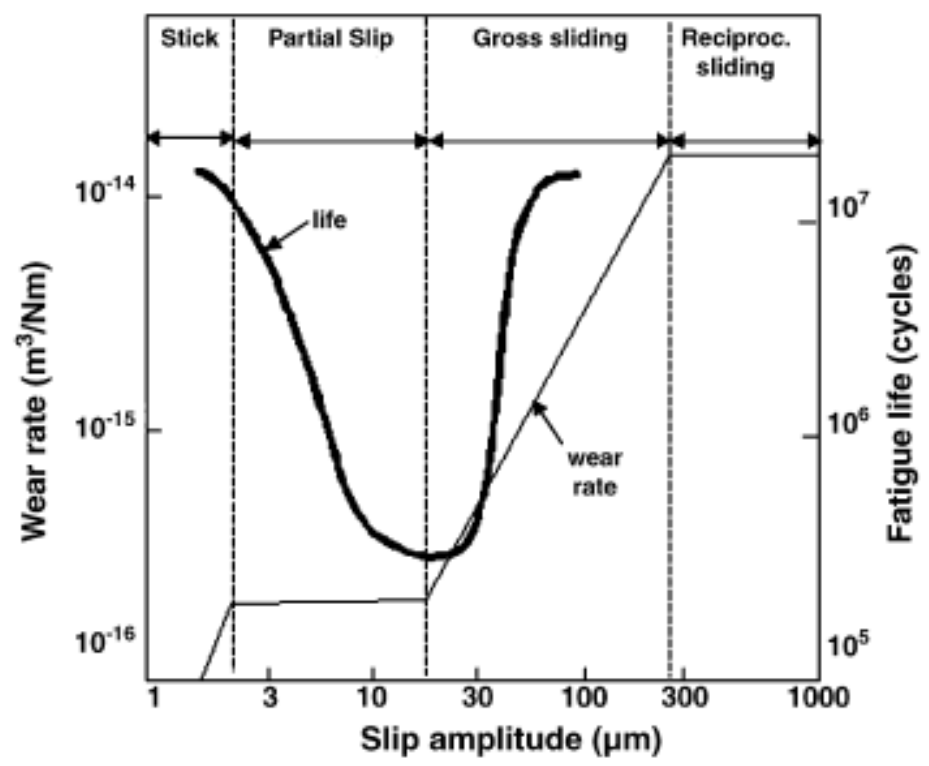

Figura 70 - Efeito de amplitude de deslizamento em (a) vida à fadiga por fretting fatigue e (b) desgaste. (VINGSBO et al. 1988)

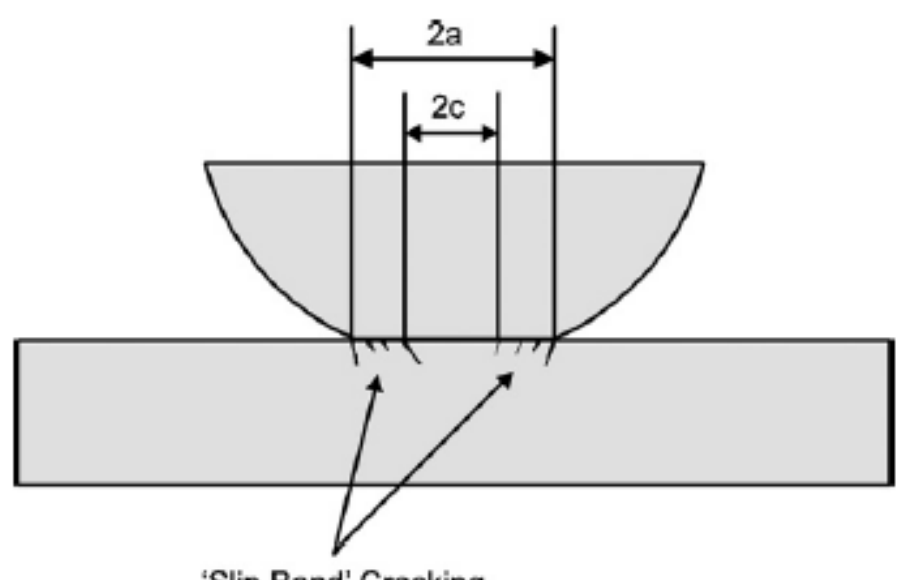

'Slip Band' Cracking

Figura 71 - Esquemática da região de contato parcial (Fonte: MADGE et al. 2007)

Devido à forte ligação entre deslizamento parcial e desgaste, alguns autores como VINGSBO \& SODERBERG (1988) passaram a sugerir que o comportamento do desgaste fosse explicado por uma relação entre vida e deslizamento. Segundo tal sugestão, condições abruptas de deslizamento seriam capazes de autodestruir trincas pequenas antes que as mesmas formassem nucleações maiores que pudessem propagar até a falha do componente.

Com base em trabalhos que previam a evolução de tensões normal e de cisalhamento na sub-superfície do material, os autores então associaram a modelagem de 
fadiga multiaxial de plano crítico de SWT ao modelo de elementos finitos utilizando o ABAQUS.

No modelo de elementos finitos, foi criado um plano de simetria ao eixo do espécime a fim de que apenas um bloco precisasse ser modelado, conforme mostra a Figura 72. No primeiro intervalo de análise, uma carga normal foi aplicada ao cilindro, ocorrendo uma pressão de contato de Hertz. Em seguida, o próximo intervalo considera uma carga cíclica de fadiga e um deslocamento pré-determinados. Tal deslocamento é representado pelo máximo deslizamento na superfície de contato após um ciclo, como pode ser visto na Figura 73. Nestes testes, este deslocamento pré-determinado é menor do que os causados pelo carregamento de fadiga, o que faz com que a força de cisalhamento bruta aja na oposição oposta ao supracitado movimento.
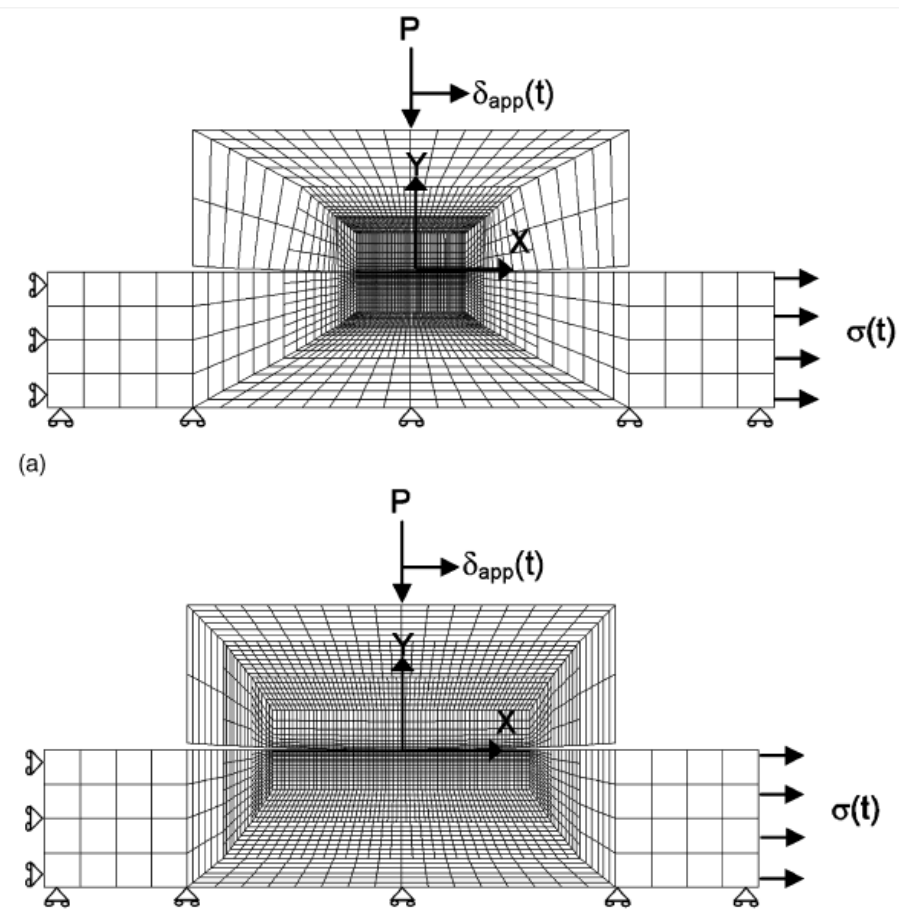

(b)

Figura 72 - Malhas da análise de elementos finitos para (a) deslizamento parcial e (b) deslizamento abrupto (Fonte: MADGE et al. 2007) 


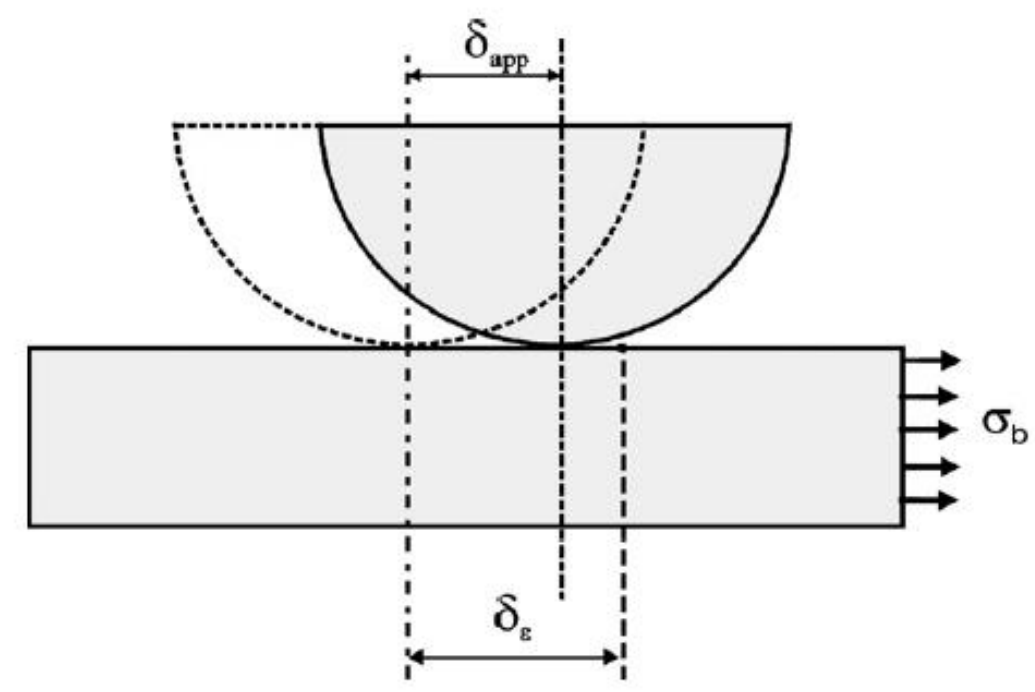

Figura 73 - Relação entre deslocamento aplicado, máximo deslocamento pré-determinado $\boldsymbol{\delta}_{\boldsymbol{a p p}} \mathrm{e}$ deslocamento devido às deformações $\boldsymbol{\delta}_{\boldsymbol{\varepsilon}}$ (Fonte: MADGE et al. 2007)

A história de carregamentos e deslocamentos implementados é mostrada na Figura 74. O critério de escoamento escolhido foi o de Von Mises, o material também foi considerado elástico durante o carregamento.

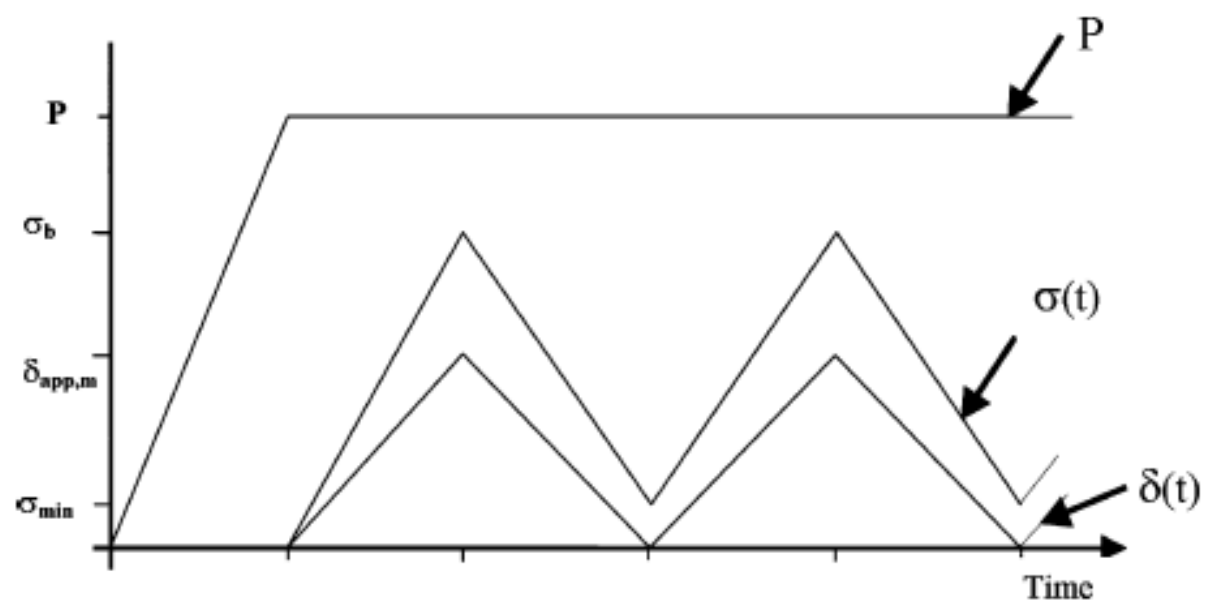

Figura 74 - Tensão normal, deslocamento tangencial e tensão cíclica implementados (Fonte: MADGE et al. 2007)

Para a informação de contato, utilizou-se a Lei de Coulomb, sendo adicionada uma subrotina onde, para valores de tensão cisalhante inferiores aos críticos, aplicava-se o multiplicador de Lagrange.

Já a validação do modelo de elementos finitos (FE) foi feita por comparação dos resultados obtidos com a solução teórica de Hills \& NOWELL (1994) (Figura 75). 

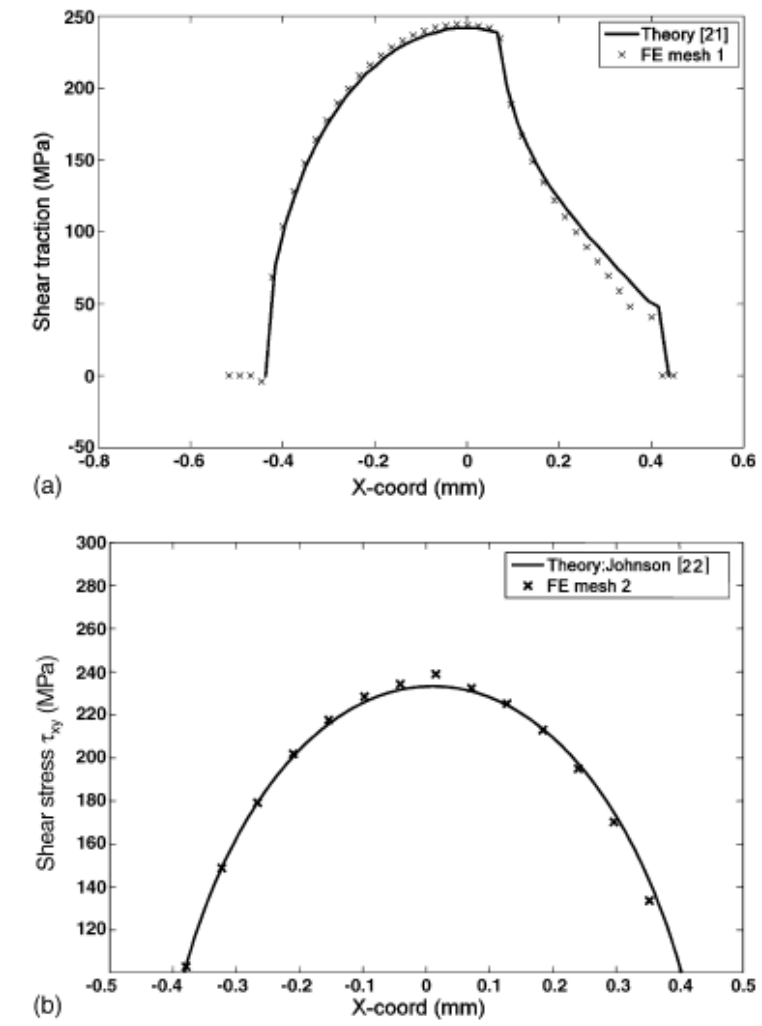

Figura 75 - Comparação da previsão por FE e das soluções teóricas de Hills e Nowell para (a) deslizamento parcial e (b) tensões de cisalhamento sub-superfíciais para deslizamento abrupto (Fonte: MADGE et al. 2007)

Às pequenas diferenças encontradas atribui-se a consideração dos meios espaços elásticos no modelo teórico, os quais não são completamente satisfeitos no modelo $\mathrm{FE}$ por conta da espessura do espécime em comparação ao tamanho do contato.

O modelo de desgaste adotado foi baseando na modificação das equações de Archard. Maiores detalhes das equações utilizadas podem ser encontrados na publicação. Para a modelagem em FE, foi utilizada a subrotina UMESHMOTION do programa ABAQUS. Como a profundidade do desgaste naturalmente influenciava nas pressões e no deslizamento atuantes, foi implementado um incremento de profundidade de desgaste para cada ciclo de fretting, associando um valor correspondente de pressão e deslizamento relativo.

Para se calcular o acumulo de danos, os autores utilizaram o modelo de MinerPalmgren modificado para a consideração do pulo de ciclos, o qual foi necessário para se reduzir o custo computacional da simulação numérica. É relevante dizer que se criou uma malha de ponto material (MPM) como referência no modelo, na qual os nós 
correspondentes aos materiais removidos por desgaste não acumulavam no dano à fadiga. Os resultados obtidos pelos autores são então ilustrados nas Figuras 76 a 81 :

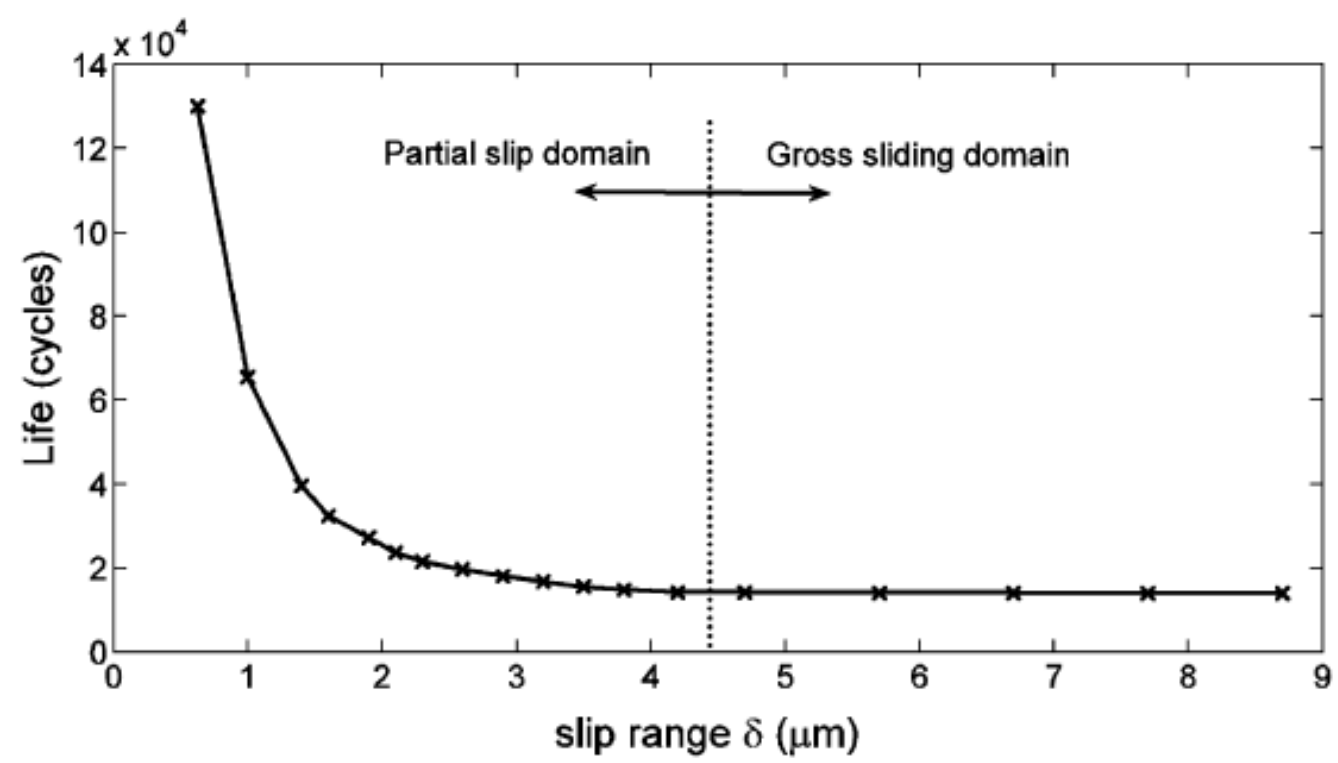

Figura 76 - Previsão de vida à fadiga em função da amplitude de deslizamento por modelo SWT baseado em FE, negligenciando os efeitos de remoção de material (Fonte: MADGE et al. 2007)

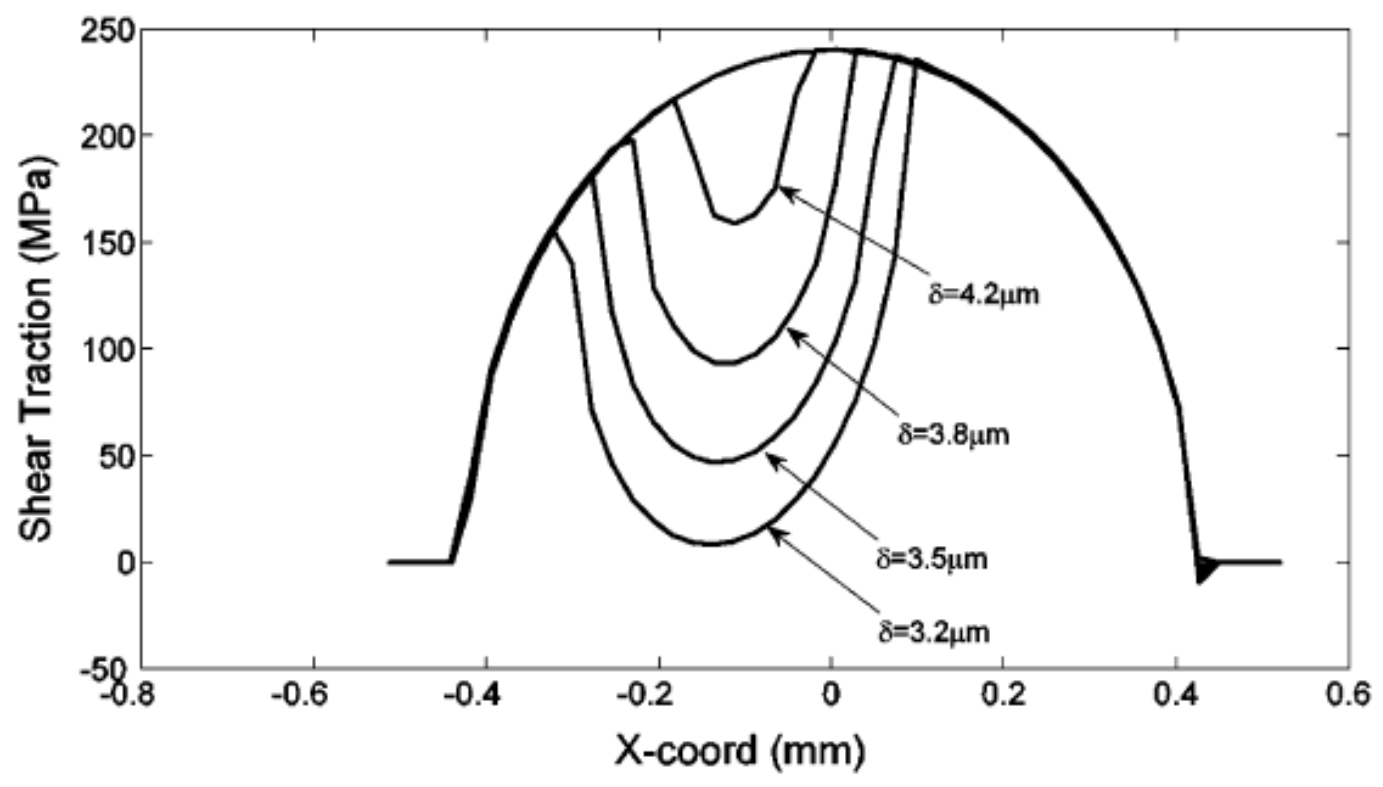

Figura 77 - Efeitos previstos na distribuição de forças cisalhantes por amplitudes de deslizamento (Fonte: MADGE et al. 2007)

Vale notar na Figura 76 o significante efeito do raio de deslizamento na vida à fadiga, o qual é estabilizado uma vez que o limite entre deslizamentos parcial e abrupto é 
atingido. A explicação deste efeito se dá pela distribuição das forças cisalhantes causadas pelas amplitudes de deslizamento, como mostra a Figura 77.

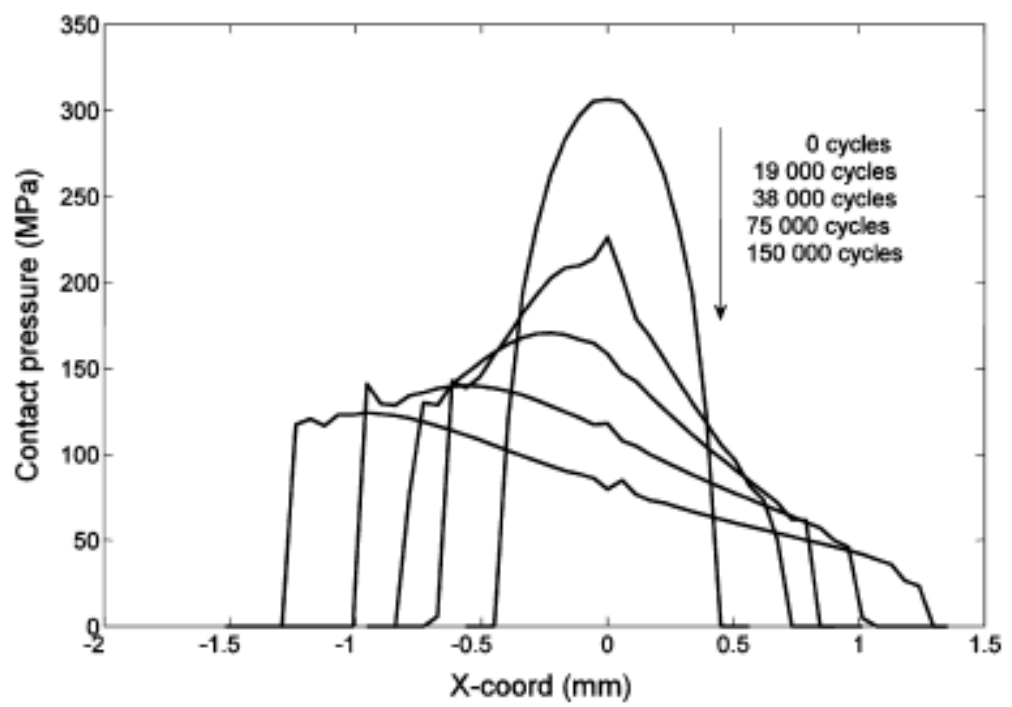

Figura 78 - Previsão da distribuição de pressão de contato com desgaste para deslizamentos abruptos (Fonte: MADGE et al. 2007)

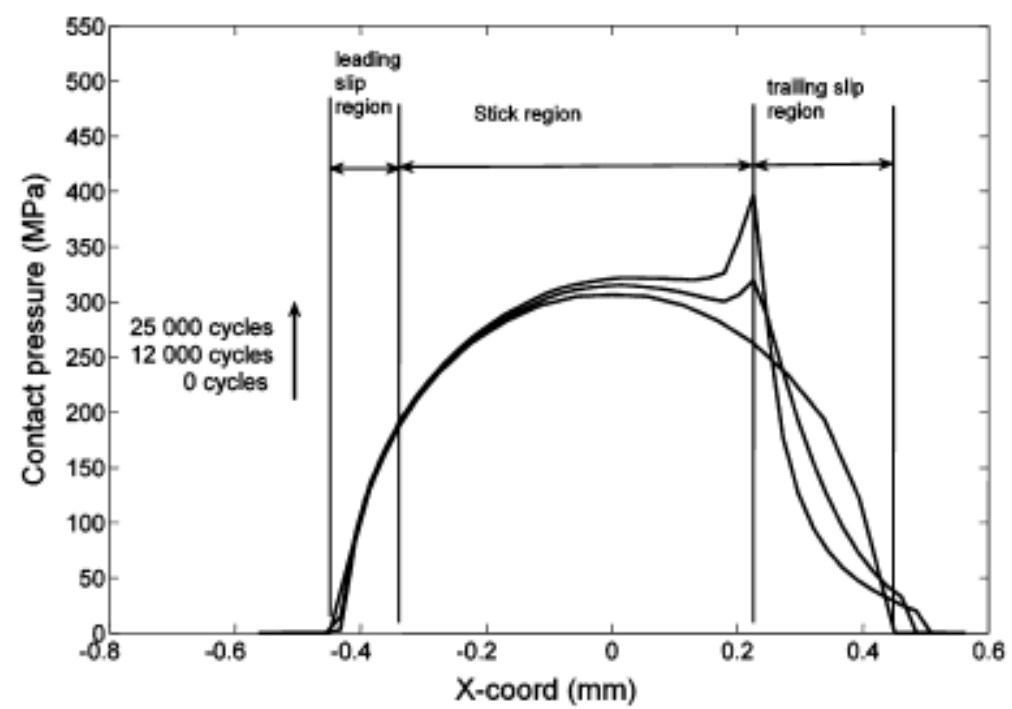

Figura 79 - Previsão da distribuição de contato para deslizamento parcial (Fonte: MADGE et al. 2007)

Analisando-se a Figura 78, fica claro que o pico de pressão no contato é reduzido significativamente ao longo dos ciclos. Devido à conformidade ocasionada pelo desgaste entre o bloco e o espécime, o comprimento do contato chega a aumentar em mais de duas vezes para os primeiros 150.000 ciclos. 
Na Figura 79, o pico de pressão previsto na interface limite entre o deslizamento e a zona de contato é consistente com a evolução do deslizamento parcial previsto por DING (2004). Ao contrário do que ocorria na condição de deslizamento abrupto, as pressões de contato não são reduzidas ao longo do número de ciclos.

A Figura 80 ilustra o dano acumulado calculado para ambos os casos. Percebe-se nitidamente que no caso do deslizamento parcial, o dano é mais localizado e de maior magnitude, ocorrendo em uma quantidade de ciclos menor.

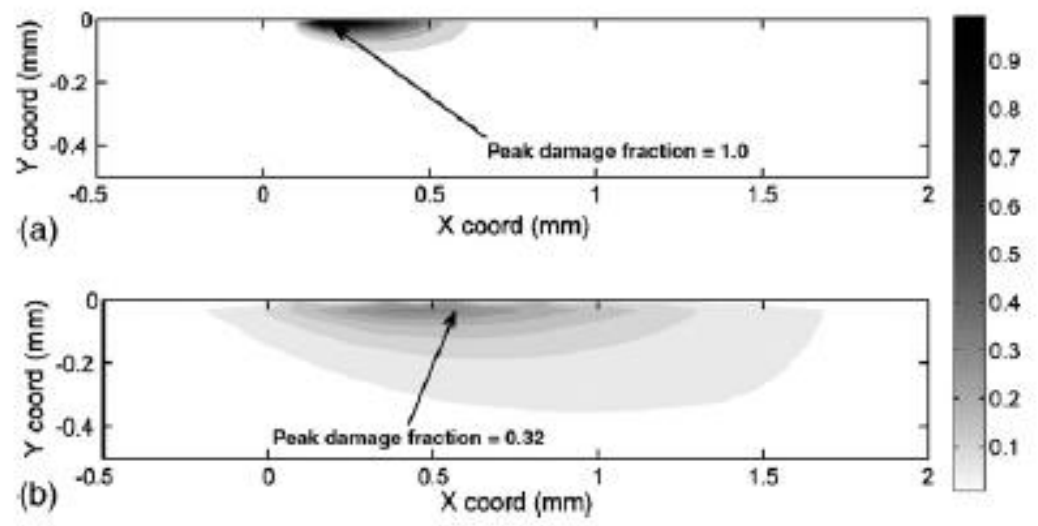

Figura 80 - Danos acumulados para o caso de (a) deslizamento parcial com 25.000 ciclos e de (b) deslizamento abrupto com 150.000 ciclos (Fonte: MADGE et al. 2007)

Por fim, para demonstrar a boa previsão da metodologia apresentada, os autores compararam seus resultados numéricos com os de JIN et al. (2004) (Figura 81).

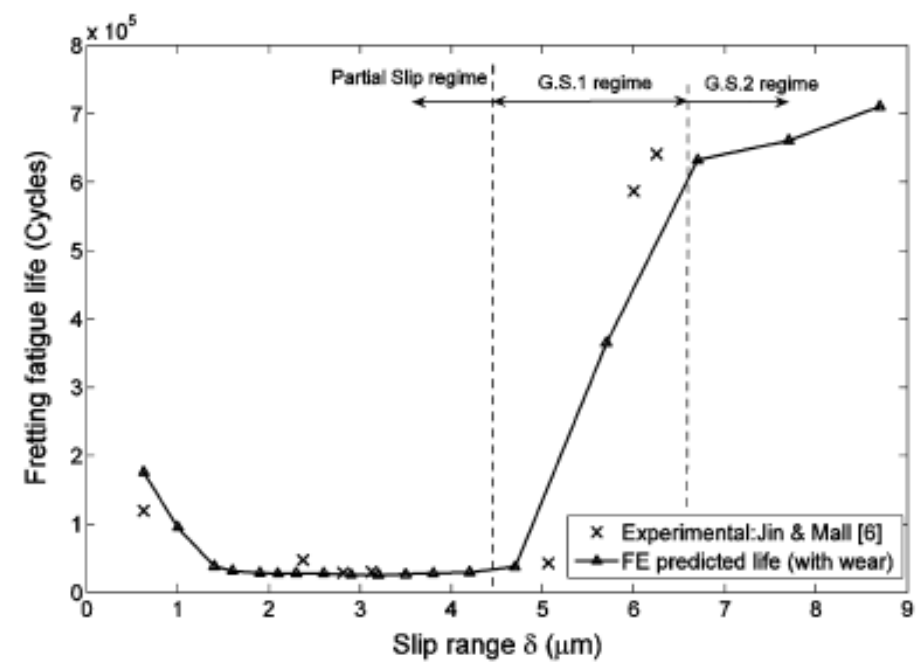

Figura 81 - Comparação das previsões do modelo de elementos finitos com os encontrados experimentalmente em outro estudo (Fonte: MADGE et al. 2007) 


\subsubsection{MODELO PROPOSTO POR KIM et al. (2011)}

KIM et al. (2011) começam afirmando que os modelos tradicionais nas últimas décadas levavam em consideração o contato como sendo fruto de uma interação de um plano de tensão linear entre um bloco infinito e outro com espessura finita. Continuam a dizer que, para uma espessura de contato realista, o modelo de plano de tensão seria satisfatório em aproximar as condições no plano central e suas vizinhanças, mas não explicaria de forma satisfatória os efeitos tridimensionais em espessuras finitas de configurações típicas de fretting fatigue.

JOHNSON (1985) estudou os efeitos de compressão que surgem por conta dos limites de borda livre nos testes de fretting fatigue com espessura finita. O impacto desses efeitos depende de detalhes geométricos e dos limites de borda livre. (KIM et al., 2011) estudaram efeitos tridimensionais utilizando modelos de elementos finitos tridimensionais e técnicas de submodelagem, obtendo resultados em boa concordância com experimentos. No entanto, o custo computacional do modelo proposto era em demasia grande para se implementar malhas finas no limite do contato, o que motivou este estudo.

Um modelo de camada híbrida com intuito de investigar os efeitos tridimensionais em espécimes de espessura finita foi então proposto baseando-se na hipótese de que as distribuições de tração convergem mais rapidamente que as tensões durante o fenômeno de fretting fatigue. 


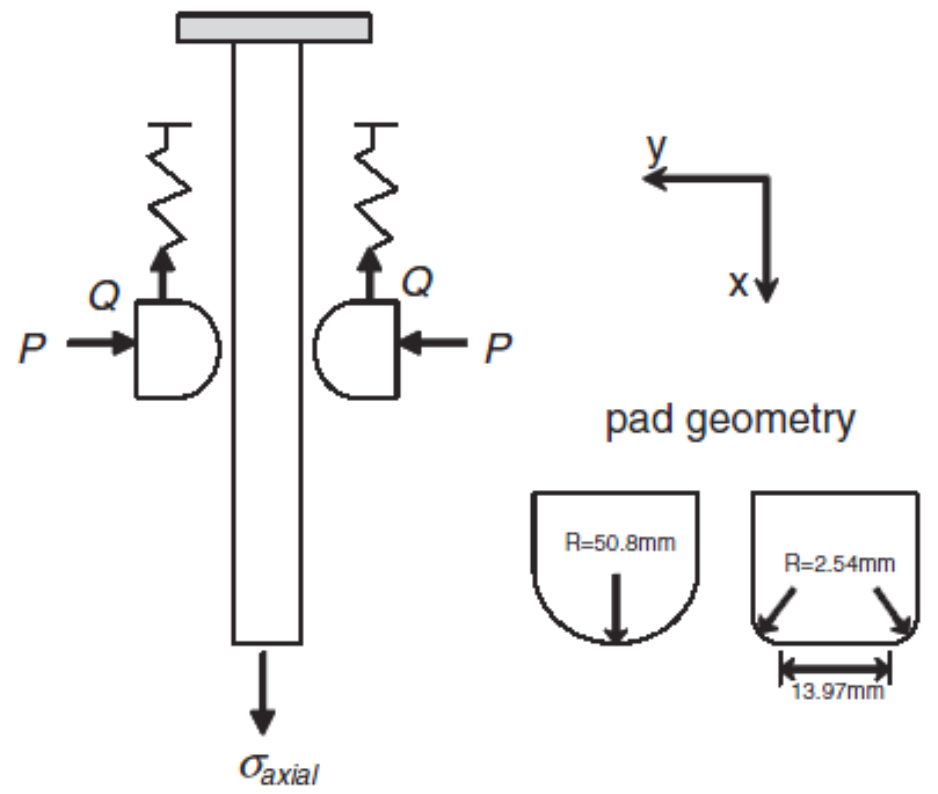

Figura 82 - Desenho esquemático do teste fretting fatigue (Fonte: KIM et al. 2011)

A Figura 82 demonstra esquematicamente a configuração de fretting estudada, a qual é constituída por um bloco plano e um par de blocos de fretting ( $P a d$ e espécime). Duas zonas de contato foram geradas no bloco plano quando o mesmo é pressionado por uma carga de contato P exercida nos blocos de fretting. Uma carga cíclica tangencial, Q, e uma tensão cíclica $\boldsymbol{\sigma}_{\text {axial }}$ foram implementadas no teste de fretting após a aplicação de carga de contato. Todos os testes foram conduzidos sob condição de deslizamento parcial, onde a carga tangencial Q é menor que $\mu \mathrm{P}, \mu$ sendo o coeficiente de fricção, o que, segundo os autores, faz com que ambas as regiões de deslizamento e grude estejam presentes na simulação. Duas configurações diferentes foram elaboradas para se investigar os efeitos tridimensionais de fretting fatigue: bloco cilíndrico em bloco plano e bloco de pontas arredondadas em bloco plano.

Por conta da alta demanda de memória e tempo computacional requerido pela malha extremamente refinada na zona crítica, a técnica de submodelagem foi utilizada. O conceito básico da submodelagem é estudar uma parte do modelo com base na interpolação do modelo inicial global. 


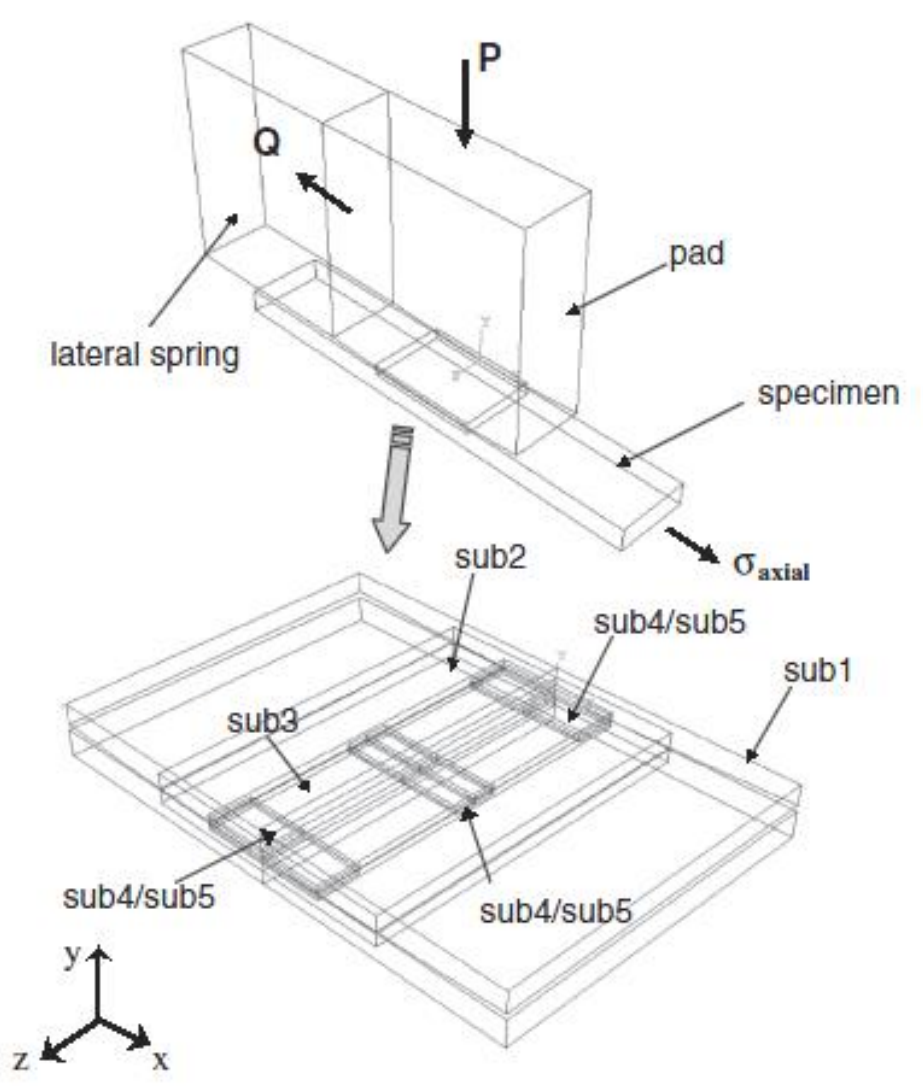

Figura 83 - Detalhes dos submodelos (Fonte: KIM et al. 2011)

Para simular o problema retratado na Figura 83, foi utilizando o software ABAQUS. O algoritmo utilizando possuía oitos nós e elementos de tijolos lineares, usando integração reduzida e contato mestre-escravo na superfície de contato entre os blocos. Uma condição de deslizamento pequena foi utilizada entre os pares de contato para transferir as cargas de um corpo para o outro. Para isto, a superfície do bloco pad foi definida como superfície de contato mestre, enquanto a do outro bloco foi definida como a superfície de contato escrava. Ambas as superfícies foram consideradas como um par de contato, o que permitia que o ABAQUS determinasse se o par estava se encostando ou estava separado durante a simulação. A região de entre os blocos foi considerada como região de contato constituída por uma região presa e uma deslizante.

A fim de reduzir o custo computacional na convergência da submodelagem proposta, os autores propuseram neste trabalho um método híbrido de análise de elementos finitos tridimensional com um plano de tensões. O modelo bidimensional de análise de elementos finitos utilizado foi o elaborado por NAMJOSHI et al. (2002) (Figura 84). 


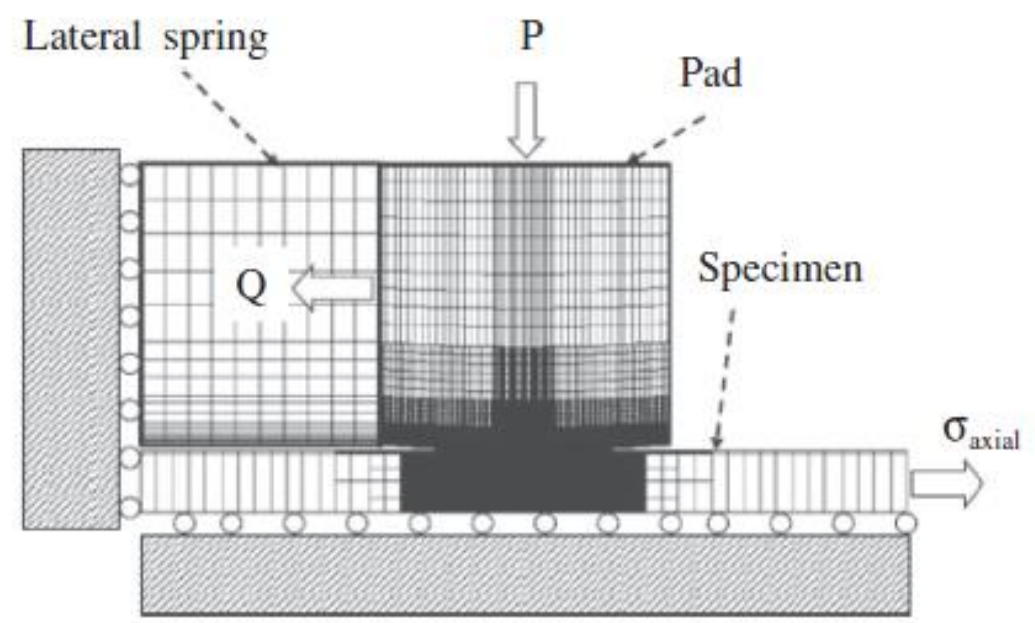

Figura 84 - Configuração da malha para o modelo bidimensional (Fonte: KIM et al. 2011)

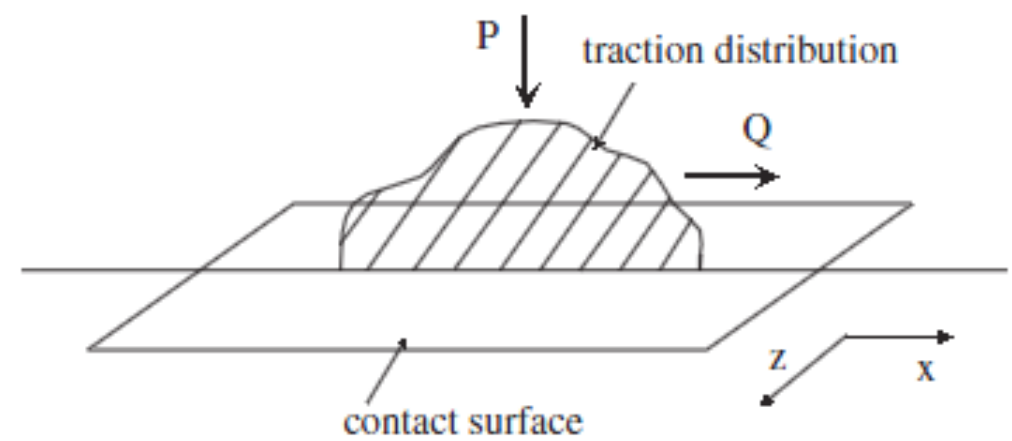

Figura 85 - Desenho esquemático da distribuição de tração na superfície de contato (Fonte: KIM et al. 2011)

O modelo elaborado no ABAQUS possuía elementos quadrilaterais. A tensão de cisalhamento ao longo da espessura do espécime (Direção Z na Figura 85) foi ignorada, pois a geometria possuía simetria em relação à espessura e a carga axial e ao cisalhamento induzidos fora aplicados somente na direção axial.

O contorno da pressão de contato mostra-se condizente com a forma da cicatriz de fretting encontrada experimentalmente, conforme mostrado na Figura 86. A pressão de contato é o fator preponderante no tamanho e na forma da supramencionada cicatriz, a qual é constante para quase toda a espessura do espécime, exceto na borda livre. 


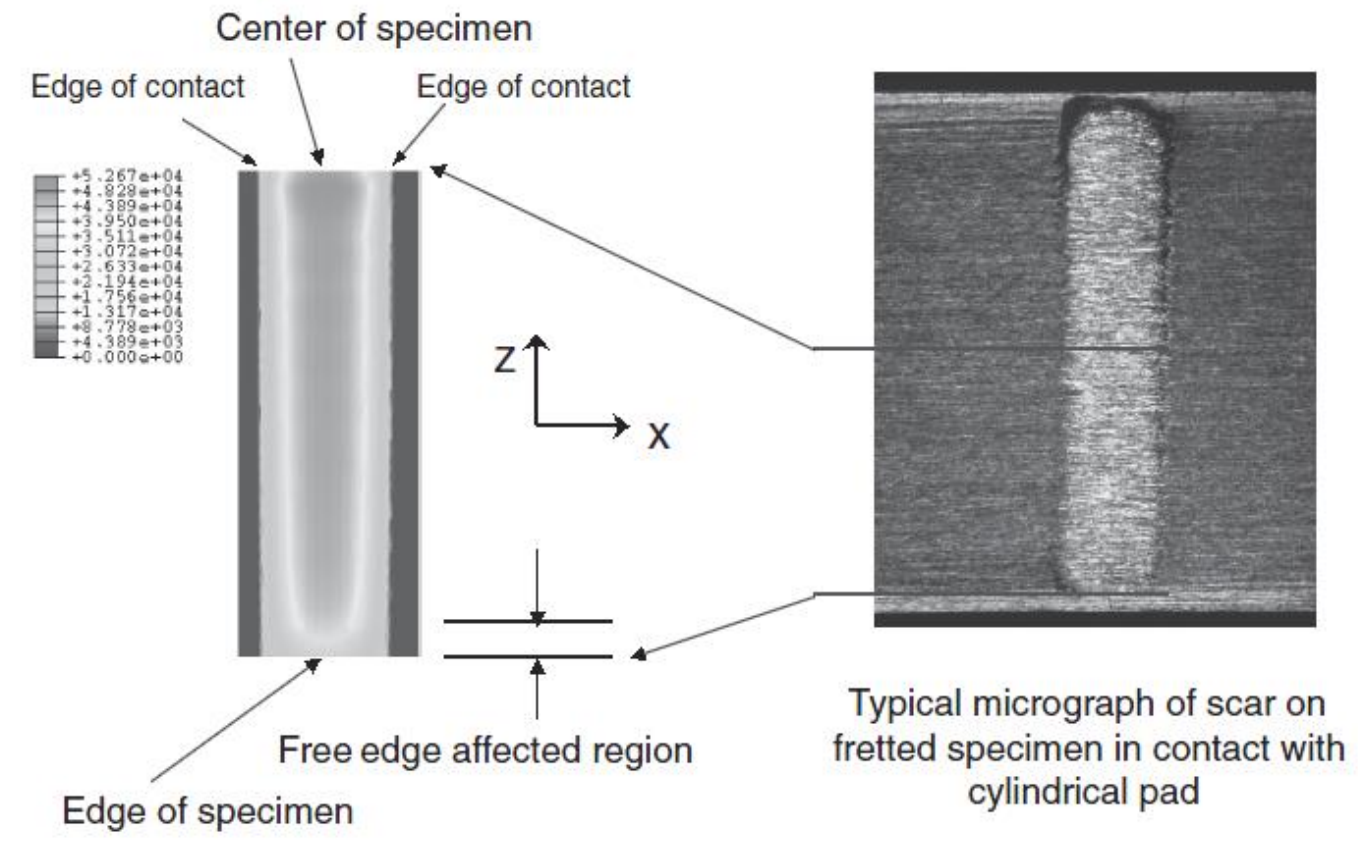

Figura 86 - Impressão do contorno da pressão de contato e micrografia típica da cicatriz do espécime submetido a fretting (Fonte: KIM et al. 2011)

A Figura 87 ilustra os perfis de tensão, no centro e nas bordas, das tensões normais longitudinais normalizadas obtidas pelo modelo tridimensional de elementos finitos. Enquanto no centro o perfil de tensão se mostra similar ao modelo bidimensional correspondente, na borda há grande variação da tensão central. Portanto, a zona de contato tende a diminuir por conta do efeito de borda livre.

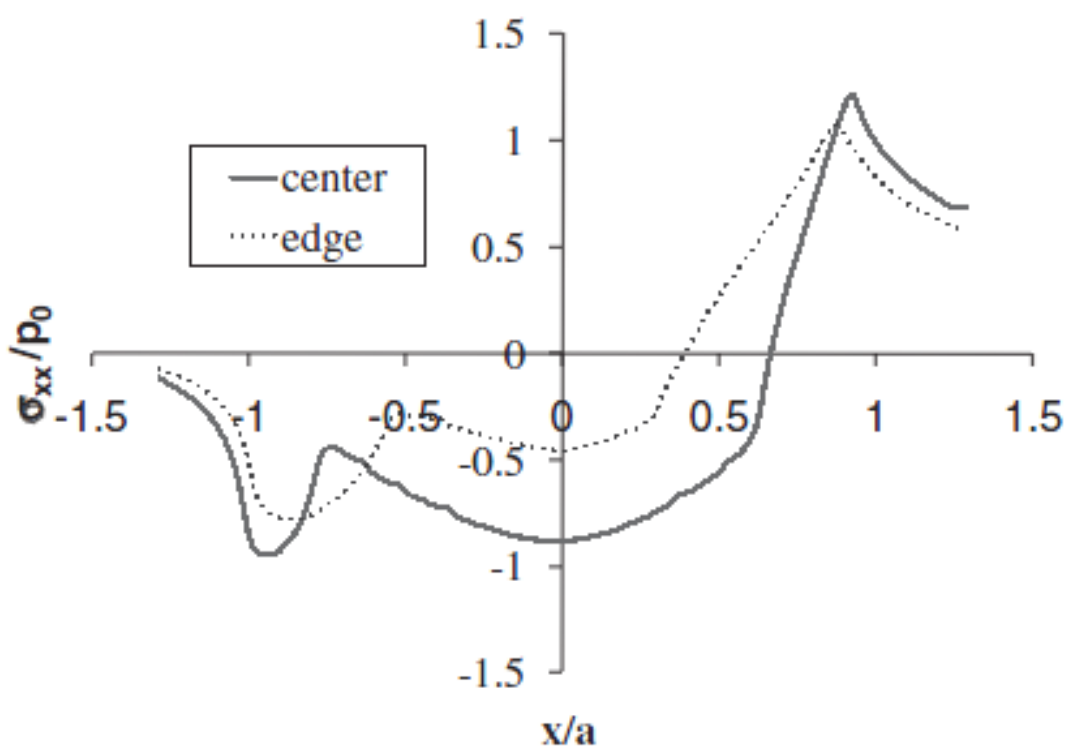

Figura 87 - Comparação entre tensões normais no cento e na borda do espécime (Fonte: KIM et al. 2011) 


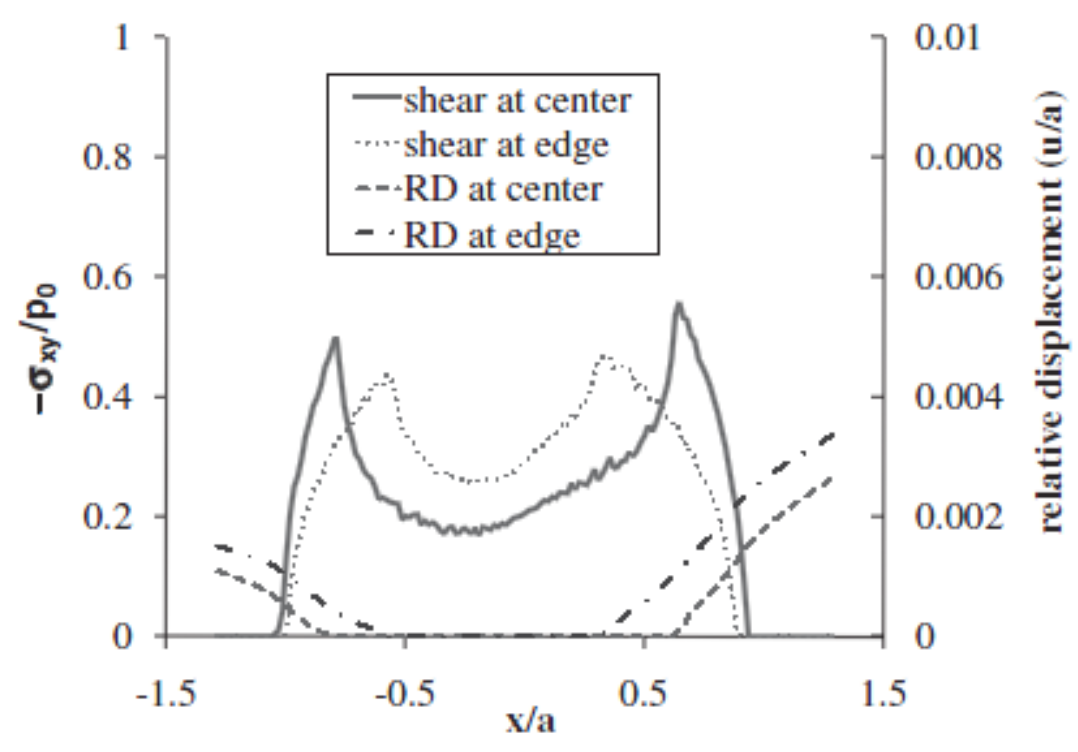

Figura 88 - Comparação da tensão de cisalhamento e deslocamento relativos para o centro e as bordas do espécime (Fonte: KIM et al. 2011)

A mudança na zona de contato é percebida no perfil da Figura 88. A tensão cisalhante nula significa que não há contato no espécime. A tensão de cisalhamento total na borda do espécime diminui se comparada à tensão equivalente no centro. Deslocamentos relativos na zona de contato também estão presentes na Figura 88. As zonas de grude no espécime diminuem significativamente e um grande deslizamento parcial é observado. As Figuras 89 e 90 ilustram as simulações do modelo híbrido e as simulações tridimensionais. 


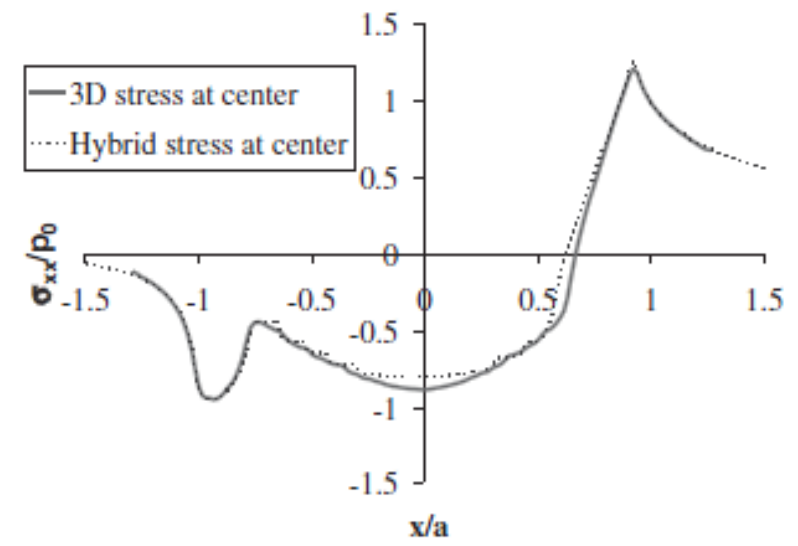

(a)

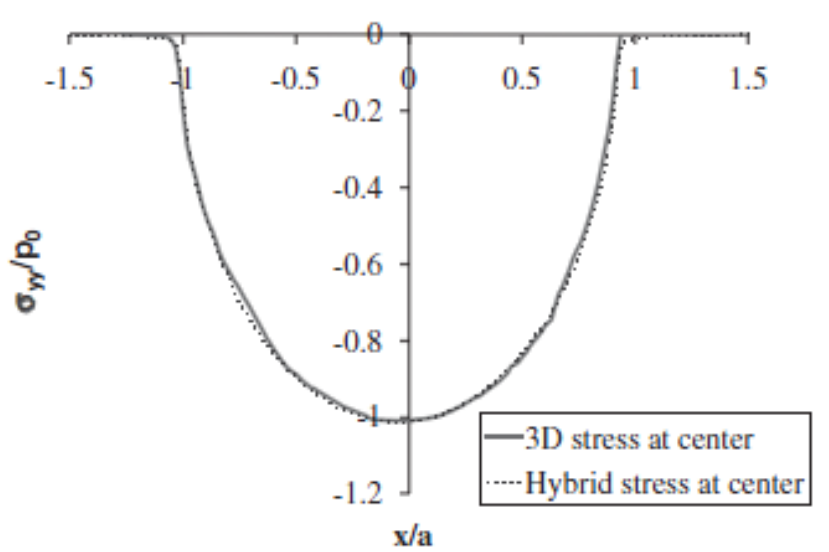

(b)

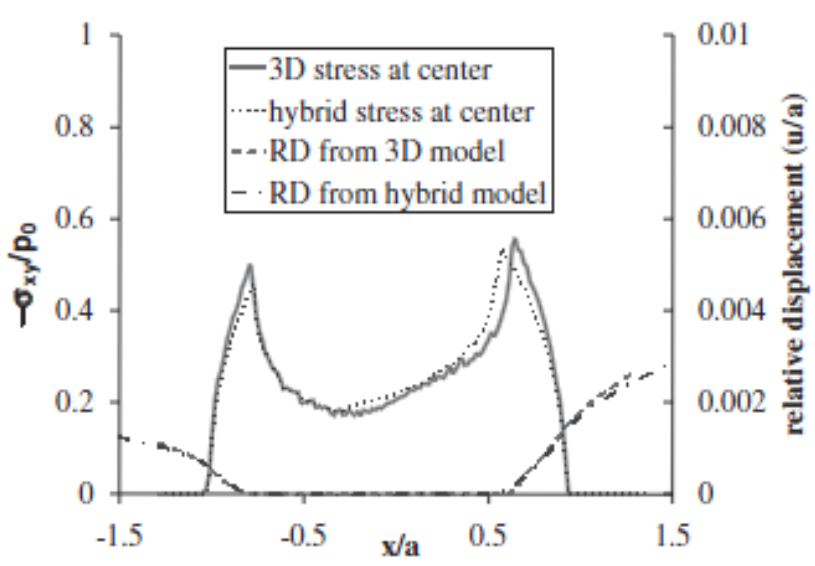

(c)

Figura 89 - Resultados de ambos os modelos no centro do contato (Fonte: KIM et al. 2011) 


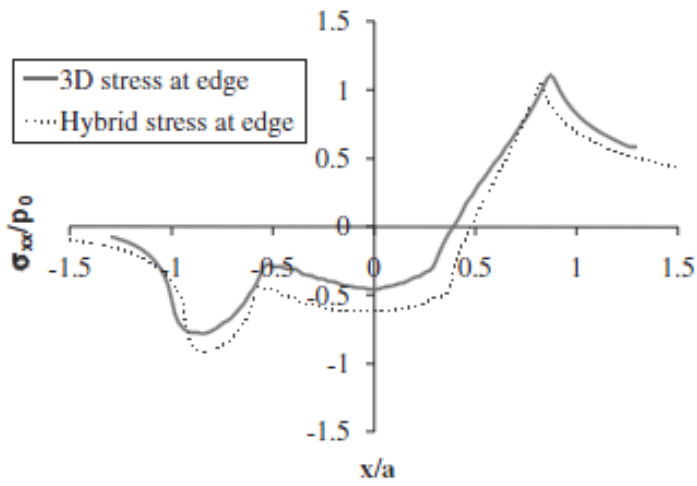

(a)

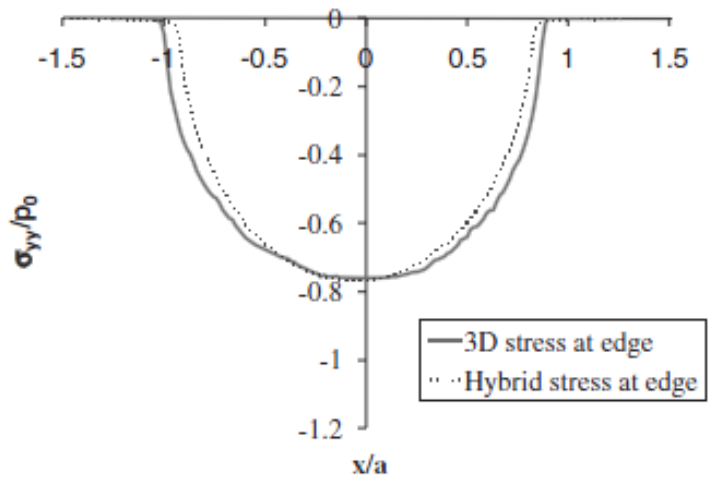

(b)

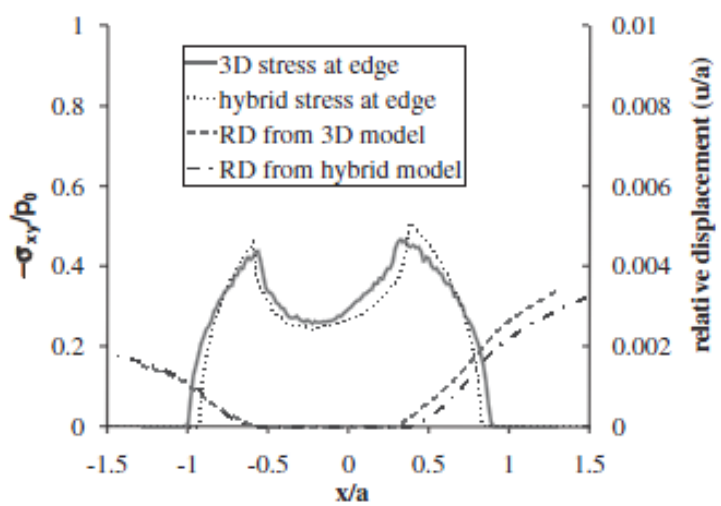

(c)

Figura 90 - Resultados dos modelos na borda do contato (Fonte: KIM et al. 2011) 
As Figuras 91 e 92 mostram as comparações dos resultados.

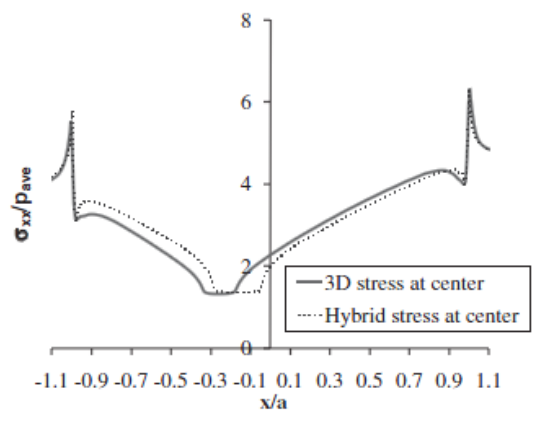

(a)

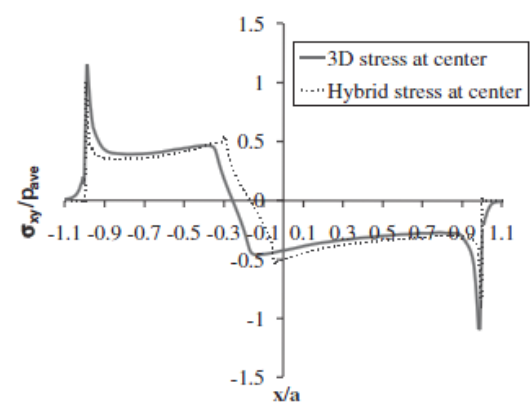

(b)

Figura 91 - Comparação das tensões no centro (Fonte: KIM et al. 2011)

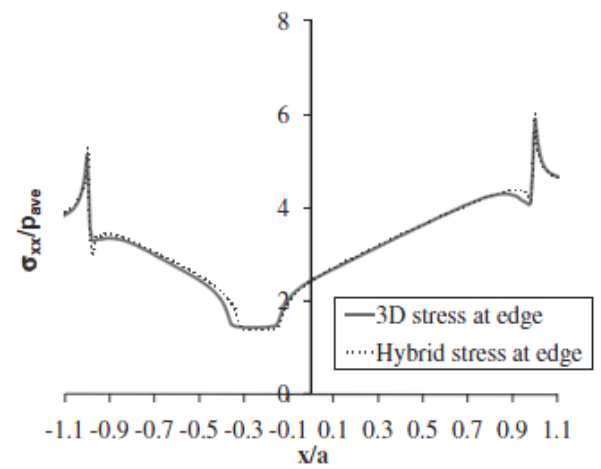

(a)

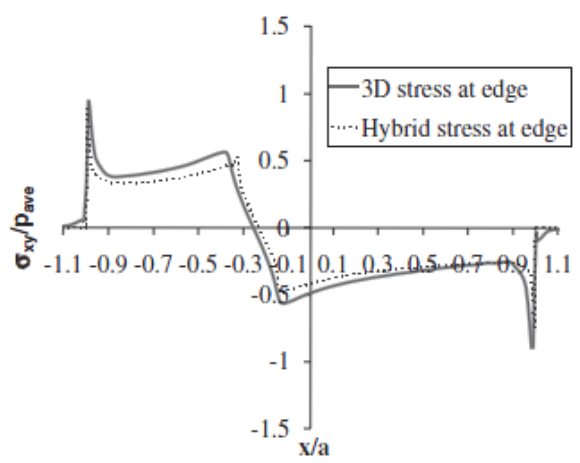

(b)

Figura 92 - Comparação dos modelos nas bordas (Fonte: KIM et al. 2011) 
KIM et al (2011) puderam então concluir que o efeito de borda livre em espessuras finitas foi observado em fretting fatigue, sendo responsável pela diminuição das distribuições de tensão próximas às bordas livres do modelo proposto. Os autores ainda salientam a necessidade de se elaborar modelos tridimensionais completos de elementos finitos para que se obtenham perfis de tensão e de movimentos relativos mais precisos.

As convergências das distribuições de tração mostraram-se muito mais rápidas que os picos das tensões, o que indica razoabilidade da presunção do modelo híbrido proposto. No centro, as convergências de distribuições de tração foram quase iguais às cargas originais, o que não ocorre nas bordas.

Por fim, o modelo híbrido de camadas foi capaz de prever o efeito de borda livre com menos que $8 \%$ de erro e utilizando apenas $5 \%$ do custo computacional original. 


\subsubsection{MODELO PROPOSTO POR BENHAMENA et al. (2012)}

Os autores optaram pela liga de alumínio $5086 \mathrm{H} 24$ por conta de suas vastas aplicações na indústria do transporte. A Figura 93 mostra uma configuração típica de testes de fretting fatigue e desenho esquemático do aparato experimental utilizado.
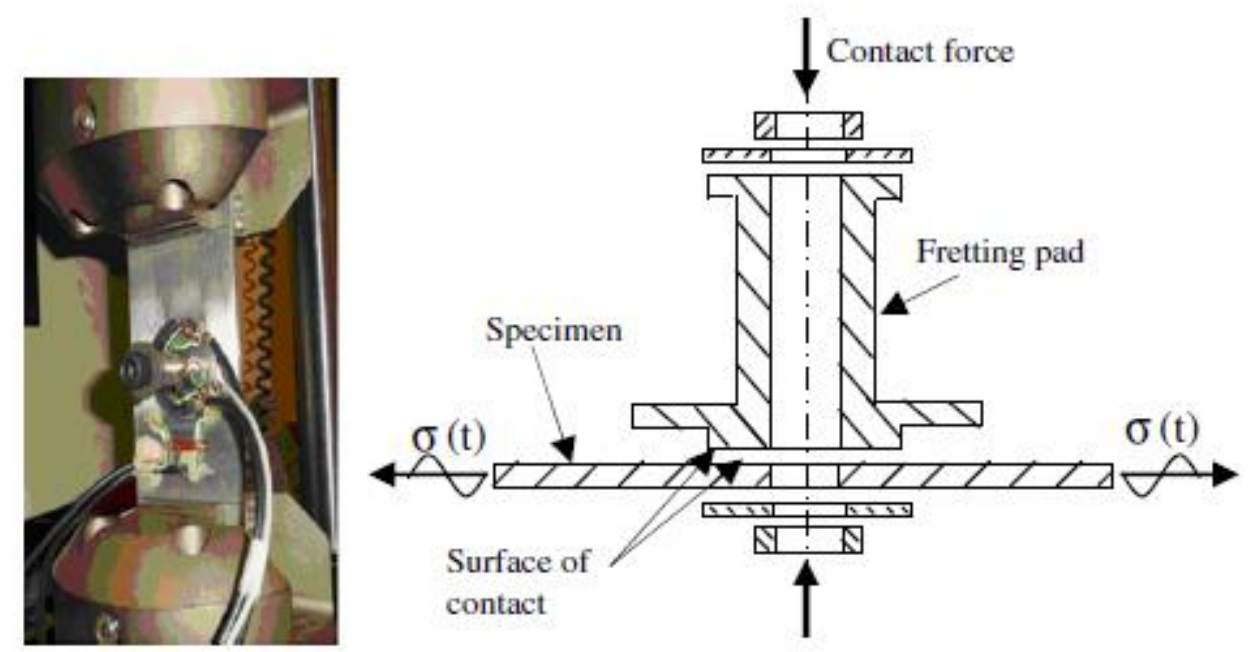

Figura 93 - Configuração de fretting e desenho esquemático da parte central do espécime (BENHAMENA et al. 2012)

Maiores detalhes da configuração experimental são encontradas no artigo original, mas é importante salientar que os autores deram tratamento de polimento especial à superfície do espécime a fim de se eliminar defeitos em sua superfície. Sete strain gauges foram instalados nos aparatos, conforme ilustrado na Figura 94. 


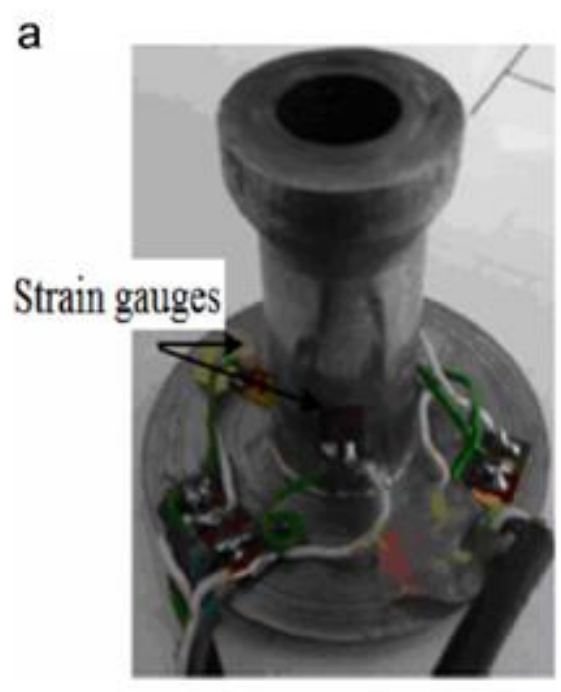

b

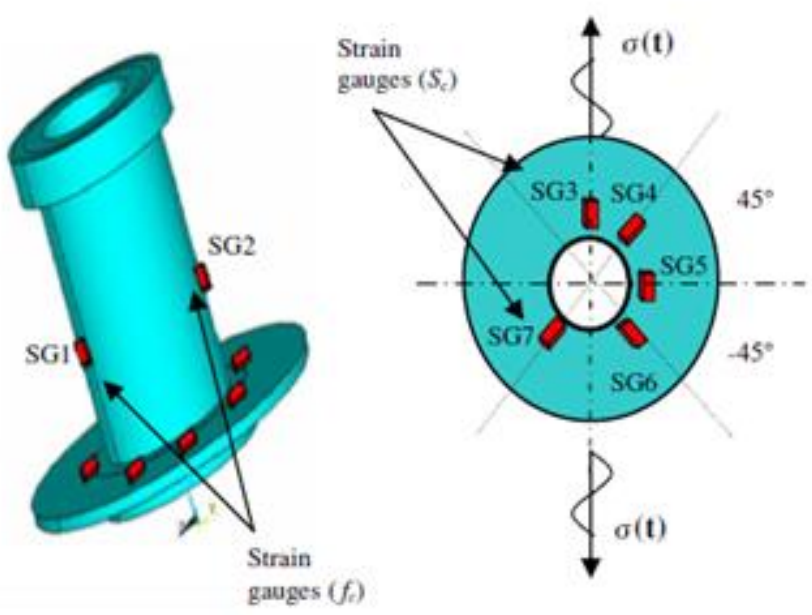

Figura 94 - Fretting pad e localização dos strain gauges (BENHAMENA et al. 2012)

Como descrito pelos autores, a carga cíclica aplicada no espécime introduz zonas de deslizamentos (deslocamentos relativos) entre o espécime e o fretting fatigue pad (FFP). O pad foi feito de aço, com superfície de contato circular, como se vê na Figura 94.

A Figura 95 ilustra a evolução da vida à fretting fatigue com a variação da carga de aperto. A vida à fretting fatigue aumenta quando a força de contato também aumenta. 


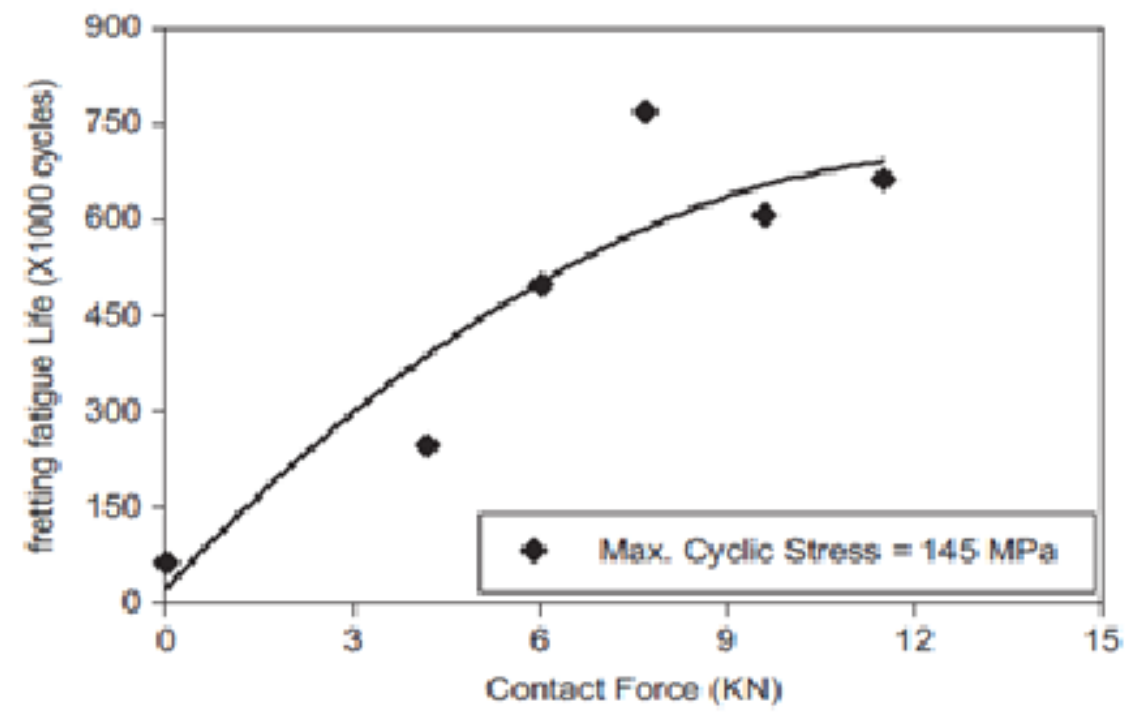

Figura 95 - Evolução da vida à fretting fatigue com a força de contato (BENHAMENA et al. 2012)

A Tabela 3 demostra a vida obtida para a iniciação de trinca com diferentes forças de contato:

Tabela 3 - Vida à fretting fatigue para diferentes de forças de contato (BENHAMENA et al. 2012)

\begin{tabular}{lllllll}
\hline Normal force (KN) & 0 & 4 & 6 & 8 & 10 & 12 \\
\hline Fretting fatigue life (cycles $\times 1000)$ & 64 & 246 & 500 & 770 & 608 & 663 \\
\hline
\end{tabular}

As diferentes micrografias obtidas para as partes da área de contato sob diferentes forças de contato são demonstradas na Figura 96. Os autores ainda salientam como a área de contato não possui definição clara e como seus aspectos variam de acordo com a área. Para as zonas A e C, que correspondem às áreas na direção do carregamento cíclico, as cicatrizes aumentam quando as forças de contato aumentam. Contudo, para zona $\mathrm{B}$, a qual é perpendicular à direção supramencionada, o oposto ocorre. 


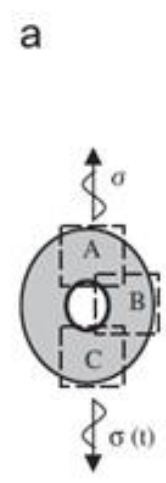

b

A

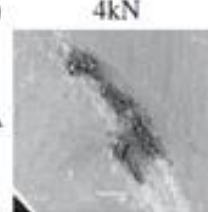

B
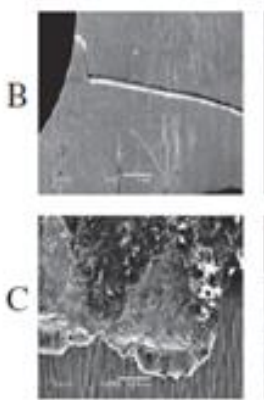

$6 \mathrm{kN}$
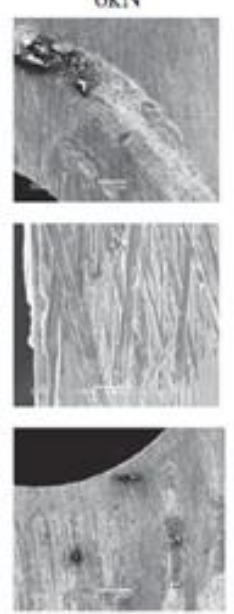

$8 \mathrm{kN}$
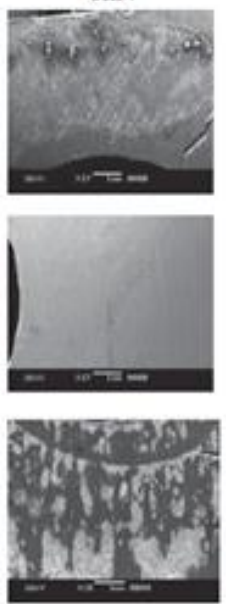

$10 \mathrm{kN}$
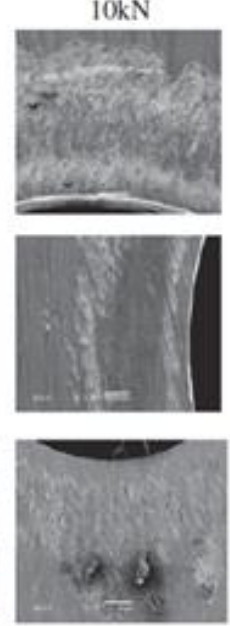

$12 \mathrm{kN}$
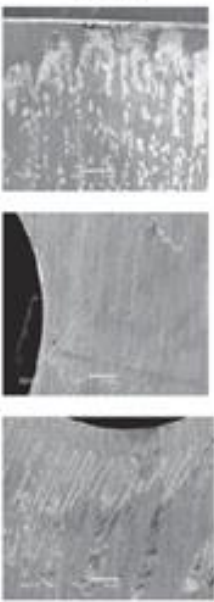

Figura 96 - Evolução da morfologia da superfície em relação às forças de aperto para diferentes áreas de contato (BENHAMENA et al. 2012)

Os locais de iniciação de trincas são mostrados na Figura 97 a. A zona D é localizada na borda do buraco com direção perpendicular à carga cíclica, enquanto a zona E corresponde ao contato em aproximadamente 45 graus. A figura $97 \mathrm{~b}$ ilustra os diferentes locais de iniciação das principais trincas de fretting fatigue sob diferentes forças de contato.

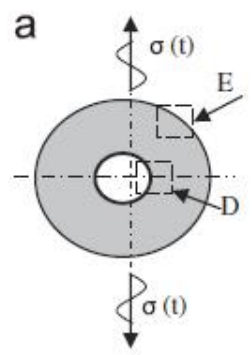

b
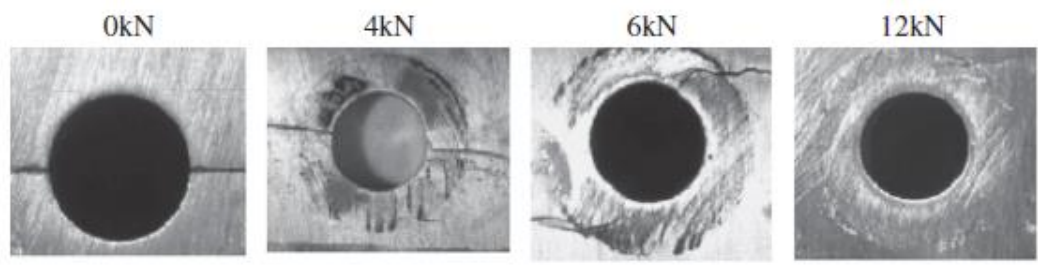

Figura 97 - (a) Desenho esquemático das zonas de iniciação de trinca e (b) iniciação de trincas para diferentes forças de prensamento (BENHAMENA et al. 2012) 


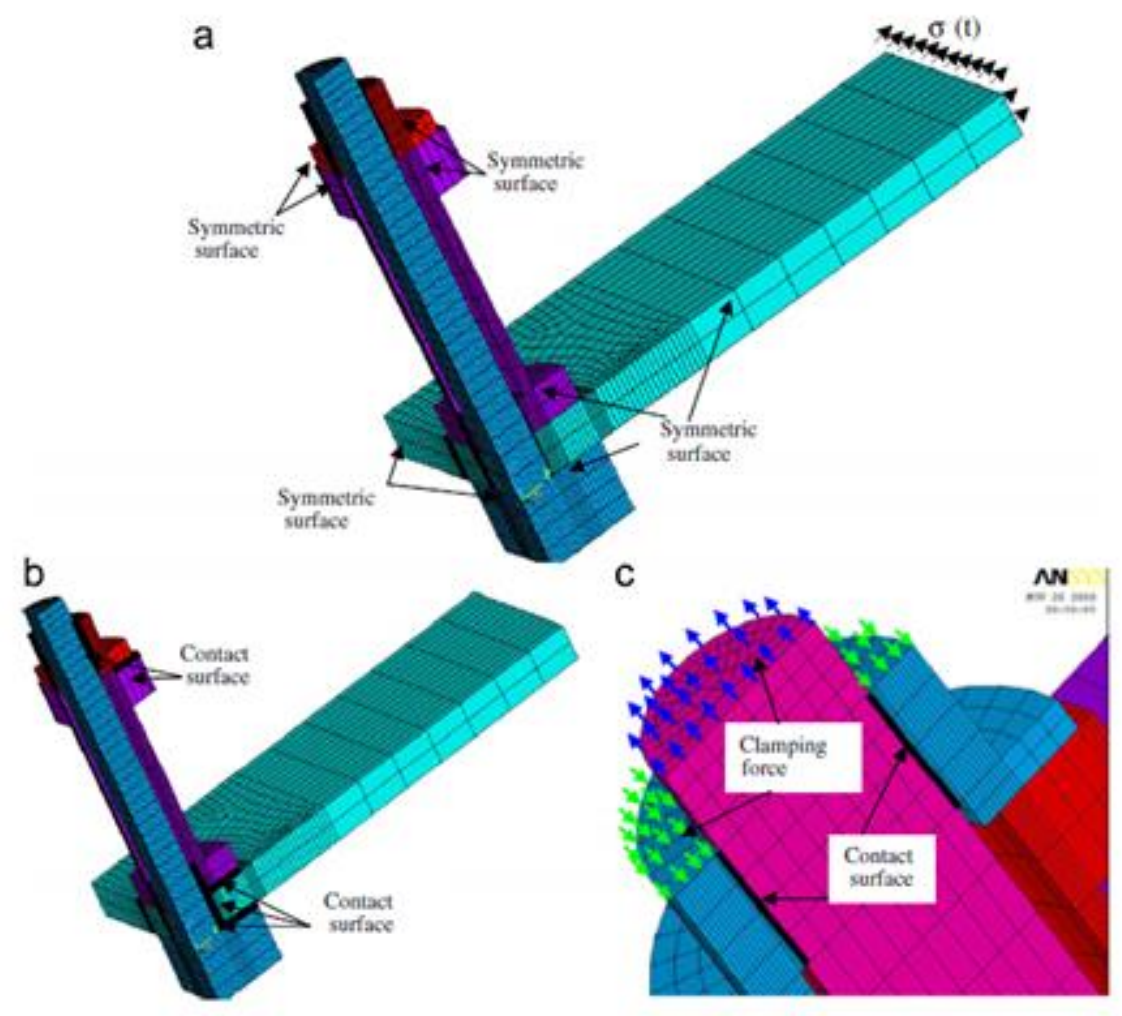

Figura 98 - (a) Geometria e malha da placa parafusada (b) modelagem da superfície de contato (c) modelagem da força de prensamento (BENHAMENA et al. 2012)

Segundo os autores, as simulações numéricas dos testes de fretting podem ser elaboradas no regime de deslizamento parcial. Embora o deslocamento relativo não possa ser facilmente modelado, ele é necessário como dado de entrada. O artigo utilizou o software ANSYS 11 para gerar um modelo tridimensional capaz de determinar os campos de tensão na zona de contato. A simetria do aparato, a qual pode ser observada na Figura 93, permite reduzir o modelo em elementos finitos para um quarto do original a fim de reduzir o custo computacional. Os elementos tridimensionais utilizados para modelar a placa parafusada foram do tipo brick (solid 45), sendo constituídos por oito nós e cada qual recebendo três graus de liberdade. Ademais, elementos de superfície (CONTAC173) e de alvo de superfície (TARGE169) foram utilizados na superfície entre as partes conectadas da placa parafusada para simular as condições de contato. A fricção entre as superfícies de contato foi modelada utilizando o modelo de Coulomb, com coeficiente igual a 0.2. A Figura 99 ilustra a distribuição de deslocamentos e tensões ao longo das bordas do buraco central (C_1) e da borda de contato (C_2). 

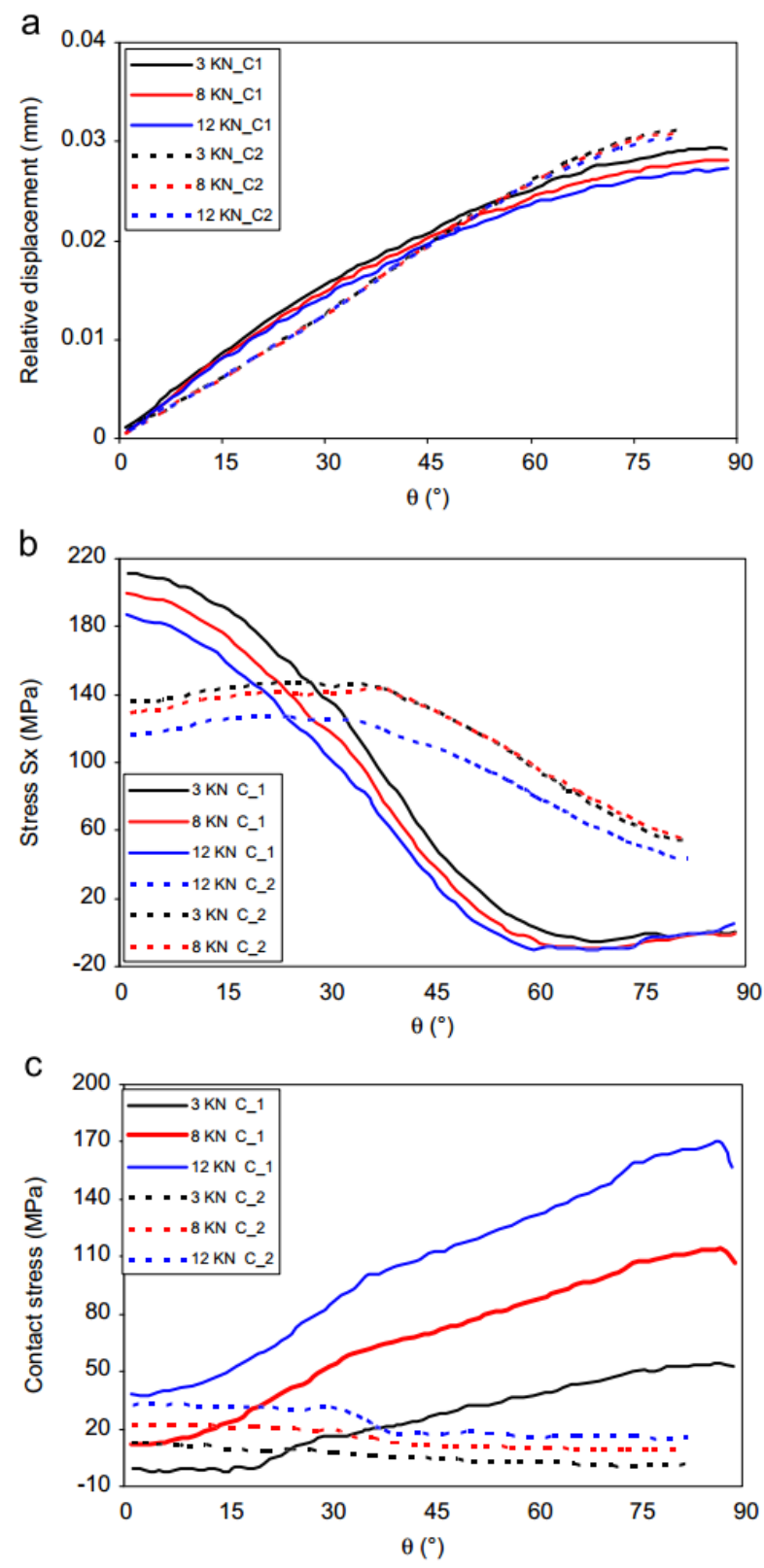

Figura 99 - (a) Deslocamentos relativos na direção do carregamento cíclico; (b) Tensões na direção do carregamento cíclico; (c) Tensões de contato nas bordas de ambos os buracos (BENHAMENA et al. 2012)

Os autores puderam concluir que os resultados numéricos e experimentais, auxiliadas por micrografia, conseguiram mostrar a interdependência da vida à fadiga de fretting com as tensões locais e os deslocamentos relativos. Por fim, concluíram também que a vida à fadiga de fretting aumenta quando as forças de contato aumentam, justificando tal fenômeno aos mecanismos de transferência de material no surgimento da trinca e às mudanças de zonas de adesão. 


\subsubsection{MODELO PROPOSTO POR LUKE et al. (2016)}

Este artigo através de testes experimentais em pequena escala e ensaios numéricos, visava avaliar as condições de tensão-deformação nas quais a iniciação de trinca por fretting poderia ocorrer em eixos ferroviários.

Os autores apontam como os testes convencionais de eixos rodoviários prétensionados costumam ser testados para a iniciação e propagação na escala natural, conforme mostrado na Figura 100.
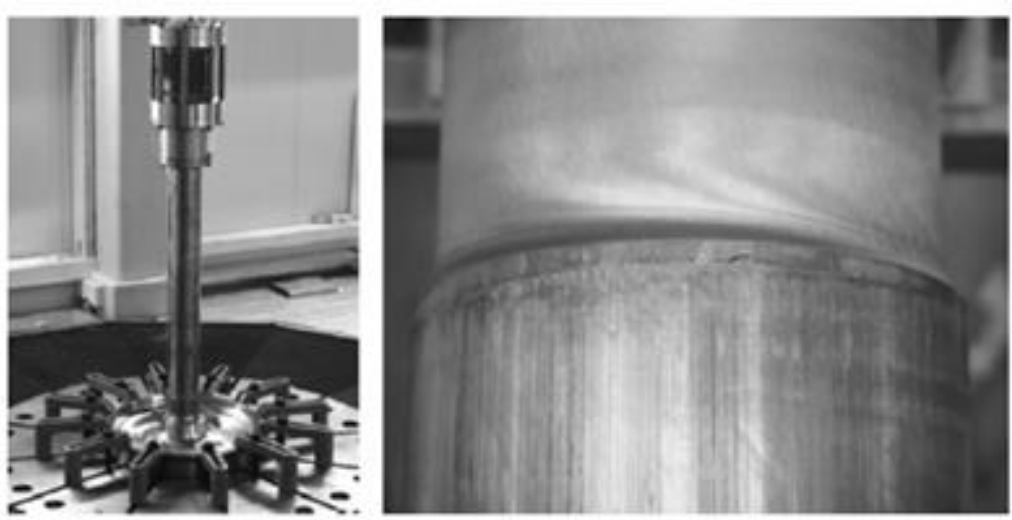

Figura 100 - Exemplo de teste de fadiga para eixos (a) e trincas presentes no mesmo (b) (Fonte: LUKE et al. 2016)

A fim de simular os diversos cenários de carregamento relevantes para o início da trinca por fretting fatigue, eles propuseram o aparato experimental ilustrado na Figura 101.
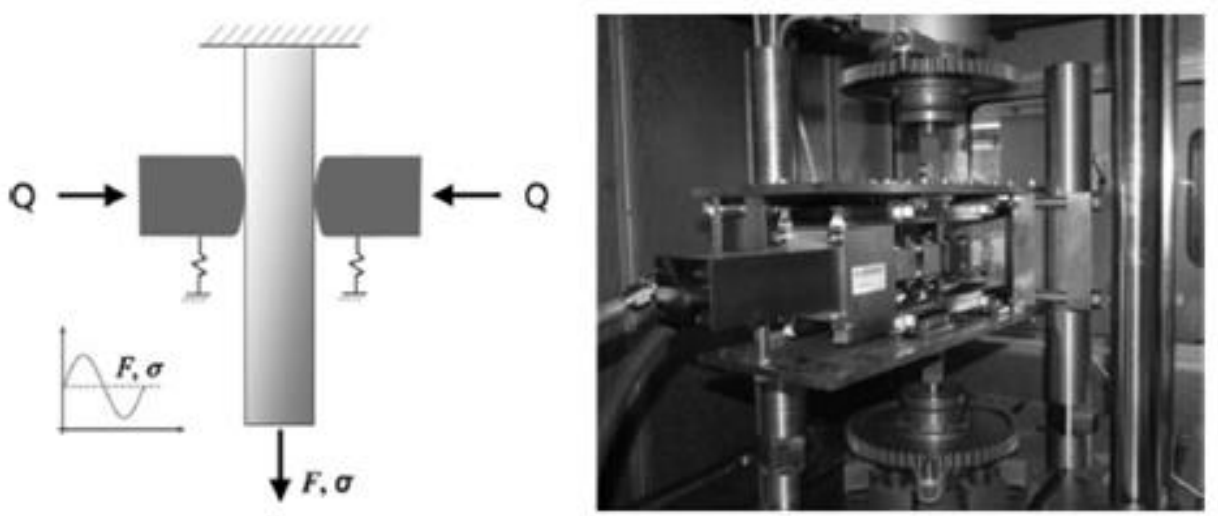

Figura 101 - Representação esquemática dos conceitos de fretting fatigue (esq.) e o teste adotado neste estudo (dir.) (Fonte: LUKE et al. 2016) 
Durante o teste, uma carga axial cíclica com amplitude constante foi aplicada à borda do espécime. Uma carga transversal de contato Q foi aplicada e controlada por sistemas hidráulicos independentes através de pads que prendiam o espécime por ambos os lados. Portanto, uma combinação de cargas pôde ser introduzida, levando a um deslizamento parcial entre o pad e o espécime na zona de contato.

A fim de possuir dados comparativos e também para validar o experimento anterior, foi feita uma análise numérica bidimensional de elementos finitos utilizando o software ABAQUS, onde se assumiu válida a hipótese do plano de tensões. Para a iteração de contato, utilizou-se coeficiente de fricção igual a 0,6.

A zona de contato inicial, $l_{c}$, correspondente à carga transversal nula é indicada na Figura 102b. Ao se aumentar a carga Q, a carga atuante faz com que o tamanho da zona de contato e as distribuições de tensão dentro do contato funcionem de maneira não linear, tal que estimar a localização inicial da trinca passa a ser função de uma combinação de $\mathrm{Q}$, de $\sigma_{a p p l}$ e do coeficiente de fricção. Baseado nos resultados de tensão-deformação, alguns elementos do FEM foram considerados como de maior potencial de iniciação de trinca. Três destes elementos, representando os resultados para $\mathrm{Q}=3 \mathrm{kN}$ são marcados na Figura 103a. No estado descarregado, tais elementos se localizam entre 50-80 $\mu \mathrm{m}$ fora da zona inicial de contato. Como mostrado na Figura $103 \mathrm{~b}$, ao se aplicar a carga $\mathrm{Q}=3 \mathrm{kN}$ e uma tensão axial de $\sigma_{a p p l}=350 \mathrm{MPa}$, os respectivos elementos se deslocam para a fronteira da zona de contato, ou seja, passam a estar dentro ou próximos da zona plástica.

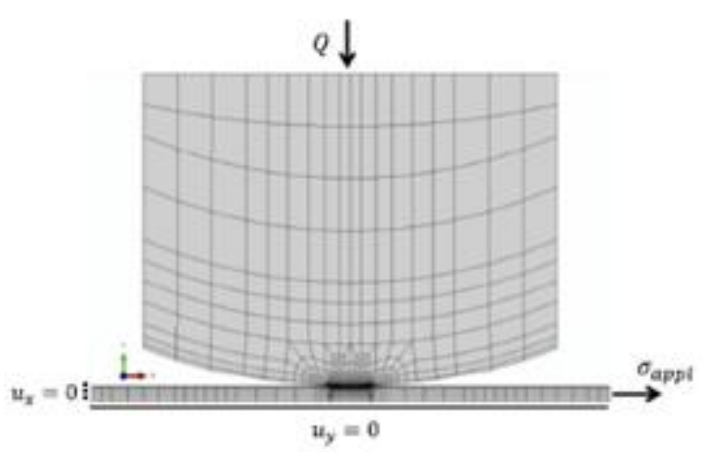

(a)

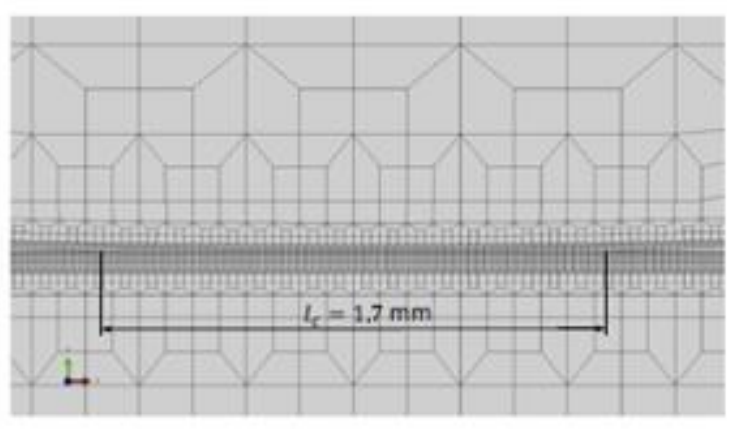

(b)

Figura 102 - Modelo em EF, mostrando espécime e PAD (a) e detalhes do contato inicial (b) (Fonte: LUKE et al. 2016) 

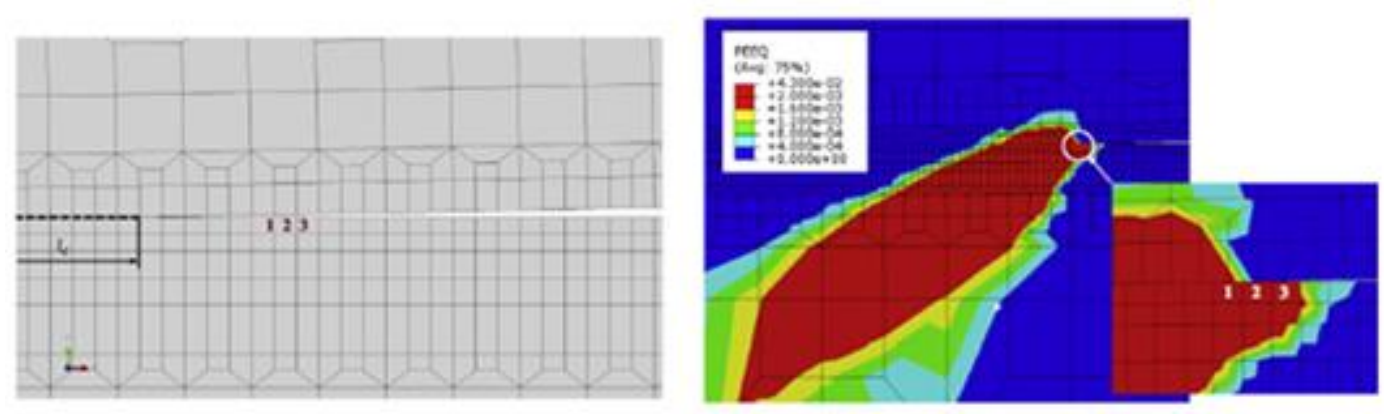

Figura 103 - Detalhes dos três elementos utilizados na avaliação da evolução da tensão em respeito a (a) zona de contato inicial e (b) zona plástica sob carregamento máximo (Fonte: LUKE et al. 2016)

Para simular as deformações plásticas do espécime na zona de contato, os autores utilizaram o modelo de LEMATRIE \& CHABOCHE (1990). Neste, uma regra de combinação de endurecimento isotrópico-cinemático para o material (EA4T) é adotada a fim de ajustar os dados de tensão-deformação em passos incrementais de tensão controlados. A Figura 104 ilustra os loops de histerese e suas respectivas aproximações pelo modelo.

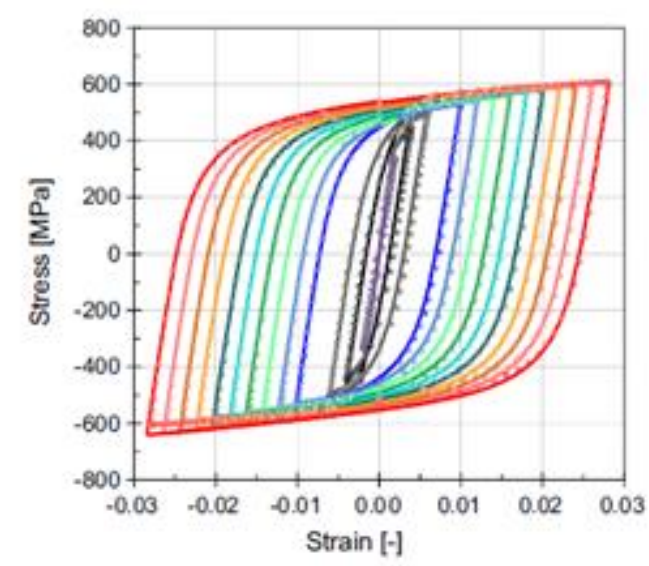

Figura 104 - Curvas de histerese para várias amplitudes usando a aproximação de Lemaitre-Chaboche e material EA4T (Fonte: LUKE et al. 2016)

Os autores não encontraram dados elastoplásticos correspondentes do material ER8 e, portanto, utilizaram as mesmas curvas de tensão-deformação para o pad. Após os cálculos, julgaram que os efeitos plásticos no pad eram irrelevantes (Figura 105 c,d). 


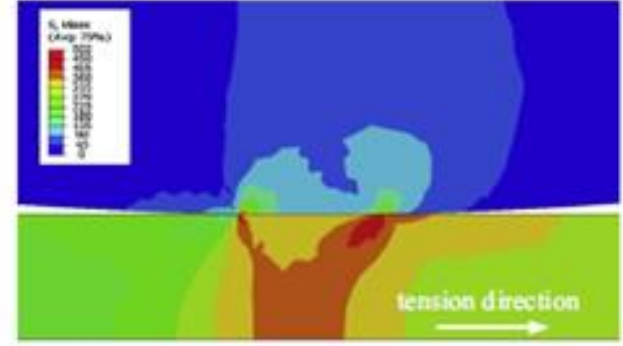

(a)

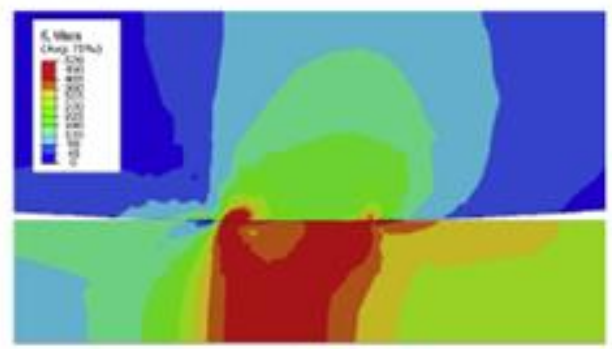

(c)

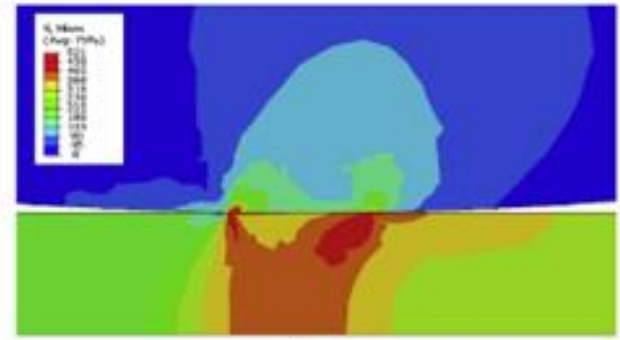

(b)

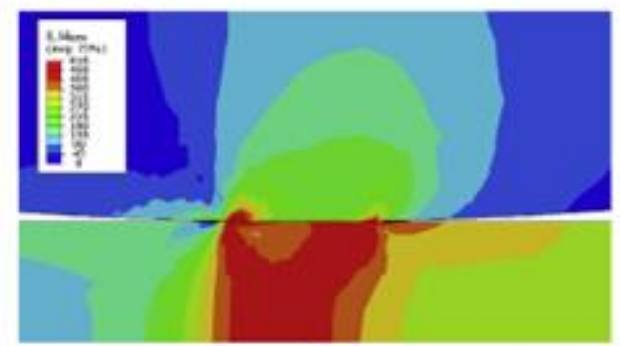

(d)

Figura 105 - Tensões de von Mises equivalentes para a máxima carga aplicada sob diferentes condições de aperto: (a) $\mathrm{Q}=1,5 \mathrm{kN}$ (b) $\mathrm{Q}=2 \mathrm{kN}$ (c) $\mathrm{Q}=3 \mathrm{kN}$ (d) $\mathrm{Q}=3 \mathrm{kN}$ com pad elástico (Fonte: LUKE et al. 2016)

A Figura 105 compara os padrões equivalentes das tensões de von Mises calculados para a carga remota de fadiga máxima de $350 \mathrm{MPa}$ e diferentes valores de cargas transversais Q. É possível ver que os picos ocorrem na superfície do espécime, próximos às bordas das zonas de contato, sempre maiores na direção da carga remota, enquanto zonas plásticas se desenvolvem em ambos os lados do contato ao se aumentar a carga normal.

Os deslizamentos parciais correspondentes dos nós dentro da zona de contato são mostrados nas Figuras 106 e 107 para as geometrias do espécime. 


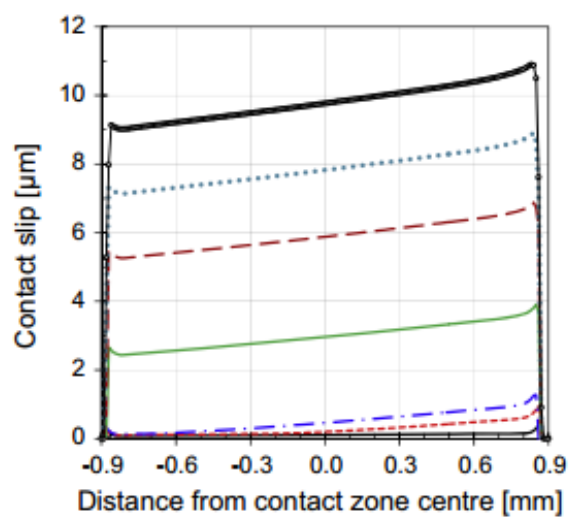

(a)

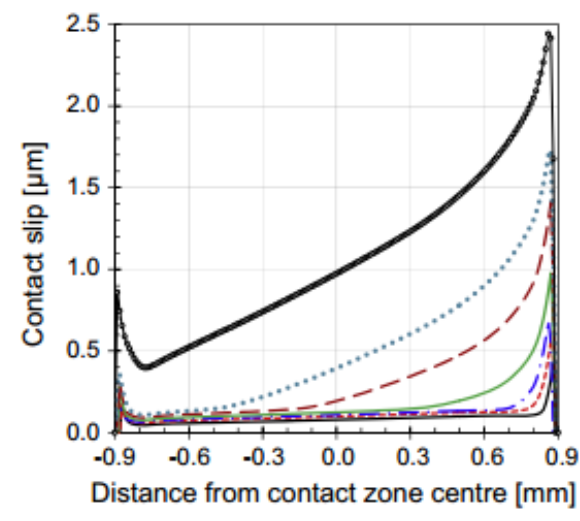

(b)

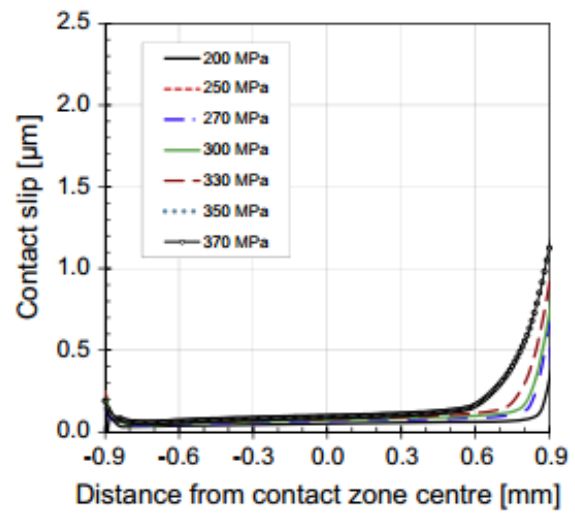

(c)

Figura 106 - Deslizamento de contato para diferentes tensões máximas aplicas e diferentes cargas de aperto (a) $\mathrm{Q}=1.5 \mathrm{kN}$ (b) $\mathrm{Q}=2 \mathrm{kN}$ (c) $\mathrm{Q}=3 \mathrm{kN}$ (Fonte: LUKE et al. 2016)

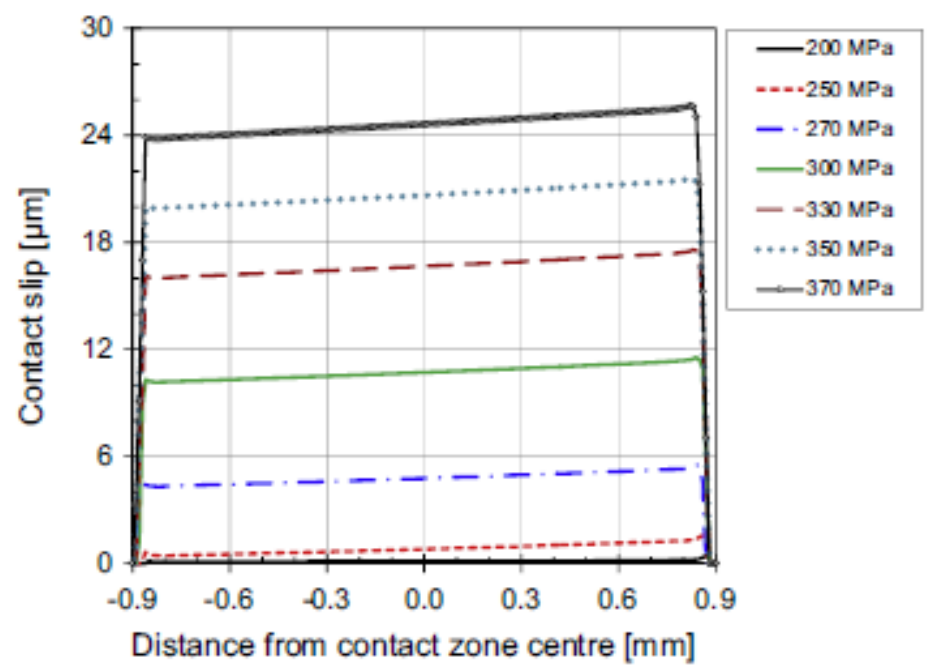

Figura 107 - Deslizamento de contato para diferentes tensões máximas aplicadas e carga de aperto Q = 1,5 $\mathrm{kN}$ (Fonte: LUKE et al. 2016) 
Infere-se da Figura 106 que o aumento da força transversal diminui consideravelmente as magnitudes dos deslizamentos, mudando também o formato da curva de distribuição. Tais resultados mostram-se coerentes com os testes padrões em escala natural.

Os autores utilizaram então os modelos de plano crítico de tensão com parâmetros de Smith-Watson-Topper e de Fatemie-Socie. Os resultados obtidos são demonstrados na Figura 108. Eles acreditam que o comportamento não suave das curvas obtidas foi em razão da não linearidade encontrada na solução numérica.
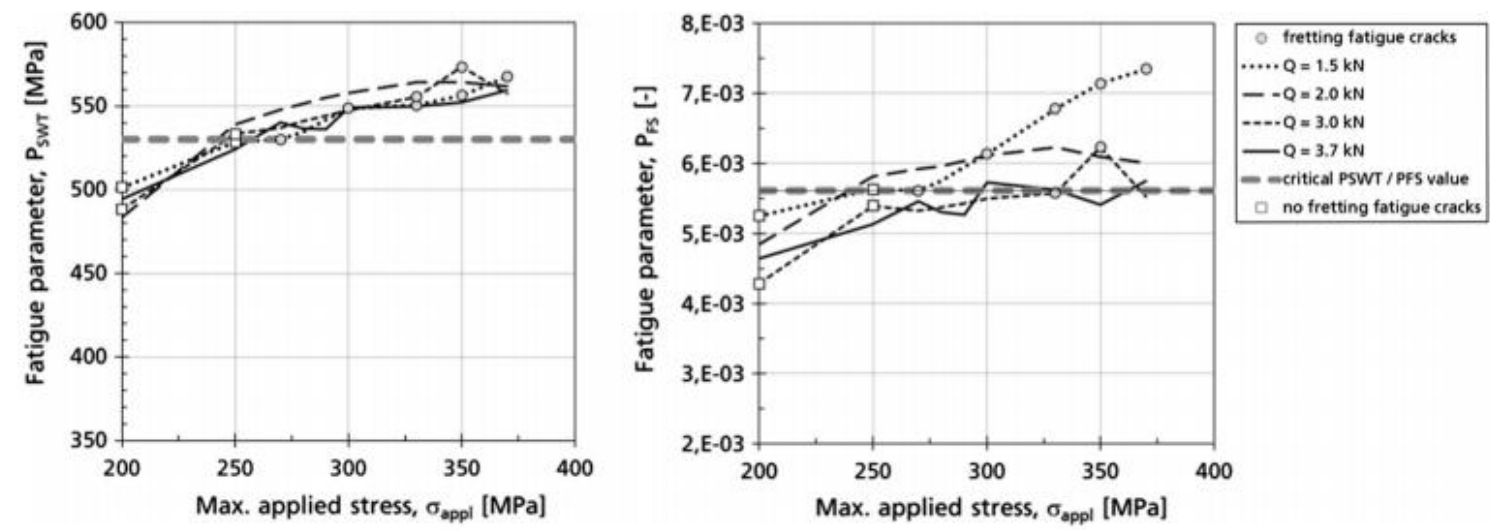

Figura 108 - Parâmetros de dano à fadiga Pswt e Pfs em função da tensão aplicada e de diferentes cargas de aperto (Fonte: LUKE et al. 2016)

A explicação para o comportamento não monótono dos parâmetros de danos por fretting fatigue é então mostrado na Figura 109, a qual ilustra os loops de tensãodeformação para o forte carregamento de $\mathrm{Q}=3 \mathrm{kN}$ e $\sigma_{a p p l}=330,350$ e $370 \mathrm{MPa}$ nomeados elementos 1, 2, 3, respectivamente. A maior área de histerese ocorre com tensão de $350 \mathrm{MPa}$, o que corresponde ao máximo da curva da Figura 109. 


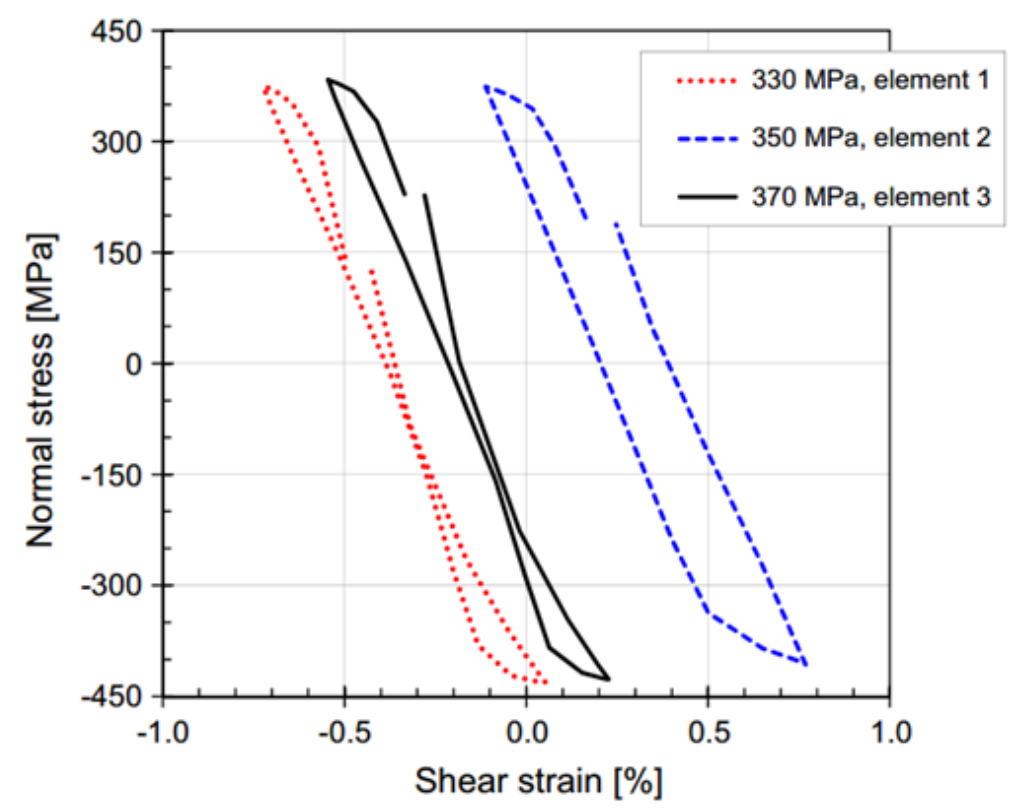

Figura 109 - Variações entre as curvas de Tensão-Deformação para diferentes carregamentos (Fonte: LUKE et al. 2016)

Os autores puderam então concluir que aumentar a área de contato facilita a iniciação da trinca por fretting fatigue. Ademais, os testes com espécimes de diferentes tamanhos revelaram que um maior deslizamento de contato implica em uma maior probabilidade de iniciação da trinca para um mesmo carregamento externo. Uma avaliação quantitativa da iniciação de trinca por fretting fatigue pareceu-lhes plausível utilizando-se os parâmetros de dano por fadiga, para condições de fadiga multiaxial e variações não proporcionais de tensão e de deformação dentro da área de contato. $O$ modelo mais adequado para as condições de fretting fatigue, foi, segundo os autores, o de Fatemie-Socie, pois ele leva em conta as deformações por conta de cisalhamento dentro da zona de contato. 


\subsubsection{MODELO PROPOSTO POR LIU et al. (2014)}

Este trabalho foi conduzido com coeficiente de fricção variável, relacionado com o espaço e o tempo da simulação numérica elaborada no ABAQUS. O modelo de elementos finitos proposto foi do tipo esfera-plano, visando simular as tensões e deformações na superfície de contato durante o teste de fretting. Para se estimar a localização da iniciação de trinca, os autores utilizaram o modelo de fadiga multiaxial de Smith-Watson-Topper.

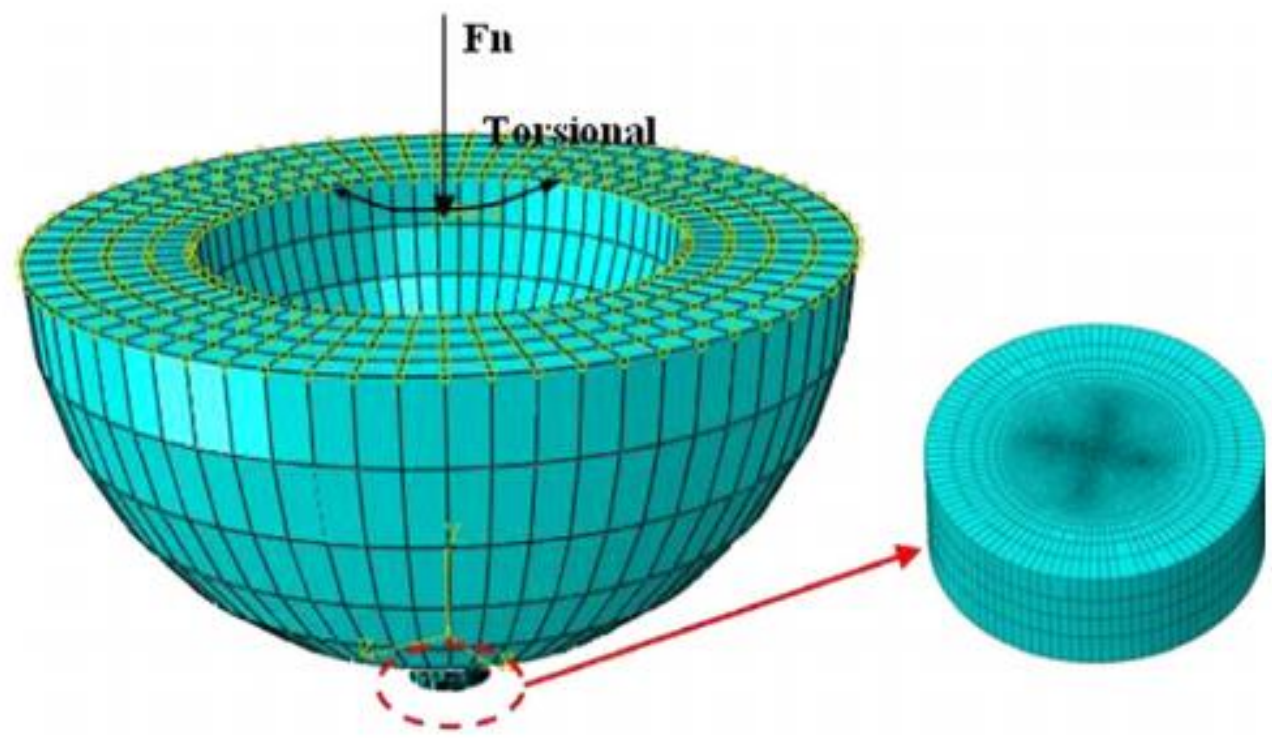

Figura 110 - Modelo de elemento finito proposto (Fonte: LIU et al. 2014)

Os autores propuseram um modelo não linear de elementos finitos no software ABAQUS para analisar as distribuições de tensões nas superfícies e subsuperfícies do corpo de prova, conforme mostrado na Figura 110. Foi utilizado um algoritmo de contato tipo mestre-escravo, de modo que penetrações excessivas de uma superfície na outra não poderia ocorrer.

Uma malha de varredura foi adotada para se capturar as complexas variações de tensão e deslizamentos relativos que pudessem ocorrer entre a superfície e a subsuperfície. Longe do contato, utilizou-se malha grosseira hexaédrica a fim de se reduzir o custo computacional. O modo de integração dos elementos foi de oito nós linear, com a qual se acreditou contornar as flutuações das distribuições de pressão causadas por elementos de segunda ordem, o que poderia causar grandes deformidades dos elementos de integração. Para a carga tangencial, foi imposta uma condição de 
contato regida pela subrotina FRIC. O modelo utilizado era o de Coulomb, com material isotrópico e ajustado pelo multiplicador de Lagrange.

Neste artigo, não se levou em conta plasticidade para a esfera. No entanto, para a parte de aço, utilizaram-se dados experimentais para leva-la em consideração.

Conforme mostra a Figura 111, para amplitudes de deslocamento demasiadamente pequenas, o torque de fricção permanece constante. Na Figura 112, que ilustra a curva de torque dos resultados simulados como função de deslocamentos angulares, a forma linear da curva log indica deslizamento parcial, enquanto a deformação da superfície é acomodada por deformações elásticas.

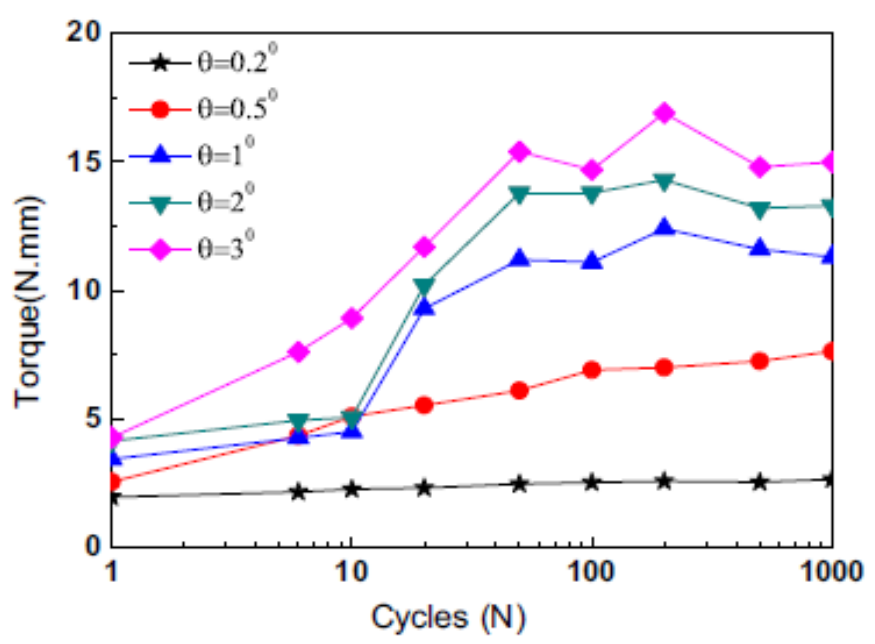

Figura 111 - Evolução das curvas de torque friccional versus ciclos de vida (Fonte: LIU et al. 2014)

O formato obtido no gráfico torque versus deslocamento angular ilustrado na Figura 113 demonstra a característica de deslizamento misto. Conforme apontam os autores, ela indica que os micros deslizamentos ocorrem na borda do contato e que a de formação da superfície é mais acomodada pela deformação elástica, mas também parcialmente pela deformação plástica. 


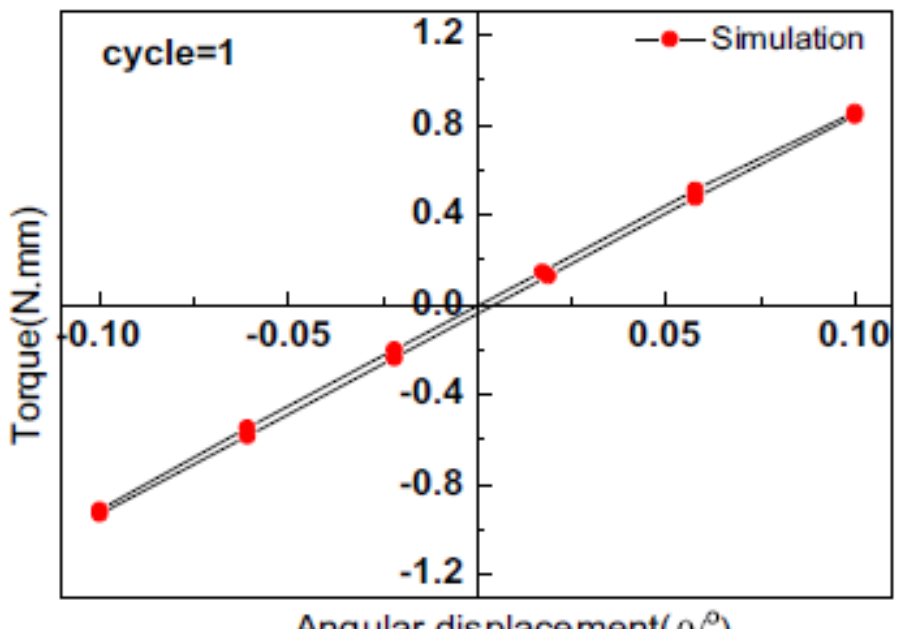

Angular displacement $(\theta /)$

Figura 112 - Curva de torque angular versus deslocamento angular em $\theta=0,1$ (Fonte: LIU et al. 2014)

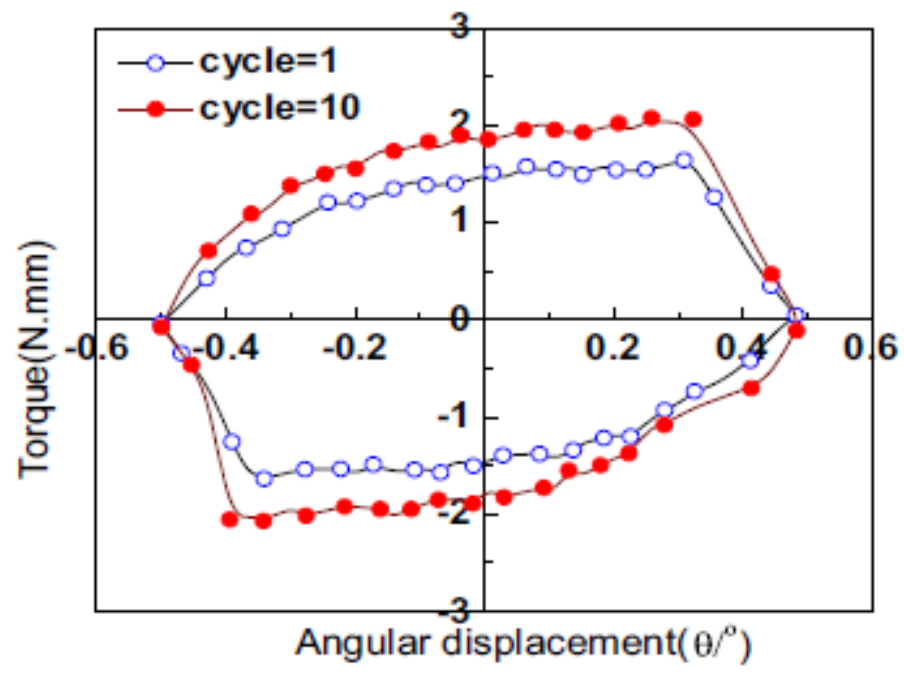

Figura 113 - Curva de torque angular versus deslocamento angular em $\theta=0,5$ (Fonte: LIU et al. 2014)

Os resultados experimentais e numéricos são mostrados na Figura 114: 

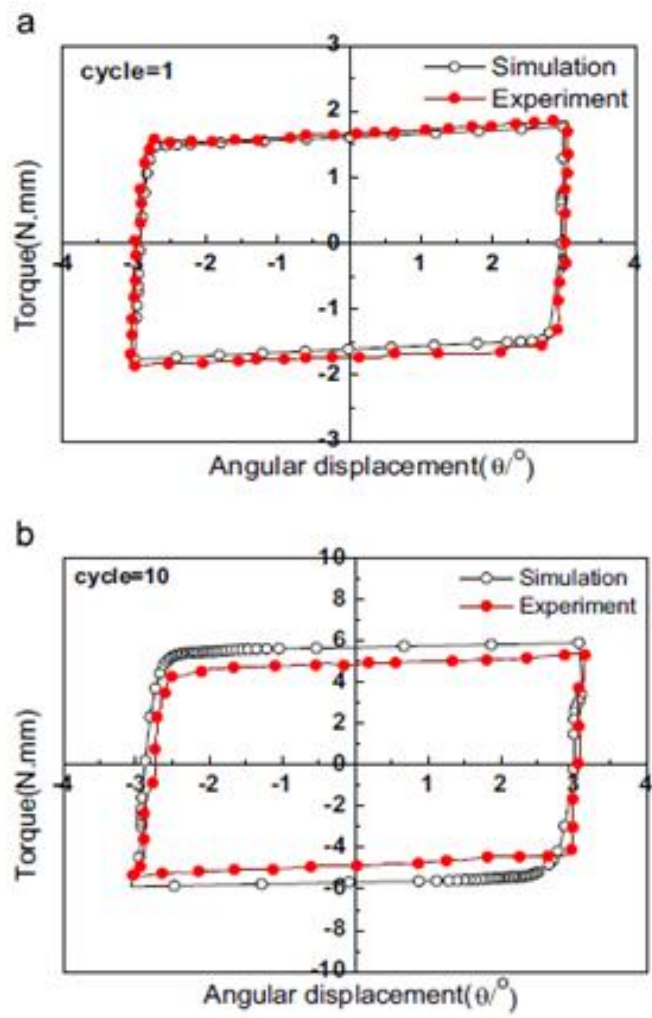

Figura 114 - Curvas de torque versus deslocamentos angulares para $\theta=3$ no (a) primeiro ciclo (b) décimo ciclo (Fonte: LIU et al. 2014)

Os resultados experimentais e numéricos se mostraram em boa concordância.

Para explicar o processo de desgaste estudado, os autores citam o trabalho de (ZHOU \& VINCENT, 2002), no qual se introduz a importância da camada branca no processo de fricção. "A camada branca é a origem dos detritos de desgaste, tendo efeito significativo na fricção e na vida ao desgaste dos materiais. A formação da camada branca dentro do fretting é causada, principalmente, por mecanismos de aquecimento por fricção e de deformações plásticas" (ZHOU et al, 2002). Como mostrado na Figura 116, a camada branca se localiza na superfície do corpo de contato. Isto significa que as deformações plásticas na superfície e as tensões cisalhantes possuem efeitos na formação da camada branca, ocorrendo trincas transversais entre a supramencionada camada e a camada de deformação plástica. 

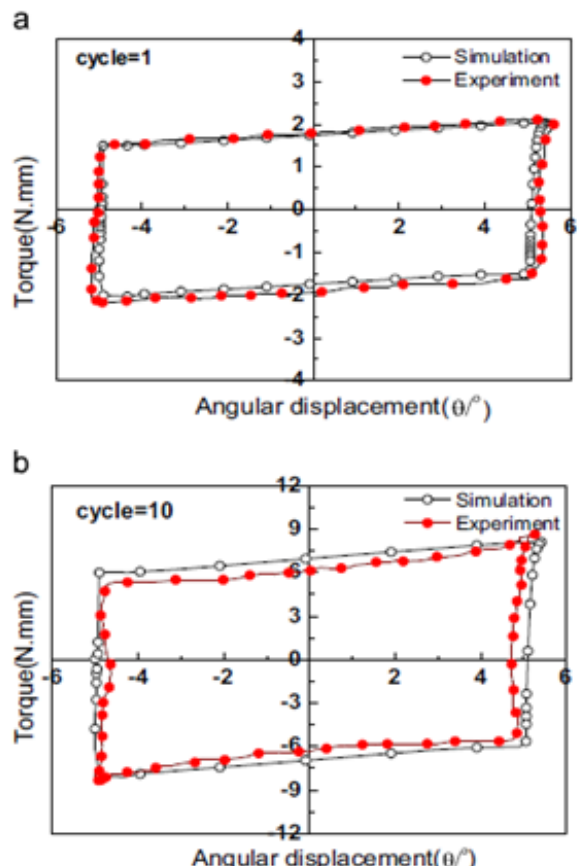

Figura 115 - Curvas de torque versus deslocamentos angulares para $\theta=5$ no (a) primeiro ciclo (b) décimo ciclo (Fonte: LIU et al. 2014)

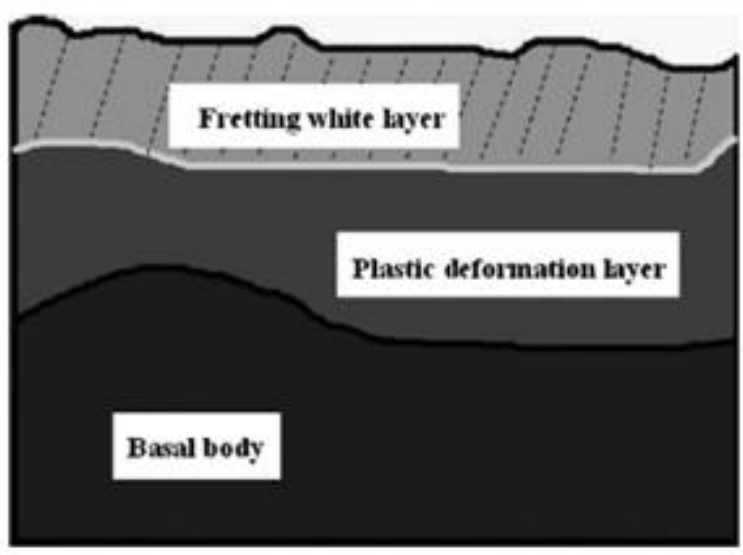

Figura 116 - Esboço da camada branca de fretting (Fonte: LIU et al. 2014)

A Figura 117 ilustra os diferentes contornos de deformação plástica para quatro diferentes deslocamentos angulares. Na Figura 117a, não há deformação plástica na superfície de contato, mas apenas uma pequena camada de deformação plástica a certa distância da mesma. Devido à dificuldade da formação da camada branca em fretting, não há, neste caso dano, ou ele é insignificante. Já na Figura 117b, a evolução da camada branca não ocorre por conta das pequenas deformações plásticas na superfície. A velocidade do desgaste mostra-se, portanto, baixa, para regimes mistos de deslizamento. Contudo, na subsuperfície, a deformação plástica não é negligenciável, logo, surgirão trincas entre a camada branca e a camada de deformação plástica. Assim, a taxa de crescimento da trinca local é maior do que a taxa de desgaste do material. 
Em relação à Figura $117 \mathrm{c}$, as deformações plásticas mostram se relevantes tanto para a superfície como a subsuperfície. Assim, a formação e evolução da camada branca ocorrem, com as trincas formadas entre a camada branca e a subcamada de deformação plástica se conectando, acelerando o processo de delaminação do material. Sob tais circunstâncias, não ocorre propagação de trinca transversal.
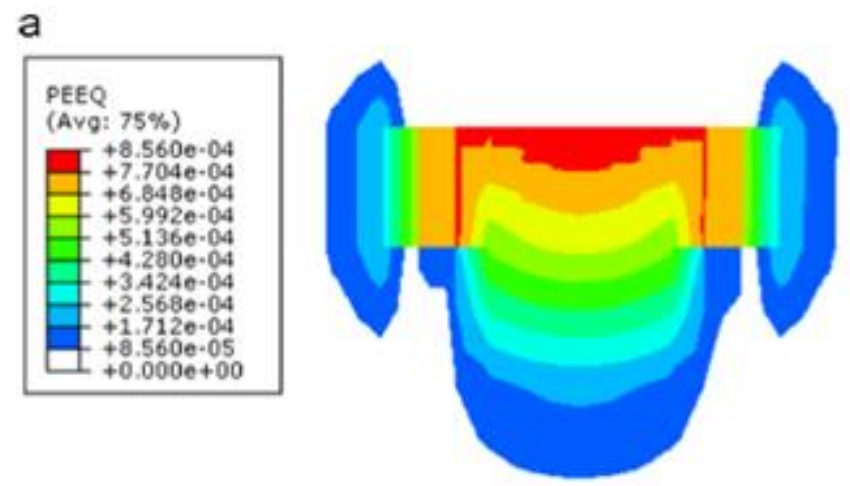

b
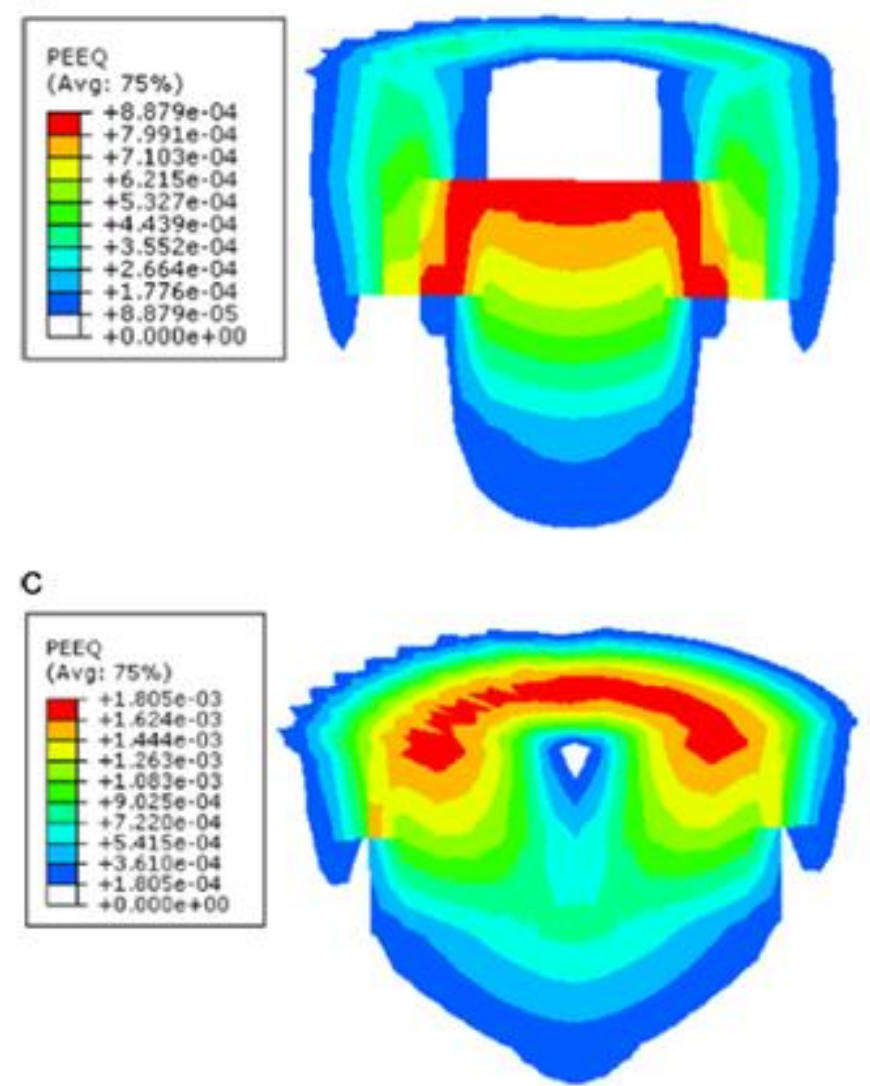

Figura 117 - Deformações plásticas para diferentes regimes de deslizamento (a) parcial (b) misto (c) total (Fonte: LIU et al. 2014)

As distribuições de tensões de cisalhamento ao longo do raio de contato e as cicatrizes de desgastes sob os três tipos de regime de deslizamento, com $\theta=0,1,0,5$ e 1,5 graus, respectivamente, são mostrados na Figura 118. Para o regime parcial, mostrado 
na Figura 118a, a tensão máxima de cisalhamento decorrente da fricção ocorre nas extremidades do contato, com valor aproximado de $60 \mathrm{MPa}$. Neste caso, conforme descrevem os autores, ocorre uma espécie de grude entre as duas camadas. Consequentemente, quase não há danos, os quais ocorrem apenas nas extremidades dos contatos. Já para o modo misto de deslizamento, ilustrado na Figura $118 \mathrm{~b}$, as superfícies de contato são dividas em uma parte de grude circular e uma de deslizamento anelar. A tensão máxima cisalhante por conta de fricção é grande na área de deslizamento, mas pequena ou inexistente na área de grude. Como consequência, os danos de superfície ocorrem apenas na área anelar. Já no regime de deslizamento bruto, ilustrado na Figura 118c, a tensão cisalhante decorrente da fricção aumenta evidentemente na zona de contato total, com o valor máximo ocorrendo no centro da área de contato. Ocorre facilmente a delaminação da camada branca por conta das ações das tensões cisalhantes e, portanto, há uma alta velocidade de desgaste da superfície.

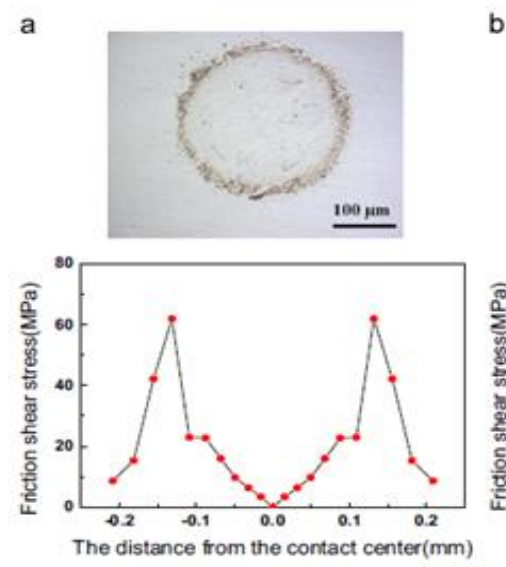

b
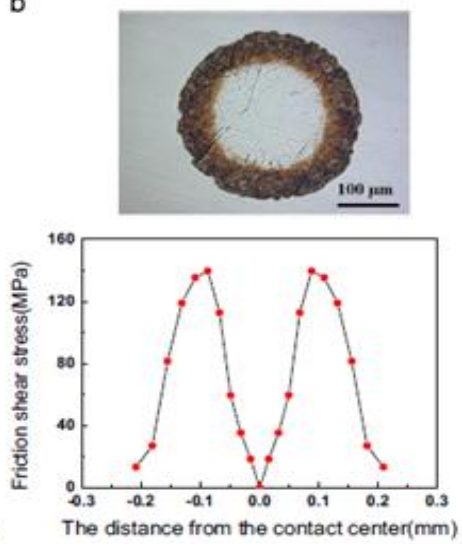

c

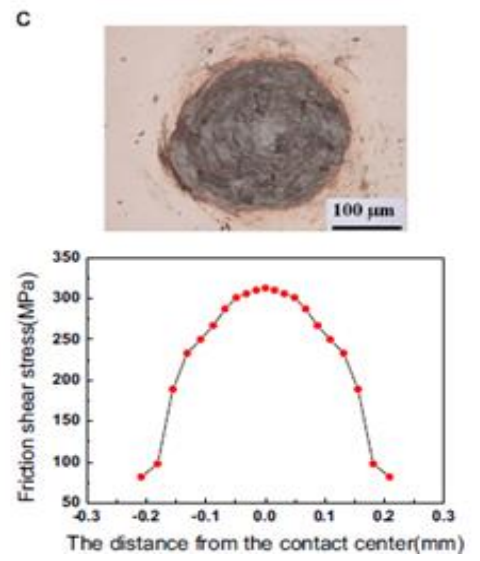

Figura 118 - Tensão cisalhante friccional e marcas de desgaste (a) Deslizamento parcial (b) Deslizamento mixto (c) Deslizamento total (Fonte: LIU et al. 2014) 
A Figura 119 mostra como a falha ocorre tanto por conta do mecanismo de desgaste, como por conta do mecanismo de fadiga no regime misto. Enquanto este diminui de forma significativa com o aumento da amplitude de deslizamento, aquele aumenta devagar com tal aumento. Portanto, a iniciação e propagação do dano principal ocorrem no regime misto de deslizamento e, para calcular a propagação dos danos, os autores utilizaram o parâmetro de SWT.

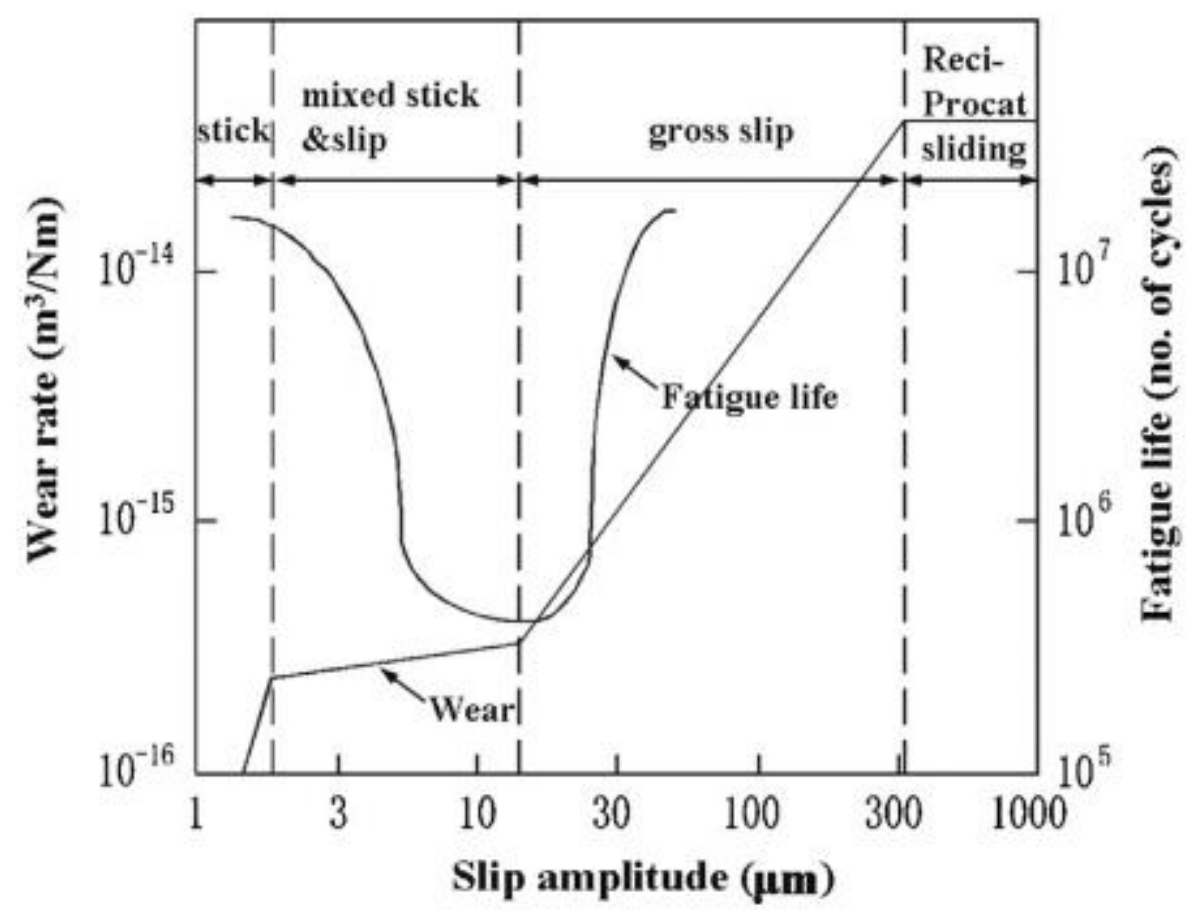

Figura 119 - Típica relação entre vida à fadiga e taxa de desgaste em função da amplitude de deslizamento (Fonte: LIU et al. 2014)

Por fim, os autores puderam concluir que o trabalho teve boa concordância da evolução das curvas de torque de fricção para as análises numérica e experimental. As considerações da evolução dos coeficientes de fricção proposta, assim como as deformações obtidas pela análise numérica aparentam descrever bem o que realmente ocorre nos experimentos. 


\subsubsection{MODELO PROPOSTO POR NIGRO et al. (2014)}

A proposta deste estudo era modelar os efeitos da microestrutura na propagação de trincas curtas. A análise numérica seguiu os modelos bidimensionais convencionais de uma estrutura cilíndrica em contato com uma estrutura plana. O processo numérico iniciou-se primeiro tratando da plasticidade dos cristais, depois determinando-se a direção de propagação da trinca e, por fim, obtendo-se as orientações dos planos de deslizamento e a velocidade de propagação das trincas.

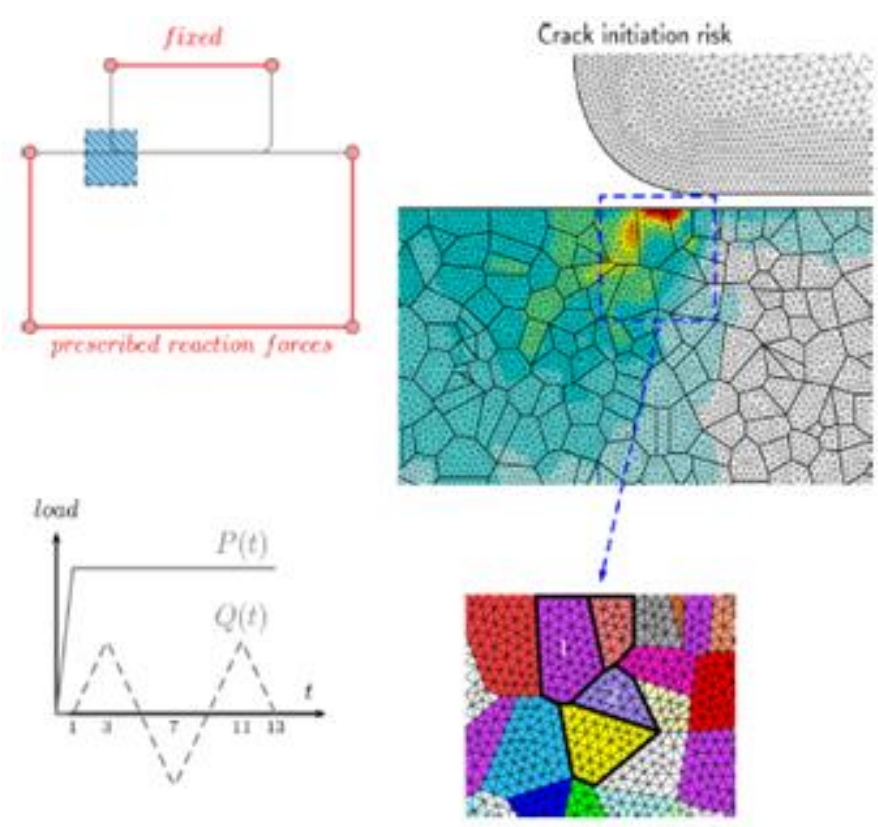

Figura 120 - Simulação da propagação de trinca na microestrutura de uma ligada de titânio. À esquerda, a geometria do teste. À direita, o local de iniciação de trinca (Fonte: NIGRO et al. 2014)

O algoritmo utilizado na simulação é mostrado na Figura 121: 


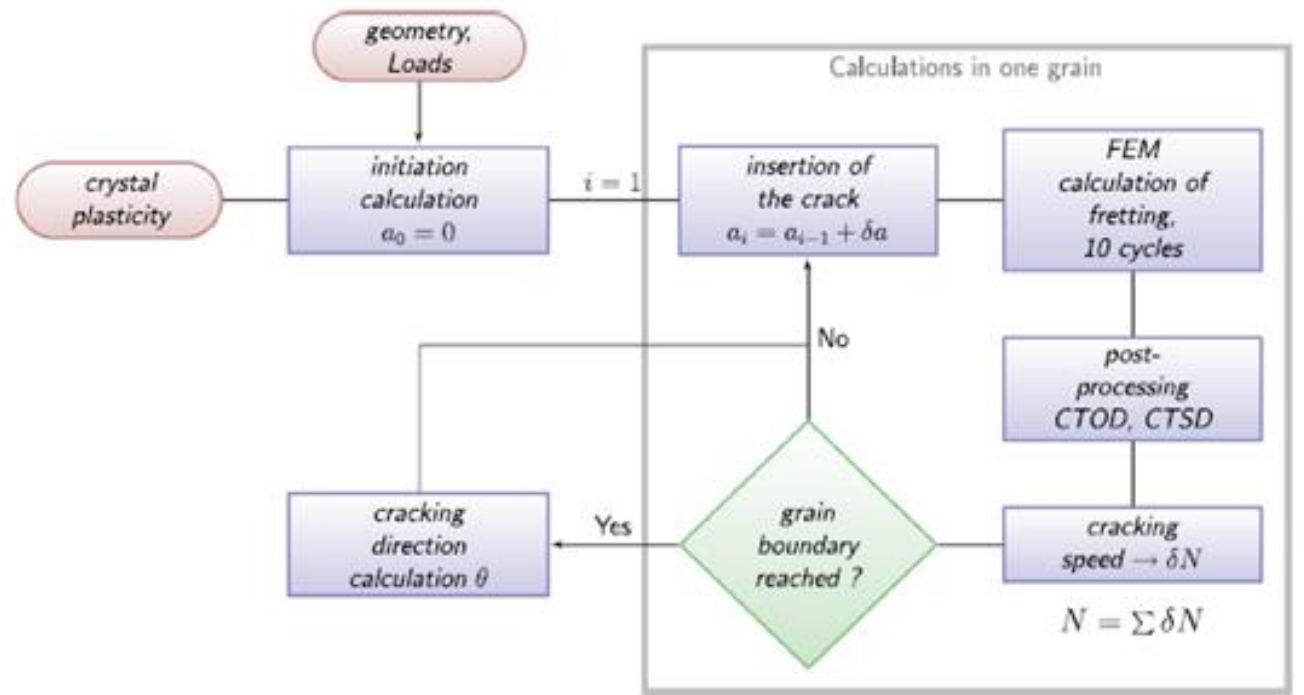

Figura 121 - Esquemática da simulação da metodologia grão a grão (Fonte: NIGRO et al. 2014)

A malha criada e os múltiplos grãos constituintes da peça são apresentadas na Figura 122.

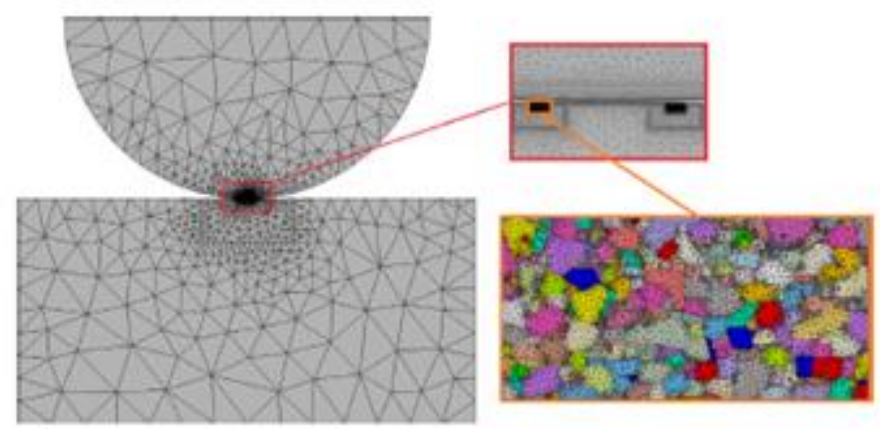

Figura 122 - Detalhes da malha e dos grãos gerados (Fonte: NIGRO et al. 2014)

As condições de contorno utilizadas são apresentadas na Figura 123: 


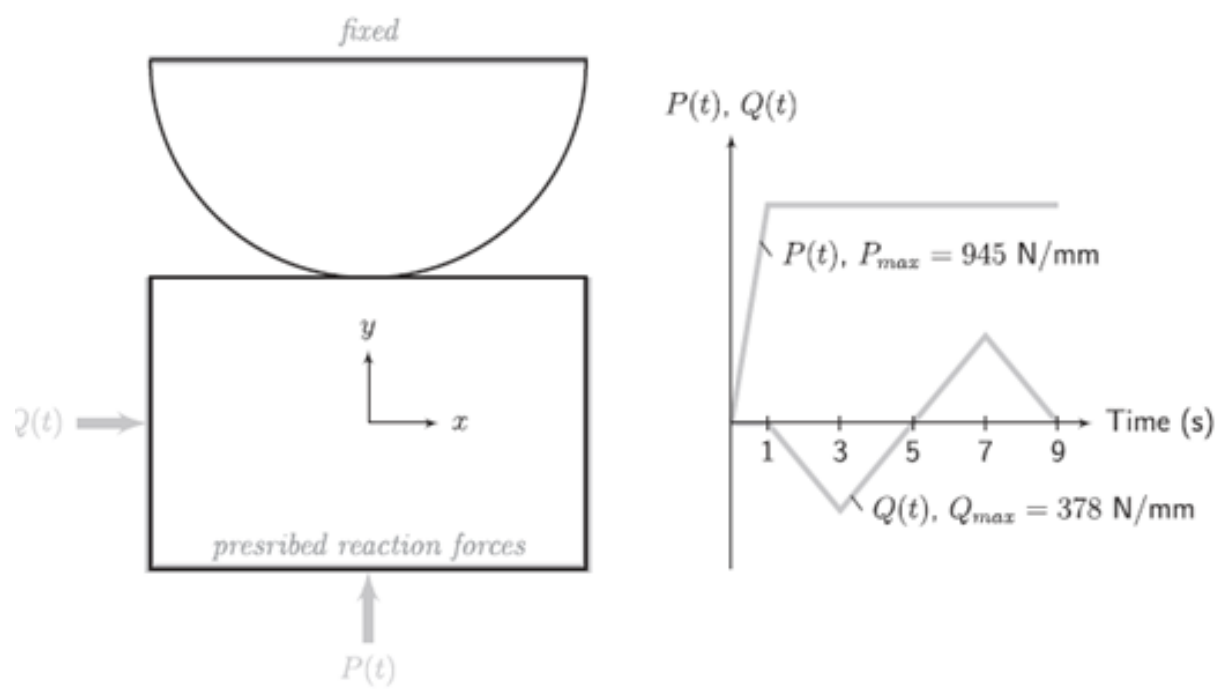

Figura 123 - Condições de contorno e de carregamento (Fonte: NIGRO et al. 2014)

Para o cálculo da direção das trincas, o parâmetro de fadiga multiaxial utilizado foi o de Crossland. Os resultados analíticos e calculados são demonstrados na Figura 124.

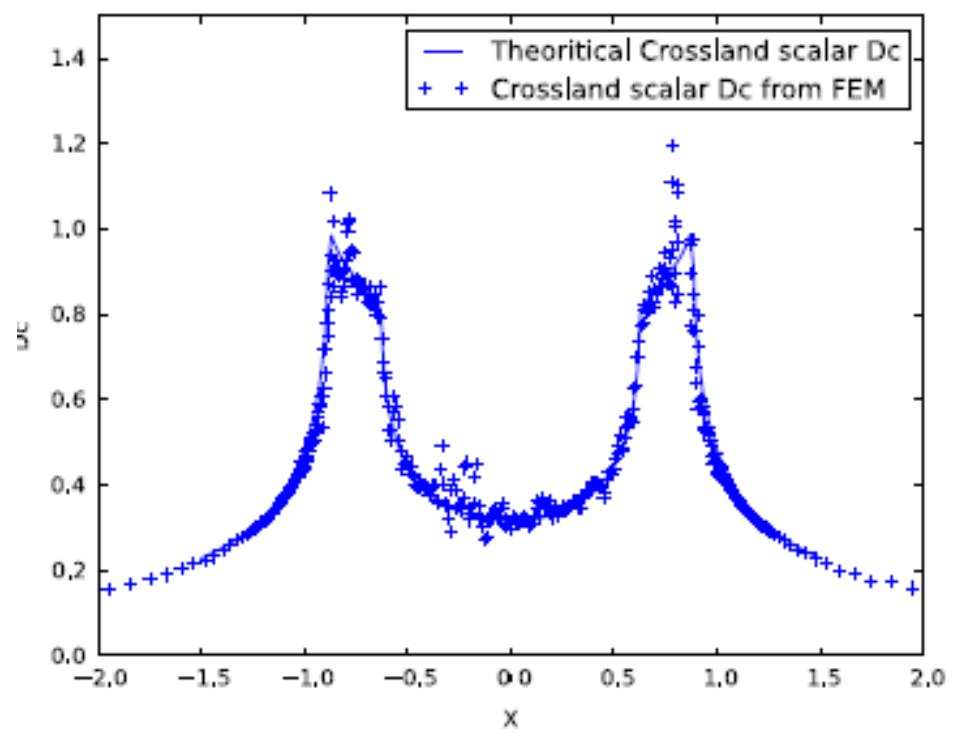

Figura 124 - Comparações dos resultados teóricos e computados para o critério de Crossland (Fonte: NIGRO et al. 2014)

A direção da trinca foi determinada para o primeiro grão, o que, segundo os autores, dá a direção do deslizamento mais ativo. Durante a propagação de trinca e parada cada grão que a mesma atravessava, a direção da trinca era reavaliada sempre que atingia um limite de um grão. O processo foi repetido por todo o fenômeno de programação, sendo necessário criar para cada novo cálculo uma nova malha com o tamanho de trinca adequado. 

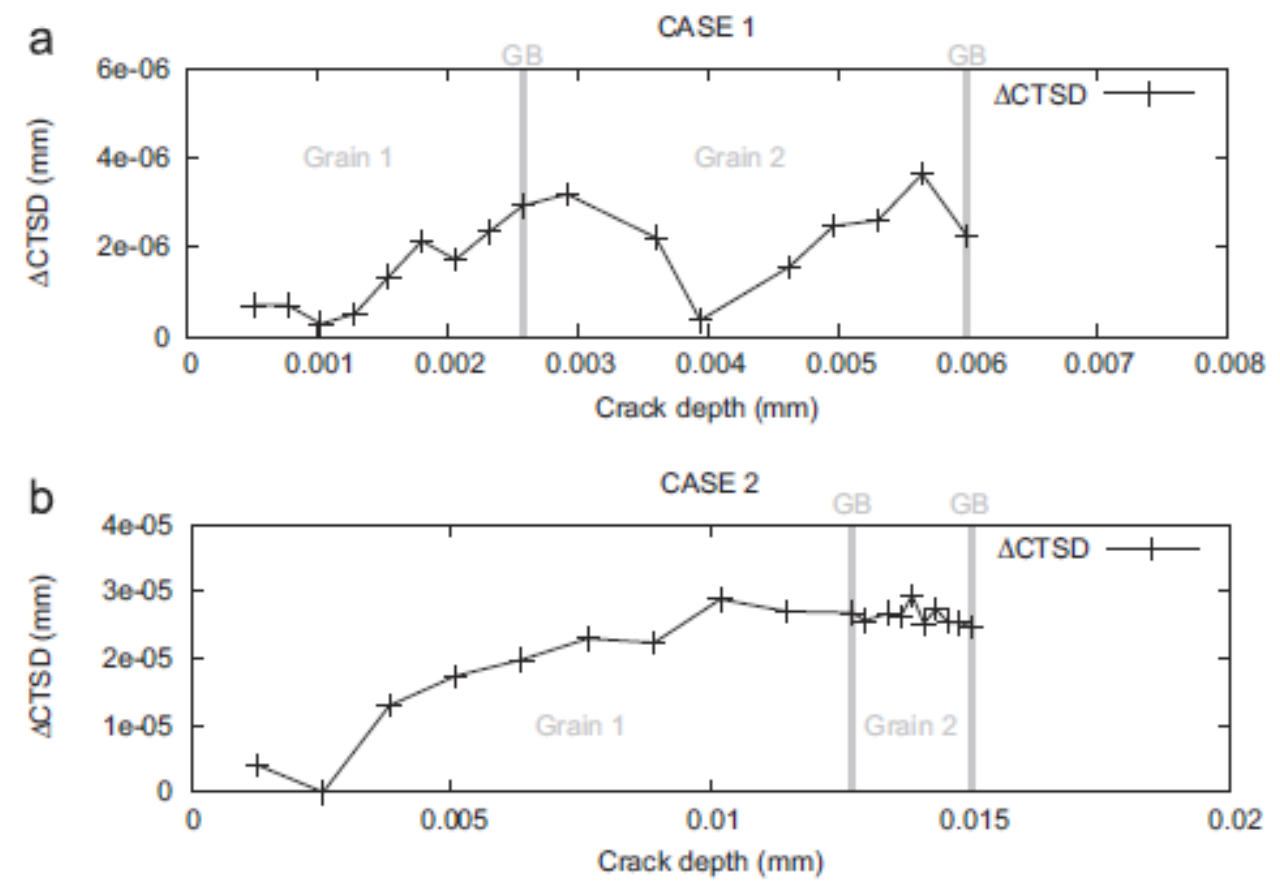

Figura 125 - Evolução do CTSD em função do tamanho da trinca para os dois casos (Fonte: NIGRO et al. 2014)

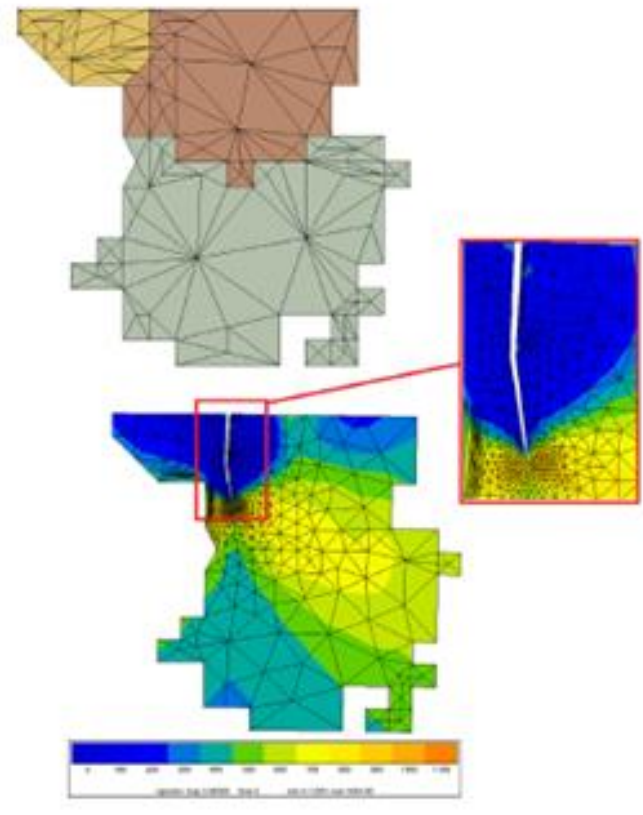

CASE 1

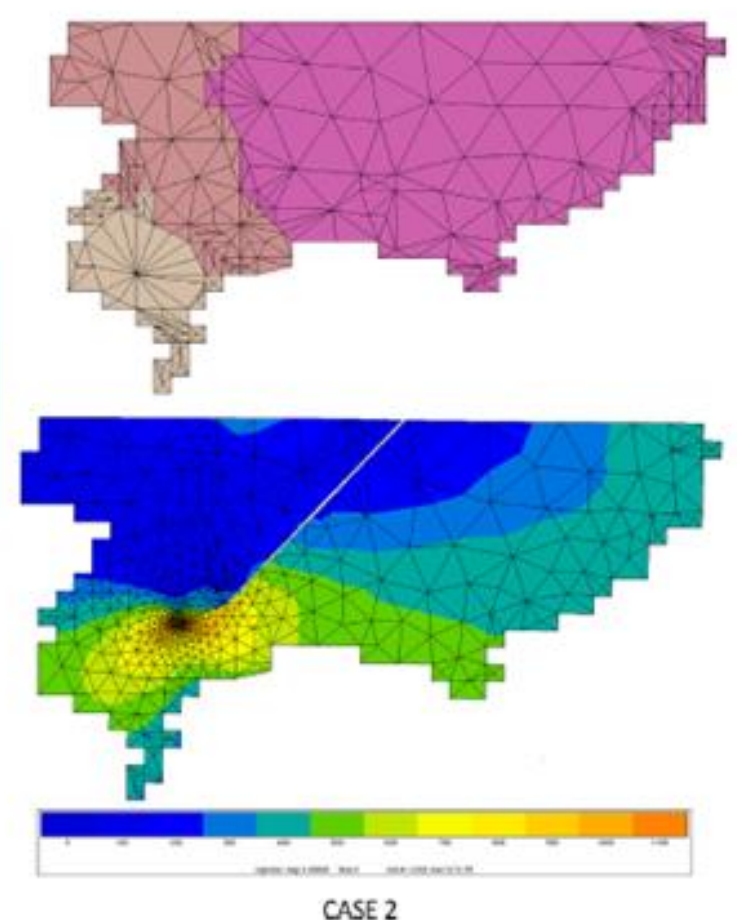

CASE 2

Figura 126 - Propagação de trincas para dois casos (Fonte: NIGRO et al. 2014)

Os autores acreditam que o modelo proposto é realista do ponto de vista da propagação de micro trincas em situações de fretting fatigue. Por meio de utilização de 
modelo constitutivo plástico dos cristais, foi possível examinar quais planos de deslizamento dos cristais eram mais favoráveis a propagação das microtrincas.

Nos testes experimental e numérico de PROUDHON et al. (2013), nos quais os autores se basearam, foi salientado o efeito de barreira que cada limite granular impõe à propagação da trinca (a velocidade de propagação desta diminui nas vizinhanças dos limites granulares). Os autores consideraram que o estudo proposto não correspondeu de forma satisfatória o fenômeno previamente observado, sendo necessário aprofundar ainda mais os estudos nos critérios de propagação de trincas curtas. Ademais, o fato das amplitudes de tensão utilizadas nos dois estudos serem diferentes pode explicar a grande variação dos processos mecânicos envolvidos nos cristais. 


\subsubsection{MODELO PROPOSTO POR FERJAOUI et al. (2015)}

Este estudo utilizou análises experimental e numérica através de elementos finitos e o software ABAQUS. Com a Mecânica dos danos contínuos (CDM) e de FEM, uma proposta da evolução do dano foi elaborada para estimar a iniciação de trinca sob fretting fatigue em uma junta de dois parafusos sobrepostos.

Para se realizar a parte experimental do estudo, os autores seguiram a norma ASTM E2789-10. O experimento consiste em três placas idênticas de alumínio liga 2024-T3 presas por um parafuso e uma carga de célula para monitor a carga. As Figuras 127 e 128 ilustram o espécime, enquanto a Figura 129 demonstra a foto do aparto experimental carregado com o espécime.

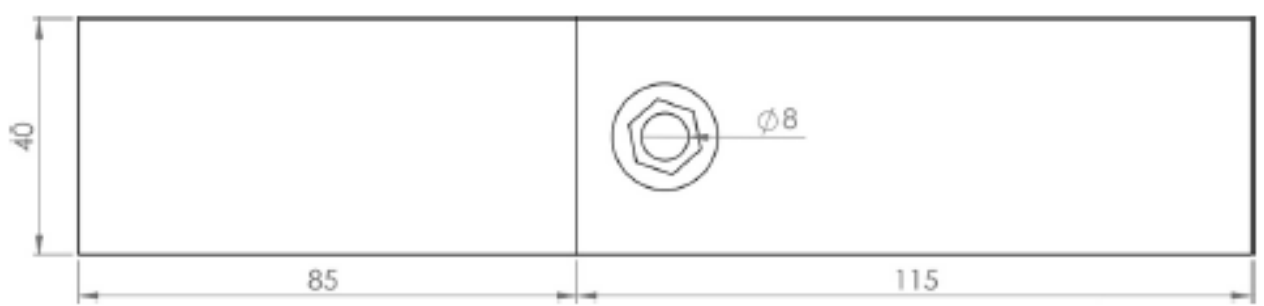

Figura 127 - Visão superior do espécime, em milímetros (Fonte: FERJAOUI et al. 2015)

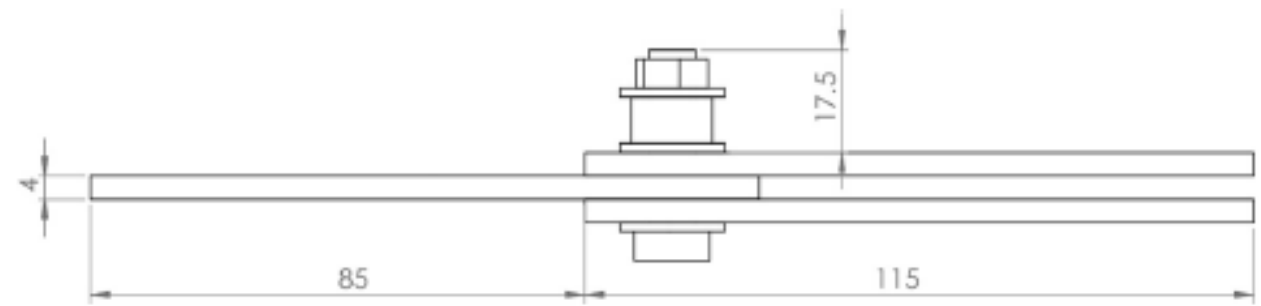

Figura 128 - Visão lateral do espécime, em milímetros (Fonte: FERJAOUI et al. 2015) 


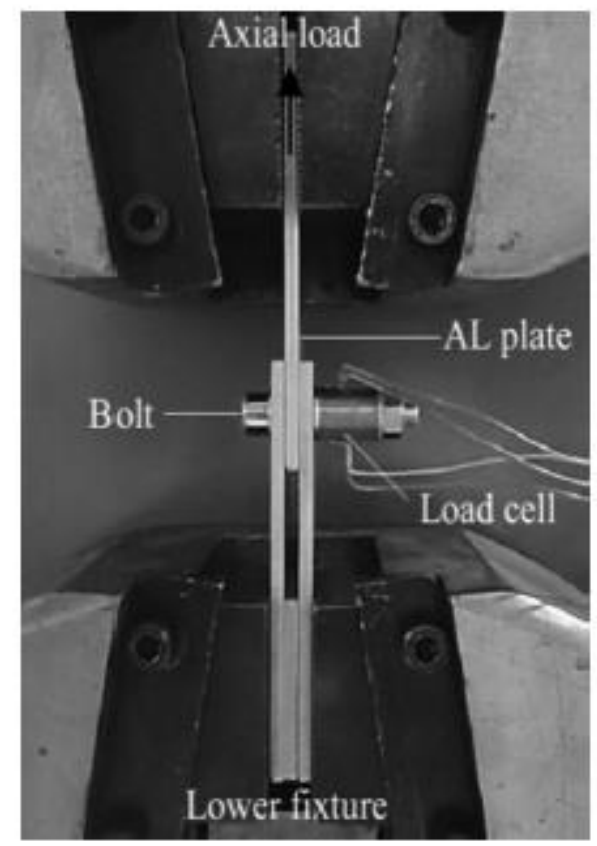

Figura 129 - Espécime no aparato experimental (Fonte: FERJAOUI et al. 2015)

Para a simulação de elementos finitos, os autores utilizaram no ABAQUS duas etapas de carregamento. Na primeira, a carga estabelecia o contato entre os pares, no qual se usou o algoritmo do próprio programa de escravo-mestre com 8 nós lineares.

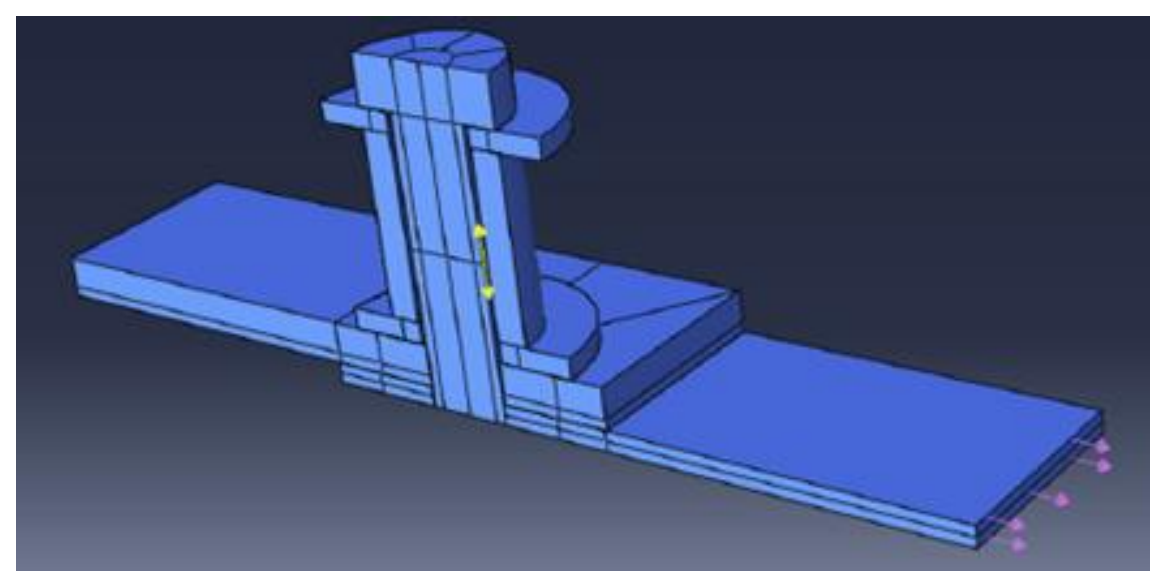

Figura 130 - Modelo em elementos finitos com cargas (Fonte: FERJAOUI et al. 2015) 


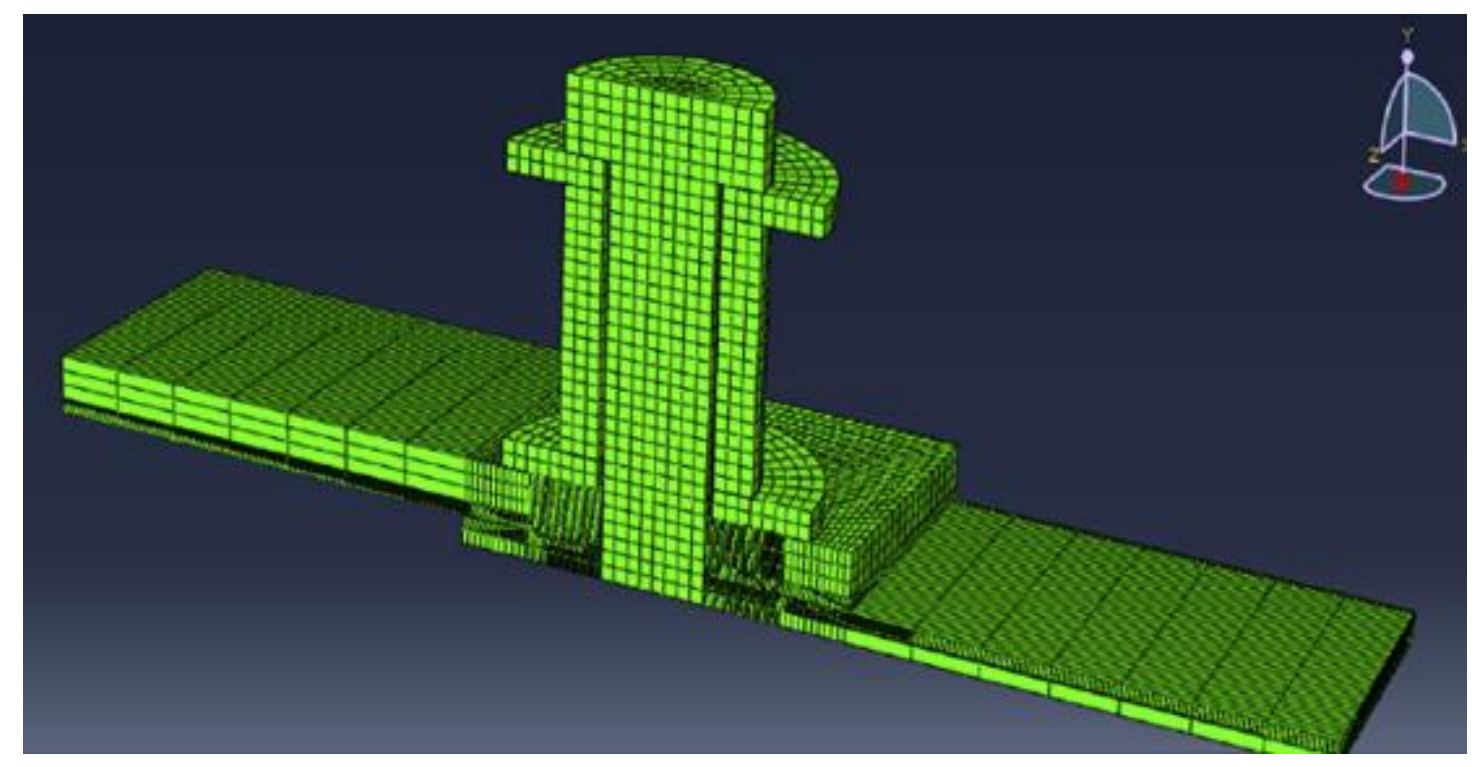

Figura 131 - Modelo em elementos finitos com malha (Fonte: FERJAOUI et al. 2015)

$\mathrm{Na}$ etapa experimental do estudo, os autores usaram uma combinação de carga axial e normal até que a falha ocorresse. As Figuras 132-134 mostram as cicatrizes de fretting obtidas.

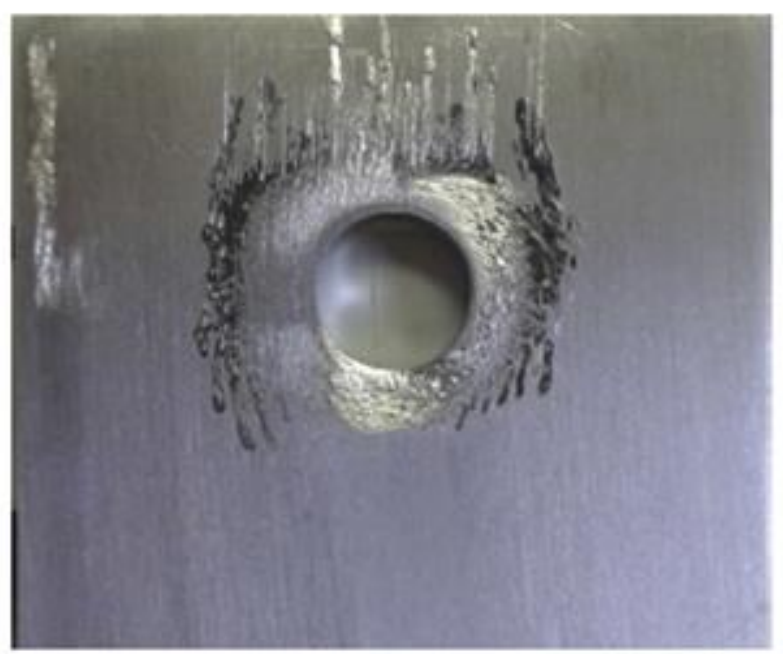

Figura 132 - Cicatriz de fretting na placa lateral (Fonte: FERJAOUI et al. 2015) 


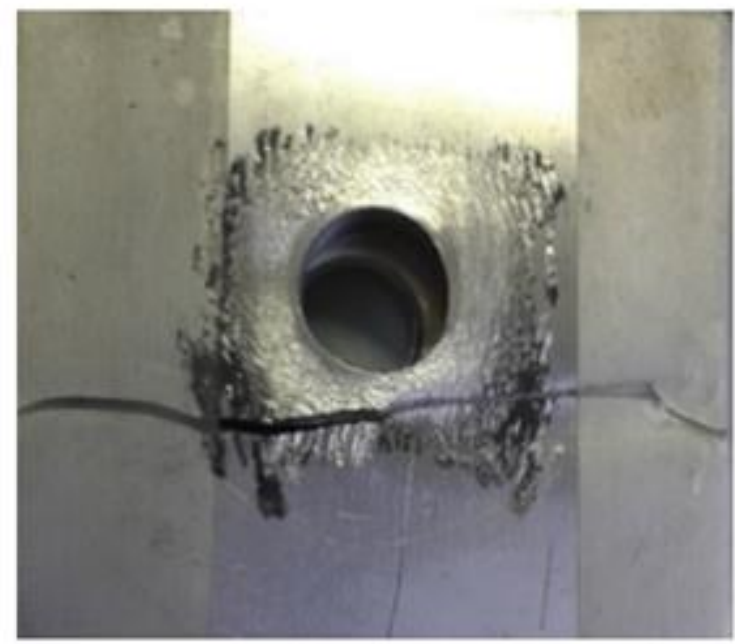

Figura 133 - Cicatriz de fretting no centro da placa $\sigma=125 \mathrm{MPa}$ (Fonte: FERJAOUI et al. 2015)

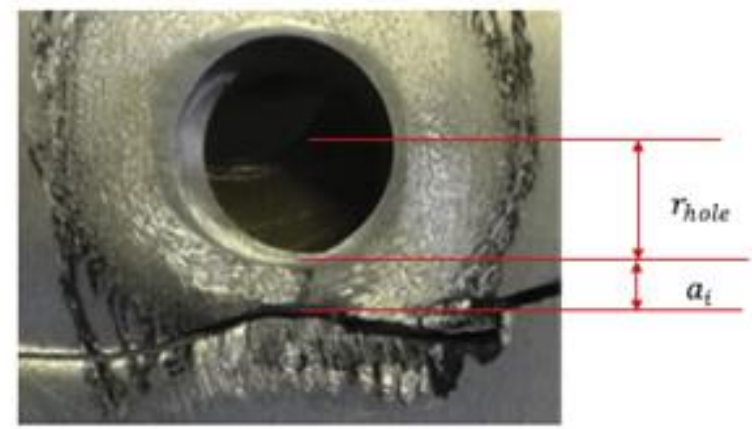

Figura 134 - Cicatriz de fretting no centro da placa $\sigma=112,5 \mathrm{MPa}$ (Fonte: FERJAOUI et al. 2015)

Tanto a Figura 133 como a 134 ilustram que a nucleação das trincas por fretting fatigue ocorreram no centro da placa, ao lado da carga axial aplicada. Para a validação do modelo numérico, a distância $a_{i}$ entre a borda do buraco e a trinca, mostrado na Figura 134 foi mensurada.

As Figuras 135 e 136 ilustram o contorno das tensões de Von Mises obtidas para o modelo numérico completo proposto e para as placas de alumínio, respectivamente. 


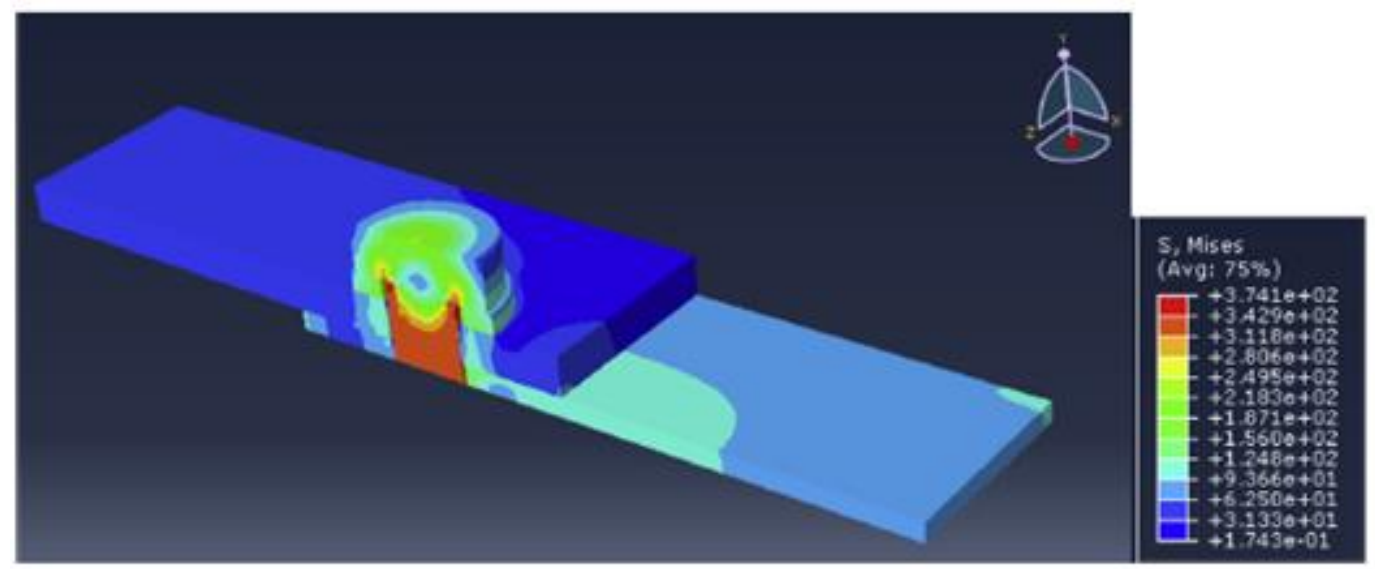

Figura 135 - Contornos de von Mises obtidos (Fonte: FERJAOUI et al. 2015)

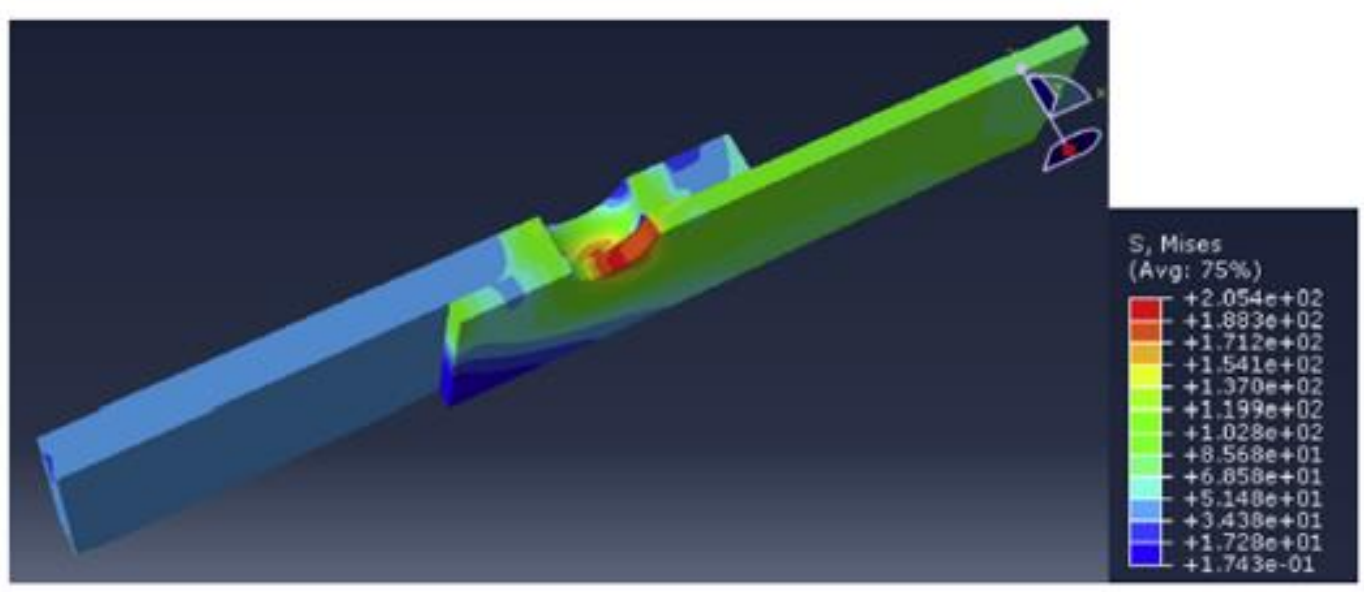

Figura 136 - Contornos de von Mises obtidos (Fonte: FERJAOUI et al. 2015)

A Figura 137 mostra os resultados das distribuições de tensão máxima principal e tensão cisalhante na interface do contato. Ambas são praticamente coincidentes em suas localizações.
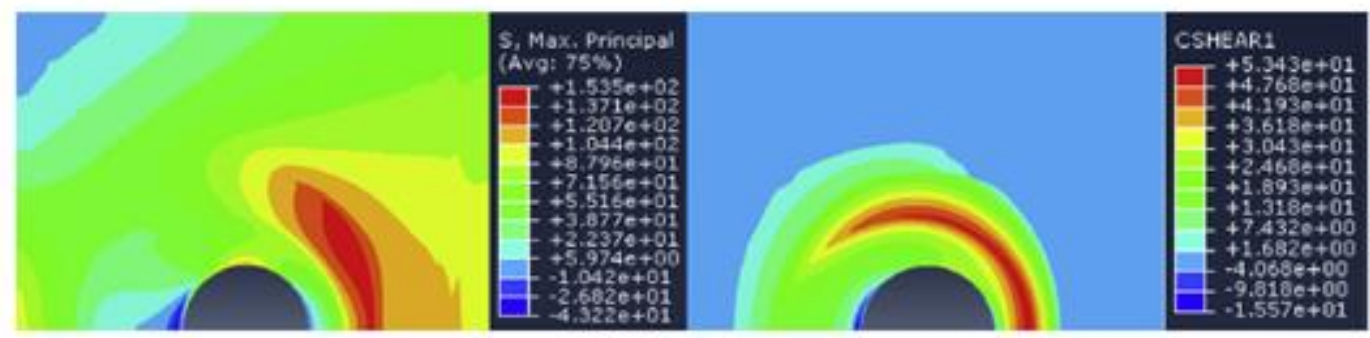

Figura 137 - Tensão principal máxima (esquerda) e tensão cisalhante (direita) na superfície de contato (Fonte: FERJAOUI et al. 2015)

Sob a condição de deslizamento parcial em fretting fatigue, a região de contato pode ser dividida em duas regiões diferentes de contato: A de grude e a de deslizamento. A pressão de contato tem papel significativo na razão de grude/deslizamento. As 
variações de contato de acordo com as cargas de aperto e axial são respectivamente ilustradas nas Figuras 138 e 139.

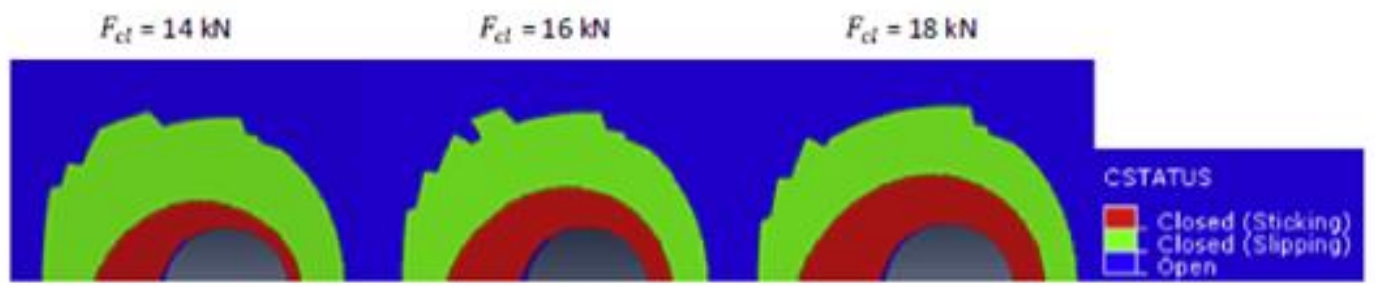

Figura 138 - Variação da superfície de contato de acordo com a força de aperto (Fonte: FERJAOUI et al. 2015)

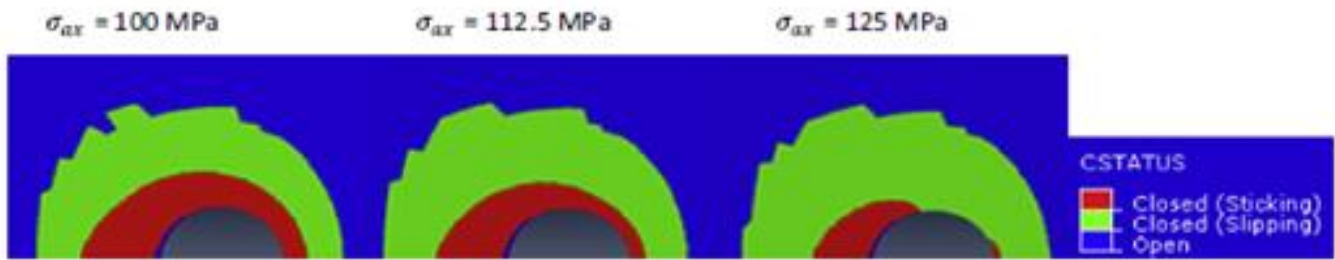

Figura 139 - Variação da superfície de contato sob diferentes tensões atuantes (Fonte: FERJAOUI et al. 2015)

Os demais resultados obtidos são mostrados nas Figuras 140-146.

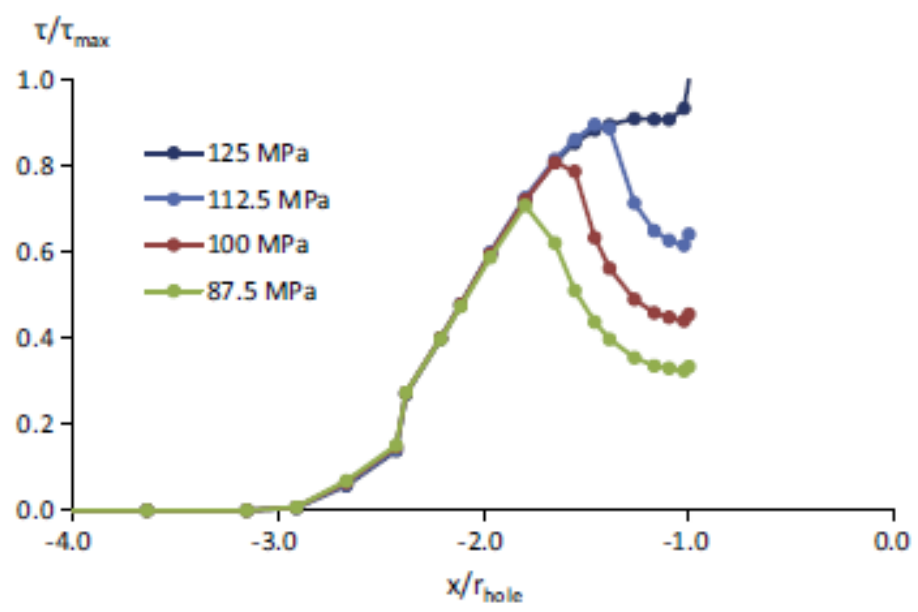

Figura 140 - Variações das tensões cisalhantes normalizadas para as diferentes cargas aplicadas (Fonte: FERJAOUI et al. 2015) 


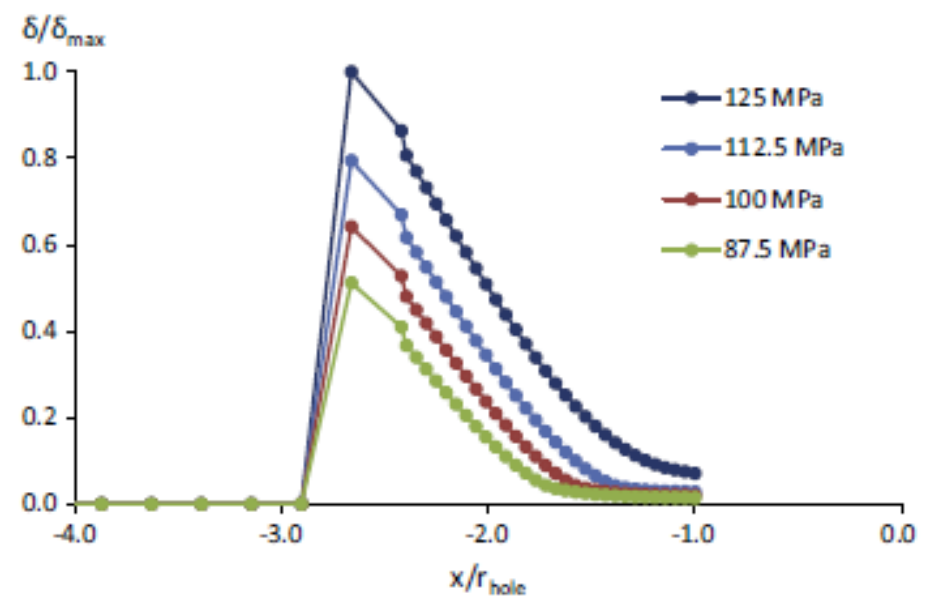

Figura 141 - Variação da amplitude de deslizamento normalizada em função da linha de contato normalizada, para diferentes cargas (Fonte: FERJAOUI et al. 2015)
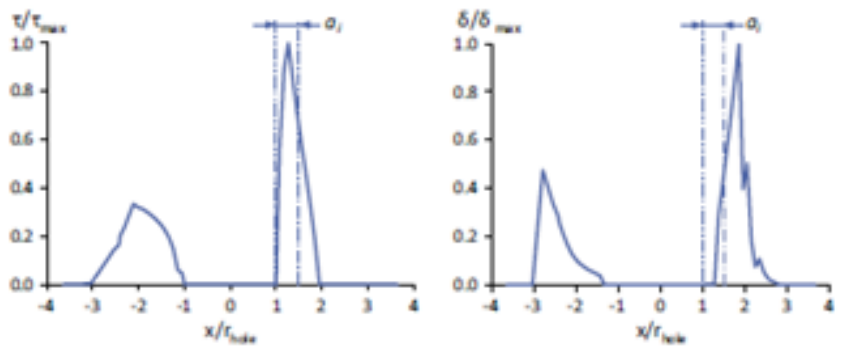

Figura 142 - Variação das tensões cisalhantes normalizadas (esq.) e amplitude de deslizamento (dir.) para a linha de contato normalizada de um determinado teste (Fonte: FERJAOUI et al. 2015)

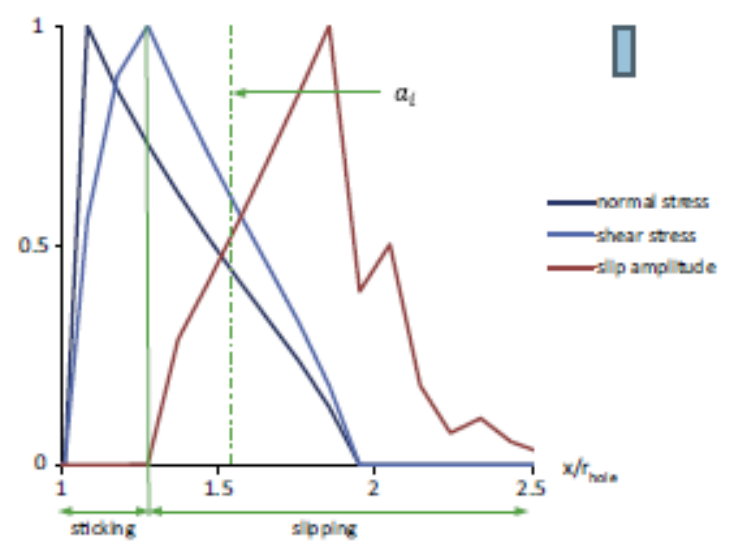

Figura 143 - Variáveis normalizadas em função da distância de contato deslizada para um determinado teste (Fonte: FERJAOUI et al. 2015) 


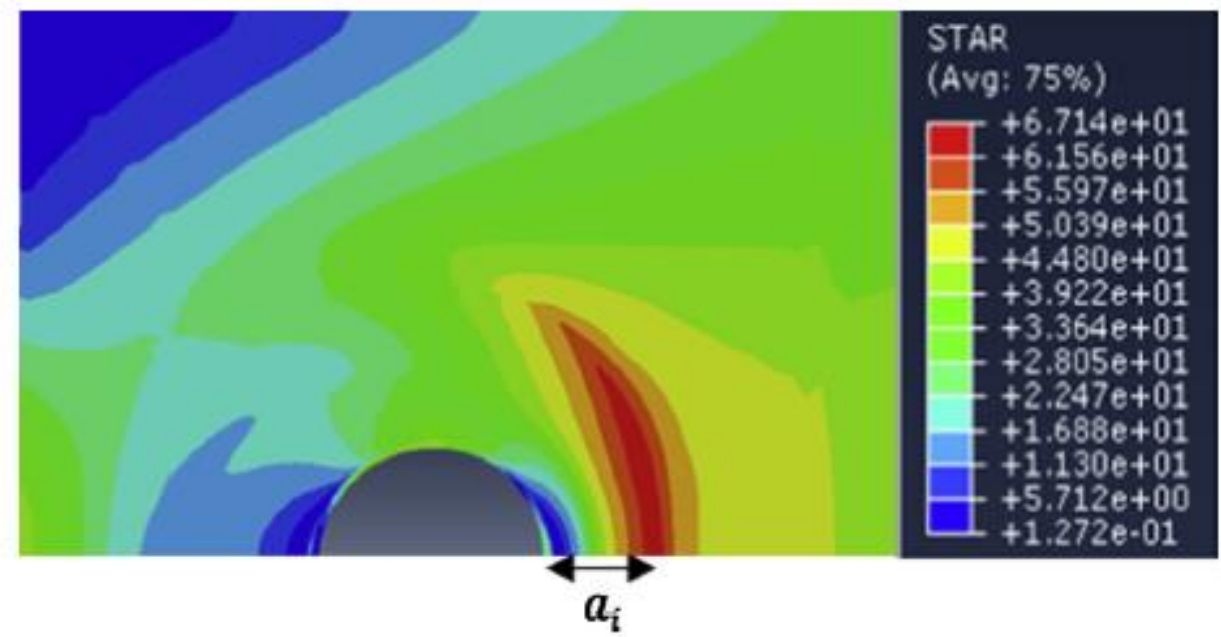

Figura 144 - Distribuição dos picos de tensão no contato (Fonte: FERJAOUI et al. 2015)

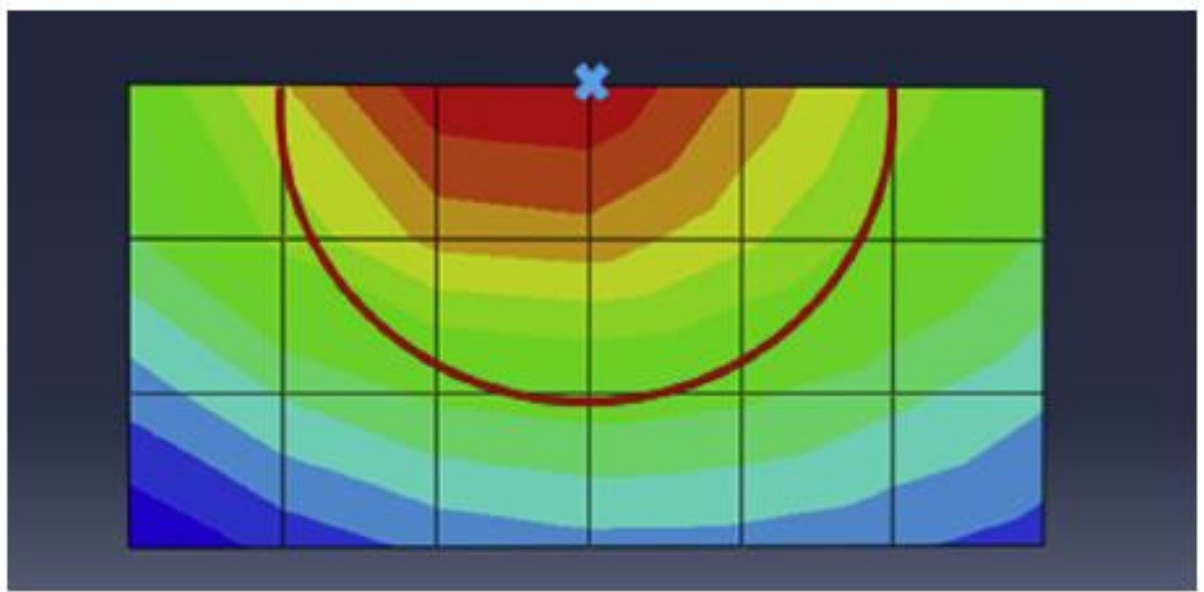

Figura 145 - Zona de processo no local de nucleação da trinca (Fonte: FERJAOUI et al. 2015) 


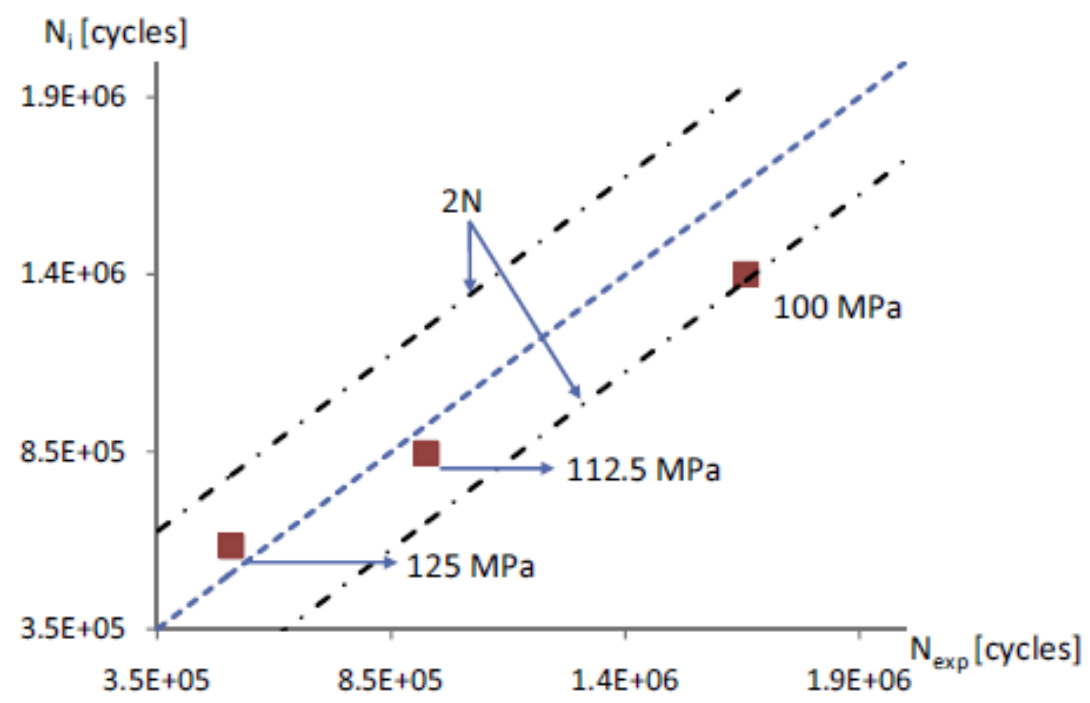

Figura 146 - Resultados computados versus resultados experimentais (Fonte: FERJAOUI et al. 2015)

Com tais resultados, os autores concluíram que a análise de elementos finitos proposta foi capaz de prover informações extras sobre os deslizamentos parciais e as distribuições de pressão que eram impossíveis de serem monitoradas experimentalmente. A Análise de elementos finitos também se mostrou capaz de mostrar os diferentes efeitos que as tensões axiais e as forças de contato produzem nos deslizamentos parciais de fretting. O local de nucleação da trinca e a vida à fadiga foram calculados utilizando o processo de zoneamento, com o numero de ciclos para a ocorrência de tal fenômeno sendo determinado experimentalmente. No caso de deslizamento parcial, a quantidade de ciclos obtidos estava entre $80 \%-90 \%$ da vida determinada experimentalmente, sendo significativamente menor no modo de deslizamento bruto. Portanto, os autores puderam concluir que a razão entre o número de ciclos para a iniciação da trinca e o número de ciclos utilizado para a propagação da trinca é afetado pela amplitude de deslizamento parcial e o regime de contato para as placas duplas parafusadas. 


\subsubsection{MODELO PROPOSTO POR TALEMI et al. (2011)}

Os dados experimentais foram obtidos pelos trabalhos de MAJZOOBI et al., (2010). Uma visão geral do aparado é demonstrada na Figura 147.

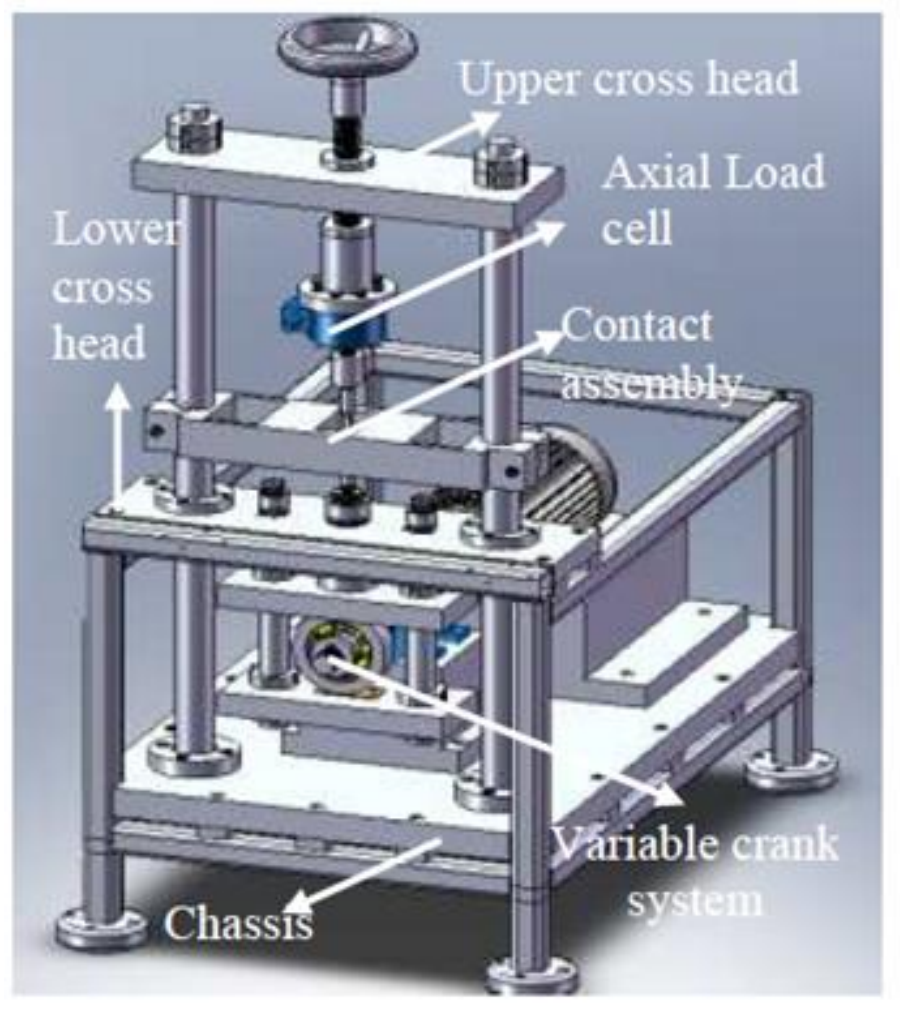

Figura 147 - Visão geral do aparato (Fonte: TALEMI et al. 2011)

A uma carga variável aplicada ao espécime através de um sistema de mecanismo de manivela, o qual é constituído por um eixo e duas placas de suspensão. O sistema de carregamento, ilustrado na Figura 147, é completamente incorporado ao cabeçote inferior, o qual é suportado por duas colunas passíveis de locomoção vertical. O sistema de carregamento contém dois pads, dois parafusos de ajuste e duas células de carga.

A carga de contato é induzida ajustando-se os dois parafusos, os quais são ajustados pelas células de cargas. Através da leitura realizada pelas células de cargas, é possível garantir que o aperto produzido pelos parafusos seja simétrico. O contato é de natureza bi planar, onde cada pad possui duas bases (superfícies de contato) pelas quais a força é exercida no espécime. 


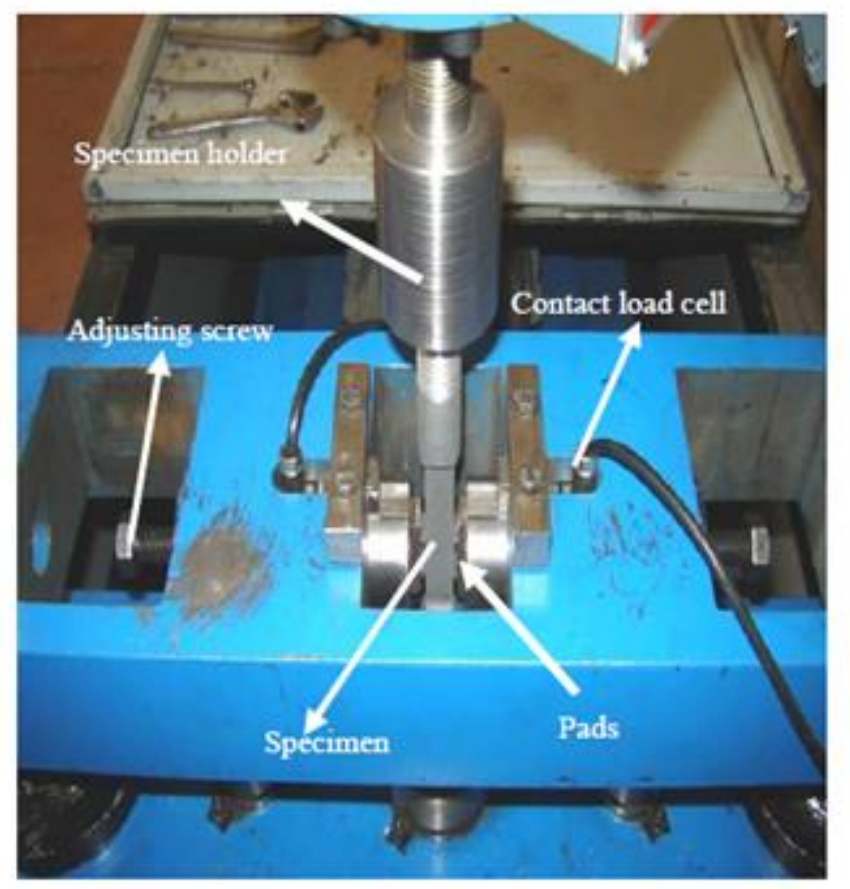

Figura 148 - Aparato experimental (Fonte: TALEMI et al. 2011)

As duas cargas de células foram montadas entre os parafusos de ajuste e os pads, conforme mostrado na Figura 148. Isto permitia a monitoração da carga de contato, tendo cada lado seu próprio display. O material utilizado no teste foi a liga de alumínio 7075-T6, com maiores detalhes encontrados em (FRANC2D/L, 1998).

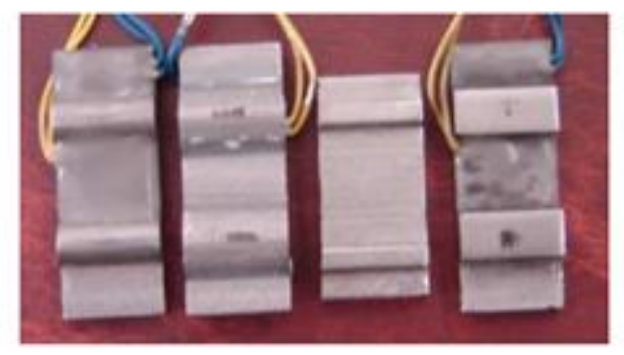

Figura 149 - Diferentes geometrias de pad utilizados (Fonte: TALEMI et al. 2011)

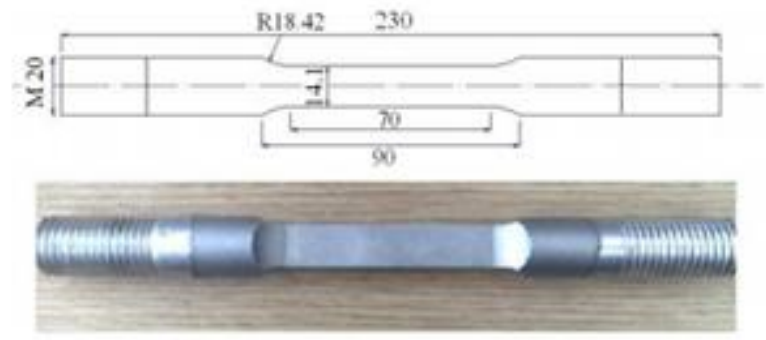

Figura 150 - Espécime plano utilizado (Fonte: TALEMI et al. 2011) 
Os autores propuseram dois tipos de simulação numérica:

(a) Modelo em elementos finitos para distribuição de tensão e determinação da trinca inicial.

(b) Uma nova abordagem de propagação de trincas em elementos finitos.

Para se determinar o local de iniciação de trinca, os autores utilizaram o Ansys Parametric Language Design, chegando ao modelo da Figura 151, o qual tenta reproduzir a esquemática clássica de testes de fretting fatigue. O modelo consiste de um conjunto de plano de tensões constituídos por quatro nós (PLAN82) para um espécime e um outro conjunto de elementos para a região de contato. Os elementos CONTA172 e TARGE169 foram utilizados na interface de contato do pad e o espécime. Tais elementos de contato permitiam a transferência de pressão entre o pad de contato e o espécime, não permitindo que o pad penetrasse no espécime. O método de Lagrange expandido foi utilizado com coeficiente de fricção igual a 0.5. Por conta das simetrias axiais, apenas um quarto da configuração do teste foi desenvolvida a fim de se poupar custo computacional. Além das condições de contorno envolvendo simetria, as demais restrições foram demonstradas na Figura 151. Visando resultados mais precisos na região de contato, os autores calcularam que o tamanho mínimo aceitável dos elementos na região seria de $9 \mu \mathrm{m} \times 9 \mu \mathrm{m}$, mas o refinamento, segundo os mesmos, foi muito mais fino, variando de acordo com cada carregamento imposto e as posições respectivas dos elementos dentro da região de contato.

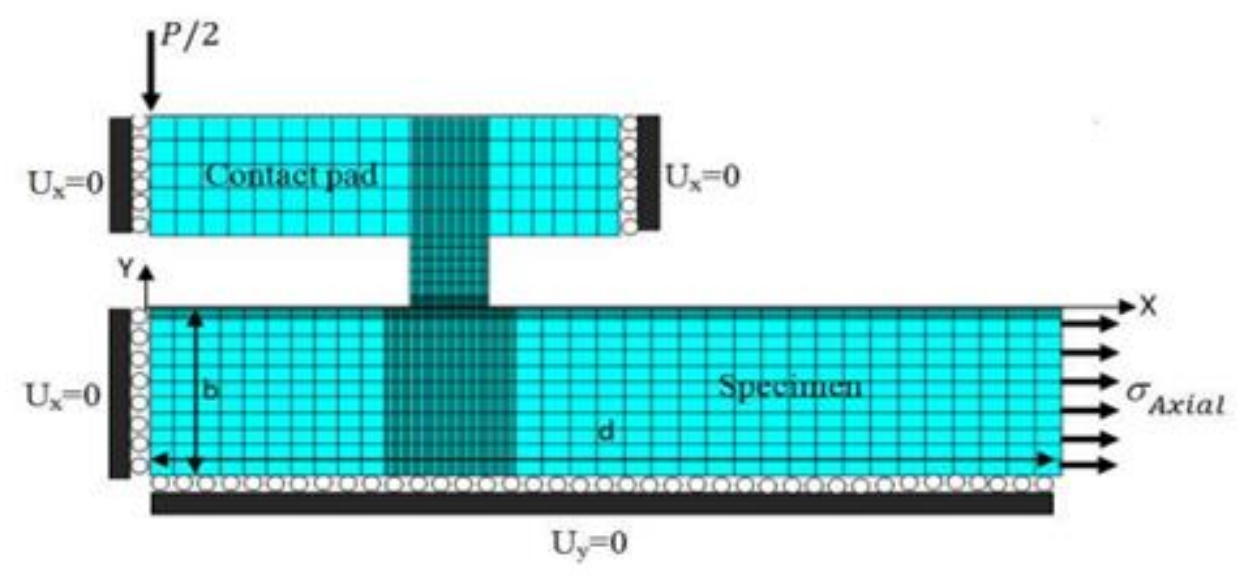

Figura 151 - Modelo numérico proposto (Fonte: TALEMI et al. 2011)

A segunda etapa do estudo numérico, referente à propagação de trinca, foi conduzida utilizando-se o código de elementos finitos FRANC2D/L. O modelo utilizado 
nesta etapa possuía as mesmas condições de contorno e igual geometria ao do apresentado na primeira etapa. Uma trinca foi então inserida no modelo na borda do contato, para que então fosse analisada pelo código FRANC2D/L, o qual é capaz de estimar o crescimento da trinca. Para a validação do tamanho da malha na nova proposição, os autores validaram as tensões comparando-as com as originais obtidas no ANSYS. Os resultados mostraram-se conformes, com desvio de menos de $1 \%$ entre ambas as soluções.

O contato foi definido como um elemento de lacuna, através da definição de um novo material na interface entre pad e espécime, com coeficiente de fricção igual a 0.5. Isto significa, conforme apontam os autores, que cada passo da propagação da trinca os efeitos de contato do pad eram levados em consideração, com os fatores de intensidade de tensão sendo atualizados para cada incremento da trinca. Tal proposta visava solucionar a maioria dos problemas apresentados em estudos anteriores que utilizam técnica de submodelagem.

A análise de propagação de trincas requer a determinação do tamanho e da orientação das mesmas. O caminho da trinca foi representado pelo caminho curvilíneo composto por S segmentos de reta, como ilustrado na Figura 152. O tamanho inicial da trinca escolhido pelos autores foi de $0.01 \mathrm{~mm}$, com orientação de 45 graus. Enquanto o caminho foi obtido pela análise de elementos finitos realizada pelo ANSYS, o tamanho e a orientação iniciais foram obtidos experimentalmente. Os autores ainda acrescentam que, além dos testes experimentais realizados pelos mesmos, diversos outros estudos apontam que testes de fretting fatigue se iniciam na borda com esta orientação. O código FRANC2D/L, segundo os autores, modifica a cada passo incremental a malha de acordo com o algoritmo de Suhara-Fukuda, o qual, por sua vez, atualiza a geometria com a configuração da trinca e gera malhas triangulares como as ilustradas na Figura 153. Para se determinar a direção de crescimento da trinca, o código utiliza a teoria da tensão máxima tangencial proposta por Erdogan e Sith. O ângulo da trinca, para um i-ésimo passo é dado pela Equação 47:

$$
\theta_{i}=\theta_{i-1}+2 \tan ^{-1}\left(\frac{K_{I \operatorname{maxi}}-\sqrt{K^{2} I \operatorname{maxi}+8 K^{2} I I \operatorname{maxi}}}{4 K_{I I \operatorname{maxi}}}\right)
$$

onde $K_{\text {Imaxi }}$ e $K_{I I}$ maxi são os máximos fatores de intensidade de tensão no i-ésimo passo correspondente aos modos de propagação de trincas, Modos I e II, respectivamente, na 
carga máxima. Desta forma, a trajetória da trinca é desenvolvida em passos incrementais para uma condição de carregamento utilizando critério de tensão máxima. Ademais, o crescimento da trinca é atribuído pelo Modo I de fator de intensidade de tensão, calculados, neste estudo, pelas técnicas integrais de Rybicki e Kamminen. Os valores obtidos foram então usados em um crescimento regido por uma função sigmoidal a fim de se determinar a vida de propagação à trinca. Por fim, o código utilizou o método $\mathrm{da} / \mathrm{dN}$ para calcular o crescimento da trinca.

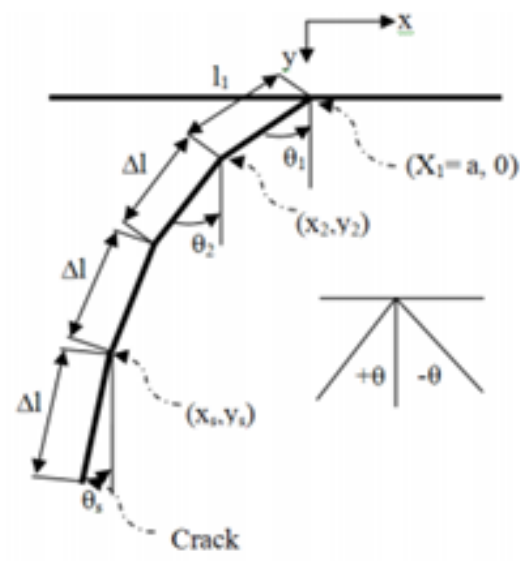

Figura 152 - Trajetória de crescimento da trinca (Fonte: TALEMI et al. 2011)

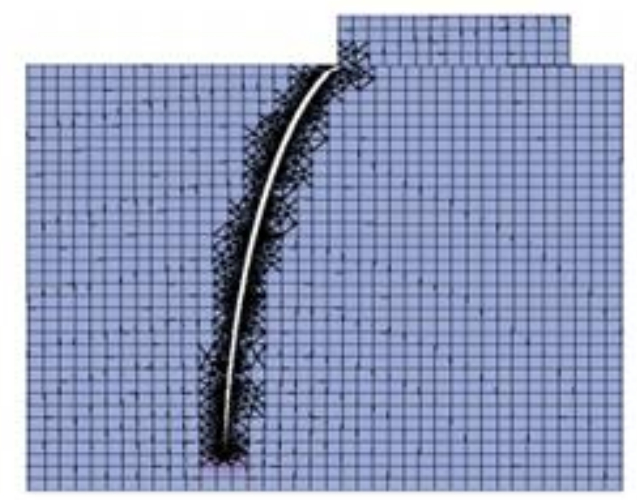

Figura 153 - Trinca inicial no FRANC2D/L (Fonte: TALEMI et al. 2011)

As simulações foram validadas através da comparação entre os tamanhos das trincas e os números de ciclos correspondentes de ambos os testes experimental e numérico. A diferença máxima observada entre os resultados foi de $24 \%$, o que os autores julgaram ser normal neste contexto de fadiga. Acrescentam, ainda, que vários parâmetros de fretting não foram modelados, como o desgaste, condições ambientais, mudanças de coeficiente de atrito por conta de detritos acumulados na região de contato, etc. Os diferentes resultados são apresentados na Figura 154. 


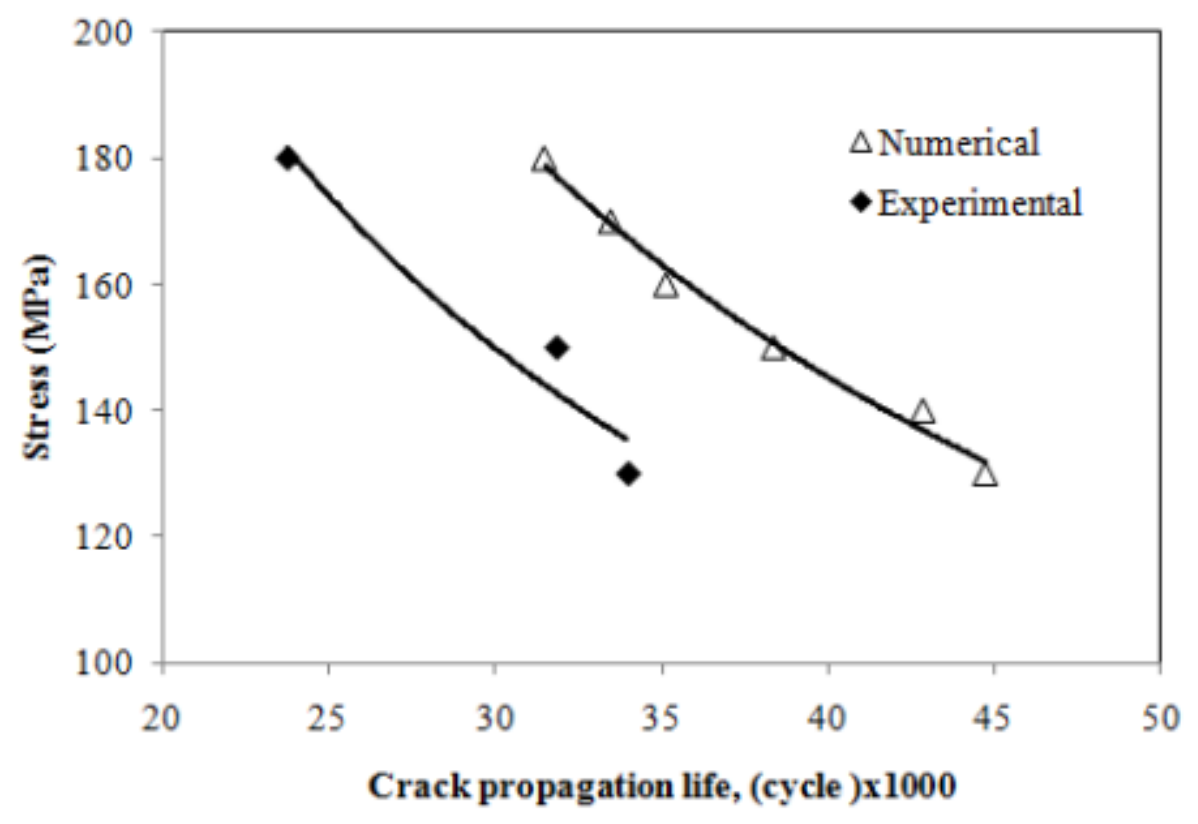

Figura 154 - Comparação entre os crescimentos da trinca experimental e numérico (Fonte: TALEMI et al. 2011)

Já em relação à influência da geometria do pad na propagação de trincas, os autores variaram a geometria dos pads de bi planar para esfera-plano a fim de determinala. Alguns dos pads clássicos são ilustrados na Figura 136, onde se percebe que a tensão máxima de von Mises é máxima na região de contato no baso esfera-plano, enquanto no outro, a supracitada tensão é máxima na borda do pad.

Os efeitos das dimensões dos pads nas propagações de trincas são ilustrados na Figura 155. É perceptível que a vida à fretting fatigue aumenta quando a largura do pad aumenta para ambos os tipos de geometria investigadas. Contudo, fica evidente que o caso esfera-plano é mais crítico em fretting fatigue. 


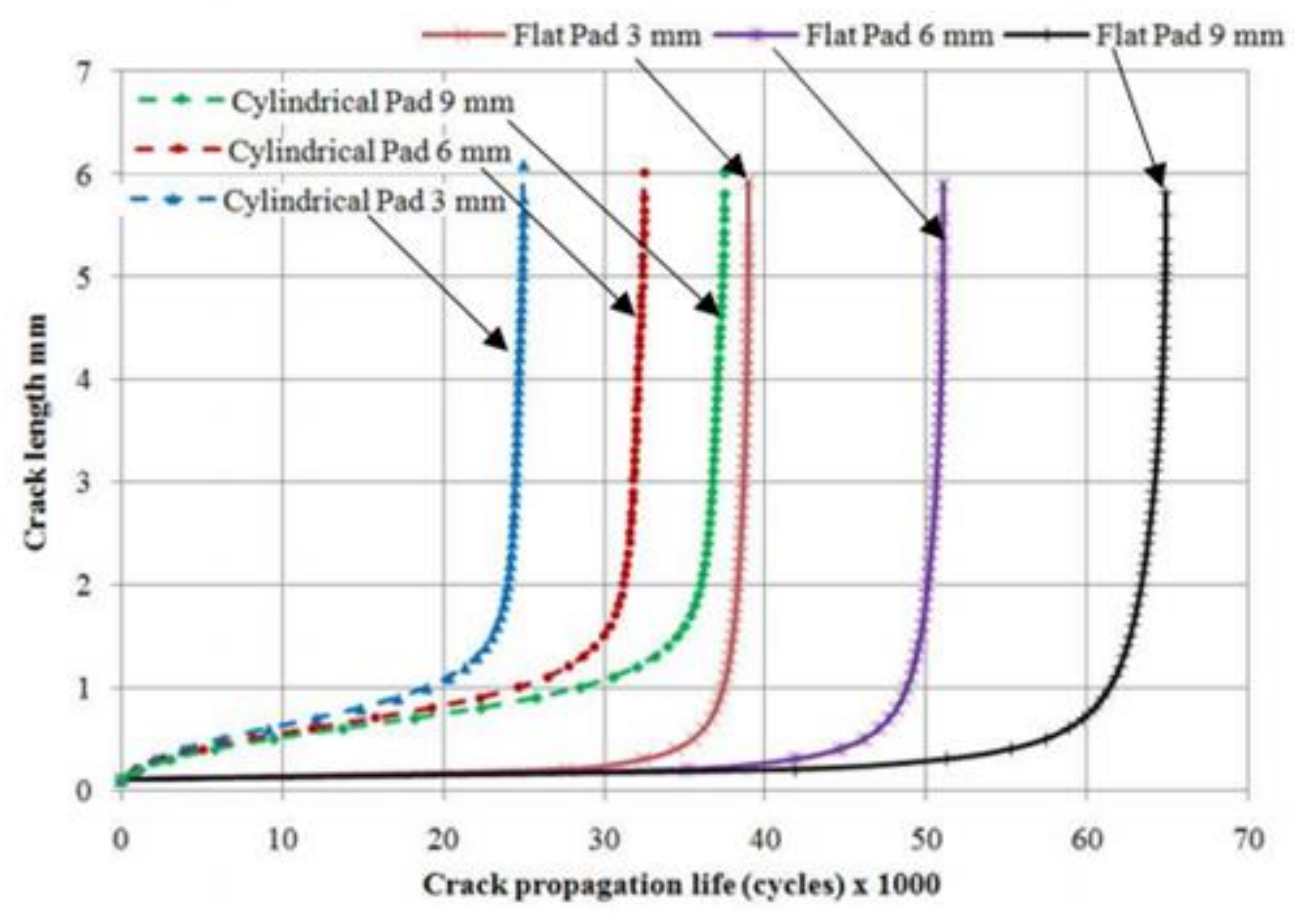

Figura 155 - Efeito da dimensão do pad na propagação da trinca (Fonte: TALEMI et al. 2011)

Por fim, os resultados, segundo os autores, permitem estimar o crescimento e orientação das trincas com razoável precisão. 


\subsubsection{MODELO PROPOSTO POR MUTOH et al. (2010)}

Os autores realizaram tanto análises numéricas como experimentais. A análise experimental contou com a abordagem clássica onde um espécime sob uma carga cíclica sofria tensões de aperto simétricas em seu centro, no caso, com pads planares.

O modelo numérico utilizou elementos finitos através do software MARC. Foram calculadas as distribuições de tensão e os deslizamentos parciais entre o espécime e o pad. O modelo idealizado é ilustrado na Figura 156, onde se percebe o uso de elementos quadrilaterais. Como as tensões nas bordas do contato são influenciadas pelo tamanho da malha, os autores calcularam a relação entre a tensão tangencial e o tamanho da malha, como mostrado na Figura 157.

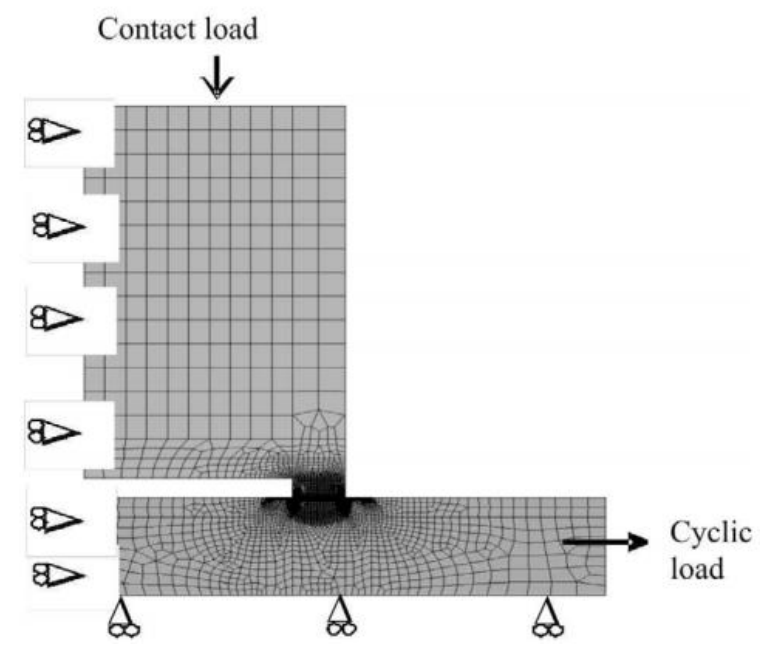

Figura 156 - Modelo numérico proposto (Fonte: MUTOH et al. 2010)

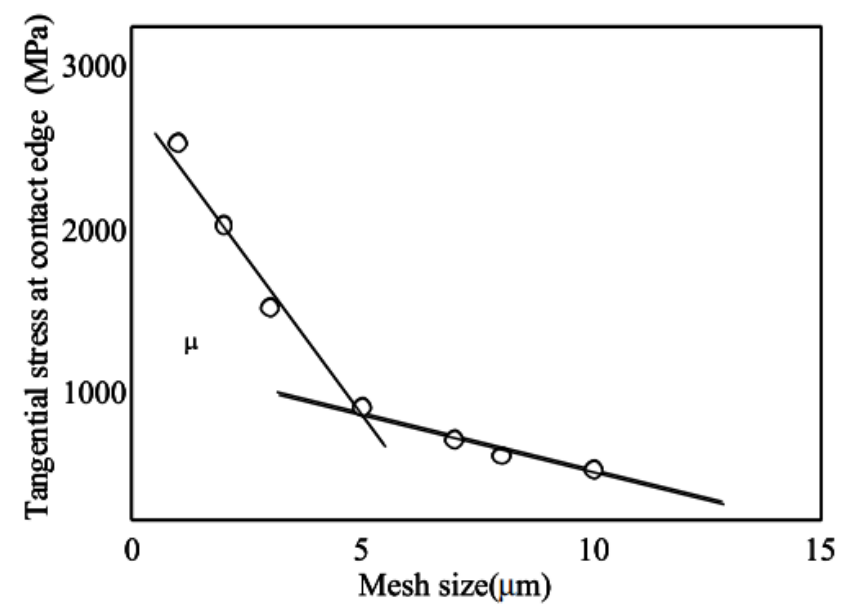

Figura 157 - Relação entre tensão tangencial na borda do contato e tamanho da malha (Fonte: MUTOH et al. 2010) 
Da Figura 157, nota-se que o ponto de interseção entre as retas se dá em $5 \mu \mathrm{m}$. Assim sendo, este foi o tamanho final escolhido para a malha na região de contato neste estudo. As condições de contorno foram aplicadas usufruindo-se das propriedades axissimétricas do modelo, permitindo redução do custo computacional. O corpo foi considerado como linear elástico. As cargas foram aplicadas em três etapas: Pressão de contato no topo do pad para se estabelecer o contato, carga máxima cíclica aplicada, carga mínima cíclica aplicada. O deslocamento parcial foi determinado como as diferenças relativas dos deslocamentos horizontais dos pontos de contato entre o pad e o espécime. O coeficiente de fricção utilizado foi de 0.7 .

Os autores estudaram a influência das alturas dos pés dos pads em suas respectivas rigidezes e como isso influenciava na vida ao fretting. Embora a rigidez para o caso de um pad plano (altura de pé nula) fosse maior que para o caso de $3 \mathrm{~mm}$, a força tangencial e o coeficiente tangencial eram os menores de todos os pads testados.

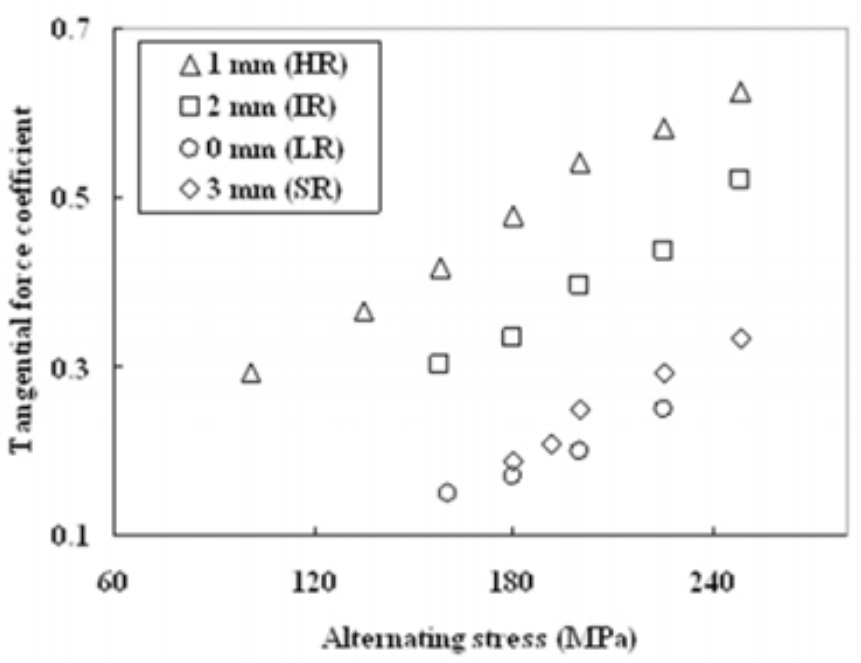

Figura 158 - Efeitos da rigidez do pad no coeficiente de força tangencial (Fonte: MUTOH et al. 2010)

Os efeitos das alturas dos pés dos pads nas tensões tangenciais na borda de contato são demonstrados na Figura 159. É possível ver que em tensões tangenciais nos pads aumentam com o aumento da rigidez (ou com a diminuição da altura do pé). Novamente, os autores ressaltam que, embora a rigidez do pad plano seja maior que a do pé com pé de $3 \mathrm{~mm}$, as tensões tangenciais no caso plano foram as menores encontradas. 


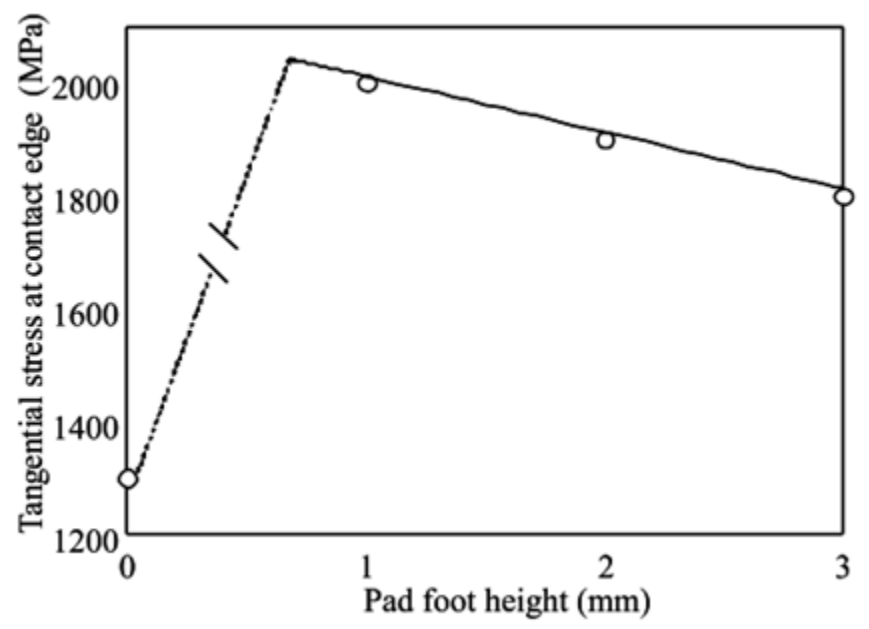

Figura 159 - Efeito da altura do pé do pad sobre a tensão tangencial no contato (Fonte: MUTOH et al. 2010)

A Figura 160 ilustra os efeitos das alturas supramencionadas nas tensões compressivas na borda do contato. A diminuição da rigidez, neste caso, aumenta as tensões compressivas. O comportamento para o pad plano é, novamente, atípico.

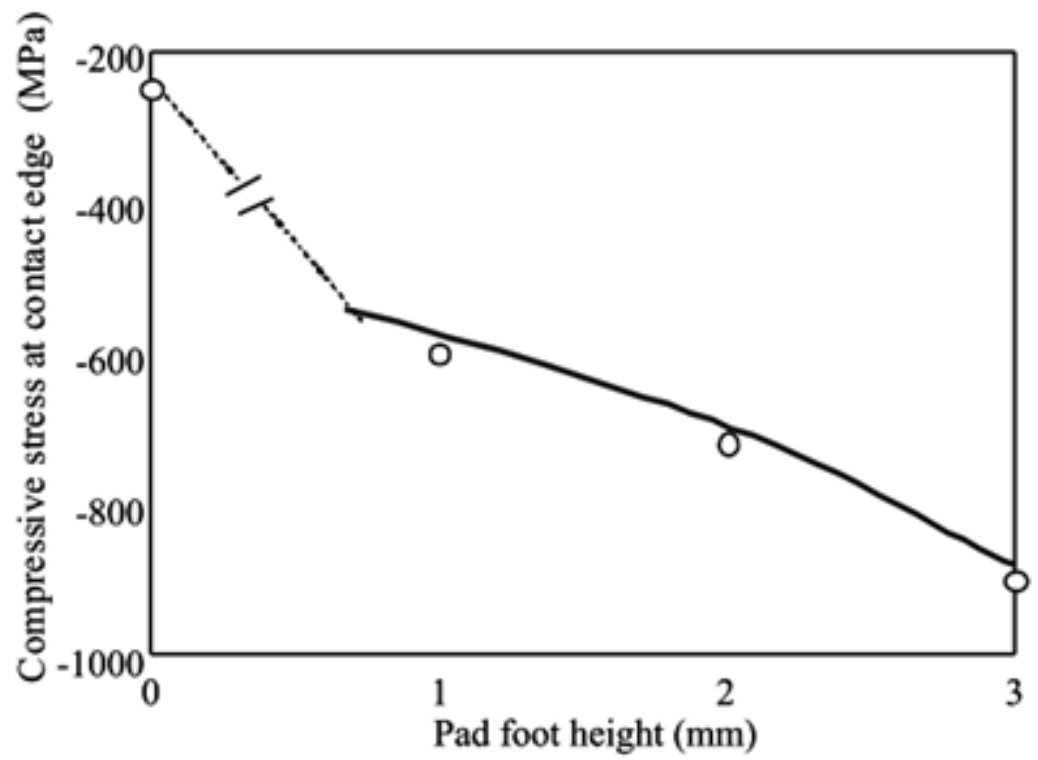

Figura 160 - Efeito da altura do pé do pad na tensão compressiva na borda do contato (Fonte: MUTOH et al. 2010)

A Figura 161, por sua vez, mostra os efeitos da altura do pé do pad nos deslizamentos relativos na zona de contato. O aumento da altura do pé, a amplitude de deslizamento diminui. Mais uma vez, o pad plano tem comportamento anômalo. 


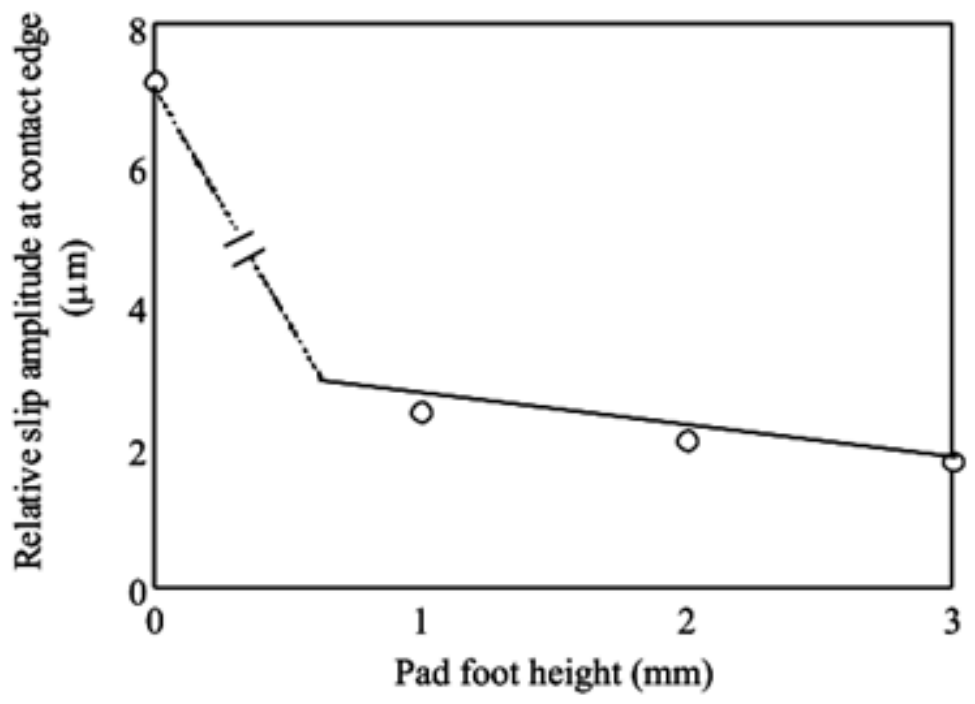

Figura 161 - Efeito da altura do pé do pad na amplitude de deslizamento parcial na borda do contato (Fonte: MUTOH et al. 2010)

Os autores observaram que as tensões compressivas geradas embaixo da borda de contato diminuem com o aumento da rigidez do pad. A presença das tensões compressivas possui um efeito benéfico na vida ao fretting, uma vez que as tensões compressivas presentes na ponta da trinca retardam o seu crescimento (MIYAGAWA et al., 1989).

Segundo estudos como os de NAKAZAWA et al. (2003), se a tensão tangencial próxima a borda do contato for maior, o dano de superfície também será mais significante e a nucleação da trinca ocorrerá mais rapidamente SPINK (1990). Diversos estudos SABELKIN et al. (2004) e MUTOH et al. (1988) apontam que o dano superficial será maior com o aumento da amplitude de deslizamento relativo.

Também é sabido que uma combinação de baixa tensão tangencial e alta tensão compressiva na borda do contato aumentará a vida à fretting fatigue e o caso oposto a reduzirá. 


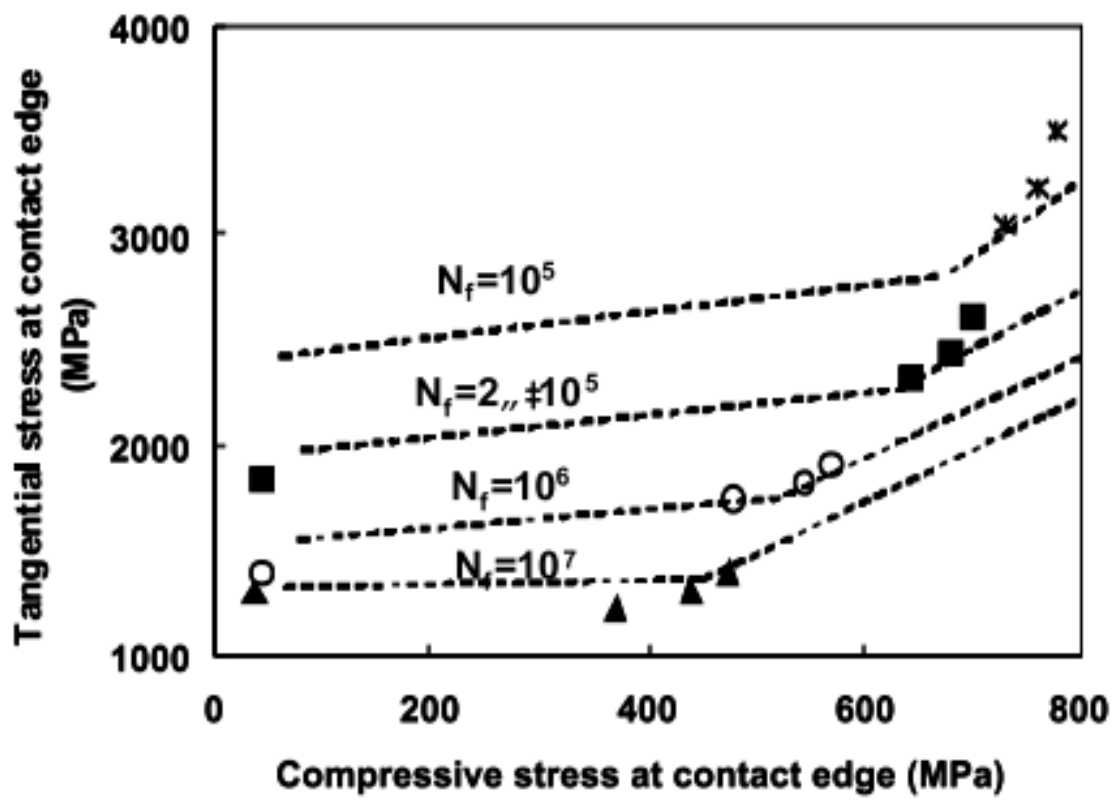

Figura 162 - Tensão tangecial versus tensão compressiva na borda do contato (Fonte: MUTOH et al. 2010)

Por fim, as curvas de tensão tangencial versus tensão compressiva na borda do contato foram obtidas, assim como suas vidas respectivas. Os resultados são demonstrados na Figura 162. Os resultados obtidos são uma combinação das análises numérica e experimental, sendo possível estimar a vida ao fretting independente da geometria do pad, caso as tensões tangenciais e compressivas no contato sejam estimadas por elementos finitos. 


\subsubsection{MODELO PROPOSTO POR GINER et al. (2011)}

Os autores implementaram um modelo por elementos finitos expandidos (XFEM) no programa ABAQUS a fim de se determinar a combinação de iniciação e de propagação de trinca. A validação foi realizada através da comparação com testes encontrados na literatura.

A fim de se determinar a nucleação da trinca, os autores utilizaram o método de fadiga multiaxial com critério de Fatemie-Socie. A segunda parte, referente à propagação da mesma, seguiu as leis de Paris e teve com base uma abordagem com funções de peso.

Conforme apontam os autores, o uso das funções de peso possui fatores limitantes ao não considerar as interações entre trinca e contato, com as eventuais mudanças nas condições de contato e seus efeitos limítrofes. Soluções analíticas, no entanto, requereriam um conhecimento prévio da configuração de distribuição de tensão. Naturalmente, a fim de se obter uma metodologia prática geral, os cálculos dos fatores de intensidade de tensão são calculados numericamente.

A escolha dos autores em utilizar X-FEM ao invés de FEM deu-se por conta do custo envolvido nas intervenções necessárias de adaptação das malhas para os diversos tamanhos de trincas. Os mesmos consideraram que uma análise em X-FEM, por necessitar de apenas uma malha para todos os casos, tornaria a análise da vida do espécime mais eficiente. O cálculo de vida foi feito pela Equação 48:

$N_{p}=\int_{a_{c}^{i}}^{a_{c}^{f}} \frac{d a}{f\left(\Delta K\left(a_{c}\right)\right)}$

onde $\mathrm{f}(\Delta K)$ representa a lei de crescimento da trinca. O modo de propagação de trinca é presumido como Modo I e que o intervalo de fator de intensidade de tensão é igual ao $\mathrm{K}$ máximo, visto que o mínimo é nulo e ocorre sem o crescimento da trinca em parte do carregamento.

A vida total então foi calculada como a soma do número de ciclos para se iniciar uma trinca de tamanho pré-definido $a_{c}$ (ilustrado pela curva Ni da Fig. 163) e a quantidade de ciclos para propagar tal trinca até a falha do material (demonstrado pela curva Np da Fig. 163). Logo, a vida total definida por Nt, onde seu valor mínimo na curva dá a vida mais curta da peça. Dada a interdependência de ambas as curvas e a 
profundidade em que ocorre a trinca, o modelo é de iniciação de trinca com tamanho variável, sendo o número de ciclos total escolhido como vida o que prover o menor valor em sua soma total.

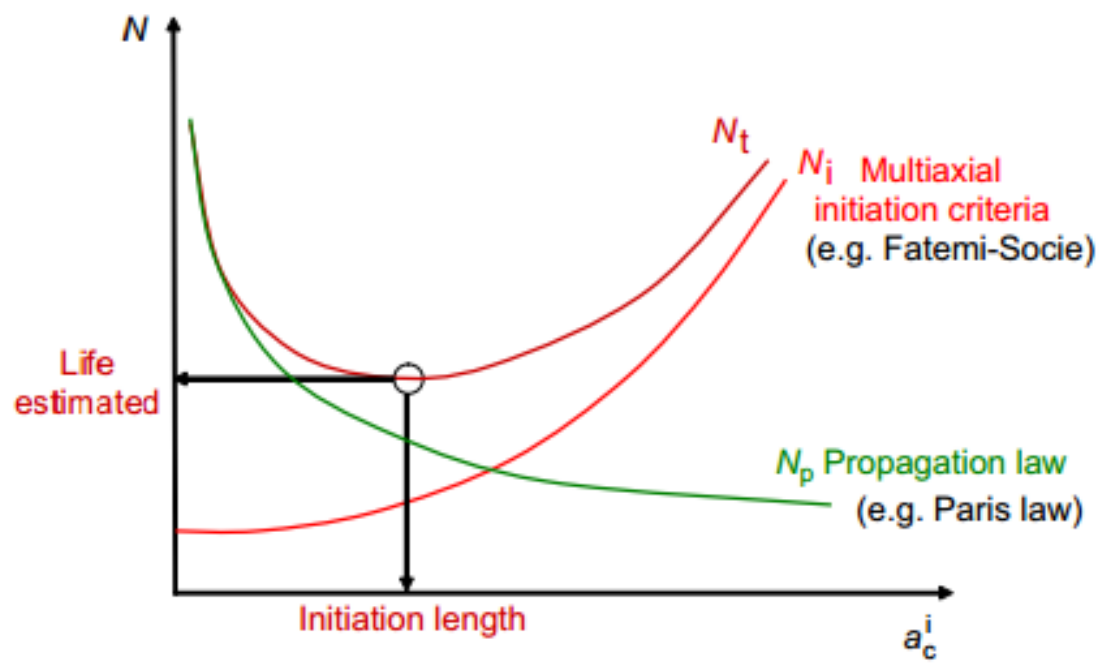

Figura 163 - Estimativa de v ida total e definição do tamanho de trinca inicial (Fonte: GINER et al. 2011)

Os modelos numéricos foram então gerados, conforme o esboço na Figura 164. O espécime possuía tamanho fixo, mas o pad teve seu raio variado de acordo com o teste. O coeficiente de fricção seguindo a lei de Coulomb também era variável.

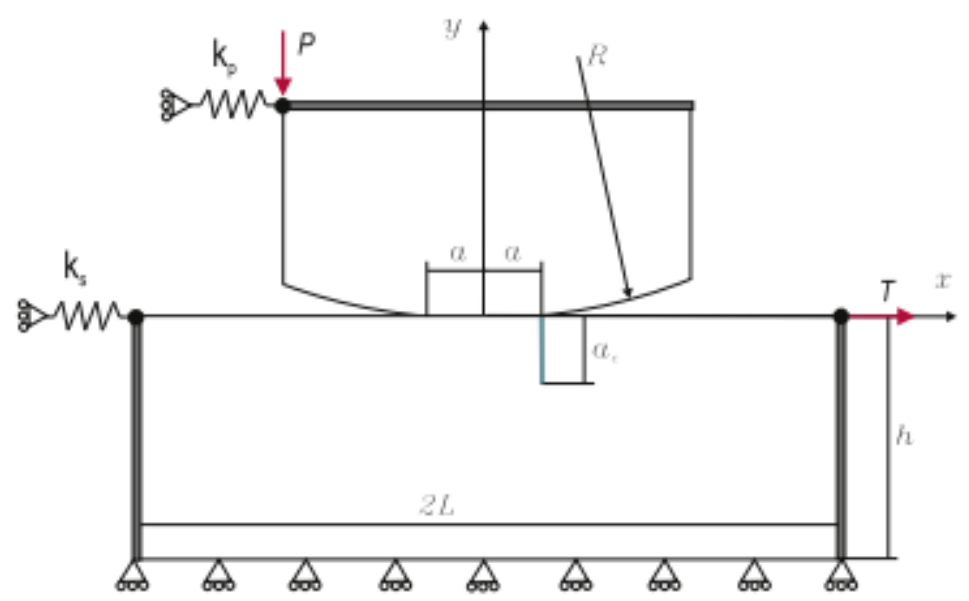

Figura 164 - Geometria dos modelos numéricos (Fonte: GINER et al. 2011)

As propriedades de rigidez impostas às molas variaram de acordo com as razões de cargas utilizadas e são apresentadas no estudo. A carga era aplicada em duas etapas, sendo a primeira referente à aplicação de $\mathrm{P}$ e a segunda à carga $\mathrm{T}$. Os autores tiveram o trabalho de aplicar a carga em pequenos incrementos de tempo, visto a não linearidade do contato. 
A análise numérica sem trincas foi então efetuada, onde os autores obtiveram os parâmetros de Fatemi-Socie (FS), conforme mostra a Figura 165.

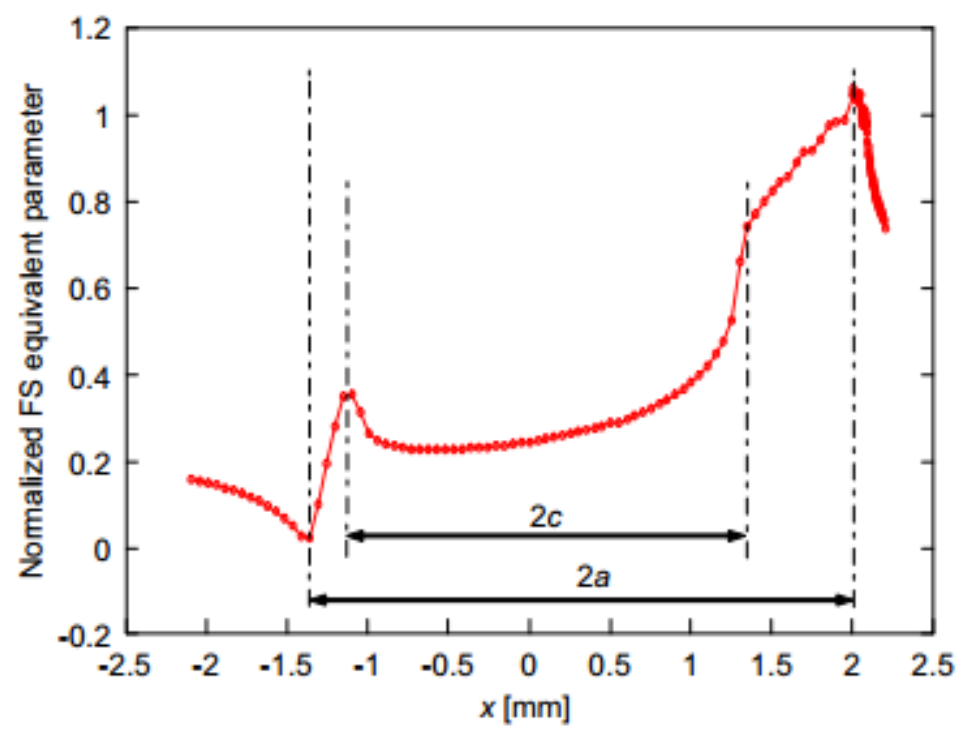

Figura 165 - Fator de intensidade de tensão normalizado para a superfície do teste 7 (Fonte: GINER et al. 2011)

A análise X-FEM realizada no ABAQUS é então ilustrada na Figura 166:

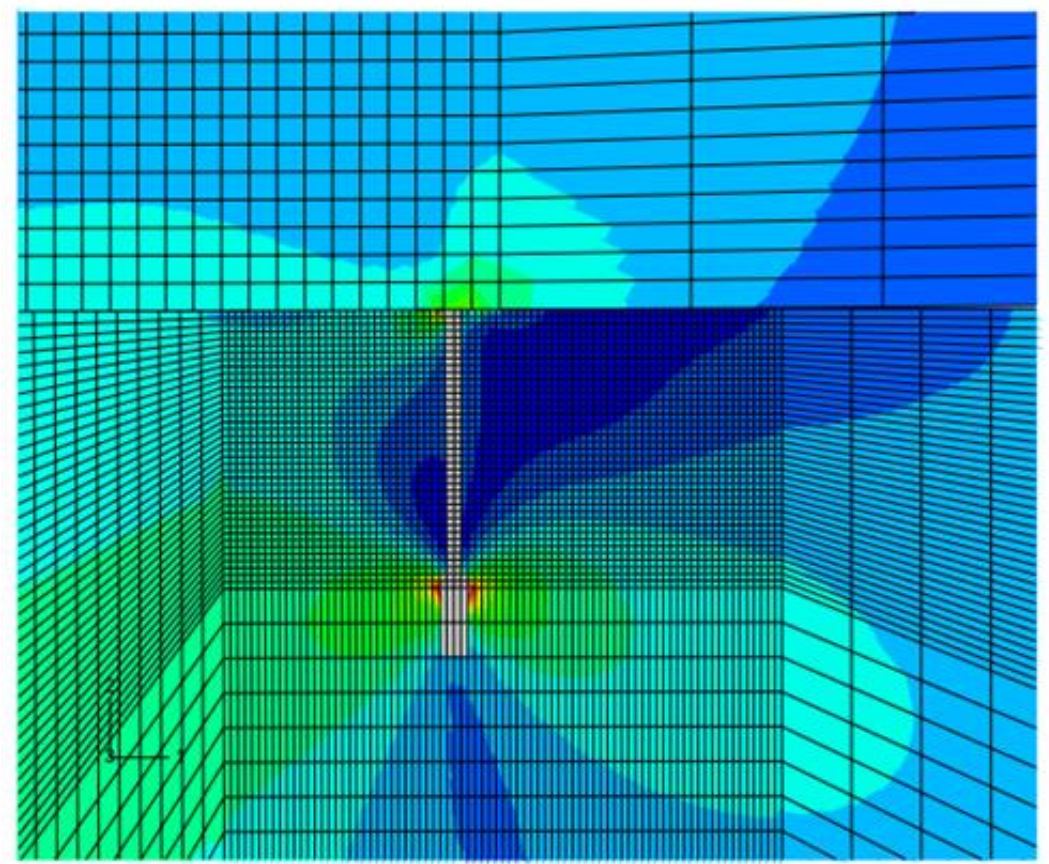

Figura 166 - Contorno de von Mises para o teste 1 (Fonte: GINER et al. 2011)

É possível observar que as distribuições de tensão são afetadas pelo contato e pelo tamanho da trinca. 
A Figura 167 ilustra os valores de $K_{I}$ obtidos com X-FEM em função do tamanho da trinca para dois testes da literatura com os quais os autores compararam seus resultados. Os resultados analíticos utilizando função de peso (WF) com trinca única sob tensão (SENT) também são apresentados na mesma figura.

Os autores ressaltam a boa concordância entre os resultados para X-FEM e WF para trincas bem pequenas, apontando que isto era esperado devido à pequena influência da trinca na distribuição do contato. Para trincas maiores, as soluções divergiram-se em torno de 5 a $10 \%$, ao que foi atribuído o efeito das interações entre contato e trinca ignorado no uso de WF. No caso de trincas ainda maiores, tal interação não é notável, mas as diferenças provêm de que as WF consideram as distribuições de pressão como uniformes, o que não ocorre na realidade.
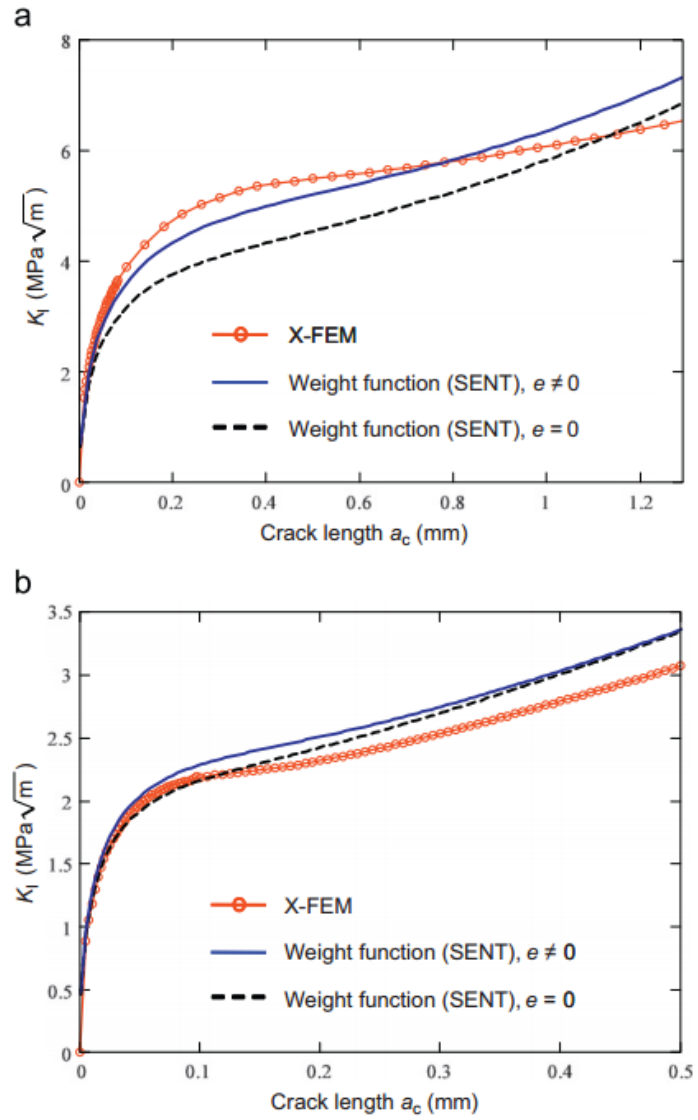

Figura 167 - Valores de Ki versus tamanho da trinca para o (a) teste 7 e (b) teste 4 (Fonte: GINER et al. 2011)

Outro fator considerável é a influência das zonas de grude $\boldsymbol{e}$ por conta das tensões envolvidas. A excentricidade $\boldsymbol{e}$ tende a diminuir com o aumento da trinca, o que faz com que as estimativas para $K_{I}$ tenham que ser reavaliadas para a correta estimativa das tensões cisalhantes. Os efeitos da excentricidade são apresentados na Figura 167. 
Com os fatores de intensidade de tensão calculados para os intervalos das trincas, os autores então puderam calcular a vida ao fretting para ambos os testes supramencionados. Os resultados em X-FEM mostraram-se ligeiramente mais próximos dos resultados experimentais comparados. Embora as vidas encontradas tenham sido similares, a diferença na vida à propagação ficou em torno de $20 \%$.

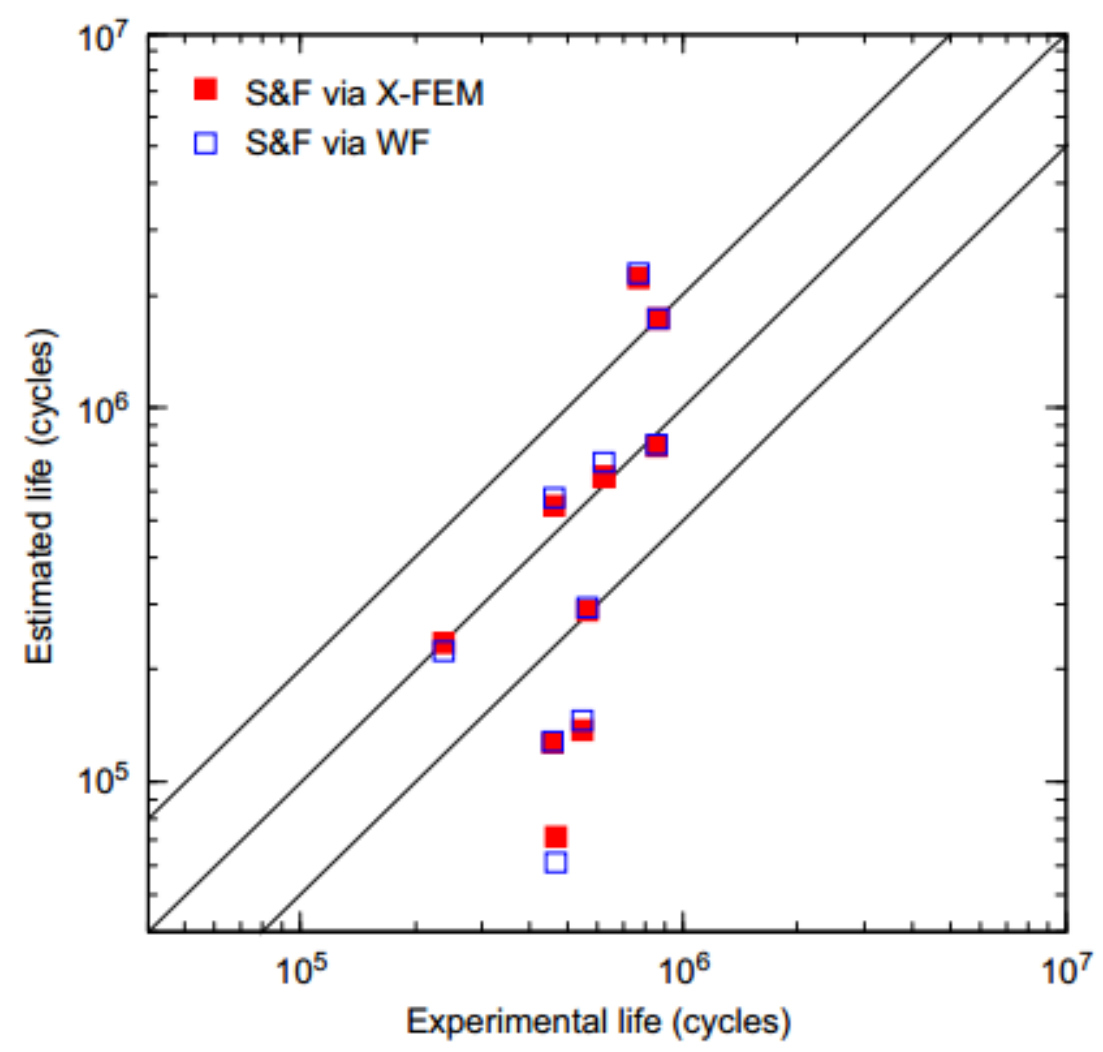

Figura 168 - Correlação entre valores estimados e experimentais para o teste S\&F (Fonte: GINER et al. 2011)

No caso do teste $A \& N$, os resultados obtidos pela metodologia proposta tendiam, de uma maneira geral, a ser mais próximos das vidas reais, conforme observado na Figura 169. 


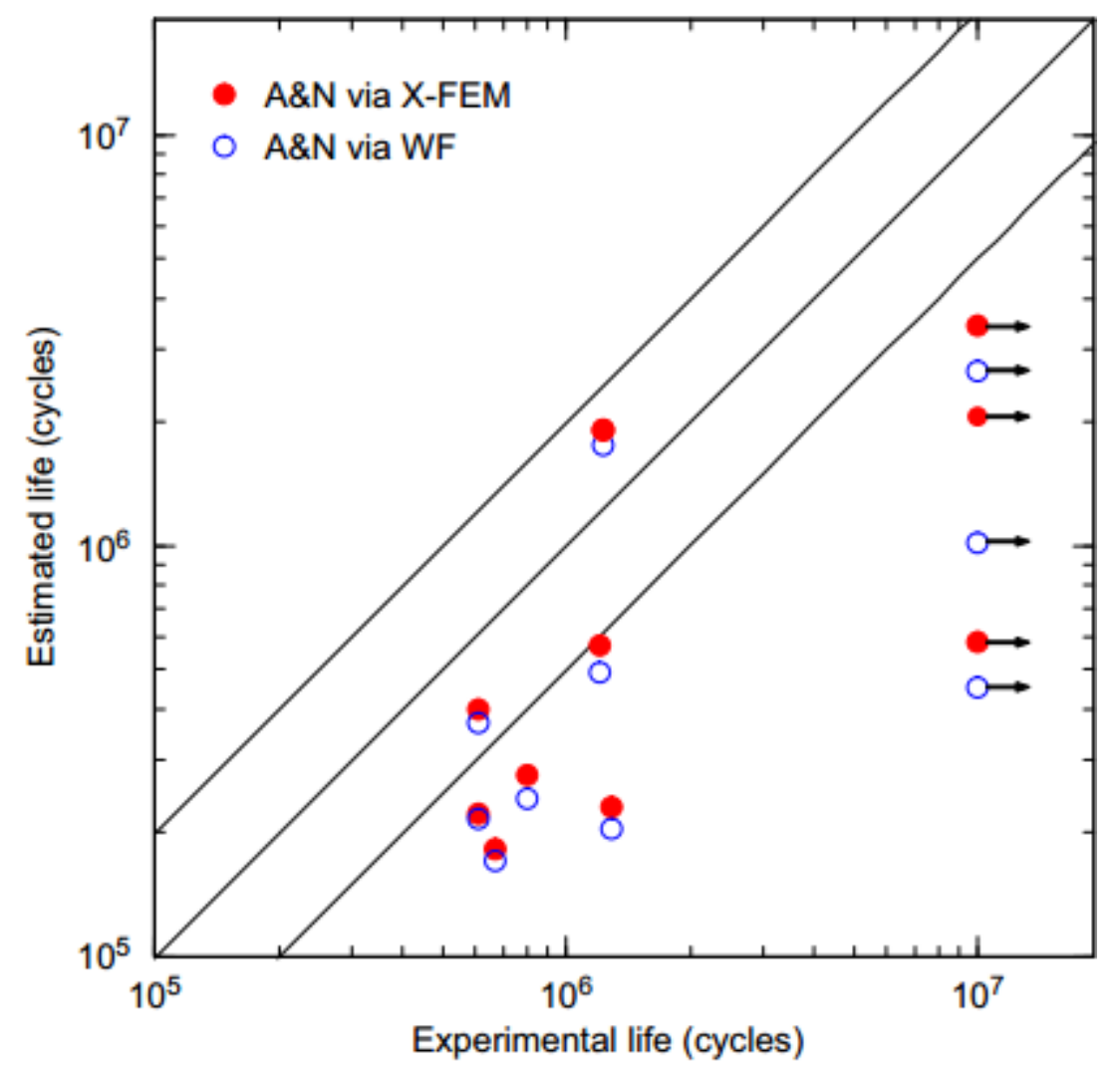

Figura 169 - Correlação entre valores estimados e experimentais para o teste A\&N (Fonte: GINER et al. 2011)

Este estudo apresentou uma forma satisfatória de simular contatos cilíndricos em testes de fretting fatigue através de X-FEM. A vantagem demonstrada em relação às funções de peso foi a incorporação ao modelo das interações da trinca e superfície. $O$ tempo despendido em evitar a reconstrução de malhas para as diferentes configurações das trincas mostrou-se importante, com os resultados finais obtidos sendo levemente mais precisos do que os obtidos por uso de função de peso. 


\subsubsection{MODELO PROPOSTO POR LÉVESQUE et al. (2011)}

A análise de elementos finitos foi elaborada no ABAQUS, onde os autores modelaram o contato entre o condutor e o engate de uma pá eólica. Uma vez que a dimensão do engate era muito superior à do fio, o mesmo foi considerado infinito.

Como simplificação, foi considerado o caso de um fio simples e um engate simples comercial. O fio simples reproduz o caso de contato entre o condutor e o engate com ângulo de 0 grau. Assim, tal angulação permite tirar proveito da simetria entre os planos e reduzir o custo da simulação, a qual teve geometria reduzida a um quarto do original, até porque, segundo os autores, ZHOU (1995) demonstrou que os efeitos de fretting ocorrem apenas de um lado do contato.

Para o carregamento, os autores basearam-se em estudos experimentais prévios e consideraram que a alternância da carga aplicada poderia ser substituída no modelo por uma carga de tração alternada. Em uma primeira etapa, o fio foi submetido a uma carga de tensão, seguindo, então, para uma carga de aperto submetida a uma área central de dimensão determinada experimentalmente. O módulo da carga foi determinado por iteração até que o tamanho de contato atingisse aproximadamente a área supracitada. Por fim, aplicou-se a carga alternada com as seguintes condições de contorno:

1) plano de simetria em $X Z(U y=0)$;

2) Plano de simetria em $\mathrm{YZ}(\mathrm{Ux}=0)$;

3) O plano paralelo a XY e que passa no eixo do fio é um plano de simetria (Uz=0); 


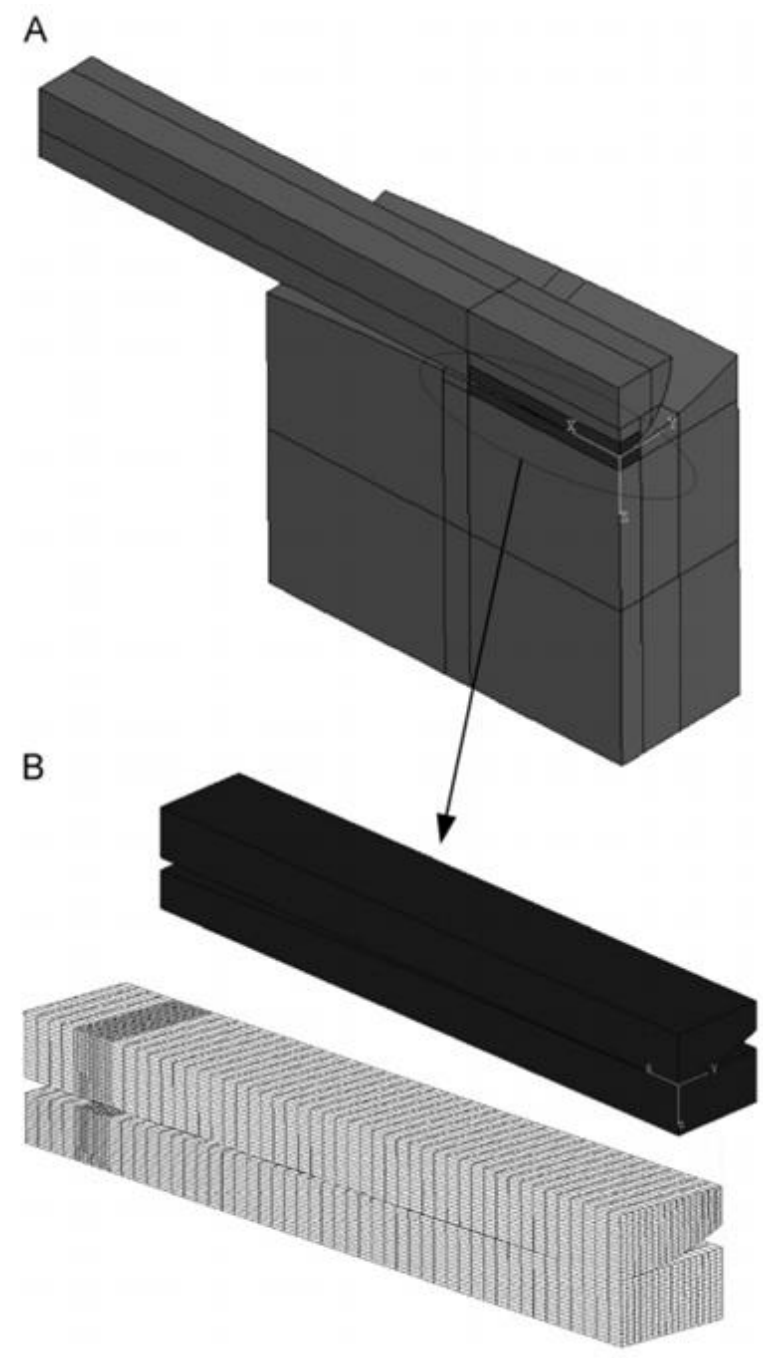

Figura 170 - Modelo geométrico global (a) e submodelo (b) (Fonte: LÉVESQUE et al. 2011)

Maiores detalhes das cargas e deslocamentos impostos encontram-se no artigo original. Os autores utilizaram o algoritmo embutido do ABAQUS de mestre-escravo, onde a superfície escrava era a do fio. A opção de deslizamento finito foi adotada, tendo sido a de deslizamento pequena também testada. Contudo, esta opção apresentou resultados insatisfatórios, com penetração de uma superfície na outra. A superfície normal ao contato foi formulada utilizando-se o multiplicador de Lagrange quando ausente de fricção. Quando o coeficiente de fricção foi embutido, as condições de contorno mostraram-se conflitantes com tal multiplicador a formulação de penalidade foi utilizada com coeficiente de fricção equivalente a 0,7 .

Devido à estabilidade encontrada no modo de resolução implícita, esta foi adotada. Por conta da complexidade e custo envolvidos em uma análise tridimensional de elementos finitos, os autores optaram por utilizar técnicas de submodelagem. $\mathrm{O}$ 
formato geométrico das peças adotados no primeiro submodelo foi o clássico esferaplano, com propriedades elastoplásticas do material.

Os autores puderam concluir com os resultados obtidos que a análise elástica não era adequada pra o contato no caso, pois a área de contato era demasiadamente larga quando comparada com o tamanho dos corpos, o que invalida a teoria dos meio-planos. A comparação com a solução bidimensional de contatos cilíndricos mostrou a importância de uma superfície livre no fio.

Ademais, o modelo elastoplásticos desenvolvido mostra discrepâncias quando comparado com os envolvendo esferas na literatura. Acredita-se que isso seja em decorrência do tamanho da área onde ocorre plasticidade. O modelo de microcontato, por exemplo, previa forças de contato de $12-20 \%$ maiores que os obtidos com o modelo de elementos finitos.

A amplitude de deslizamento encontrada no modelo de elementos finitos foi comparada a de solução elástica de contato esférico. A magnitude dos deslizamentos teve a mesma ordem de grandeza, mostrando-se uma boa estimativa rápida para quantificar o deslizamento. No entanto, a área de deslizamento foi considerada demasiadamente pequena se comparada com o observado em condutores post-mortem. 


\section{MODELO PROPOSTO}

\subsection{O PROBLEMA}

O fenômeno de fretting está presente em diversas estruturas de engenharia, como em peças de motores e turbinas, em conexões aparafusadas e rebites, em eixos de rolamento e fios de cabos. O trabalho aqui proposto visa fornecer uma solução genérica para diversos casos de fretting e pode ser entendido como uma simplificação do problema físico demonstrado na Figura $2 \mathrm{~b}$.

Por conta do alto custo envolvido em estudos experimentais de modelos reais nos quais o fenômeno está presente, foi desenvolvido, neste trabalho, um modelo baseado em elementos finitos através do software comercial ANSYS. O modelo criado fez proveito de simetria axial no eixo $\mathrm{x}$, um vez que apenas os efeitos de carga de remota de fadiga foram estudados, sendo demonstrado na Figura 171.

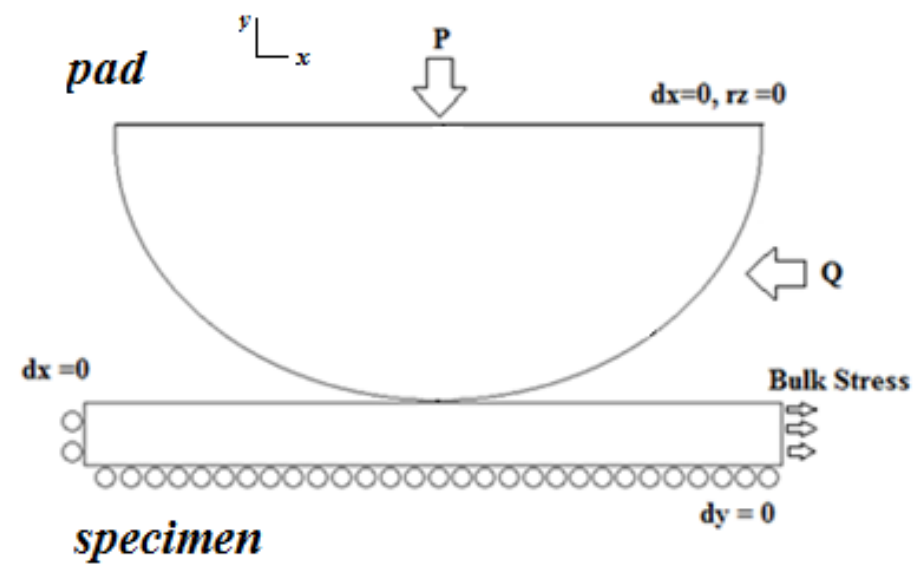

Figura 171 - Simplificação geométrica adotada

\subsection{VISÃO GERAL DO MODELO}

O objetivo primário do modelo proposto é visualizar os comportamentos dos fatores concentradores de tensão de acordo com a variação de alguns parâmetros relevantes envolvidos no fenômeno: propriedades dos materiais, dimensão do pad, carga remota de fadiga e coeficiente de atrito entre as superfícies. Para que se fizesse esta análise, foi utilizada análise numérica por meio de elementos finitos no ANSYS. Afim de se averiguar os efeitos de uma propriedade específica nos $K_{p}$, algumas propriedades da simulação foram fixadas no modelo numérico e a propriedade a ser estudada sofreu então variações, como é ilustrado esquematicamente na Figura 172: 


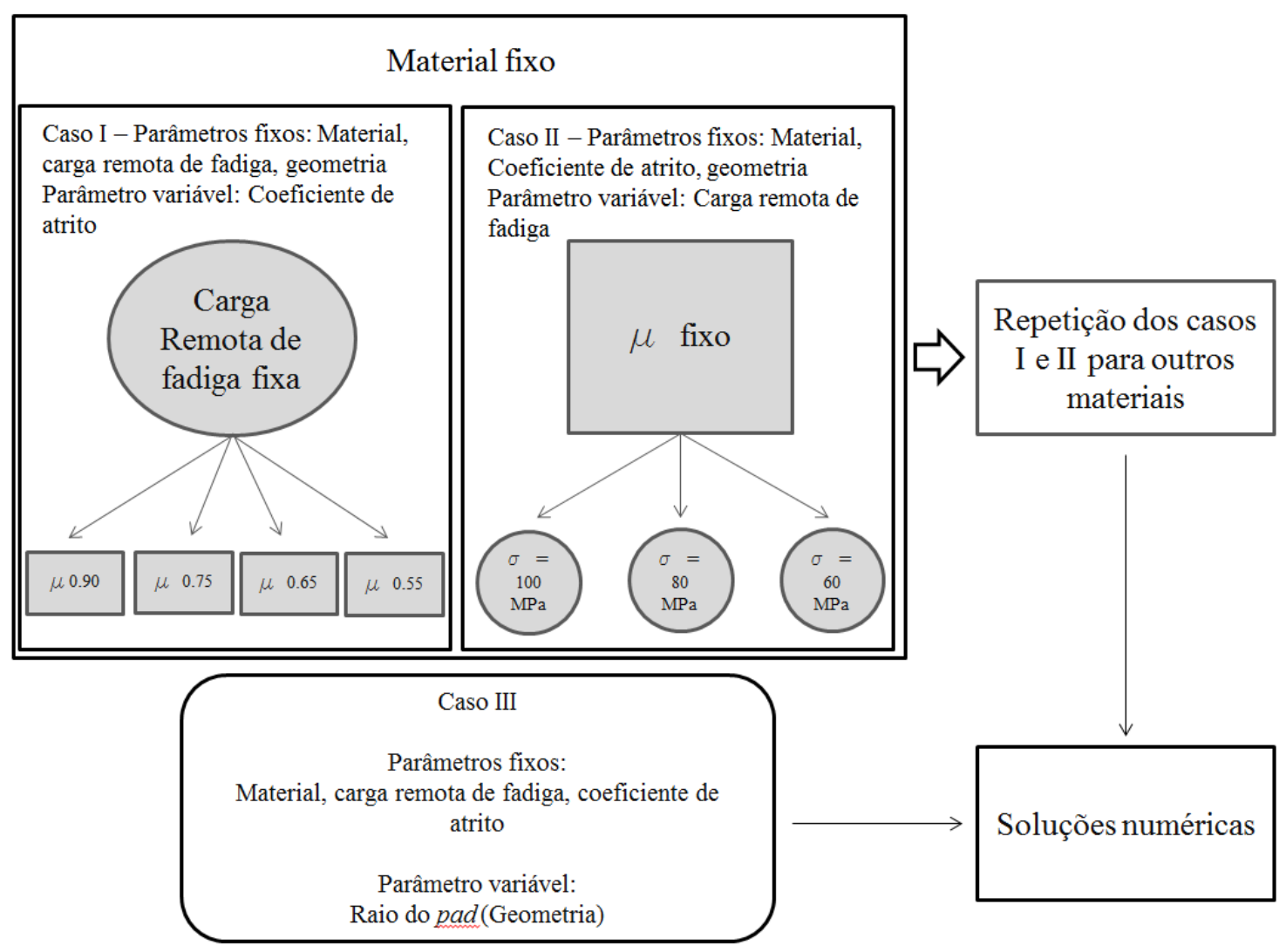

Figura 172 - Resumo esquemático dos parâmetros de entrada para a simulação numérica

Como pode ser visualizado na Figura 172, para cada material, para cargas remotas de fadiga de $\sigma=100,80$ e $60 \mathrm{MPa}$, os coeficientes de atrito entre as superfícies foram estabelecidos em $\mu=0,90,0,75,0,65$ e 0,55 , totalizando em 12 resultados numéricos para cada material. Os critérios para as escolhas desses valores são elucidados a seguir. Foram escolhidos três materiais para ser estudados: aço, titânio e alumínio, os quais são amplamente empregados em componentes de engenharia onde o fretting está presente. Às 36 simulações numéricas geradas, foi acrescida mais uma representando o terceiro caso, onde apenas a geometria do pad foi alterada.

As etapas posteriores à simulação numérica e a visão geral do modelo são então esquematicamente ilustradas na Figura 173: 


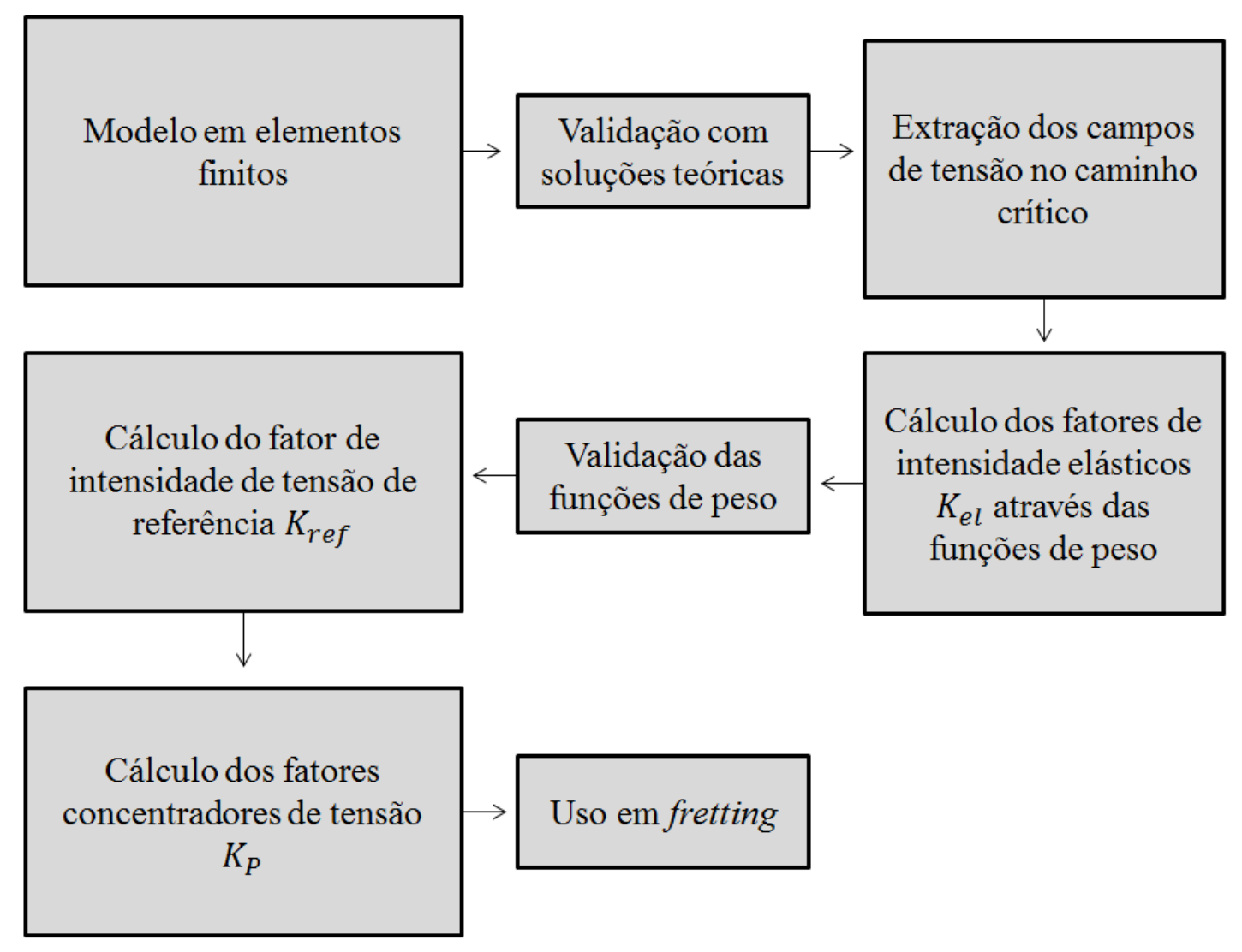

Figura 173 - Visão geral do modelo

Por tanto, a primeira etapa consistiu em elaborar o modelo em elementos finitos, cujos detalhes são explicados na seção 4.4. Para uma mesma geometria determinada, todos os parâmetros estudados foram fixados, exceto um deles, pois assim poder-se-ia estabelecer uma relação entre o parâmetro variável e sua respectiva influência em $K_{p}$. Os parâmetros estudados foram coeficiente de atrito, carga remota de fadiga, propriedades elásticas dos materiais e raio do pad. Outros parâmetros envolvidos no fenômeno de fretting foram pré-estabelecidos e não variaram neste estudo, como a largura e espessura do espécime e a carga de aperto. Os resultados obtidos numericamente foram então validados usando as soluções teóricas elaboradas por NOWELL \& HILLS (1987). Com resultados satisfatórios, prosseguiu-se para a extração dos campos de tensão em trajetória retilínea sob o ponto crítico da superfície do espécime, o qual será demonstrado mais detalhadamente na seção 4.7. As tensões obtidas permitiram, então, o cálculo dos fatores de intensidade de tensão elástico $K_{e l}$ através das funções de peso, descrito mais detalhadamente na seção 4.8. Uma validação numérica foi então elaborada comparando-se os resultados aos obtidos por TADA et al. (2000). Estabelecendo-se o fator de intensidade de tensão de referência $K_{r e f}$, os diversos $K_{p}$ para cada situação 
estudada puderam ser finalmente computados. Este procedimento é melhor detalhado na seção 4.9.

A solução proposta neste trabalho tem o intuito de se estimar a vida ao fretting usando fatores de concentração de tensão modificados, $K_{p}$, para as ligas supracitadas. $\mathrm{O}$ uso de $K_{p}$ foi previamente feito para análises de solda de forma satisfatória por GHAREMANI et al. (2016). Ao contrário do fator concentrador de tensão $K_{t}$, que limita-se a estimar os aumentos de tensão na superfície pela presença de um entalhe, $K_{p}$ pode ser utilizado para estimar tais aumentos de tensão decorrentes de trincas em entalhes e defeitos geométricos abaixo de suas superfícies. Uma motivação para o seu uso em fretting fatigue ao invés do usual é que, ao contrário do comportamento de $K_{t}$, cujas curvas não são ajustáveis para equações, $K_{p}$ apresenta curvas de dispersão facilmente ajustáveis. A Figura 174 demonstra a diferença entre seus comportamentos.

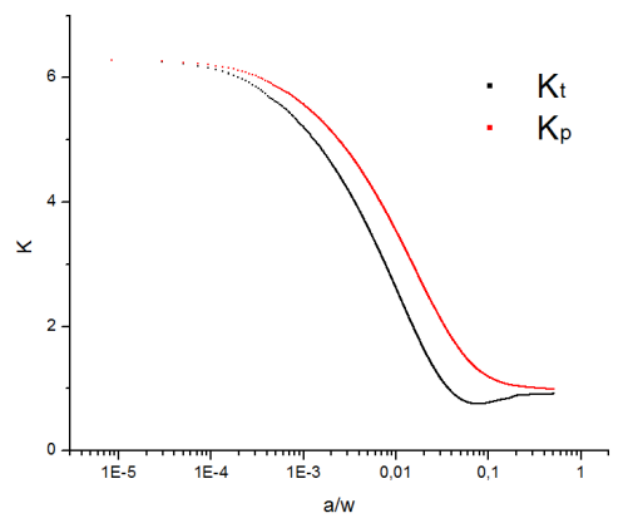

Figura $174-$ Alumínio, $\sigma_{\text {bulk }}=100 \mathrm{MPa}, \mu=0,90$ curvas $\mathrm{K}_{\mathrm{t}}$ e $\mathrm{K}_{\mathrm{p}}$

\subsection{CONSIDERAÇÕES PRELIMINARES}

Diversas soluções para análise de fretting estão presentes na literatura, sendo o método dos elementos finitos atualmente a mais popular ferramenta entre estas soluções. Embora diversos estudos como os de TALEMI et al.(2011) e BAIETTO et. al (2013) apresentem bons resultados, a complexidade envolvida no estudo de fretting faz com que os modelos normalmente representem apenas condições específicas.

Com o intuito de se evitar a necessidade remodelagens com o crescimento da trinca, alguns autores propuseram o uso de X-FEM (GINER et al. (2011), PIERRES et al. (2010)), enquanto outros associaram o uso de funções de peso a FIT (TALEMI et al. (2010), NAVARRO et al. (2003)). Em relação à plasticidade, vários estudos utilizaram funções pré-embutidas no software comercial ABAQUS ou técnicas de submodelagem 
que permitissem a inserção de propriedades elastoplásticas dos materiais (LUKE et al. (2010), NIGRO et al. (2011), DING et al.(2014), LÉVESQUE et al. (2013).

Vários modelos utilizaram critérios de fadiga multiaxial para determinar a direção da nucleação da trinca (GINER et al. (2011), NAVARRO et al. (2003), NIGRO et al. (2011), RAMMOHAN et al. (2012), LIU et al. (2014)), geralmente associados a modelos de propagação, com alguns ignorando os efeitos tridimensionais da propagação da trinca. Enquanto alguns elaboraram seus modelos numéricos já tridimensionalmente (KIM et al. (2011), RAMMOHAN et al. (2012)), outros propuseram o uso de simplificações bidimensionais associadas a modelos tridimensionais (BAIETTO et al. (2013). Por outro lado, há ainda soluções que apenas utilizam fatores de correção para se levar em conta tais efeitos (NAVARRO et al. (2003)).

Neste estudo, utilizou-se o software comercial ANSYS para se elaborar a análise numérica. Ligas de aço, de alumínio e de titânio foram escolhidas pelas suas importâncias em engenharia e pela abundância de dados na literatura que pudessem ser usados futuramente para comparações. A configuração geométrica foi obtida de acordo com o estudo publicado por TALEMI et al. (2014).

Diversos estudos de fretting, como os demonstrados no capítulo 3, apresentam configurações bastante similares à proposta como, por exemplo, os das Figuras 60, 72 e 102. Em alguns estudos, ao invés da restrição total lateral do deslocamento no eixo $\mathrm{x}$, utilizaram-se molas. Outros modelos também apresentam uma mola em uma ou ambas as laterais do pad a fim de se controlar a reação Q através da variação da rigidez da mola. A reação Q surge no pad perpendicularmente ao sentido da força de aperto $\mathrm{P}$ uma vez aplicada a carga remota de fadiga. Já as condições aqui utilizadas podem ser encontradas em trabalhos como o de TALEMI et al. (2014) e o de LUKE et al. (2016), como ilustrado na Figura 102. 


\subsubsection{REGIME DE DESLIZAMENTO E DETERMINAÇÃO DE $\sigma_{B_{\text {Bulk }} \text { max }}$ e de $\mu$}

MADGE et al. (2007) sintetizam bem o consenso literário de que dentre as diversas variáveis presentes no estudo de fretting, são geralmente aceitas como primárias a pressão de contato, a amplitude de deslizamento e o coeficiente de atrito entre o pad e o espécime.

É possível notar, como mostrado na Figura 70, que a forma de contato mais danosa é uma zona mista entre o deslizamento parcial e o deslizamento abrupto. No entanto, uma vez sob deslizamento parcial, haverá sempre tendência de diminuição da vida com o aumento da amplitude de deslizamento, sendo o oposto observado para o caso de deslizamento abrupto. A mesma figura permite concluir que, enquanto há enorme desgaste presente no fenômeno de deslizamento abrupto, o mesmo se encontra praticamente constante e em baixa magnitude para o deslizamento parcial. Sendo assim, considerando-se um problema de fretting fatigue e não de fretting wear, seria mais sensato estudar a condição de deslizamento parcial. A afirmação feita por MADGE et al. (2007) de que é comumente aceito na literatura que o deslizamento parcial é a forma mais danosa de contato reforça ainda mais a direção do estudo.

Com base em FOUVRY et al. (2004), é possível afirmar que os deslizamentos abruptos associam-se a altas energias de dissipação com altos volumes de desgaste, enquanto os deslizamentos parciais estão relacionados a baixas energias de dissipação com baixos volumes de desgaste. Neste último caso, há uma clara associação com o efeito de surgimento de trincas, sobretudo nas vizinhanças do contato.

Assim, este estudo tratará apenas das condições de deslizamento parcial. Embora o conteúdo base tenha sido exposto no Capítulo 2, vale ressaltar que tal condição ocorre sempre que a reação no pad $\mathrm{Q}$ seja inferior ao produto entre o coeficiente de atrito e a carga de aperto, ou seja, $Q<\mu P$.

Diversos trabalhos, como o de TALEMI et al. (2014) demonstram que o coeficiente de atrito entre o pad e o espécime não é constante no início do ensaio, mas tende a se estabilizar após cerca de mil ciclos sob deslizamento parcial. Assim, é comum adotar-se tal valor estabilizado para os modelos numéricos. Os valores utilizados geralmente são extraídos experimentalmente. Neste trabalho, optou-se por adotar 
coeficientes de atrito $(\mu)$ de $0,55,0,65,0,75$ e 0,9 , os quais representam valores encontrados na literatura.

A alteração do $\mu$ na simulação altera as condições de carregamento máximas que podem ser impostas ao modelo. Enquanto alguns modelos apresentam cargas de aperto variáveis, outros, como o estudo aqui apresentado, fixaram um valor constante para a carga de aperto. Naturalmente, diferentes cargas de aperto produzem efeitos diversos sob o modelo e a influência da intensidade desta carga pode ser encontrada abundantemente na literatura, como por exemplo, em FERJAOUI et al. (2015) e LUKE et al. (2016). Estes, vale ressaltar, ainda afirmam que o aumento da área de contato facilita a iniciação de trinca por fretting fatigue. Uma análise da teoria de NOWELL et al. (1986) permite a verificação que tais valores influenciam diretamente no tamanho da área de contato, tendo-se, evidentemente, influência na nucleação da trinca. A carga de aperto neste estudo foi fixada para o valor extraído de TALEMI et al. (2014), para cada coeficiente de atrito utilizado, surgiu uma carga de reação Q máxima correspondente, tendo como origem a aplicação da carga remota de fadiga e a restrição de movimento descritas.

A estimativa para a máxima carga remota de fadiga foi feita pelas equações de equilíbrio, onde a mesma causava a reação na restrição lateral e na restrição em cima do pad, como mostrado na Figura 176. A verificação da condição de deslizamento parcial era de fácil verificação pelo modelo de elementos finitos: Sempre que o valor máximo para a reação $\mathrm{Q}$ era extrapolado por conta de uma excessiva carga remota de fadiga imposta, o $\mu$ não era suficiente para garantir o contato, o que podia ser facilmente verificado pela ausência da zona de perturbação prevista por NOWELL et al. (1986) e também pela absorção da carga imposta na restrição lateral do espécime, revertida em reação. A Figura 175 ilustra tal fenômeno, onde a curva à esquerda mostra a tensão cisalhante para o modelo com a condição de deslizamento parcial satisfeita e à direita mostra a tensão cisalhante para o modelo sob condição de deslizamento abrupto. 

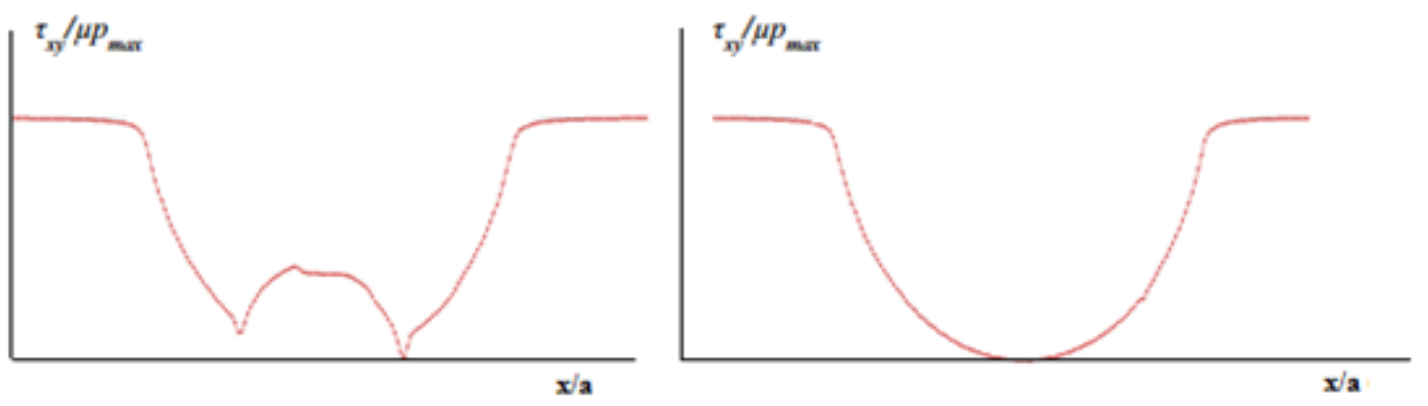

Figura 175 - Comportamento das tensões cisalhantes para deslizamentos parcial (esq.) e abrupto (dir.)

A escolha das cargas remotas de fadiga neste modelo foi feita de tal modo que o valor de carga remota máxima de fadiga $\sigma=100 \mathrm{MPa}$ era o maior carregamento para que todos os materiais ainda se encontrassem em regime de deslizamento parcial sob as condições impostas. As demais cargas foram escolhidas como razões arbitrárias em cima deste critério para se estudar o efeito da variação da carga remota de fadiga sobre o $K_{p}$.

\section{4 MODELO NUMÉRICO}

\subsubsection{GEOMETRIA, CONDIÇÕES DE CONTORNO E DE CARREGAMENTO}

O problema típico de fretting é constituído por dois pads em contato com um espécime central (Figura 101). É perfeitamente possível, para o estudo de efeitos de carga remota de fadiga, tirar proveito da simetria situado no eixo central (na direção x) do espécime e simular apenas uma metade, poupando enormes custos computacionais.

Neste trabalho, tirou-se proveito de tal simetria e utilizaram-se as condições de contorno e carregamento ilustradas na Figura 176. 


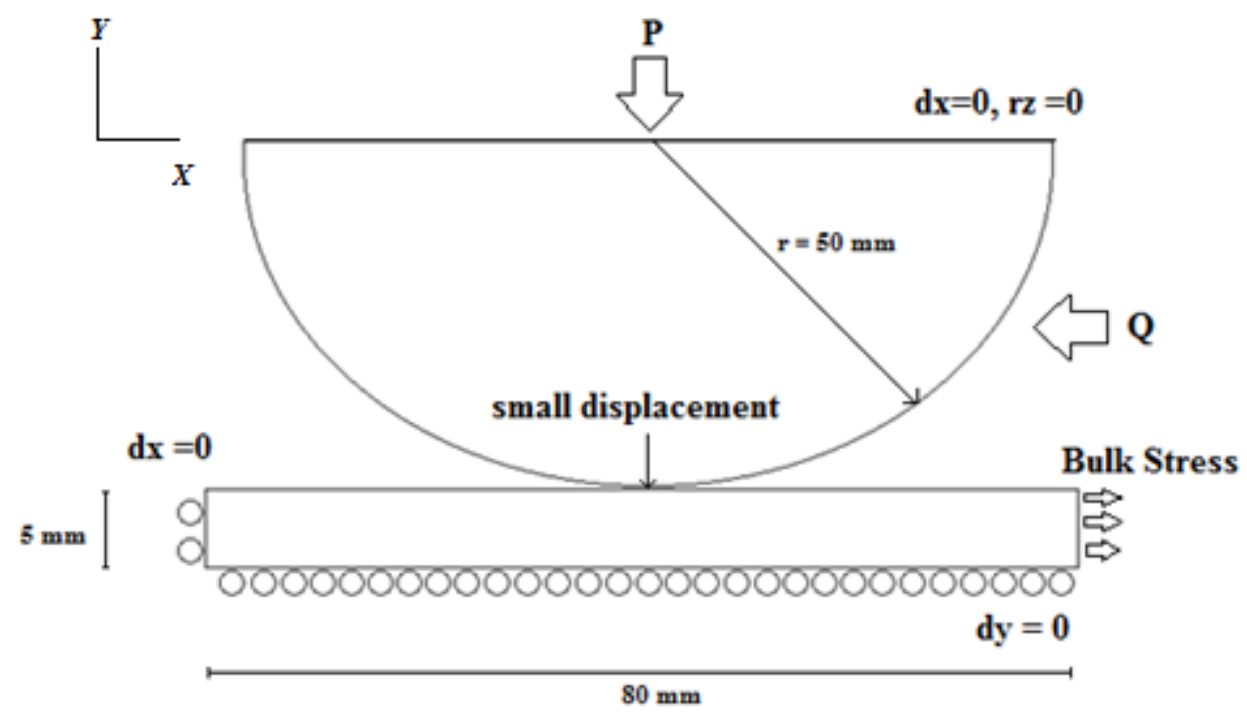

Figura 176 - Condições de contorno e carregamento

A reação Q ilustrada na Figura 176 não foi aplicada diretamente no modelo, tendo surgido por conta da aplicação da carga remota de fadiga e das restrições de deslocamento impostas ao modelo. É importante enfatizar que o modelo apresentado possuí uma desvantagem em relação ao modelo com restrições laterais utilizando molas, os quais possuem maior controle sobre a reação Q por meio da variação do coeficiente elástico das molas. A variação deste coeficiente permite diminuir os efeitos reativos indesejáveis decorrentes do momento fletor que surge pela restrição de movimento no eixo $\mathrm{x}$ do canto esquerdo do espécime ao se aplicar a carga remota de fadiga. Tais efeitos, no entanto, foram mínimos para a configuração geométrica adotada e, por este motivo, não se viu necessidade em adotar o sistema de molas. A simulação foi dividida em quatro espaços de tempo:

No primeiro passo, um deslocamento de $-5 \times 10^{-4} \mathrm{~mm}$ foi imposto ao pad na direção do espécime. Isto foi feito para contornar possíveis excessos de restrições causadas por conflitos entre as condições de contato e deslocamentos prescritos. Isto constitui em um tratamento para se evitar condições de contorno complicadas e prevenir dificuldades de convergência do modelo. Tal imposição impede possíveis deslocamentos com comportamento de corpo rígido, os quais, se não restringidos, causam singularidade da matriz de rigidez e interrompem a simulação prematuramente (QI, 2013).

No segundo passo, a carga de aperto $\mathrm{P}$ foi aplicada em seu valor máximo, no valor de $543 \mathrm{~N}$, enquanto a carga remota de fadiga passou a ser aplicada, atingindo seu 
ápice no passo três. Ou seja, a carga variou linearmente de 0 a $\sigma_{\max }$ em 1 s nos passos descritos. O quarto passou apenas manteve as cargas de aperto e máxima de fadiga, a fim de se averiguar a estabilização dos resultados do fim do terceiro passo.

Com o intuito de se averiguar a influência da carga remota de fadiga no comportamento de $K_{p}$, foram elaborados para cada material modelos com $\sigma_{\max }=100$, 80 e $60 \mathrm{MPa}$. Embora diferentes materiais possibilitem a aplicação de cargas remotas de fadiga máximas diferentes uma das outras, adotou-se o caso mais crítico (mínimo) para o qual todos os outros modelos ainda se encontrariam em condição de deslizamento parcial. A razão para adotar-se uma mesma carga máxima para todos os materiais é porque se desejava também estudar os efeitos que as mudanças de propriedades dos materiais teriam no comportamento de $K_{p}$. Outra propriedade importante no estudo de fretting é o coeficiente de atrito. Com este motivo, mantendo-se fixas as demais propriedades, produziram-se modelos com variações dos mesmos para 0,9, 0,75, 0,65 e 0,55 . Isto resultou em 12 modelos diferentes para cada material, sendo produzidas 36 simulações, como foi resumido na Figura 172.

\subsubsection{DETALHES DO MODELO}

Os modelos foram constituídos por elementos do tipo PLANE182, tanto para o pad quanto para o espécime. A quantidade de nós e elementos gerados para cada um dos materiais é mostrado na Tabela 4. Os elementos de contato, com discretização do tipo superfície-superfície, eram do tipo CONTA172 e TARGE169. Para a verificação dos efeitos de carregamento, utilizaram-se elementos do tipo SURF153.

A resolução numérica era do tipo estático, com método de Newton-Raphson assimétrica, com matriz de montagem assimétrica e resolução de equação tipo sparse. $\mathrm{O}$ contato foi definido pelo método de Lagrange expandido, cujo coeficiente determinado foi de 0.75 , cujo valor foi obtido pela validação do modelo, apresentada a seguir. 
Tabela 4 - Detalhes do modelo

\begin{tabular}{|c|c|c|c|c|c|}
\hline Material & $\begin{array}{c}\text { Quantidade } \\
\text { de nós }\end{array}$ & $\begin{array}{c}\text { Elementos de } \\
\text { contato }\end{array}$ & $\begin{array}{c}\text { Elementos } \\
\text { sólidos }\end{array}$ & $\begin{array}{c}\text { Total de } \\
\text { elementos }\end{array}$ & $\begin{array}{c}\text { Tempo } \\
\text { despedido (s)* }\end{array}$ \\
\hline Aço & 121069 & 1665 & 119923 & 121591 & 1488.6 \\
\hline Alumínio & 151435 & 1683 & 150260 & 151946 & 2192.3 \\
\hline Titânio & 121069 & 1665 & 119923 & 121591 & 1634.3 \\
\hline
\end{tabular}

*O computador utilizado para a simulação foi um Intel Core i5-6400 CPU @2.70 GHz com 32 GB de memória RAM e placa de vídeo GeForce GTX 970 com sistema operacional Windows 764 bits.

\subsubsection{MALHA}

O estudo de TALEMI et al. (2014) serviu como base para a adoção de geometrias adotados neste estudo (Figura 176). Também foi adotado um tamanho de malha na zona de contato recomendado pelos mesmos. A malha grosseira para o espécime e para o pad possuíam 200 divisões no formato quadrático. A região de contato entre o pad e o espécime, conforme mostrado na Figura 177, sofreu um refinamento para elementos quadráticos com arestas de $50 \mu \mathrm{m}$ para a região externa e $5 \mu \mathrm{m}$ para a região interna. A definição dos tamanhos das regiões de refinamento foi feita com base nos tamanhos de contato obtidos analiticamente. Tal refinamento possibilitou a obtenção de resultados mais precisos para cada um dos contatos, os quais variaram de tamanho de acordo com o material.
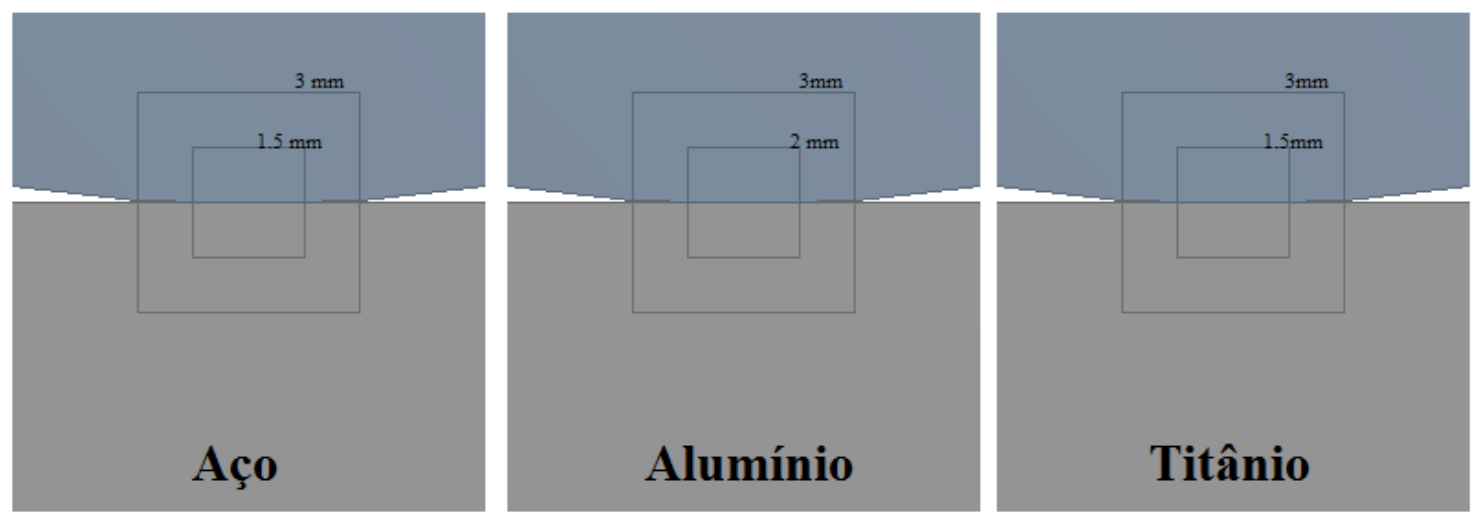

Figura 177 - Região de contato na malha para cada material 

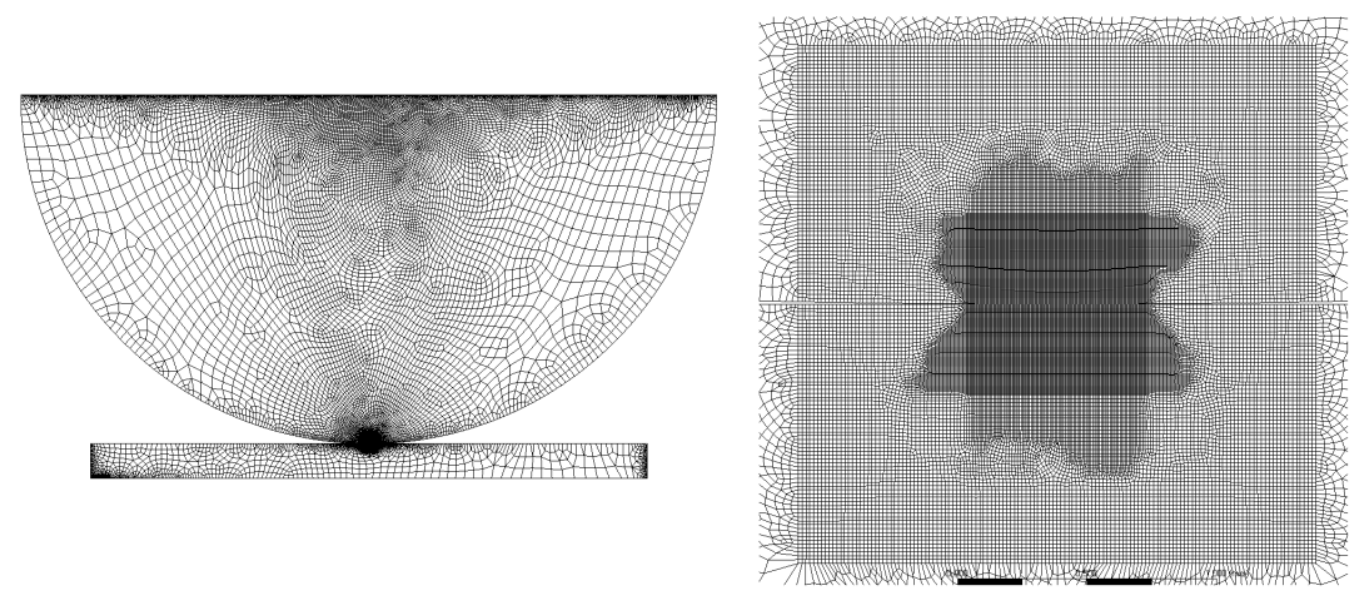

Figura 178 - Malha discretizada total (esq.) e zoom do contato (dir.)

\subsection{VALIDAÇÃO DO MODELO}

Naturalmente, a simples convergência dos resultados obtidos era insuficiente para demostrar a validade do modelo numérico proposto. Assim, utilizando-se as Equações (8-12), foi possível traçar uma comparação entre os resultados numérico e teórico.

Para os devidos cálculos, a Tabela 5 apresenta os valores de entrada necessários, os quais também foram utilizados no modelo numérico.

Tabela 5 - Propriedades utilizadas

\begin{tabular}{|c|c|c|c|}
\hline Material & Alumínio & Aço & Titânio \\
\hline Módulo de elasticidade & $70 \mathrm{GPa}$ & $200 \mathrm{GPa}$ & $120 \mathrm{GPa}$ \\
\hline Coeficiente de Poisson & 0.33 & 0.30 & 0.32 \\
\hline
\end{tabular}

O valor utilizado para o raio do espécime condiz com a previsão do semi-plano infinito, pois como o meio tamanho de contato a encontrado é demasiadamente menor que a meia espessura $\mathbf{b}$ do espécime, ou seja, $\mathrm{a} / \mathrm{b}<<1$. Para o alumínio, os valores encontrados analiticamente foram: $\mathrm{a}=0,9118 \mathrm{~mm}, \mathrm{c} / \mathrm{a}=0,40$ para os valores de entrada $\mathrm{P}=543 \mathrm{~N}, \mathrm{Q}=296,25 \mathrm{~N}, P_{0}=379,11, \mu=0,65$ e uma carga remota de fadiga de 100 MPa. 


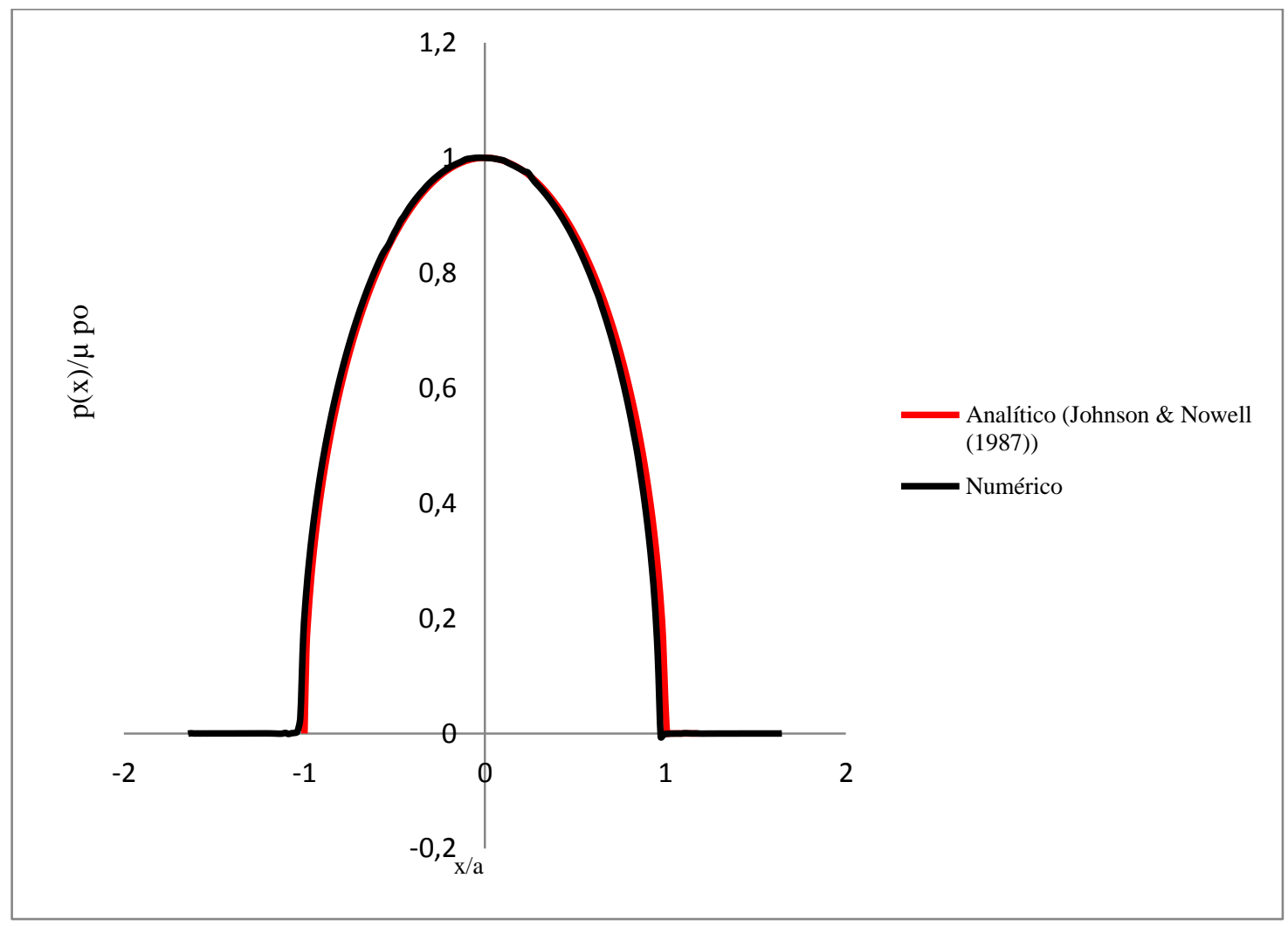

Figura 179 - Tensão normal - comparação entre resultado numérico e teórico

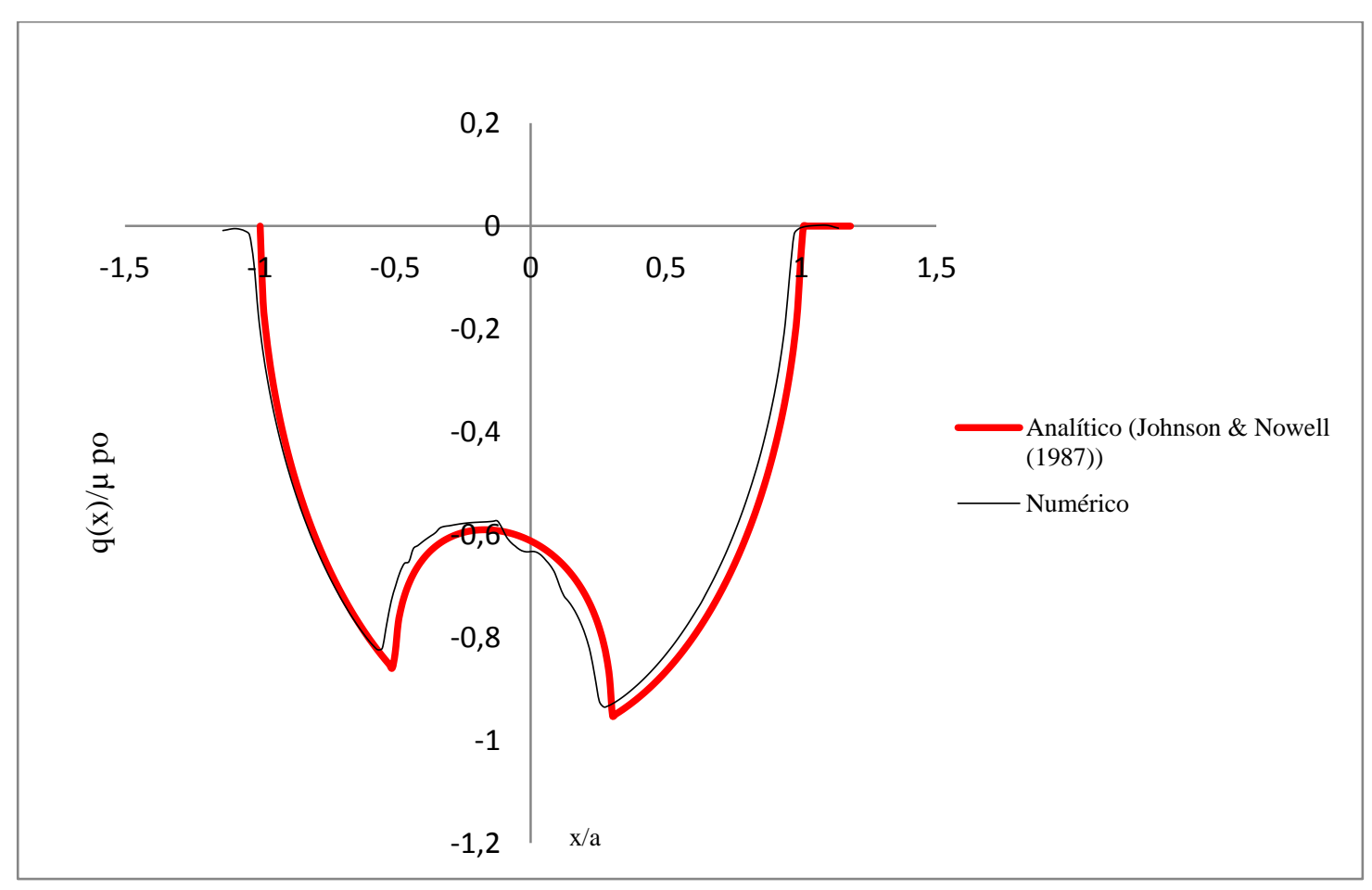

Figura 180 - Tensão cisalhante - comparação entre resultado numérico e teórico

As figuras 179 e 180 ilustram as comparações entre os resultados teóricos e os resultados numéricos para as tensões normal e cisalhante normalizadas em função da distância do contato. Os resultados mostram-se em boa concordância. A divergência 
entre as pressões máximas de contato teórica e numérica é inferior a 1\% (379,11 MPa teórico ante 381,7 MPa numérico). Diferenças similares foram encontradas para os demais materiais. Enquanto para as tensões normais as curvas numéricas são praticamente coincidentes com as obtidas analiticamente, é possível notar que, para as tensões cisalhantes, embora próximas, elas não são exatamente coincidentes, com pequenos distúrbios sendo encontrados na zona de aderência do contato. Isto provavelmente ocorre por conta de formulação feita pelo ANSYS e por conta da ocorrência de pequenos momentos fletores no pad em virtude da restrição lateral imposta e das forças reativas decorrentes da carga remota de fadiga.

O coeficiente de Lagrange expandido utilizado foi de 0,75 . A diferença para os valores obtidos para os coeficientes de Lagrange de 0,65 e 0,85 não eram apreciáveis e a Figura 181 ilustra a comparação para os valores obtidos, os quais são tão próximos que são indistintos graficamente.

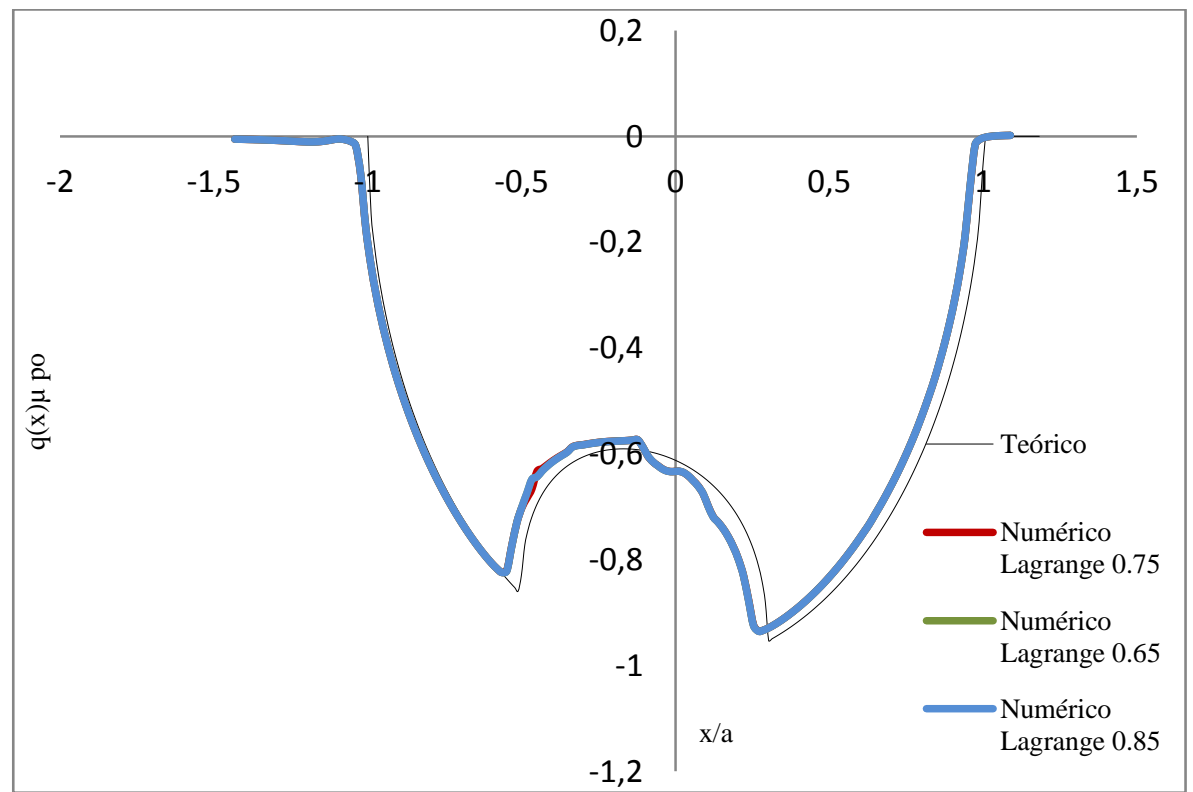

Figura 181 - Comparação entre os coeficientes de Lagrange

\subsection{COMPORTAMENTO DOS CAMPOS DE TENSÕES}

A análise neste trabalho foi formulada considerando-se o estado plano de deformações, ou seja, $\varepsilon_{z},=\gamma_{x z}=\gamma_{y z}=0$, pois a seção bidimensional da análise foi retirada de uma situação real em que a estrutura não era delgada, com uma dimensão sendo bem superior às outras duas. Para o ensaio de aço com $\sigma_{b u l k}=100 \mathrm{MPa} \mathrm{e} \mu=0.9$, os campos de tensão $\sigma_{x}, \sigma_{y}$ e $\tau_{x y}$ no espécime após o carregamento podem ser visualizados nas Figuras 182, 183 e 184, respectivamente. 


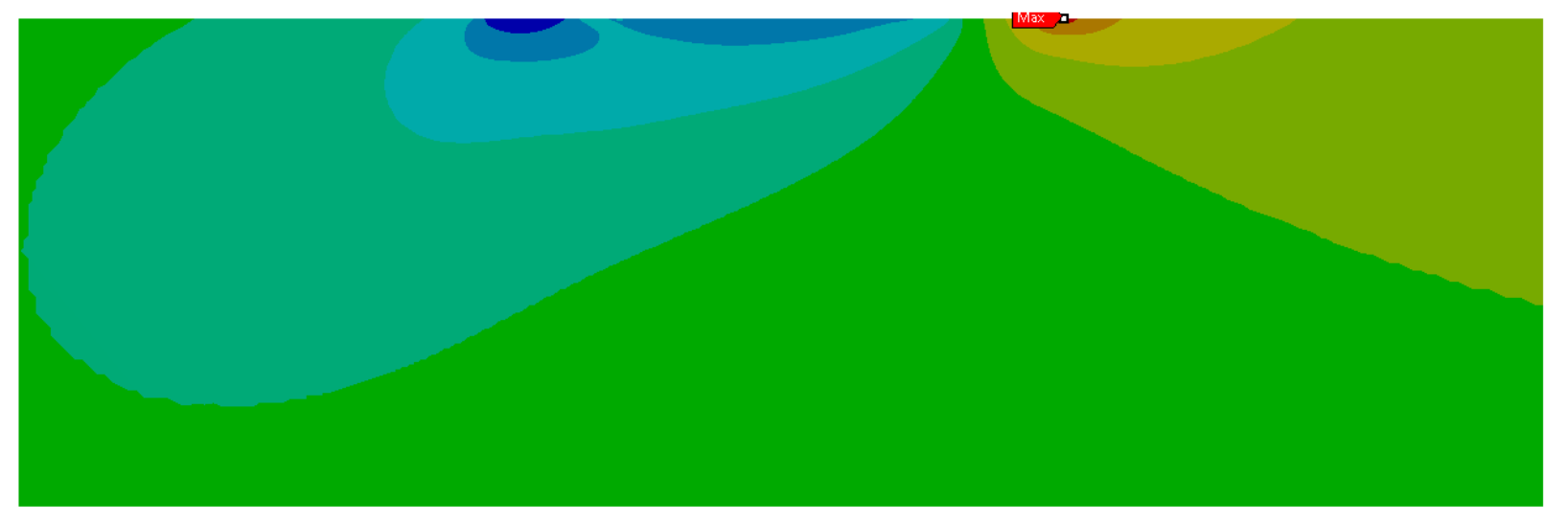

$\sigma_{x}$

920,95 Max

725,34

529,72

334,11
138,5
$-57,107$
$-252,72$

$-448,73$

$-643,94$ Min

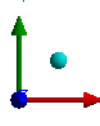

Figura 182 - Campos de tensão $\boldsymbol{\sigma}_{\boldsymbol{x}}$ para o ensaio de aço $\boldsymbol{\sigma}_{\boldsymbol{b u l k}}=100 \mathrm{MPa}$ e $\boldsymbol{\mu}=0.9$

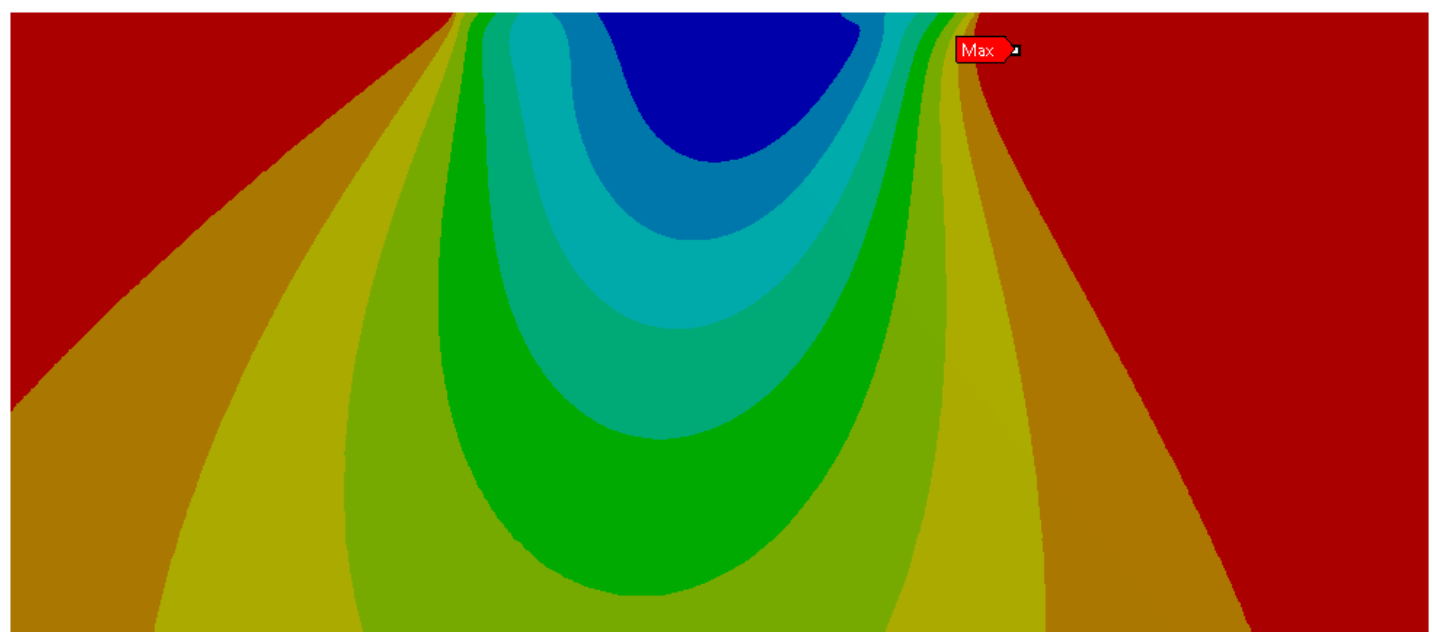

\section{$\sigma_{y}$}

15,829 Max

$-55,006$

$-125,84$

$-196,67$

$-338,34$

$-409,18$

$-480,01$

$-550,84$

$-621,68 \mathrm{Min}$

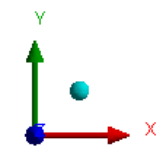

Figura 183 - Campos de tensão $\boldsymbol{\sigma}_{\boldsymbol{y}}$ para o ensaio de aço $\boldsymbol{\sigma}_{\boldsymbol{b u l k}}=100 \mathrm{MPa}$ e $\boldsymbol{\mu}=0.9$

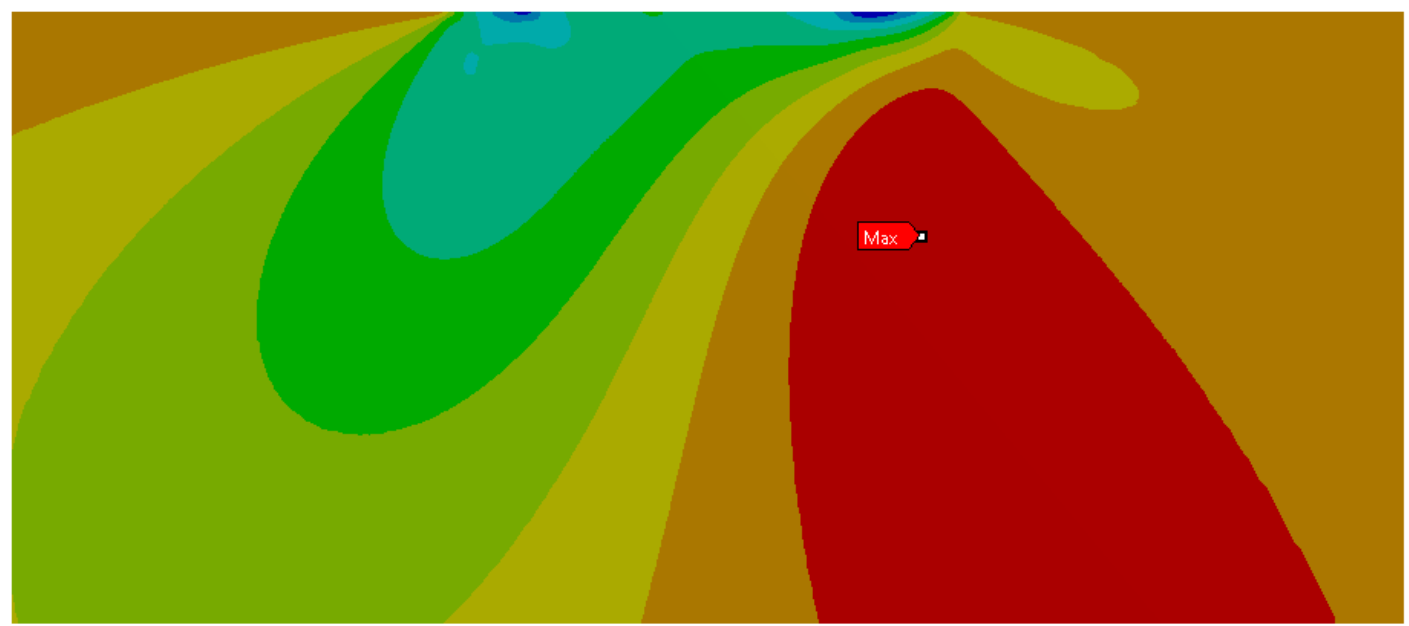

$$
\tau_{x y}
$$

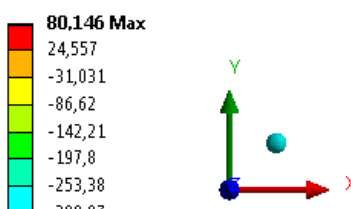

Figura 184 - Campos de tensão $\boldsymbol{\tau}_{\boldsymbol{x y}}$ para o ensaio de aço $\boldsymbol{\sigma}_{\boldsymbol{b u l k}}=100 \mathrm{MPa}$ e $\boldsymbol{\mu}=0.9$

A Figura 185, por outro lado, mostra a evolução das tensões máximas ao longo do tempo. 


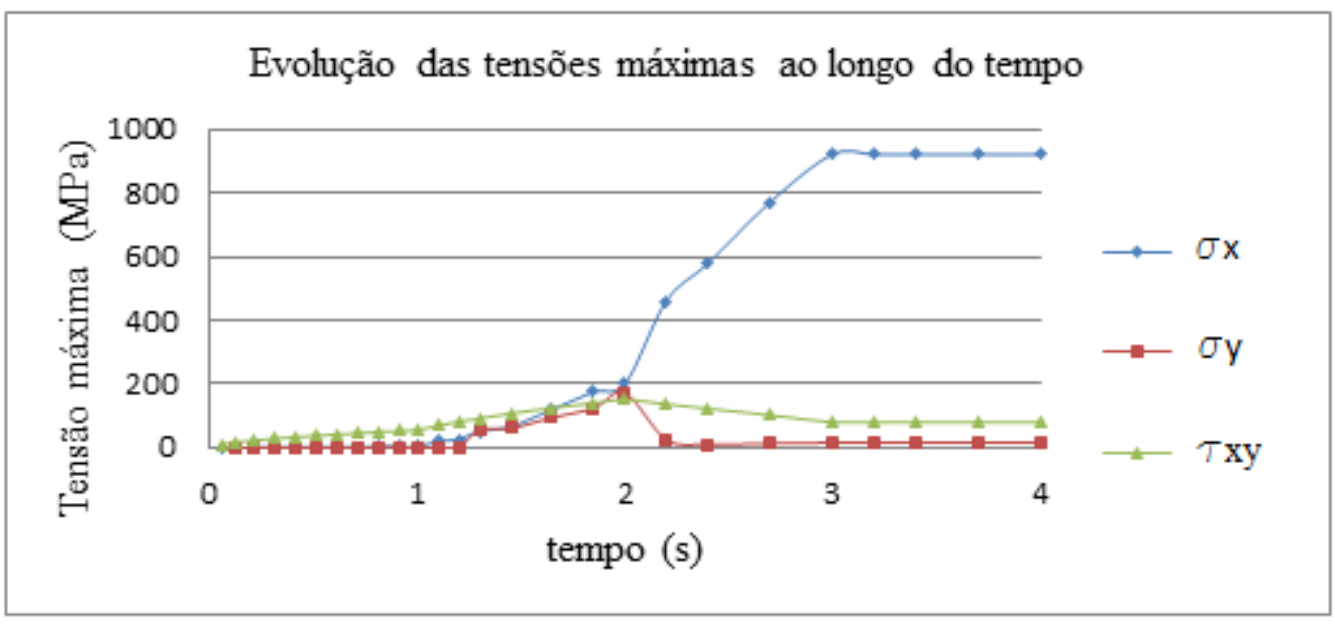

Figura 185 - Evolução das tensões máximas ao longo do tempo - Aço $\sigma_{\text {bulk }}=100 \mathrm{MPa}$ e $\mu=0.9$

A evolução das tensões ao longo trajetória escolhida como crítica, cujo critério escolhido é apresentado na seção 4.7 é apresentada na Figura 186 :

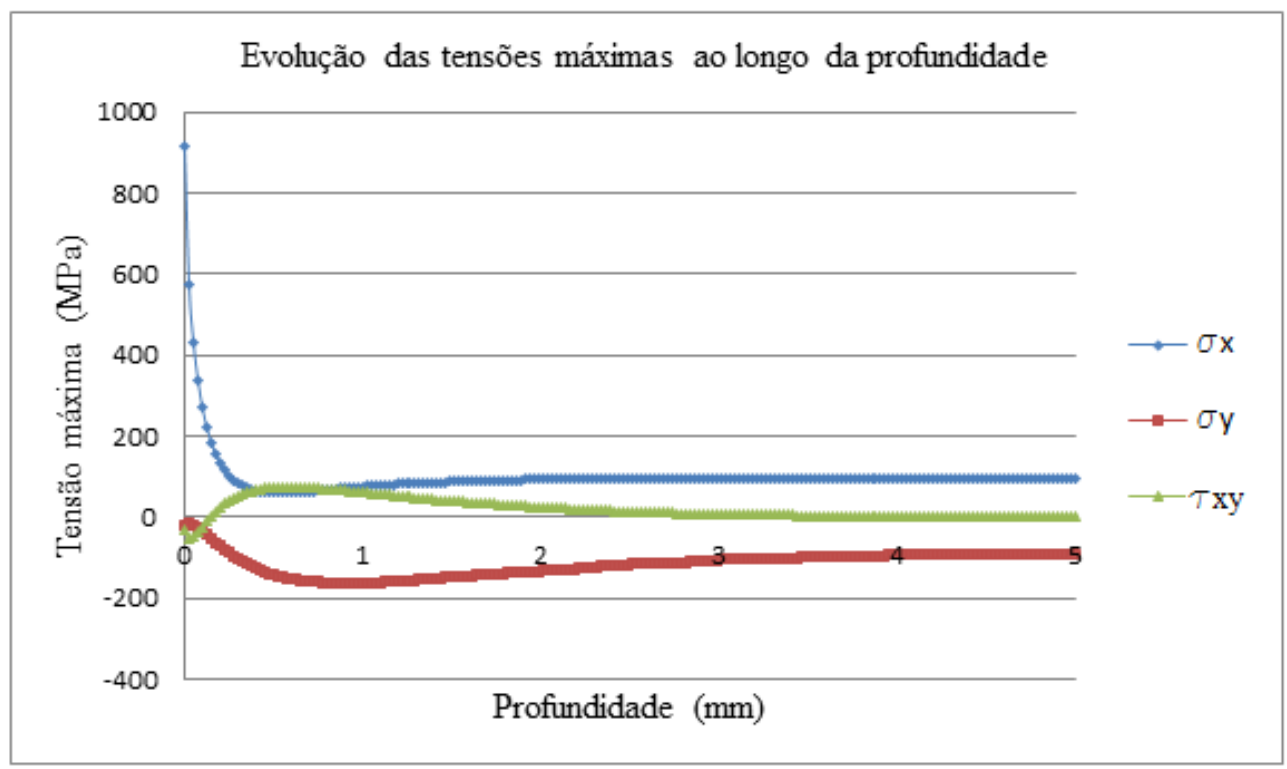

Figura 186 - Evolução das tensões máximas ao longo da profundidade - Aço $\sigma_{b u l k}=100 \mathrm{MPa}$ e $\mu=0.9$

Comportamentos similares são encontrados para outras simulações, onde há apenas mudança na magnitude das tensões envolvidas, como é demonstrado na Figura 187: 


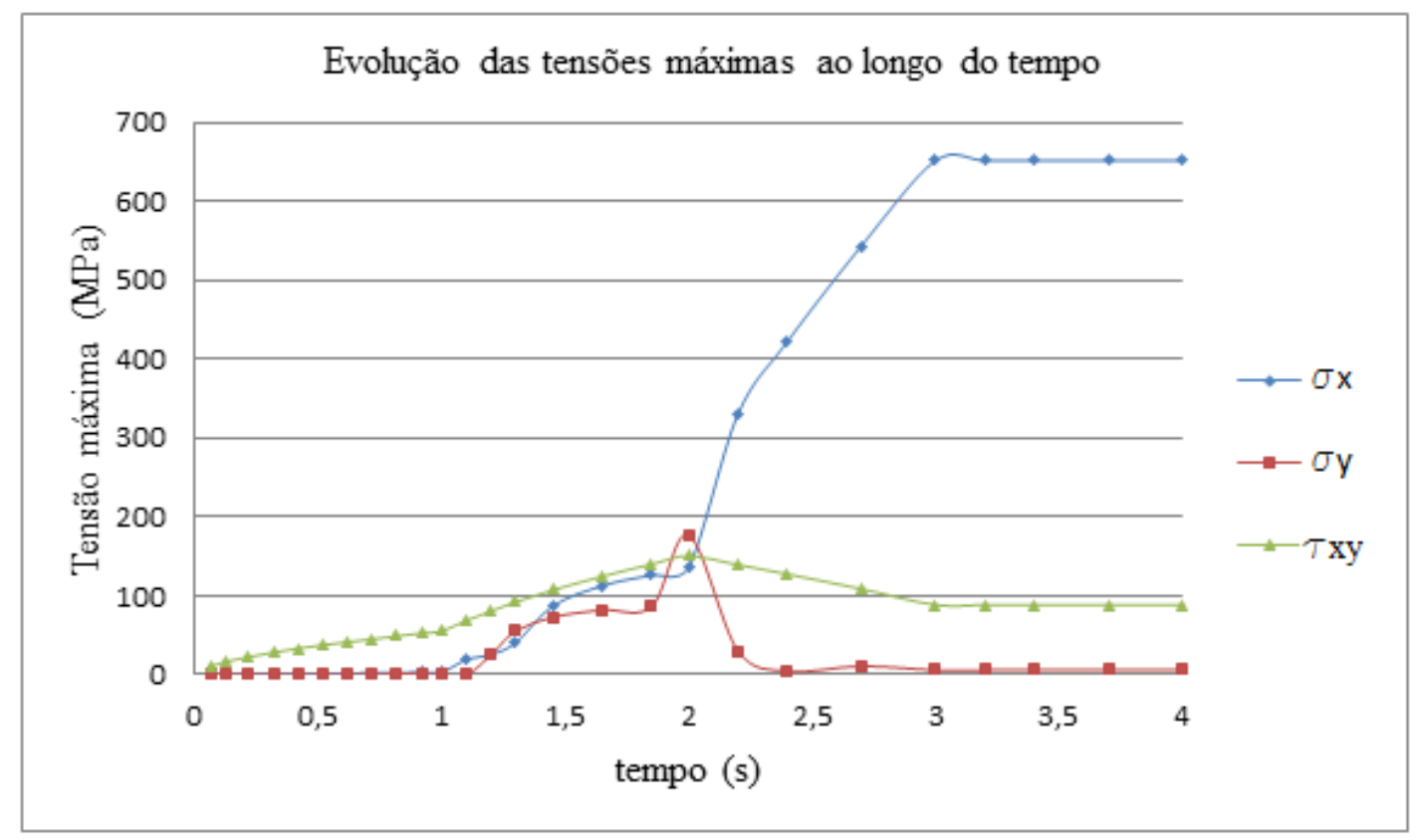

Figura 187 - Evolução das tensões máximas ao longo do tempo - Aço $\sigma_{b u l k}=80 \mathrm{MPa}$ e $\mu=0,55$

É possível notar ao se visualizar as Figuras 185 e 186 que a tensão que trará resultado significativo na evolução da trinca será $\sigma_{x}$. A tensão $\tau_{x y}$ possui ordem de grandeza de aproximadamente apenas $5 \%$ de $\sigma_{x}$ quando $\sigma_{x}=\sigma_{x_{\max }}$ e $\sigma_{y}$ torna-se praticamente nula também neste momento. A ordem de grandeza desta relação altera-se para casos como o da Figura 187, onde a carga remota de fadiga é de menor valor atingido valores próximos a $15 \%$. No entanto, como será visto na seção 4.10, os esforços causados por esta tensão poderão ser negligenciados sem prejuízo significativo da análise.

\subsection{TRAJETÓRIA DE PROPAGAÇÃO DA TRINCA}

Neste estudo, foi considerado que o surgimento da trinca deu-se no ponto de maior tensão normal e então seguiu sua trajetória em linha reta, próximo à borda do contato. Abordagens similares foram utilizadas em PENG et al. (2014) e NAVARRO et al. (2003). Este demonstra que a propagação em determinados materiais, como ligas de alumínio, são praticamente perpendiculares à superfície do espécime. No entanto, aquele aponta que para materiais como o aço, o trecho inicial percorreria provavelmente uma trajetória de cerca de $60^{\circ}$ até a profundidade máxima do contato hertziano, seguindo então uma trajetória praticamente perpendicular à superfície (Figura 188). Mesmo que alguns modelos indiquem que a nucleação da trinca iniciar-se-ia no ponto de maior 
tensão cisalhante para alguns materiais, a direção da propagação seria então regida pela máxima tensão normal.

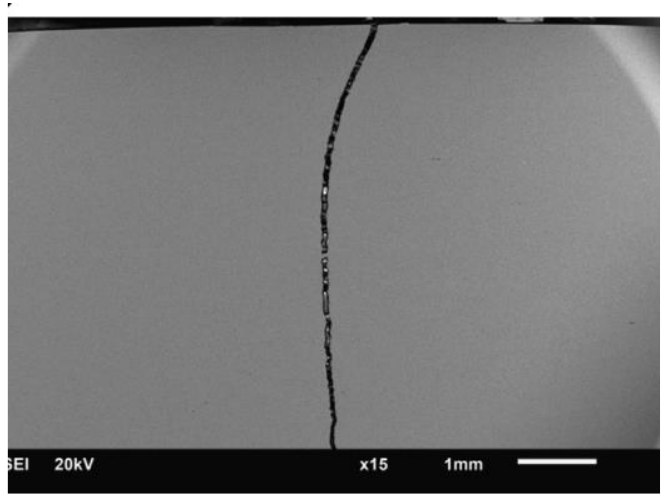

Figura 188 - Caminho da trinca sob fretting (Fonte: PENG et al., 2014)

É possível averiguar-se a razoabilidade da proposição: Considere-se, como ilustrado na Figura 189, que a nucleação ocorra no ponto de maior tensão de cisalhamento (coordenadas $(\mathrm{X} 2,0)$ ) e que a trajetória seguiria em $60^{\circ}$ até o ponto da profundidade do contato hertziano $(\mathrm{X} 1, \mathrm{Y} 1)$, até que finalmente seguisse em linha reta para a distância onde ocorreria a fratura do espécime $(\mathrm{X} 1, \mathrm{Y} 2)$. $\mathrm{O}$ valor da profundidade do contato foi estabelecido por JOHNSON (1985) como sendo $z=0.78$ a, onde a é a meia largura do tamanho do contato. Assim, a distância entre X2 e X1 é dada pela Equação 49. Portanto, para as simulações realizadas, conquanto o ponto de máxima tensão normal se aproximasse da coordenada (X1,0), poder-se-ia considerar a aproximação como extremamente próxima da situação real. Ademais, se o valor de Y2 for consideravelmente maior que Y1, a trajetória é predominantemente retilínea e perpendicular à superfície. 
$X 2-X 1=\frac{0.78 a}{\operatorname{tg} 60^{\circ}}$

Eq. (49)

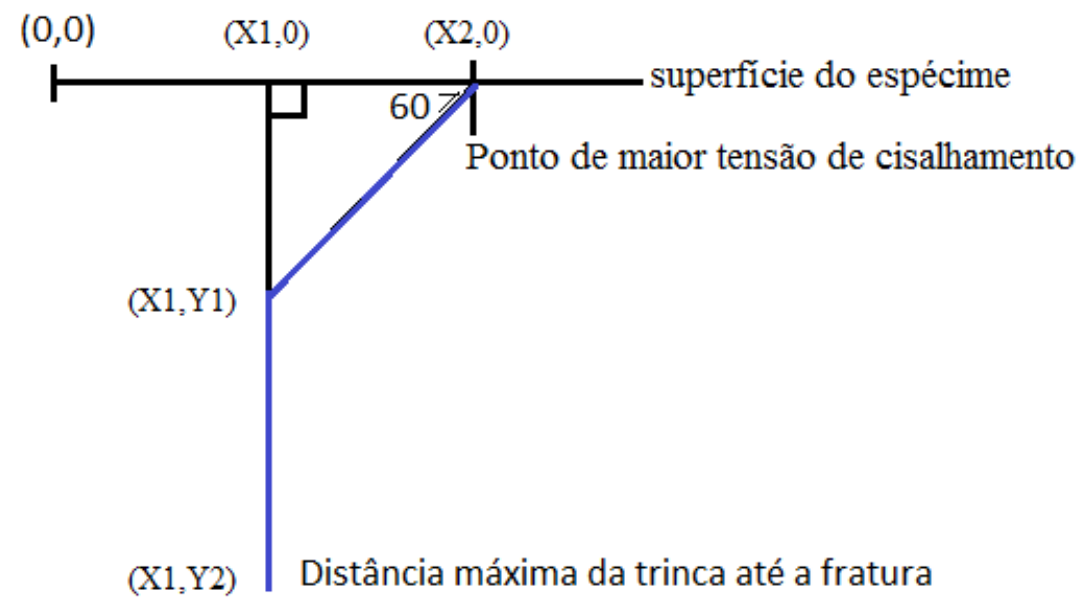

Figura 189 - Geometria da trajetória da trinca

Considerando-se a propagação da trinca em $60^{\circ}$ para o aço e um meio tamanho de contato de Hertz a=0.561, a Tabela 6 mostra os valores de coordenadas obtidos numericamente e analiticamente e suas comparações. $\mathrm{O}$ valor de $\mathrm{Y} 2$ para todos os casos é de metade da largura do espécime, ou seja, Y2 = $2.5 \mathrm{~mm}$.

Tabela 6 - Valores geométricos obtidos para o aço

\begin{tabular}{|c|c|c|c|c|c|}
\hline \multicolumn{7}{|c|}{ Aço } \\
\hline Coeficiente de atrito & 0.55 & 0.65 & 0.75 & 0.90 & \\
\hline Coordenada X1 analítica & 0,539 & 0,598 & 0,636 & 0,665 & $\mathrm{~mm}$ \\
\hline Coordenada X1 numérica & 0,553 & 0,553 & 0,553 & 0,553 & $\mathrm{~mm}$ \\
\hline Coordenada X2 numérica & 0,791 & 0,851 & 0,888 & 0,918 & $\mathrm{~mm}$ \\
\hline Distância X2-X1 analítica & 0,253 & 0,253 & 0,253 & 0,253 & $\mathrm{~mm}$ \\
\hline Coordenada Y1 analítica & 0,437 & 0,437 & 0,437 & 0,437 & $\mathrm{~mm}$ \\
\hline Diferença entre X1 teórico e analítico & 1 & 4 & 8 & 11 & $\%$ \\
\hline
\end{tabular}

Vale notar que há forte relação entre as diferenças encontradas e o ângulo adotado, o qual é por si só uma simplificação. Para 55, por exemplo, as diferenças anteriormente obtidas seriam da ordem de 7\%, 1\%, 3\% e 6\%, em ordem respectiva de coeficientes de atrito crescentes. Ademais, para valores próximos à profundidade máxima do contato previsto por Hertz, há convergência dos valores de tensão para os diversos $\mu$, o que permite que a consideração supracitada seja aplicável a todos os $\mu$ a partir desta profundidade, como mostra a Figura 190. 


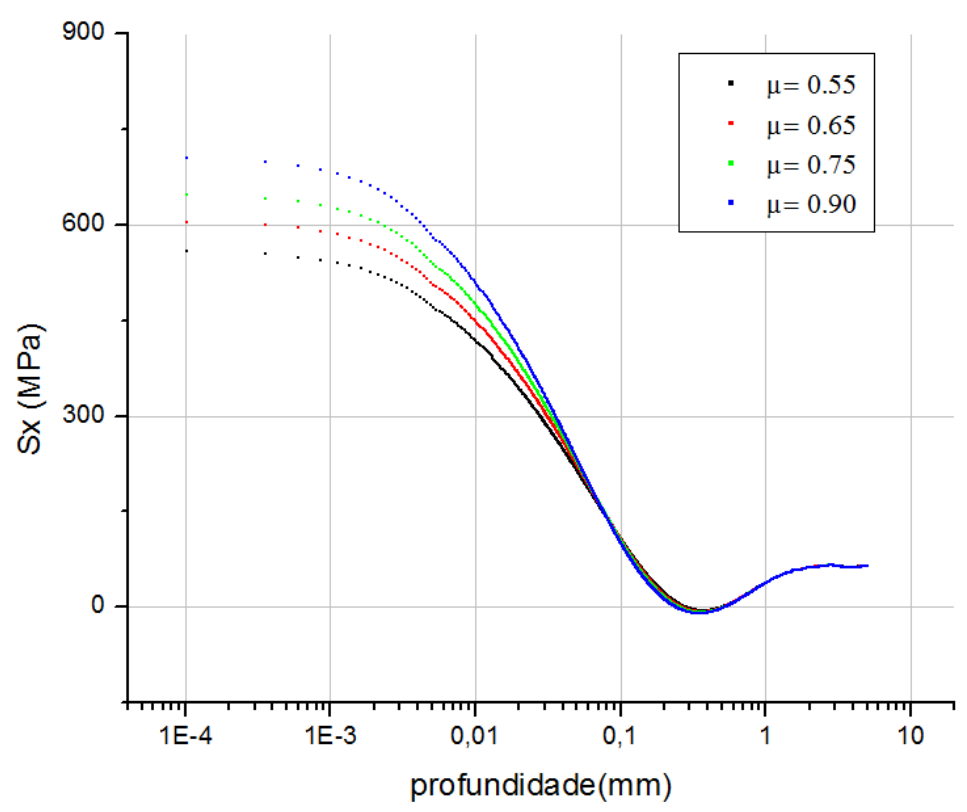

Figura 190 - Convergência do contato em relação à profundidade para o aço (REMOTA 60 MPa)

Considerando-se a propagação da trinca em $60^{\circ}$ para o titânio e um meio tamanho de contato de Hertz a=0.70, a Tabela 7 mostra os valores de coordenadas obtidos numericamente e analiticamente e suas comparações. O valor de Y2 para todos os casos é de metade da largura do espécime, ou seja, Y2 $=2.5 \mathrm{~mm}$.

Tabela 7 - Valores geométricos obtidos para o titânio

\begin{tabular}{|c|c|c|c|c|c|}
\hline \multicolumn{9}{|c|}{ Titânio } \\
\hline Coeficiente de atrito & 0.55 & 0.65 & 0.75 & 0.90 & Unidade \\
\hline Coordenada X1 analítica & 0,469 & 0,558 & 0,596 & 0,635 & $\mathrm{~mm}$ \\
\hline Coordenada X1 numérica & 0,685 & 0,685 & 0,684 & 0,684 & $\mathrm{~mm}$ \\
\hline Coordenada X2 numérica & 0,784 & 0,873 & 0,910 & 0,950 & $\mathrm{~mm}$ \\
\hline Distância X2-X1 analítica & 0,315 & 0,315 & 0,315 & 0,315 & $\mathrm{~mm}$ \\
\hline Coordenada Y1 analítica & 0,545 & 0,545 & 0,545 & 0,545 & $\mathrm{~mm}$ \\
\hline Diferença entre X1 teórico e analítico & 22 & 13 & 9 & 5 & $\%$ \\
\hline
\end{tabular}

Vale notar que embora as diferenças encontradas sejam consideravelmente superiores às encontradas para o aço, há também enorme correlação entre as mesmas e o ângulo da trajetória da trinca, cujo valor utilizado baseou-se em um ensaio para aquele material. Um ângulo de $65^{\circ}$, por exemplo, forneceria diferenças para os $\mu$, em ordem crescente, respectivamente de $16 \%, 7 \%, 3 \%$ e $1 \%$, as quais soam razoáveis. Ademais, vale destacar que enquanto os maiores erros para o aço encontravam-se na faixa superior dos $\mu$, os maiores erros para a liga de titânio estudada encontram-se na faixa inferior dos 
$\mu$. Isto pode ser atribuído aos efeitos do módulo de elasticidade de cada material na análise do contato.

Para o alumínio, a utilização do ângulo de $60^{\circ}$ mostrou-se completamente insatisfatória, conforme é mostrado na Tabela 8. O valor de Y2 utilizado seguiu o mesmo padrão dos anteriores, com $\mathrm{Y} 2=2.5 \mathrm{~mm}$.

Tabela 8 - Valores geométricos obtidos para o alumínio

\begin{tabular}{|c|c|c|c|c|c|}
\hline \multicolumn{7}{|c|}{ Alumínio } \\
\hline Coeficiente de atrito & 0.55 & 0.65 & 0.75 & 0.90 & Unidade \\
\hline Coordenada X1 analítica & 0,373 & 0,440 & 0,477 & 0,507 & $\mathrm{~mm}$ \\
\hline Coordenada X1 numérica & 0,879 & 0,879 & 0,879 & 0,879 & $\mathrm{~mm}$ \\
\hline Coordenada X2 numérica & 0,784 & 0,851 & 0,888 & 0,918 & $\mathrm{~mm}$ \\
\hline Distância X2-X1 analítica & 0,411 & 0,411 & 0,411 & 0,411 & $\mathrm{~mm}$ \\
\hline Coordenada Y1 analítica & 0,711 & 0,711 & 0,711 & 0,711 & $\mathrm{~mm}$ \\
\hline Diferença entre X1 teórico e analítico & 51 & 44 & 40 & 37 & $\%$ \\
\hline
\end{tabular}

Novamente, os maiores erros são encontrados na faixa inferior dos $\mu$. Este padrão segue a mesma lógica observada, visto que o alumínio possui módulo de elasticidade inferior à do titânio (que possua vez possui módulo de elasticidade menor que o aço). Ou seja, a diminuição do módulo de elasticidade sugere originar trajetórias de trincas mais próximas de uma trajetória perpendicularidade à superfície. Felizmente, esta hipótese é confirmada pelo estudo de NAVARRO et al. (2003), onde as trajetórias para a liga de alumínio utilizada são próximas de uma linha reta perpendicular à superfície (Figura 44).

Observando-se atentamente é possível notar que, para o alumínio, as coordenadas obtidas para a máxima tensão normal e a máxima tensão de cisalhamento encontram-se demasiadamente próximas uma das outras. Assim, torna-se inviável a consideração geométrica anterior, visto que se necessitaria de ângulos da trajetória próximos a $90^{\circ}$. Embora haja solução matemática para a última consideração, não há motivos práticos que justifiquem a não adoção da coordenada de máxima tensão normal como havia sido proposto, pois, além de fornecer a solução mais favorável à segurança, uma vez que as tensões normais obtidas serão ligeiramente maiores, a diferença encontrada seria demasiadamente pequena. Valores angulares próximos à trajetória perpendicular à 
superfície também foram encontrados experimentalmente e demonstrados no modelo de Navarro et al. (2003), como ilustrado na Figura 44.

Em relação à simplificação da trajetória completamente perpendicular, é possível adotar, como fizeram NAVARRO et al. (2003), um fator de correção para se levar em conta o formato da trajetória da trinca, determinada experimentalmente. A Figura 191 ilustra a diferença entre os FIT obtidos em modo I com funções de peso para a simplificação adotada neste estudo e a simplificação proposta por PENG et al. (2014) considerando uma inclinação de $60^{\circ}$ inicial.

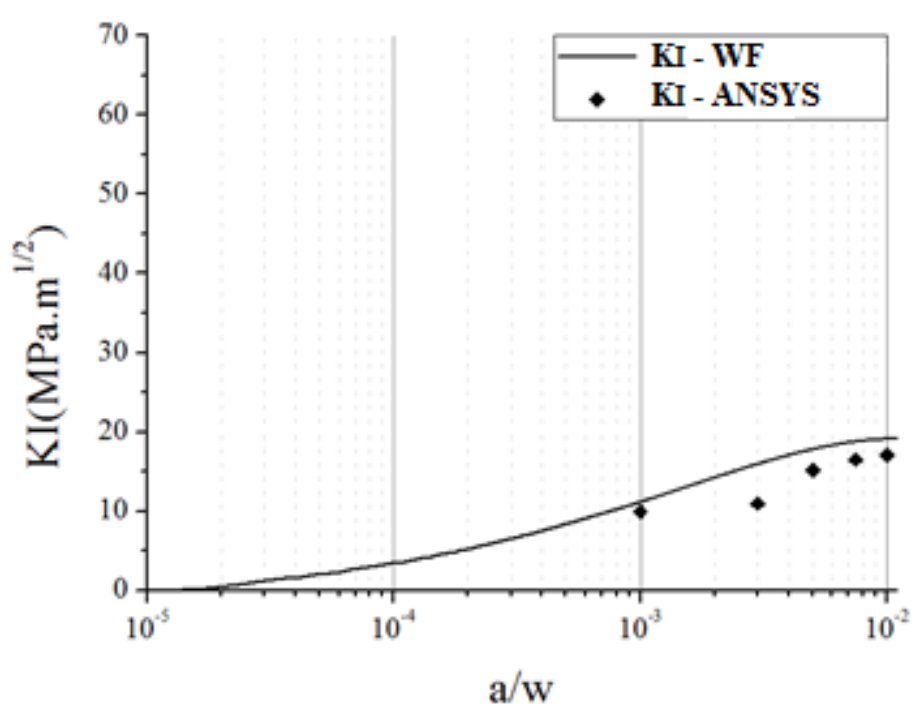

Figura 191 - Valores de KI obtidos por função de peso (WF) e com trinca inclinada inicialmente $\left(\mathbf{6 0}^{\circ}\right)$ Fonte: (R̂̂GO, 2017)

\subsection{DETERMINAÇÃO DE $K_{e l}$}

Após as simulações numéricas, os campos de tensão foram extraídos em 15 intervalos com 200 pontos cada, seguindo a trajetória retilínea abaixo da coordenada do pico de tensão normal na superfície do espécime. Este valor corresponde ao número máximo que o ANSYS permite extrair para cada solicitação. Quanto mais próximo à superfície, menor foi o intervalo entre as coordenadas verticais utilizadas, de modo que dos 3000 pontos obtidos em cada simulação para o campo de tensão, mais de 2600 se encontravam ainda dentro dos quadrados de refinamento geométrico. Isso foi feito para que se obtivesse uma maior precisão dos valores de tensão sob o efeito do contato. 
A extração dos valores das tensões e suas coordenadas correspondentes permitiu, através da Equação 33, o cálculo do fator de intensidade de tensão elástico em modo I. Assim, para cada parâmetro variado, gerou-se uma nova simulação e uma curva de FIT correspondente, totalizadas em 36. Os fatores de intensidade de tensão elásticos consideram a não linearidade da distribuição de tensões ao longo da trajetória da trinca. Para o caso da formação de uma trinca predominante, os parâmetros M1, M2 e M3 apresentados na Equação 37 são calculados conforme a Eq. 50, apresentadas por TADA et al.(2000).

Eq. (50)

$$
\begin{aligned}
& M_{1}=\frac{-0.029207+\frac{a}{w}\left\{0.213074+\frac{a}{w}\left[-3.029553+\frac{a}{w}\left(5.901933-\frac{a}{w} 2.657820\right)\right]\right\}}{1.0+\frac{a}{w}\left(-1.259723+\frac{a}{w}\left\{-0.048475+\frac{a}{w}\left[0.481250-\frac{a}{w}\left(-0.526796+\frac{a}{w} 0.345012\right)\right]\right\}\right)} \\
& M_{2}=\frac{0.451116+\frac{a}{w}\left\{3.462425+\frac{a}{w}\left[-1.078459+\frac{a}{w}\left(3.558573-\frac{a}{w} 7.553533\right)\right]\right\}}{1.0+\frac{a}{w}\left(-1.496612+\frac{a}{w}\left\{0.764586+\frac{a}{w}\left[-0.659316-\frac{a}{w}\left(0.258506+\frac{a}{w} 0.114568\right)\right]\right\}\right)} \\
& M_{3}=\frac{0.427195+\frac{a}{w}\left\{-3.730114+\frac{a}{w}\left[16.276333+\frac{a}{w}\left(-18.799956+\frac{a}{w} 14.112118\right)\right]\right\}}{1.0+\frac{a}{w}\left(-1.129189+\frac{a}{w}\left\{0.033758+\frac{a}{w}\left[0.192114+\frac{a}{w}\left(-0.658242+\frac{a}{w} 0.554666\right)\right]\right\}\right)}
\end{aligned}
$$

Onde a é o tamanho da trinca e w é a espessura do espécime.

A validação da função de peso utilizada foi feita comparando-se os valores obtidos pela mesma com os de um modelo elaborado no ANSYS com uma trinca e carga remota aplicada. A Figura 192 representa o modelo elaborado, para o qual a/w=0,5 e o círculo interno $\mathrm{C} 1$ continha elementos de $5 \mu \mathrm{m}$ e o círculo externo continha elementos de $50 \mu \mathrm{m}$. O valor encontrado para $K_{I}$ foi de $2.445,2 \mathrm{MPa} \mathrm{mm}^{1 / 2}$ usando o ANSYS e 2.464,2 MPa mm ${ }^{1 / 2}$ por função de peso (RÊGO, 2017). Logo, uma diferença de $0,8 \%$ foi obtida. 


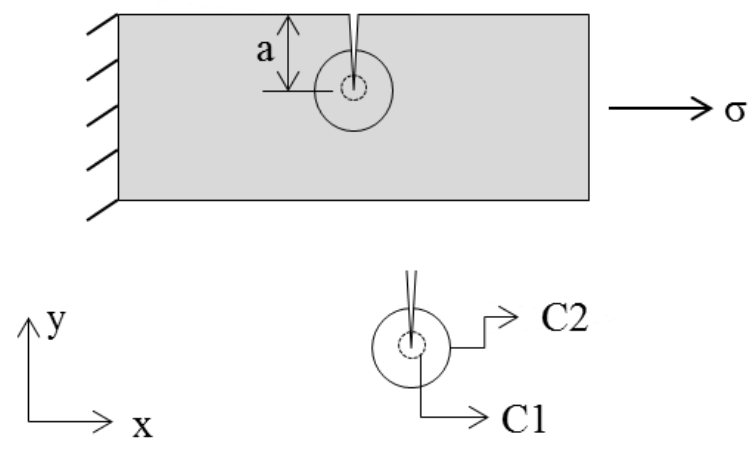

Figura 192 - Modelo numérico com trinca para validação da função de peso (Fonte: Rêgo, 2017)

A diferença entre os valores obtidos por função de peso e pelo modelo com trinca no ANSYS é ilustrada na Figura 193.

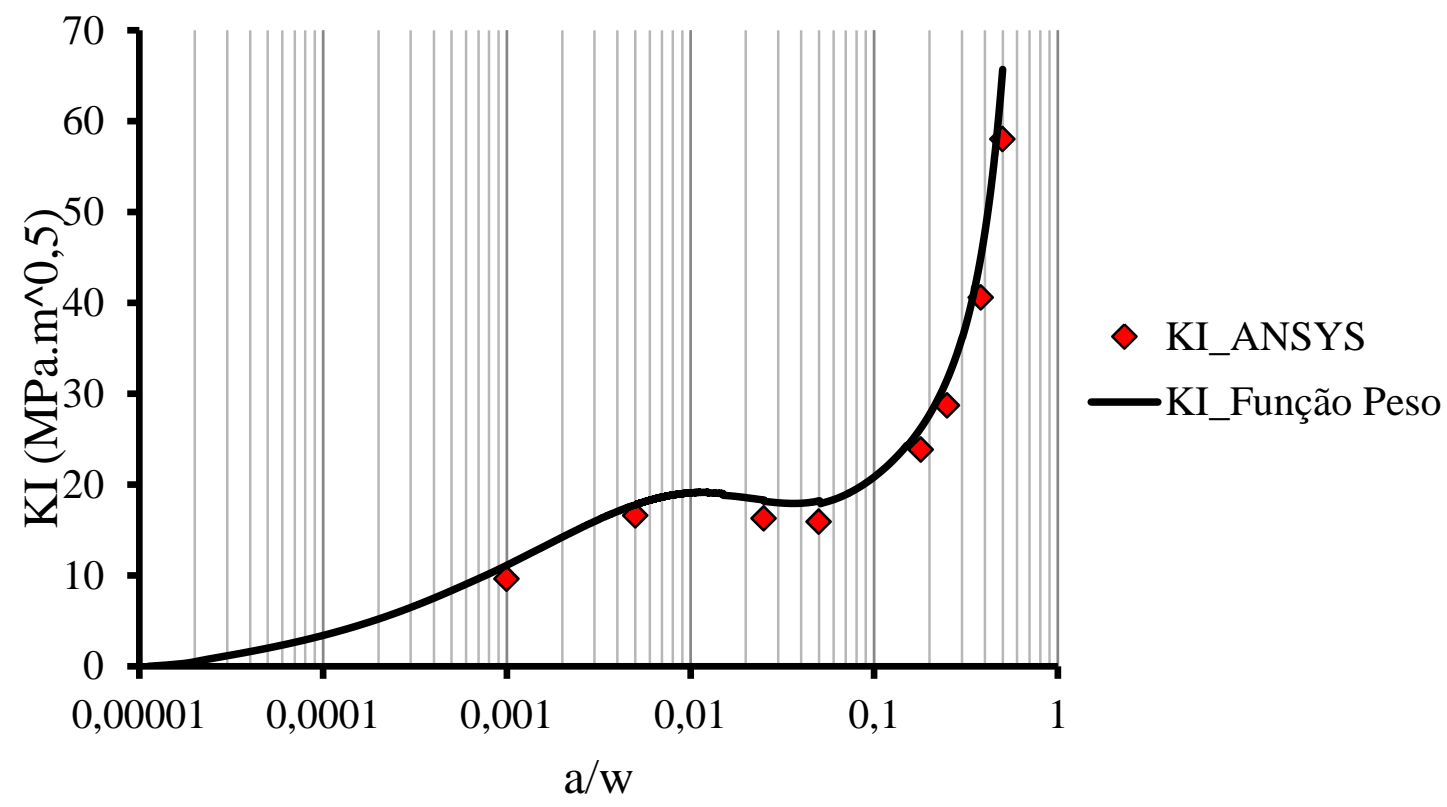

Figura 193 - Comparação entre a função de peso (WF) e o modelo numérico (Fonte: RÊGO, 2017, adaptado)

\subsection{DETERMINAÇÃO DE $K_{p}$}

O cálculo do fator de intensidade de tensão modificado proposto por GHAREMANI et al. (2016) é então finalmente computado pela Equação 51, a qual também pode ser escrita na forma:

$K_{p}=\frac{K_{e l}}{K_{r e f}}=\frac{K_{e l}}{f\left(\frac{a}{w}\right) \Delta \sigma_{b u l k} \sqrt{\pi a}}=\frac{K_{e l}}{F \sqrt{\pi a}}$ 
A Figura 194 ilustra os efeitos das variações do coeficiente de atrito nos valores de $K_{p}$. Para um mesmo material, quanto maior o coeficiente de atrito, maiores os valores de $K_{p}$ obtidos para uma mesma carga remota de fadiga aplicada. Isto se deve ao aumento nos valores de $K_{e l}$ mas não os de $K_{r e f}$, porquanto a tensões oriundas do contato exerçam influência. Isto fica mais visível para valores de trincas menores, as quais ainda sofrem enorme influência destas tensões. Nota-se também que há convergência das diversas curvas de $K_{p}$ antes mesmo do fim da zona de influência de contato, a qual foi definida por JOHNSON (1985) como $\mathrm{z}=0,78 \mathrm{a}$, fornecendo $\mathrm{z}=0,44 \mathrm{~mm}$ ou $\mathrm{a} / \mathrm{w}=0,176$ para o caso da Fig. 194. Isto ocorre porque os incrementos de tensão causados pelo aumento do coeficiente de atrito são pequenos, sendo apenas apreciáveis para pequenos valores de a/w. Por fim, é perceptível que as curvas de $K_{p}$ apresentaram excelentes ajustes, cujas equações são apresentadas em anexo, junto das demais curvas e equações para as ligas de alumínio e titânio, as quais apresentaram comportamentos similares.

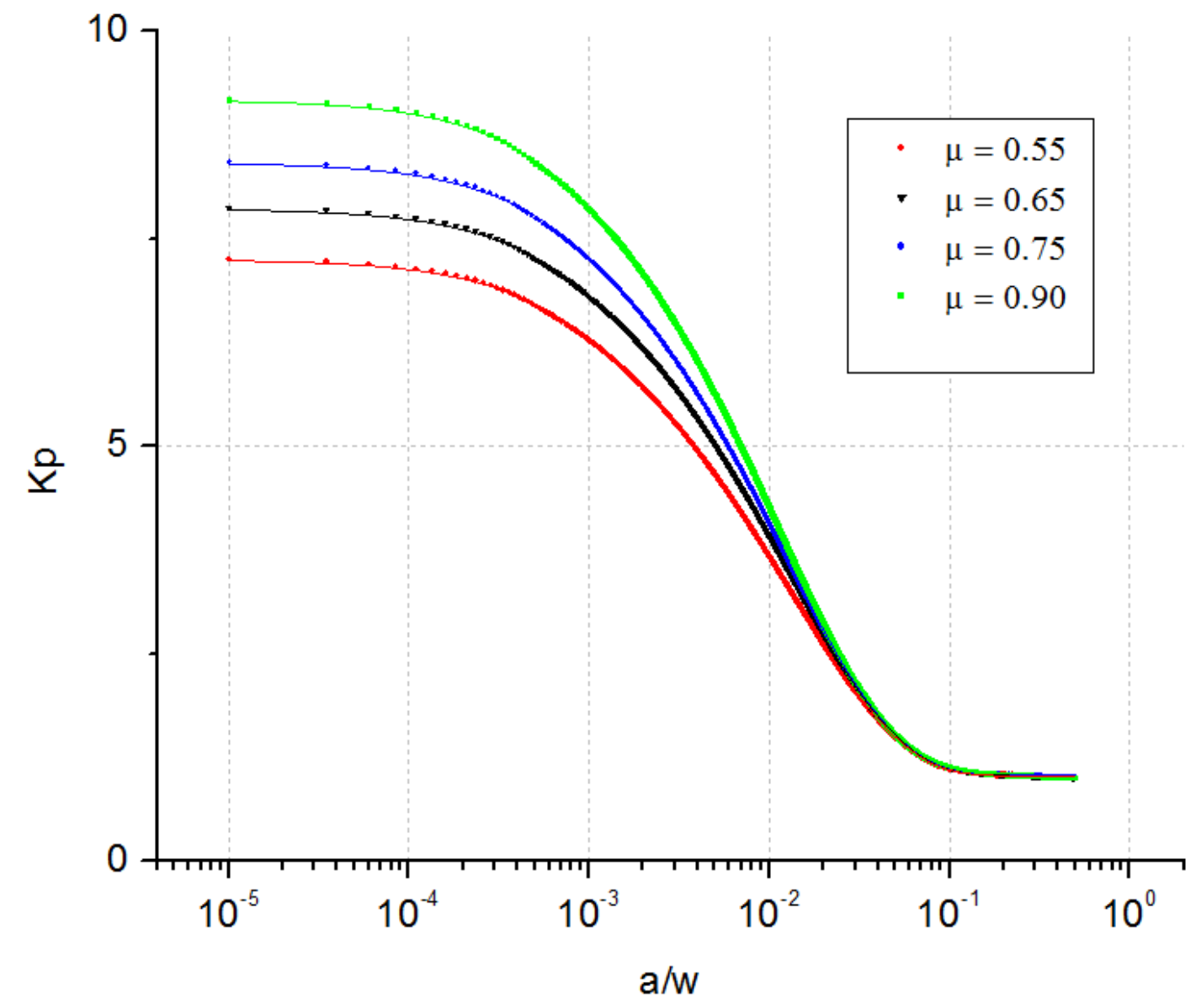

Figura 194 - Aço - Curvas de $K_{p}$ e seus respectivos ajustes para $\sigma_{\text {bulk }}=100 \mathrm{MPa}$ variando $\mu$ 
A Figura 195 por sua vez ilustra, para um mesmo material, os efeitos da variação da carga remota de fadiga para coeficientes de atrito fixos. Quanto maior a carga aplicada, menor o valor de $\mathrm{K}_{\mathrm{p}}$ para pequenas razões de $\mathrm{a} / \mathrm{w}(\approx 0.005)$. Isto ocorre porque aumentar a carga remota faz com que os valores de $\mathrm{K}_{\mathrm{ref}}$ sejam acrescidos substancialmente mais que os de $\mathrm{K}_{\mathrm{el}}$. Percebe-se, também, que quando comparadas às curvas ilustradas anteriormente, há uma mudança na declividade das mesmas. A convergência das curvas de $\mathrm{K}_{\mathrm{p}}$ no caso de alteração das cargas remotas de fadiga ocorre apenas quando a pressão de contato não exerce praticamente influência no crescimento da trinca. Embora a curva de ajuste para a carga remota de $60 \mathrm{MPa}$ mostre resultados satisfatórios até $\mathrm{a} / \mathrm{w} \approx 0,03$, trincas maiores não poderiam ser previstas de forma consistente e confiável. Comportamentos similares foram obtidos para outros coeficientes de atrito e também para a liga de titânio sob tal carregamento, a qual apresentou resultados ligeiramente melhores. No entanto, a liga de alumínio apresentou bons ajustes para todos os níveis de carga remota de fadiga e coeficientes de atrito.

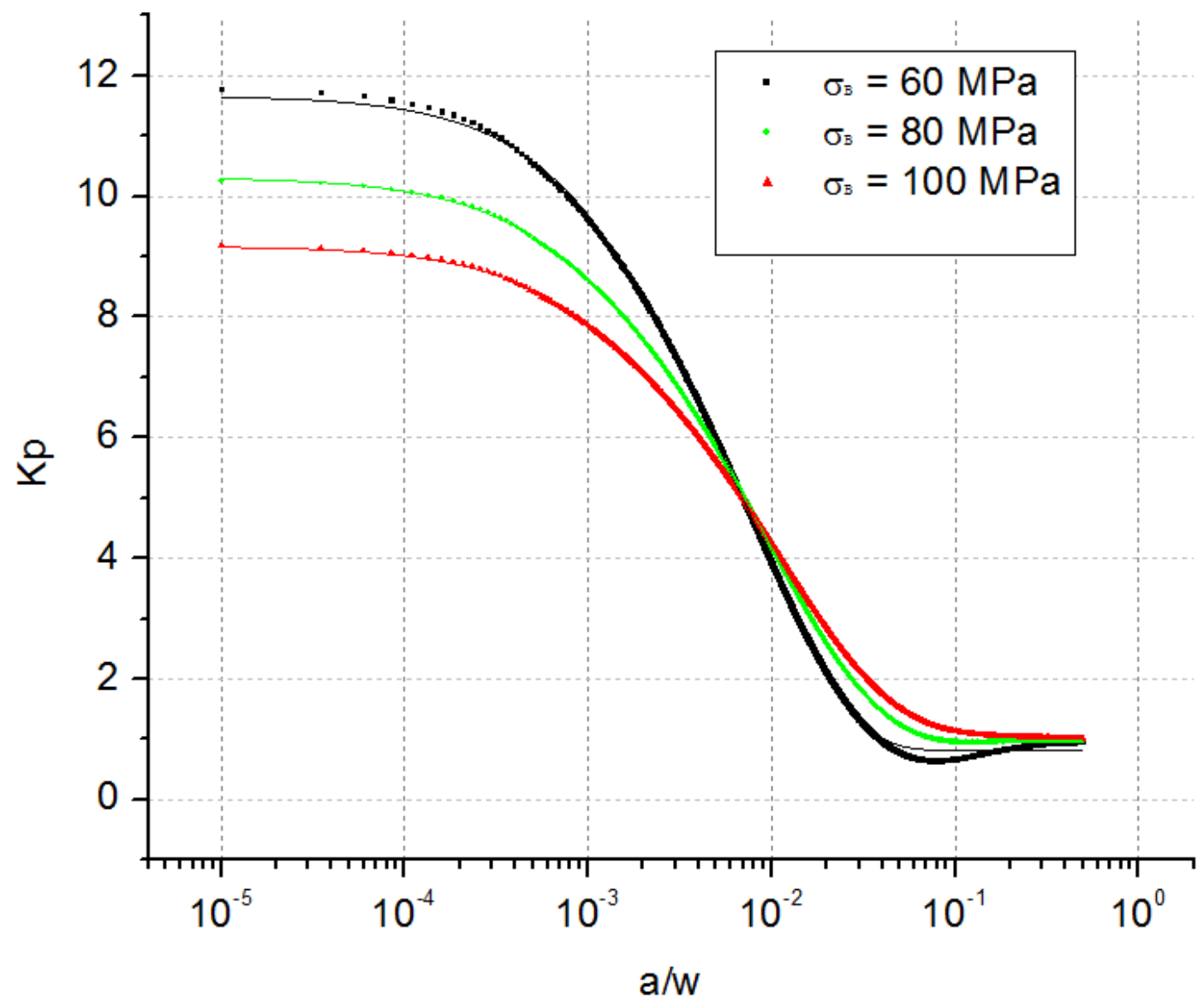

Figura 195 - Aço - Curvas de $\mathbf{K}_{\mathbf{p}}$ e seus respectivos ajustes para $\mu=0,9$ variando as cargas remotas de fadiga 
Para coeficientes de atrito e cargas remotas de fadiga fixos com variação de materiais, as curvas de $K_{p}$ e seus respectivos ajustes são apresentados na Figura 196. Quanto maior o módulo de elasticidade do material, maiores os valores de $\mathrm{K}_{\mathrm{p}}$ encontrados para um mesmo tamanho de trinca. Quanto maior a pressão de contato, maiores os valores de $\mathrm{K}_{\mathrm{el}}$, mas não há significativa alteração para $\mathrm{K}_{\mathrm{ref}}$. Assim, as curvas de $\mathrm{K}_{\mathrm{p}}$ comportaram-se de maneira esperada, visto que o aumento do módulo de elasticidade resulta em uma maior pressão de contato aplicada ao espécime. Portanto, materiais mais rígidos apresentam maiores valores de $\mathrm{K}_{\mathrm{p}}$ para pequenas trincas (a/w $\approx 0,009$ neste caso), invertendo-se o cenário para quando a influência da zona de contato se reduz, pois $\mathrm{K}_{\text {ref }}$ - agora ligeiramente aumentado - permanece inalterado, enquanto os incrementos de $\mathrm{K}_{\mathrm{el}}$ se reduzem. As curvas de $\mathrm{K}_{\mathrm{p}}$ foram bem ajustadas, exceto quando o espécime foi submetido à carga remota mínima, para a qual apenas o alumínio apresentou bom ajuste. Tal ocorrência deveu-se provavelmente aos efeitos extremos causados pelo alto módulo de elasticidade do aço combinado aos efeitos de cargas remotas baixas, tornado a curva de $\mathrm{K}_{\mathrm{p}}$ não suave, com estrutura similar as obtidas em fatores concentradores de tensão $\mathrm{K}_{\mathrm{t}}$.

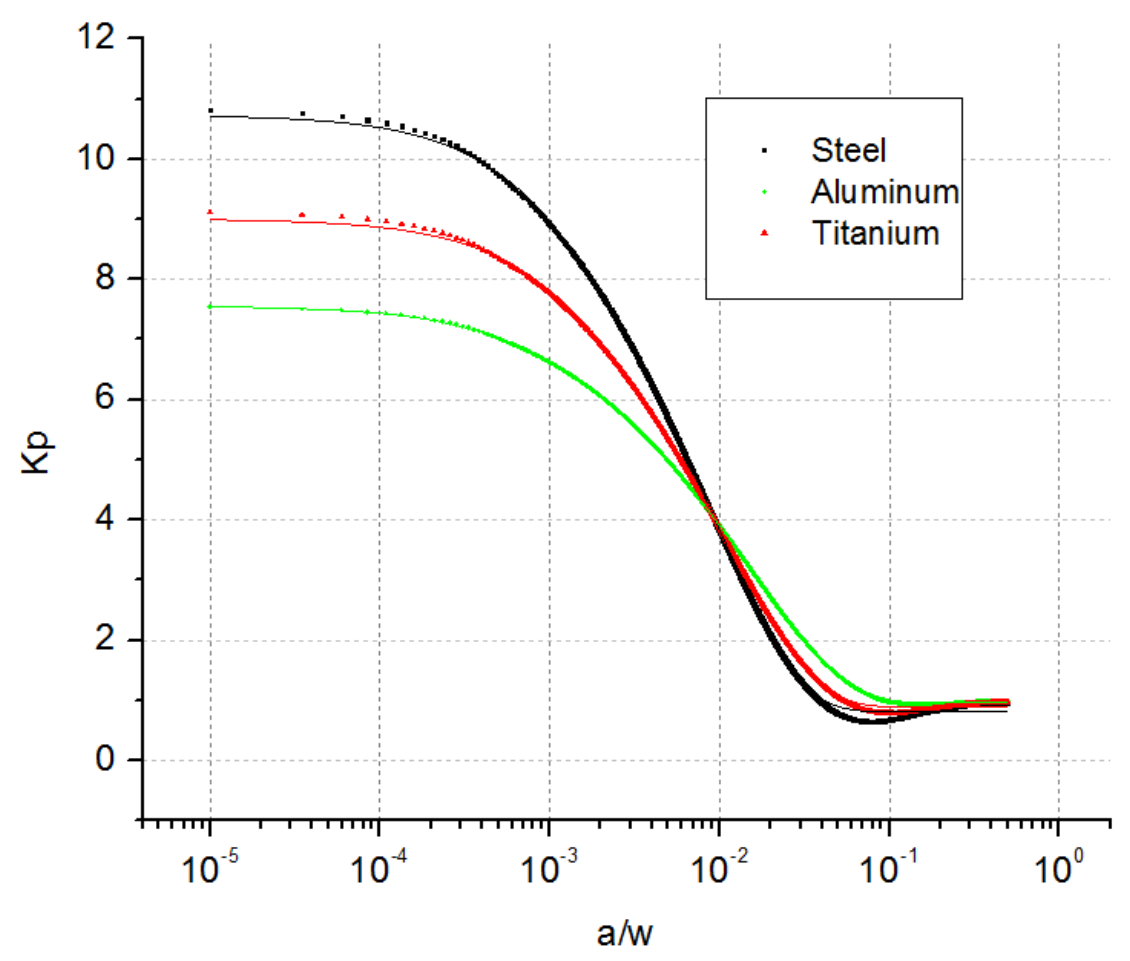

Figura 196 - Ligas de titânio, aço e alumínio - Curvas de Kp e seus respectivos ajustes para $\mu=0,65$ e $\sigma_{\text {bulk }}=100 \mathrm{MPa}$ 
Por fim, a Figura 197 demonstra as consequências da variação dos raios do pad com todos os demais parâmetros fixos. Quanto menor o raio do $\mathrm{pad}$, maior o valor de $\mathrm{K}_{\mathrm{p}}$ até valores de $\mathrm{a} / \mathrm{w} \approx 0,01$. Tal comportamento mostra-se em acordo com a hipótese anterior de que maiores pressões de contato causariam $\mathrm{K}_{\mathrm{el}}$ a se elevarem inicialmente de forma mais abrupta, enquanto $\mathrm{K}_{\text {ref }}$ aumentaria apenas ligeiramente. Pads menores produzem menor área de contato e maiores pressões de contato para uma mesma carga de aperto. As curvas obtidas foram suaves e puderam ser facilmente ajustadas.

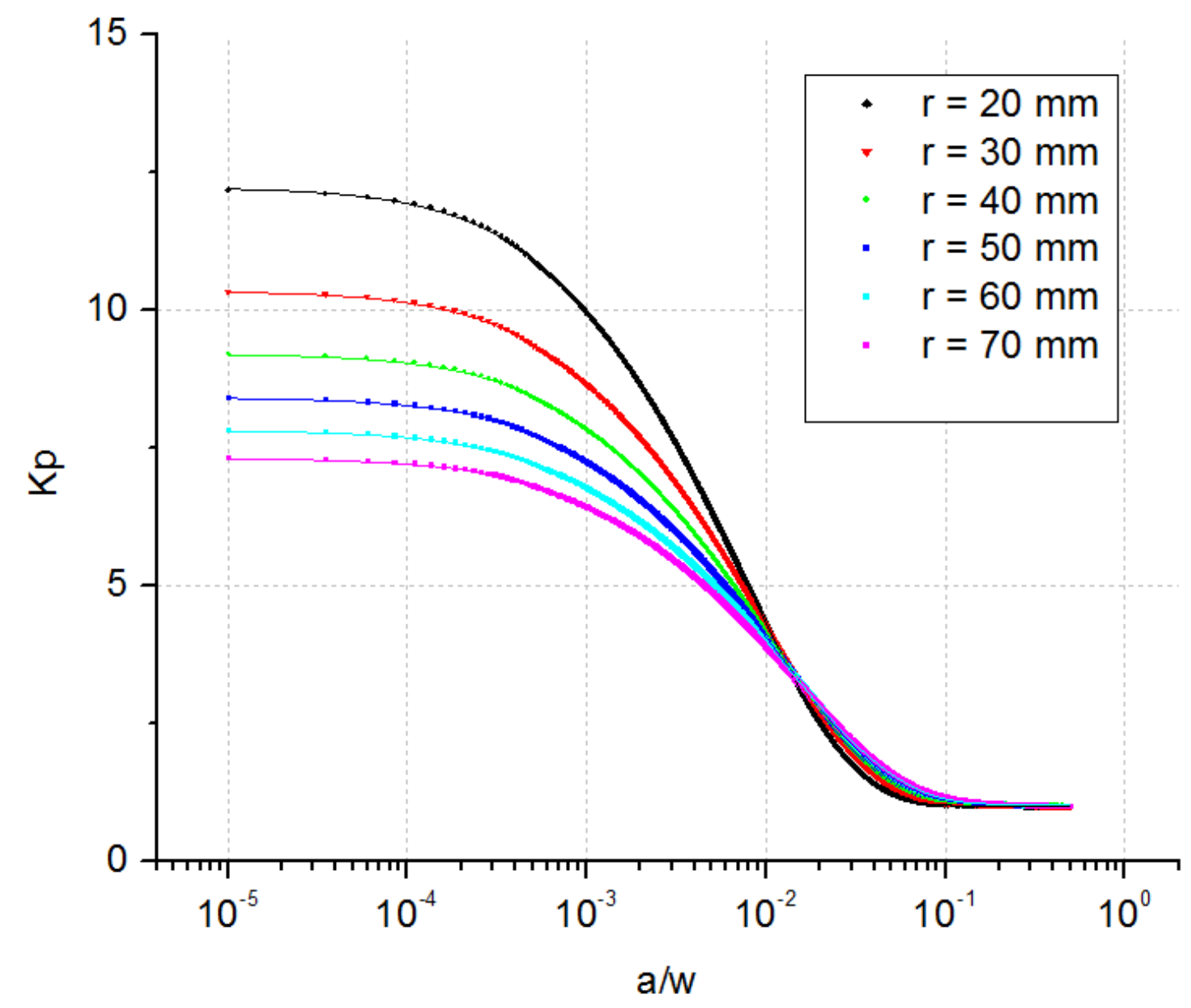

Figura 197 - Aço - Curvas de $\mathrm{K}_{\mathrm{p}}$ para $\sigma_{\text {bulk }}=100 \mathrm{MPa}$ e $\mu 0.75$ variando o raio do pad 


\subsection{EFEITOS DA NEGLIGÊNCIA DE $K_{I I}$}

Até o presente momento, todos os cálculos foram feitos para o modo I de fratura, onde há predominância das forças trativas no surgimento da trinca. Embora os campos de tensão, apresentados na seção 4.6, indiquem que não há tensões cisalhantes significativas quando comparadas com as tensões trativas, é razoável comprovar que a adoção do fator de intensidade de tensão para modo I se aproxima muito do caso misto (modo I + modo II).

Primeiramente, foi conduzida uma análise no ANSYS, como havia sido feito na seção 4.9, com o intuito de se determinar os $K_{I I}$ para a mesma geometria apresentada na Figura 192. A mesma função de peso previamente utilizada para o modo I foi adotada e bons resultados foram obtidos até $\mathrm{a} / \mathrm{w} \approx 0,1$, conforme demonstra a Figura 198.

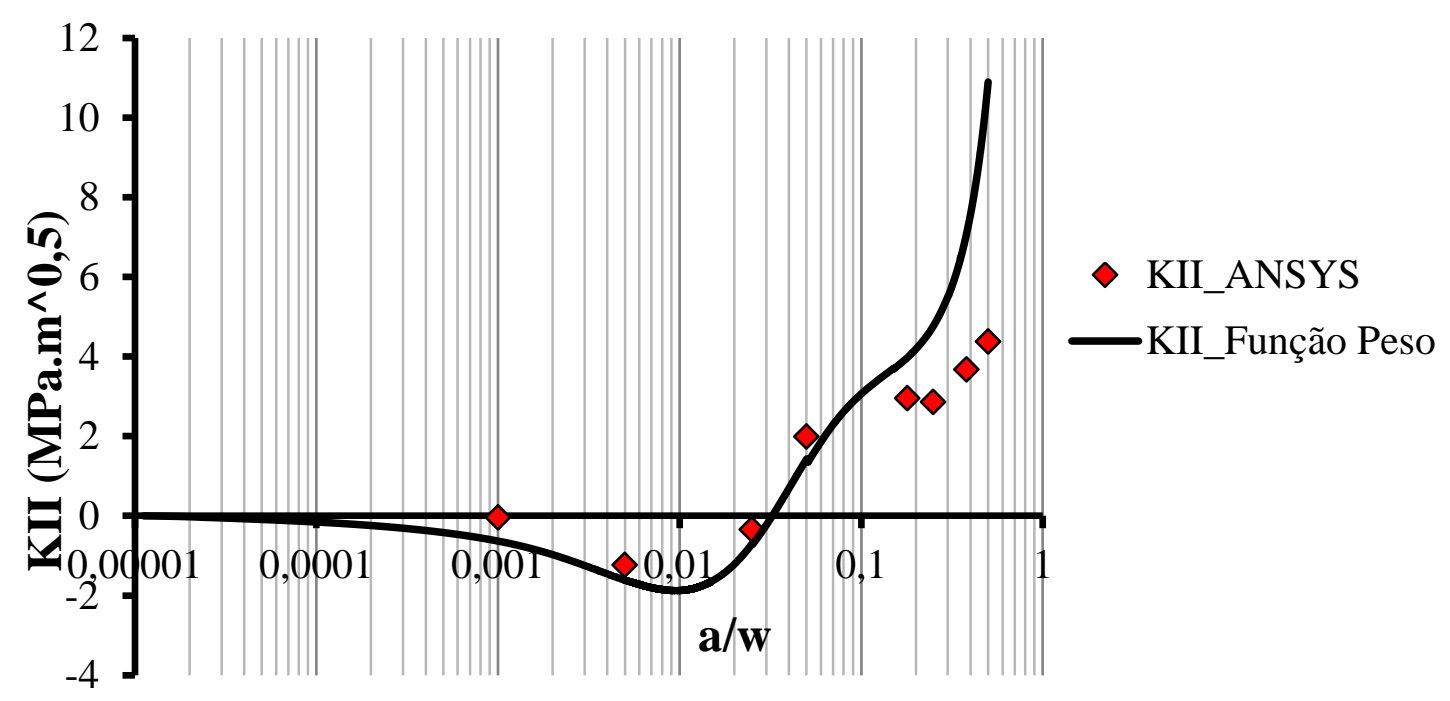

Figura 198 - Conformidade entre os resultados numéricos e pela função de peso para o modo II - (Fonte: RÊGO, 2017, adaptado)

Os resultados obtidos pela função de peso foram então utilizados para se computar os fatores de intensidade de tensão em modo misto. A Figura 199 ilustra a comparação entre $K_{I}$ e $K_{I I}$. 


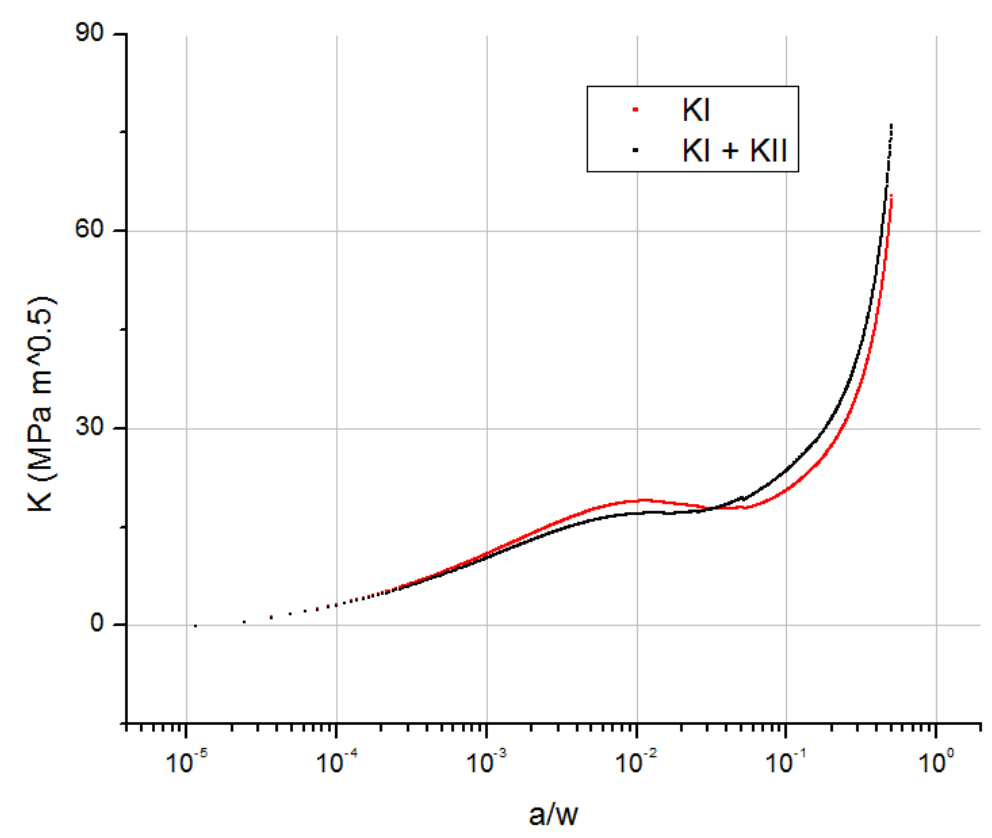

Figura 199 - Comparação entre os FIT no modo misto e modo I

Os resultados obtidos mostram que os fatores de intensidade de tensão para modo I ou para o modo misto são muito próximos. A diferença média entre os dois resultados foi de aproximadamente $3,43 \%$ e, portanto, os efeitos de $K_{I I}$ serão ignorados neste estudo.

\subsection{USO DE $K_{p}$ EM FRETTING FATIGUE}

Os resultados apresentados neste trabalho foram computados para trincas com propagação bidimensional. Como trincas reais propagam-se em estruturas tridimensionais, é necessário fazer uma correção dos primeiros valores, chamados de fatores de correção 3D, como os propostos por NAVARRO et al. (2003) e NEWMAN et al. (1984). Uma segunda correção necessária está relacionada a simplificação de uma trinca completamente retilínea. O trabalho de NAVARRO et al. (2003), por exemplo, sugere um valor de 0,78 para a liga de Al-7075. Seria necessário estabelecer os fatores de correção adequados em comparação com dados experimentais, uma vez que os diferentes materiais podem apresentar trajetórias de trincas diferentes.

Embora os resultados dos $K_{p}$ corrigidos consideram a presença da trinca ao longo do trecho onde foram extraídos os campos de tensão, eles são limitados a limitação das tensões elásticas locais. Contudo, para a análise de fretting, os efeitos plásticos presentes nos materiais, sobretudo na região de contato, não podem ser ignorados. Para isto, é necessário que se utilize a Mecânica da Fratura Baseada em Deformação, a qual 
computa os FIT utilizando deformações, ao contrário da Mecânica da Fratura Linear Elástica, a qual utilizaria as tensões para computá-los.

Para uma linha de tensão infinita de espessura w e um tamanho de trinca a, submetida a uma tensão normal $\sigma$ em modo I, o fator de intensidade de tensão em modo I é computador pela Equação 52:

$K_{I}=K_{\text {ref }}=f\left(\frac{a}{w}\right) \Delta \sigma_{\text {bulk }} \sqrt{\pi a}$

Onde:

$f\left(\frac{a}{w}\right)=\Delta \sigma_{b u l k} \sqrt{\pi a}\left(0,857+0,265\left[\frac{a}{w}+\left(1-\frac{a}{w}\right)^{5,5}\right]\right) /\left(1-\frac{a}{w}\right)^{1,5}$

A Equação 52 é justamente o denominador da Equação (51). Quando submetido a um entalhe ou a um fator concentrador de tensão, o FIT é modificado para levar em consideração a nova condição de contorno (neste estudo, o fator concentrador de tensão é causado pela pressão de contato exercida pelo pad no espécime, simulando a problemática do fretting). O cálculo do fator concentrador de tensão pode prosseguir caso seja possível calcular o fator de intensidade de tensão elástico, $K_{e l}$.

Para se obter o histórico de deformações abaixo da superfície do espécime e suas respectivas tensões, os $K_{p}$ são então utilizados com a regra de Neuber e as curvas cíclicas de Ramberg-Osgood (uma para cada material). Os dados de saída podem ser então utilizados em uma lei de crescimento de trinca, como a de Paris-Erdogan modificada (Equação 30), obtendo-se a vida associada ao crescimento da trinca. 


\section{CONCLUSÃO}

Neste trabalho, foram apresentados um estudo bibliométrico indicando as tendências de estudos numéricos do fenômeno de fretting, assim como resumos de alguns estudos recentes acerca do tema. Isto permitiu ao leitor visualizar o que tem sido estudado dentro do assunto e como isso tem sido feito, também mostrando a importância do estudo do fenômeno em questão.

Uma abordagem para a utilização de um fator concentrador de tensão modificado $K_{p}$ foi então proposta, cuja determinação deu-se por meio do método dos elementos finitos em conjunto com função de peso. As propriedades destas funções, as quais permitem a superposição de efeitos, permitiu que uma análise de uma simulação numérica baseada no método dos elementos finitos sem o surgimento de trinca fosse extrapolada para o caso em que as mesmas estivessem presentes.

Foram, então, expostas as diversas minúcias envolvidas na construção do modelo numérico que emulava a situação de fretting, onde um pad estava em contato com um espécime sob carga remota de fadiga: a necessidade de se controlar a carga tangencial de reação $\mathrm{Q}$, o coeficiente de atrito, a carga de aperto $\mathrm{P}$ e a própria carga remota de fadiga. Tais fatores precisavam ser controlados para que se garantisse a condição de deslizamento parcial entre o pad e o espécime, situação que se desejava estudar. Percebeu-se a presença de esforços reativos indesejáveis no modelo (por conta de momento fletor), mas de magnitudes desprezíveis. No entanto, uma sugestão para trabalhos futuros é eliminar a presença dos mesmos.

Os critérios para as escolhas dos parâmetros envolvidos foram então explicados, assim como as simplificações adotadas. Uma vez estabelecidos, os diferentes resultados foram validados com soluções teóricas e numéricas. Para a validação analítica, os resultados foram comparados com as soluções propostas por HILLS \& NOWELL (1994), demonstrando resultados satisfatórios. Já a validação numérica, também apresentando boa conformidade, foi elaborada comparando-se os resultados obtidos através das funções de pesos com resultados extraídos de funções pré-embutidas do programa ANSYS. O estudo então demonstrou os efeitos de simplificações adotadas, justificando sua adoções. 
Os diversos $K_{p}$ foram computados e ilustrados junto de suas curvas de ajustes. Em seguida, foram apresentadas as análises de seus comportamentos, os quais concordam com as previsões da literatura (como, por exemplo, de seu efeito ocorrer até a profundidade prevista por JOHNSON (1985). A despeito da complexidade da natureza intrínseca ao fretting, as curvas obtidas para os diferentes $K_{p}$ mostraram boa previsibilidade no comportamento e, pelo menos para a maioria dos casos, puderam ser perfeitamente ajustadas em equações.

Trabalhos futuros poderão calibrar os valores obtidos levando-se em conta também outras propriedades envolvidas em fretting, como por exemplo, a carga de aperto, a carga de reação Q, entre outros. A comparação numérica com ligas específicas com propriedades experimentais determinadas mostra-se interessante para futura calibração, visto que assim os fatores de correção supracitados poderiam ser devidamente determinados. É necessário que se aplique em trabalhos futuros o proposto na seção 4.11 .

Por fim, acredita-se que o modelo desenvolvido neste trabalho propõe uma forma simples para se estimar a vida à fretting fatigue. Com as sugestões realizadas, é possível criar um banco de dados vasto quiçá de aplicabilidade industrial. 


\section{REFERÊNCIA BIBLIOGRÁFICA}

ANSYS, Inc. (2010), Customer Training Material, ANSYS Mechanical Structural

Nonlinearities

BAIETTO, M. C., PIERRES, E., GRAVOUIL, A., BERTHEL, B., FOUVRY, S., \& TROLLE, B. (2013). Fretting fatigue crack growth simulation based on a combined experimental and XFEM strategy. International Journal of Fatigue, 47, 31-43.

BANNANTINE, J. A., COMER, J. J., \& HANDROCK, J. L. (1989). Fundamentals of Metal Fatigue Analysis .pdf. New Jersey: Prentice Hall.

BENHAMENA, A., ABDELWAHEB, A., TALHA, A., \& BENSEDDIQ, N. (2012). Effect of contact forces on fretting fatigue behavior of bolted plates: Numerical and experimental analysis. Tribology International, 48, 237-245.

CALLISTER JR., W. D. (2000). Ciência e Engenharia de Materiais: Uma introdução (5th ed.). LTC.

CARDOSO, R. A. (2015). Problema de propagação de trincas em condições de fretting. Dissertação de mestrado, Universidade de Brasília.

CASTro, J. T. P. de, \& MEGGiOlARO, M. A. (2009a). FADIGA, Técnicas e Práticas de Dimensionamento Estrutural sob Cargas Reais de Serviço. Volume 1 - Iniciação de trincas.

CASTRO, J. T. P. de, \& MEGGIOLARO, M. A. (2009b). FADIGA, Técnicas e Práticas de Dimensionamento Estrutural sob Cargas Reais de Serviço”. Volume 2 Propagação de Trincas, Efeitos Térmicos e Estocásticos.

CIGRE. (2006) Fatigue Endurance Capability of Conductor / Clamp Systems - Update of Present Knowledge. Cigre, n. August 2005, p. 1-58

DABAYEH, A. A.; BERUBE, A. J.; TOPPER, T. H. (1998) An experimental study of the effect of a flaw at a notch root on the fatigue life of cast $\mathrm{Al} 319$. International Journal of Fatigue, v. 20, n. 7, p. 517-530.

DING, J., KANG, G., ZHU, Y., \& ZHU, M. (2014). Finite element analysis on bending fretting fatigue of 316L stainless steel considering ratchetting and cyclic hardening. International Journal of Mechanical Sciences, 86, 26-33.

ESTARLE, R. F. D. S. (2014). Avaliação comparativa para estimativa da parada de trincas curtas na fadiga por fretting. Dissertação de Mestrado, Universidade de Brasília.

EWING, J. A., \& HUMPHREY, J. C. W. (1903). The fracture of metals under repeated alternation of stress.

FADEL, A. A.,(2010), Avaliação do efeito de tracionamento em elevados níveis de EDS sobre a resistência em fadiga do condutor IBIS(CAA 397,5 MCM), Tese de doutorado, Universidade de Brasília.

FERJAOUI, A., YUE, T., ABDEL W., M., \& HOJJATI-TALEMI, R. (2015). Prediction of fretting fatigue crack initiation in double lap bolted joint using Continuum 
Damage Mechanics. International Journal of Fatigue, 73, 66-76.

FOULQUIER, J. (1988). Comportement en fretting fatigue des alliages T7175 et 2124 T351. Rapport Aerospatiale.

GHAREMANI, K.; WALBRIDGE, S.; TOPPER, T. (2016) A methodology for variable amplitude fatigue analysis of HFMI treated welds based on fracture mechanics and small-scale experiments. Engineering Fracture Mechanics, v. 163, p. 348-365.

GINER, E., NAVARRO, C., SABSABI, M., TUR, M., DOMINGUEZ, J., \& FUENMAYOR F. J. (2011). Fretting fatigue life prediction using the extended finite element method. International Journal of Mechanical Sciences, 53(3), 217225.

GLINKA, G., \& REINHARDT. (2000). Calculation of stress intensity factors for cracks of complex geometry and subjected to arbitrary nonlinear stress fields. Fatigue and Fracture Mechanics $31^{\text {st }}$ volume, p348-370.

GLINKA, G., \& SHEN, G. (1991). Universal features of weight functions for cracks in mode I. Engineering Fracture Mechanics, 40(6), 1135-1146.

GODET, M. (1990), Third-bodies in tribology. Wear, 136(1):29-45.

GRIFFITH, A. A. (1921). The Phenomena of Rupture and Flow in Solids. Philosophical Transactions of the Royal Society of London.

HILLS, D. A., \& NOWELL, D. (1994). Mechanics of Fretiing Fatigue.

HIN, T. S., (2004), Engineering materials for biomedic application. World Scientific Publishing Co.

HOEPPNER, D. W., CHANDRASEKARAN, V. \& ELLIOT CHARLES B. (2000), Fretting fatigue: current technology and practices, ASTM international.

HURRICKS, P. L. (1970). The mechanism of fretting: A review. Wear, 15:389-409.

INGLIS, C. E. (1913). Stress in a plate due to the presence of cracks and sharp corners. Transactions of the Intitution of Naval Architects.

IRWIN, G. R. (1957), On the stress distribution at the base of a stationary crack.

JOHNSON, K. L. (1985). Contact Mechanics. Cambridge University Press.

KIM, H. S., MALL, S., \& GHOSHAL, A. (2011). Two-Dimensional and ThreeDimensional Finite Element Analysis of Finite Contact Width on Fretting Fatigue. Materials Transactions, 52(2), 147-154.

LEMATRIE, J., \& CHABOCHE, J.-L. (1990). Mechanics of solid materials. Cambridge University Press.

LÉVESQUE, F., Goudreau, S., Cloutier, L., \& Cardou, A. (2011). Finite element model of the contact between a vibrating conductor and a suspension clamp. Tribology International, 44(9), 1014-1023.

LINDROTH, P., MARQUIS, G., \& GLINKA, G. (2013). Fatigue crack growth of 
arbitrary planar cracks in welded components. Welding in the World, 57(3), 425435.

LIU, J., SHEN, H. M., \& YANG, Y. R. (2014). Finite element implementation of a varied friction model applied to torsional fretting wear. Wear, 314(1-2), 220-227.

LUKE, M., BURDACK, M., MOROZ, S., \& VARFOLOMEEV, I. (2016).

Experimental and numerical study on crack initiation under fretting fatigue loading. International Journal of Fatigue, 86, 24-33.

MADGE, J. J., LEEN, S. B., McCOLL, I. R., \& SHIPWAY, P. H. (2007). Contactevolution based prediction of fretting fatigue life: Effect of slip amplitude. Wear, 262(9-10), 1159-1170.

MAJZOOBI, G. H., \& R., H. (2010). Trans. Ind. Inst. Met.

MUTOH, Y., JAYAPRAKASH, M., ASAI, K., \& ICHIKAWA, K. (2010). Effect of contact pad rigidity and fretting fatigue design curve. Transactions of the Indian Institute of Metals, 63(2-3), 181-186.

NAMJOSHI, A., MALL, S., JAIN, V. K., JIN, O. (2002). Fretting fatigue crack initiation in Ti-6Al-4V, Fatigue Fracture Engineer Material Structural 25, 955-964.

NAVARRO, C., GARCÍA, M., \& DOMÍNGUEZ, J. (2003). A procedure for estimating the total life in fretting fatigue. Fatigue \& Fracture of ..., 459-468.

NEWMAN, J.C. \& RAJU, I.S. (1984), Stress-intensity factor equations for crack in three-dimensional finite bodies subjected to tension and bending loads. NASA Techcnical Memorandum 86793.

NIGRO, C., SUN, L., MERIAUX, J., \& PROUDHON, H. (2014). Microstructural simulations of the initiation and propagation of short fretting cracks in a Ti-6Al-4V contact. Tribology International, 74, 103-109.

NOROOZI, A. H., GLINKA, G., \& LAMBERT, S. (2005). A two parameter driving force for fatigue crack growth analysis. International Journal of Fatigue, 27(1012), 1277-1296.

NOWELL, D. \& HILLS, D. A. (1987), Mechanics of fretting fatigue tests, Pergamon Journals Ltd., Int. J. Mech. Sci. Vol. 29, No. 5, pp. 355-365

PENG, J.F., ZHU, M.H., CAI, Z.B., LIU, J.H., ZUO, K.C., SONG, C. \& WANG, W.J. (2014), On the damage mechanisms of bending fretting fatigue. Tribology international 76, p.133-141.

PIERRES, E., BAIETTO, M. C., GRAVOUIL, A., \& MORALES-ESPEJEL, G. (2010). 3D two scale X-FEM crack model with interfacial frictional contact: Application to fretting fatigue. Tribology International, 43(10), 1831-1841.

PROUDHON, H., SUN, L.,MERIAUX, J., RUIZ-SABARIEGO, J. A., \& CAITELLAUD, G. (2013). Simulation microstructurale de la propagation de fissure courtes dans un contact de fretting em TA6V. Matér Tech.

QI, G. (2013). Computational Modeling for Stress Analysis of Overhead Transmission 
Line Stranded Conductors Under Design and Fretting Fatigue Conditions, 207.

RAMMOHAN, Y. S., \& MURTHY, H. (2012). Three dimensional finite element analysis of partial slip contacts subjected to combined loading. Finite Elements in Analysis and Design, 56, 9-19.

RÊGO, E. M. F. do, \& MIRANDA, A. C. de O. (2016). Análises numéricas para estudo de fretting em cabos. Congresso Nacional de Engenharia Mecânica.

RÊGO, E. M. F. do (2017). Qualificação de tese, Universidade de Brasília.

ROSSMANITH, H. P. (1982). Grundlagen der Bruchmechanik. Springer.

STEPHENS, R. I., FATEMI, A., STEPHENS, R. R., \& FUCHS, H. O. (2001). Metal Fatigue in Engineering (2nd ed.). Willey-Interscience. http://doi.org/10.1115/1.3225026

SURESH, S., (1998), Fatigue of Materials, $1^{\text {st }}$ Edition, Cambridge University Press.

SZOLWINSKI, M.P. \& FARRIS T.N (1998), Observation, analysis and prediction of fretting fatigue in 2024-T351 aluminum alloy. Wear 221, 24-36.

TADA, H., PARIS, P. C., \& IRWIN, G. R. (2000). The Stresses Analysis of Cracks Handbook (3rd ed.). ASME Press. http://doi.org/10.1115/1.801535

TALEMI, R. H., WAHAB, M. A., \& BAETS, P. De. (2011). Numerical modelling of fretting fatigue. Journal of Physics: Conference Series, 305, 12061.

TALEMI, R.H, WAHAB, M. A., PAUW, J. De \& BAETS, P. De.( 2014). Prediction of fretting fatigue crack initiation and propagation for cylindrical contact configuration, Tribology International 76, p 73-91.

VINGSBO, O., \& SODERBERG, S. (1988). ON FRETTING WEARS. WEAR 126.

YASTREBOV, V. A. (2010), Introduction to computational contact mechanics. WEMESURF short course on contact mechanics and tribology.

WANG, X., \& GLINKA, G. (2009). Determination of approximate point load weight functions for embedded elliptical cracks. International Journal of Fatigue, 31(1112), 1816-1827.

ZHOU, Z. R., \& VINCENT, L. (2002). Fretting Wear. Science Press. 
ANEXO I - Demais gráficos de $K_{p}$

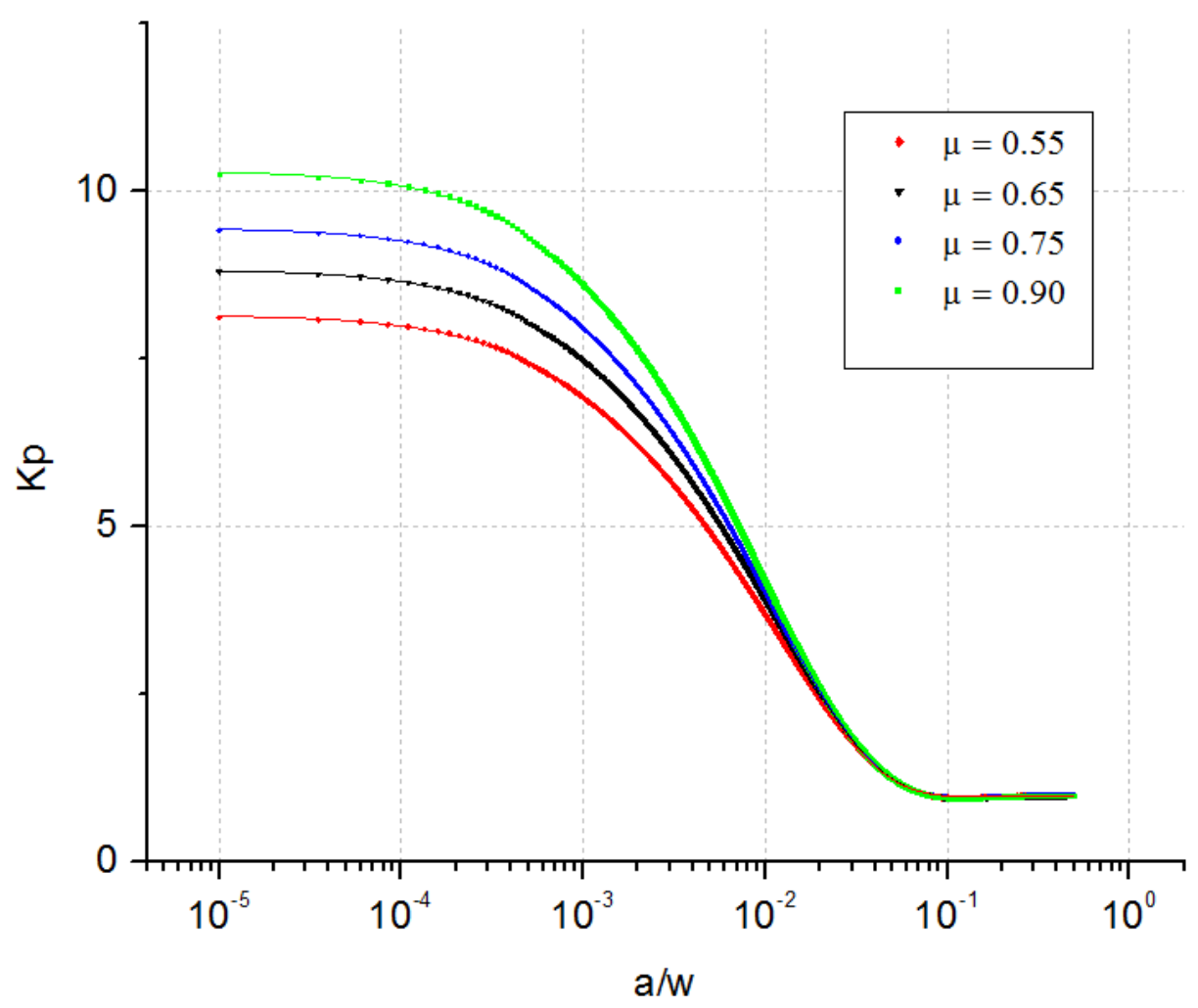

Figura $200-$ Aço $-\sigma_{\text {bulk }}=80 \mathrm{MPa}$

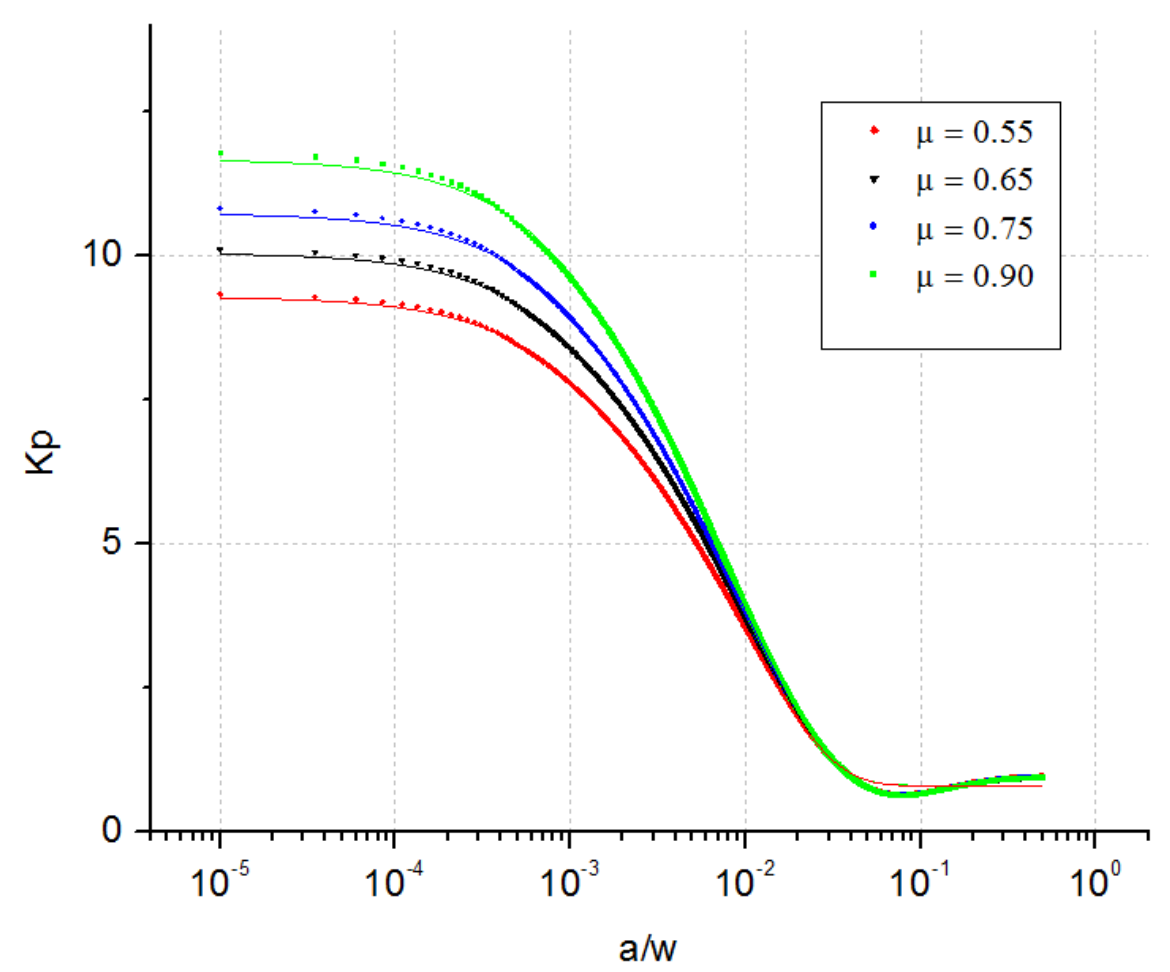

Figura $201-$ Aço $-\sigma_{\text {bulk }}=60 \mathrm{MPa}$ 


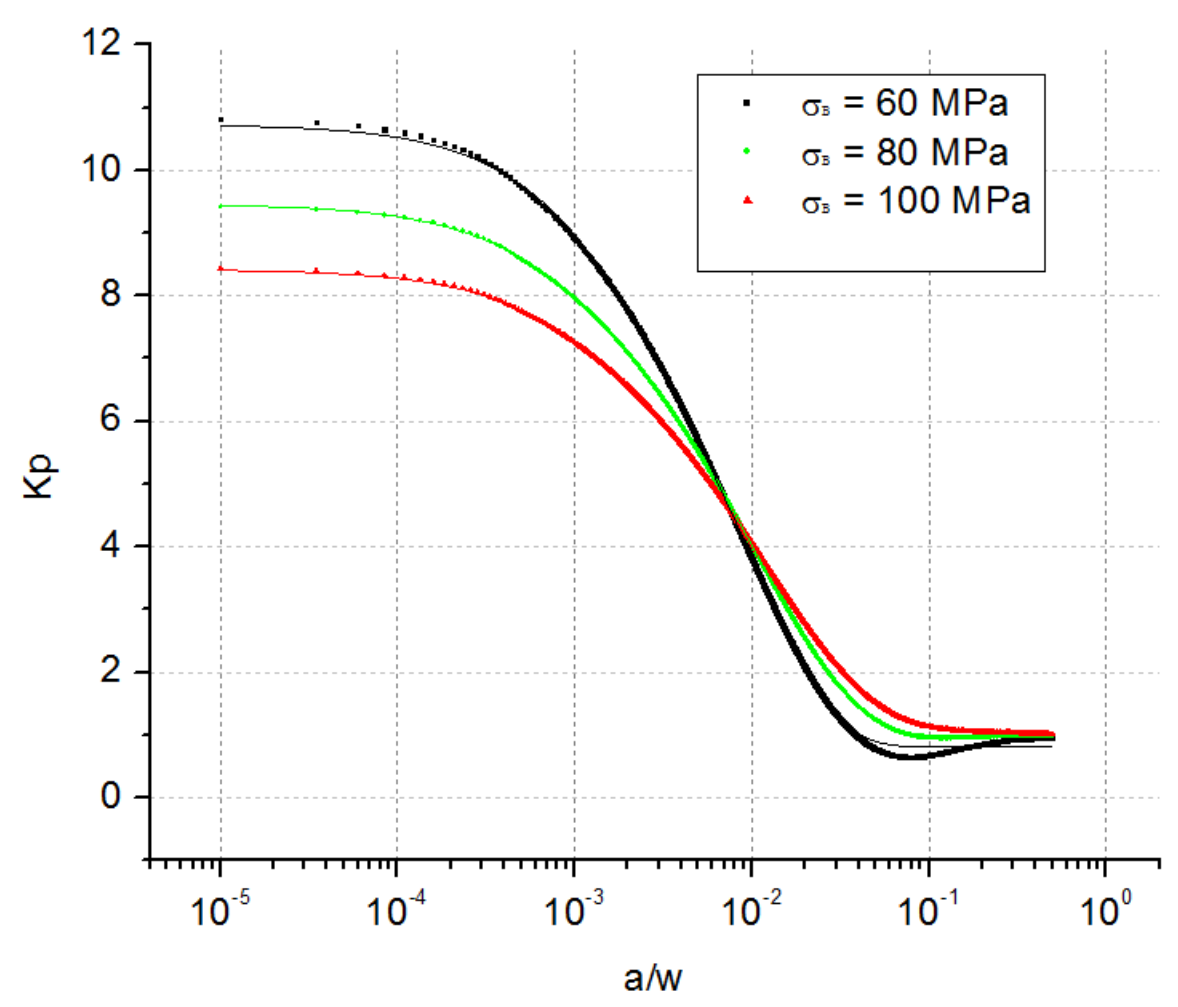

Figura 202 - Aço - $\mu$ 0,75

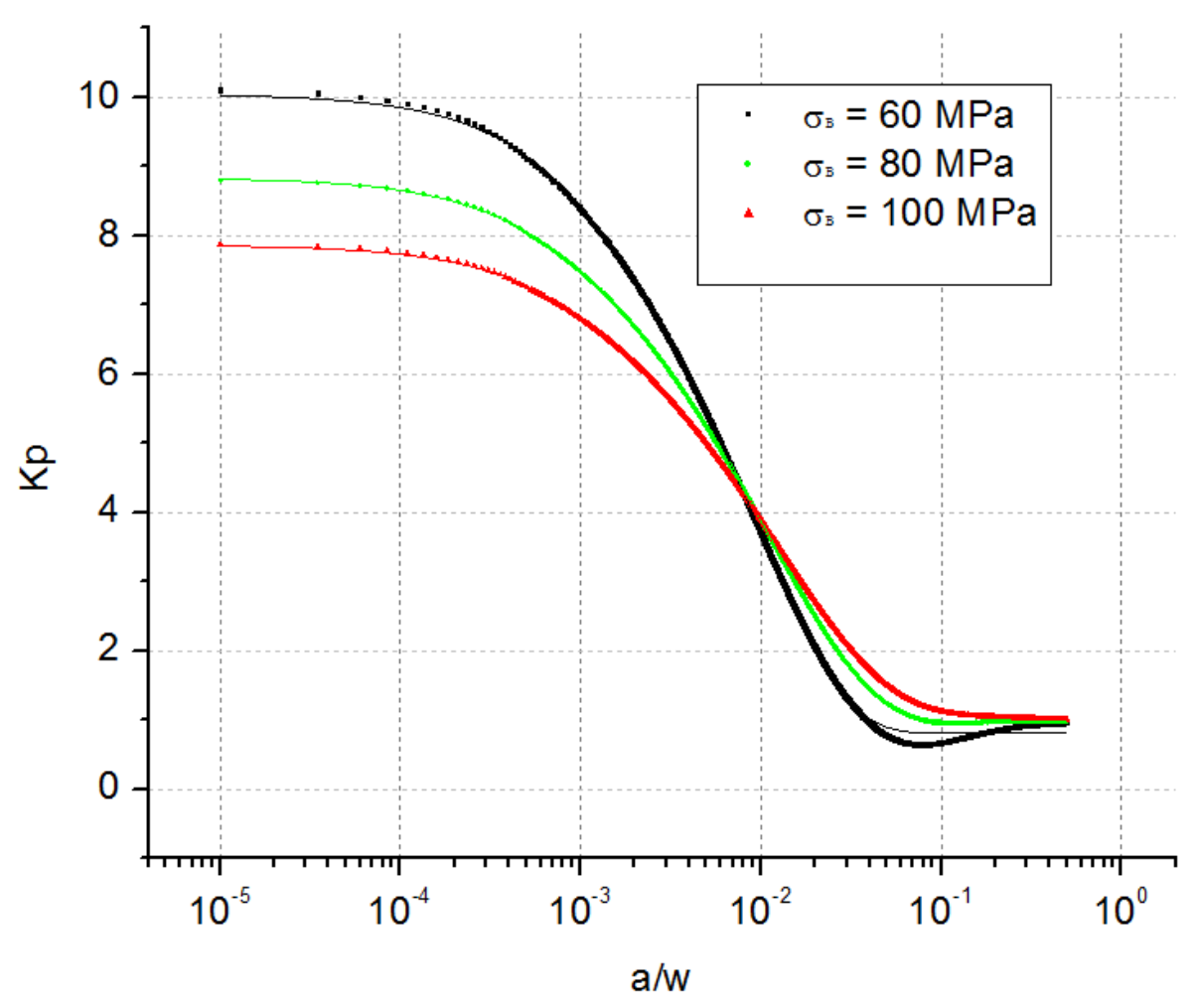

Figura 203 - Aço - $\mu$ 0,65 


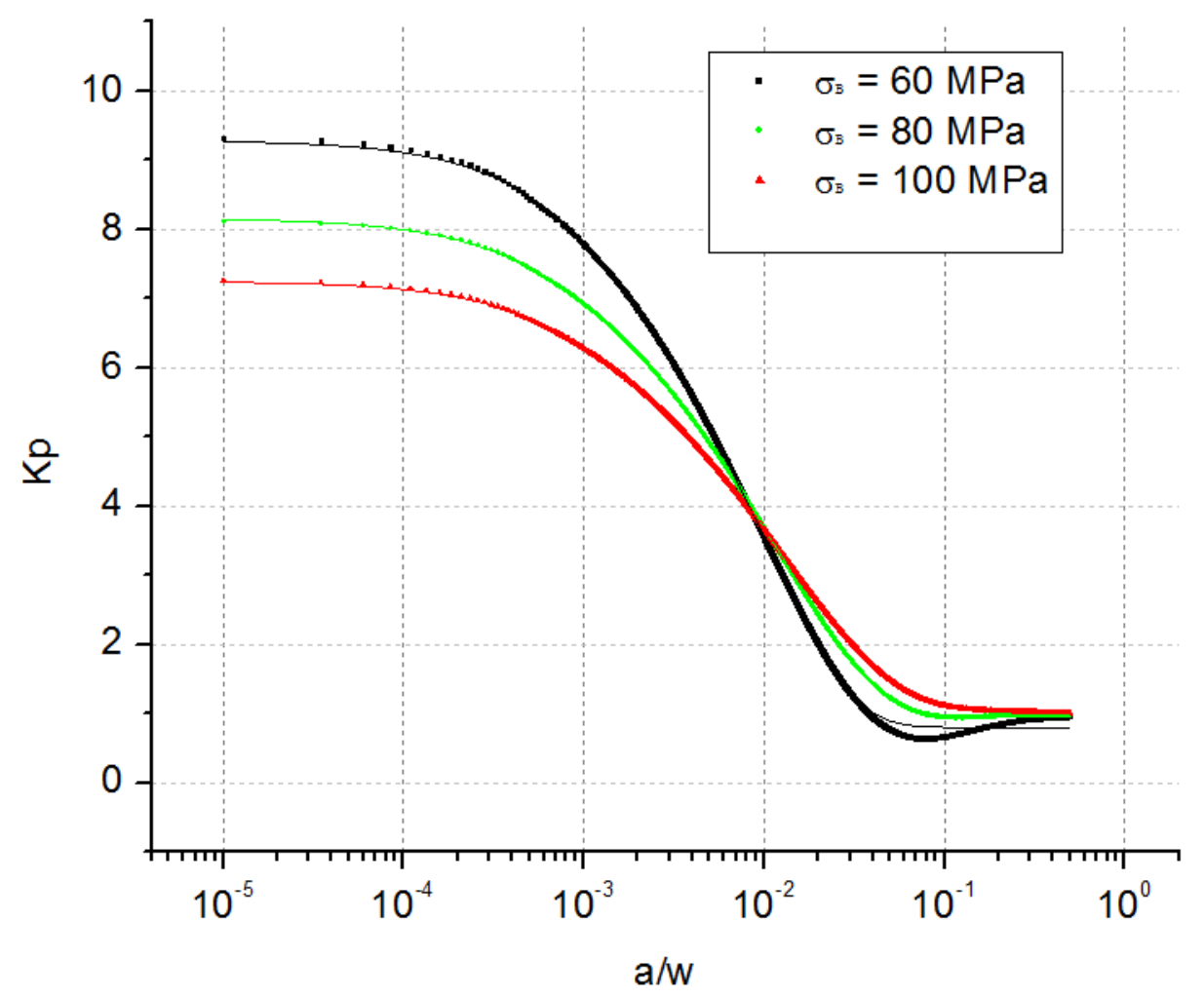

Figura 204 - Aço - $\mu$ 0,55

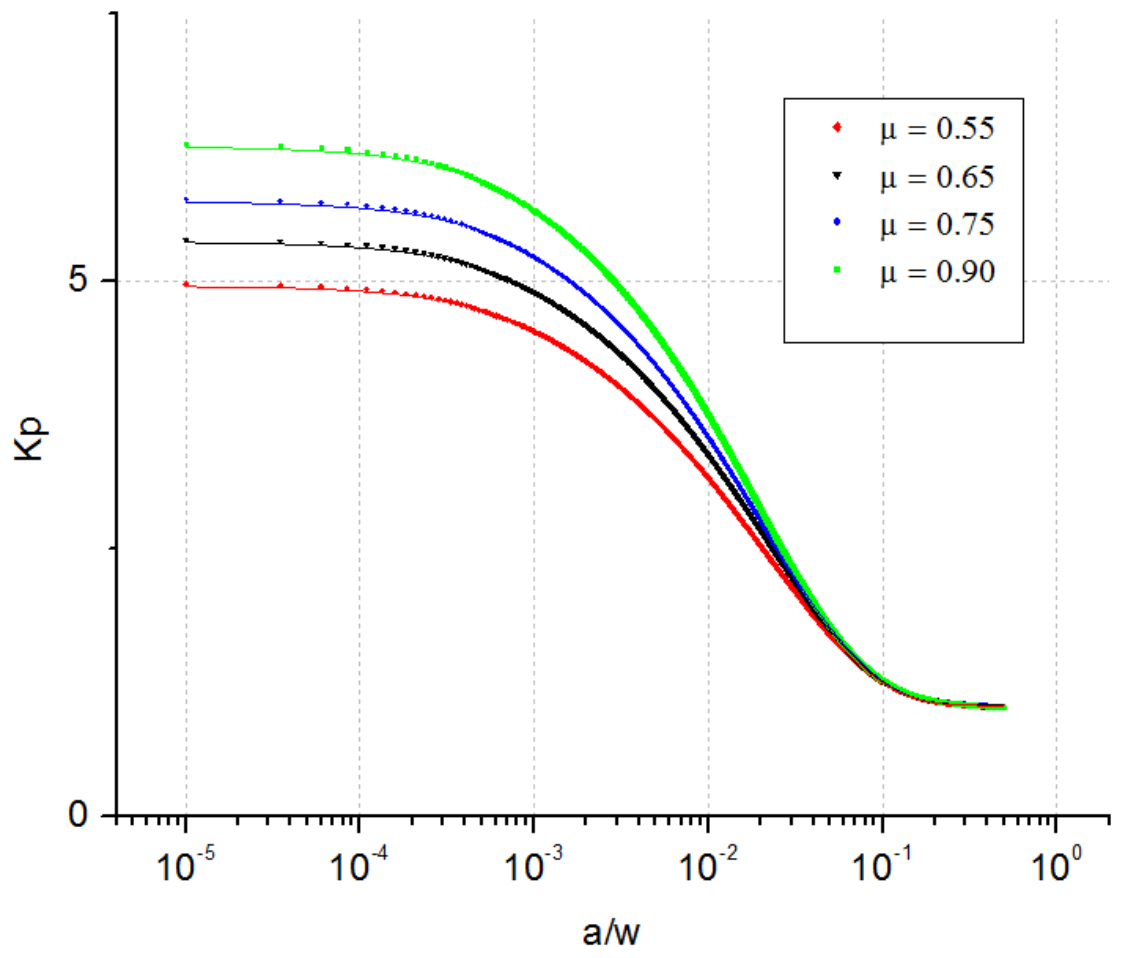

Figura $205-$ Alumínio $-\boldsymbol{\sigma}_{\text {bulk }}=100 \mathrm{MPa}$ 


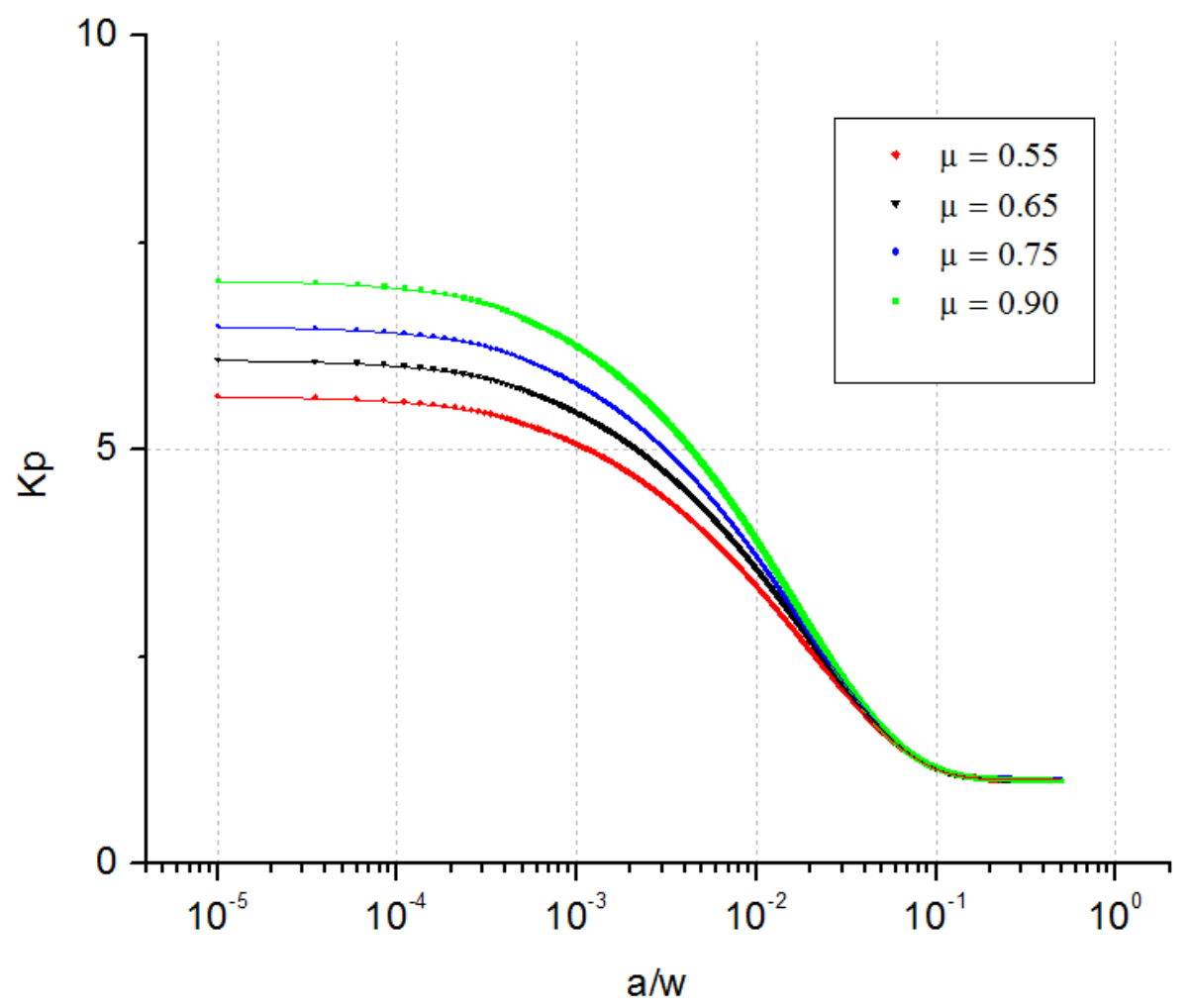

Figura 206 - Alumínio $-\sigma_{\text {bulk }}=80 \mathrm{MPa}$

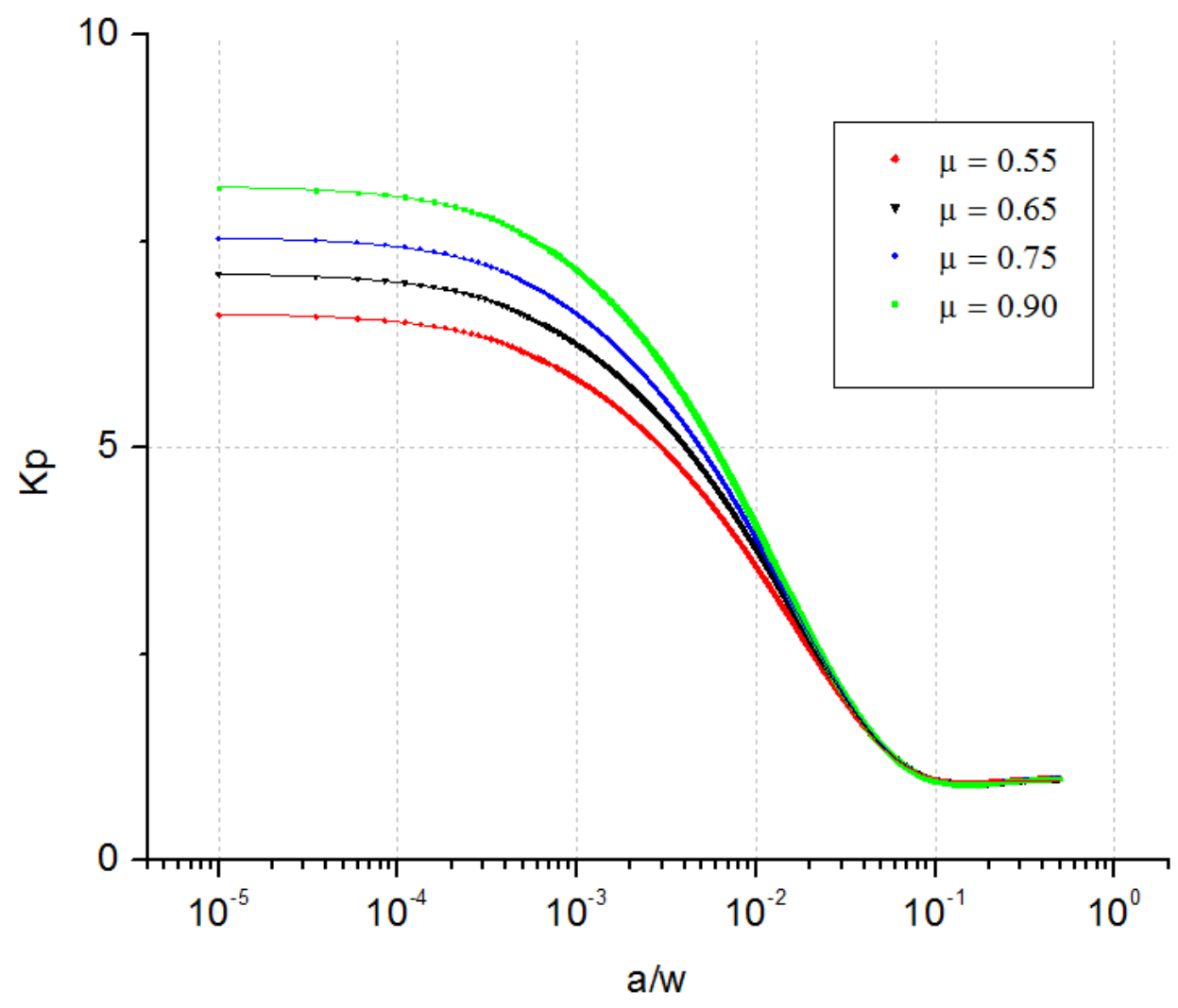

Figura 207 - Alumínio $-\sigma_{\text {bulk }}=60 \mathrm{MPa}$ 


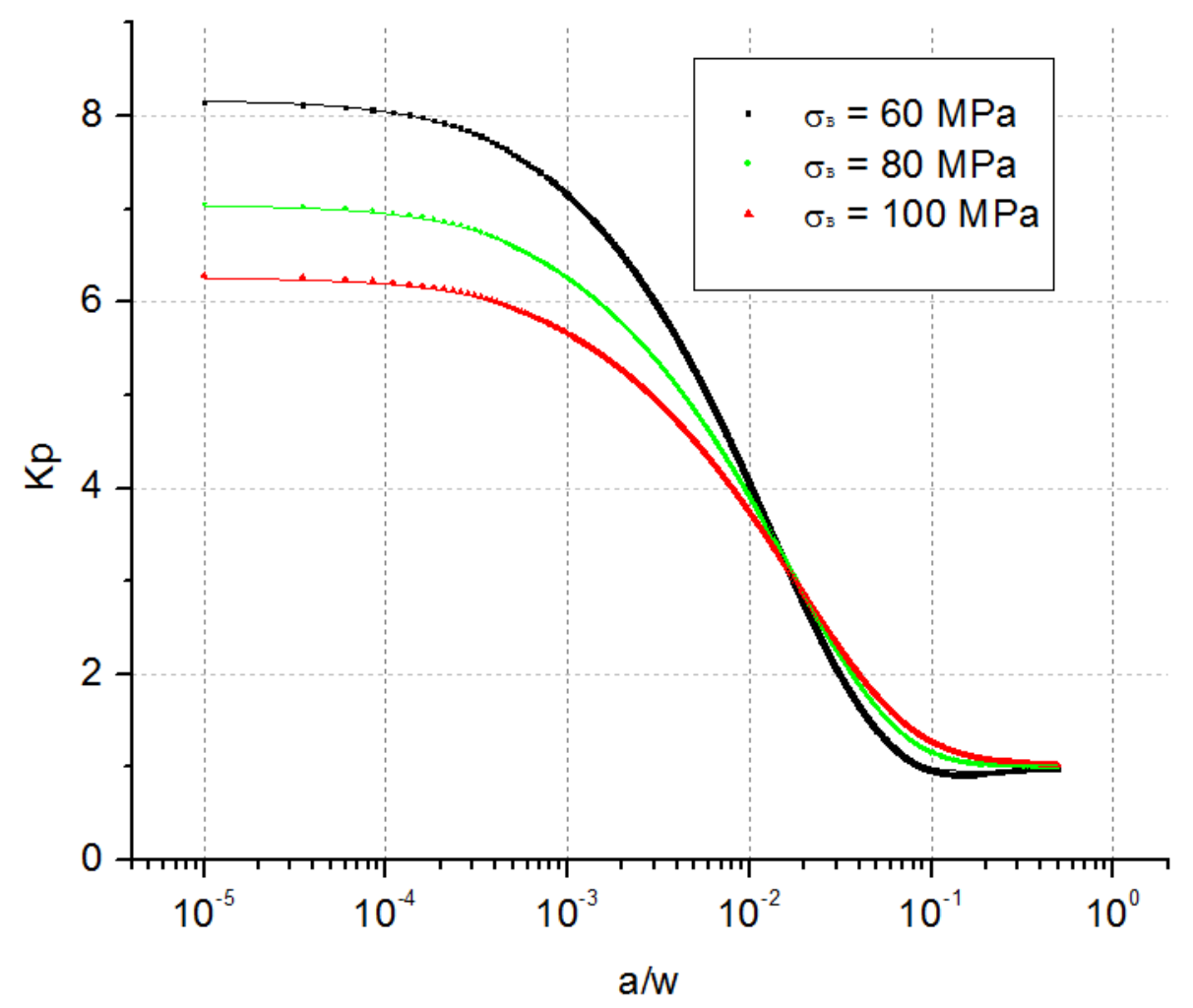

Figura 208 - Alumínio - $\mu$ 0,90

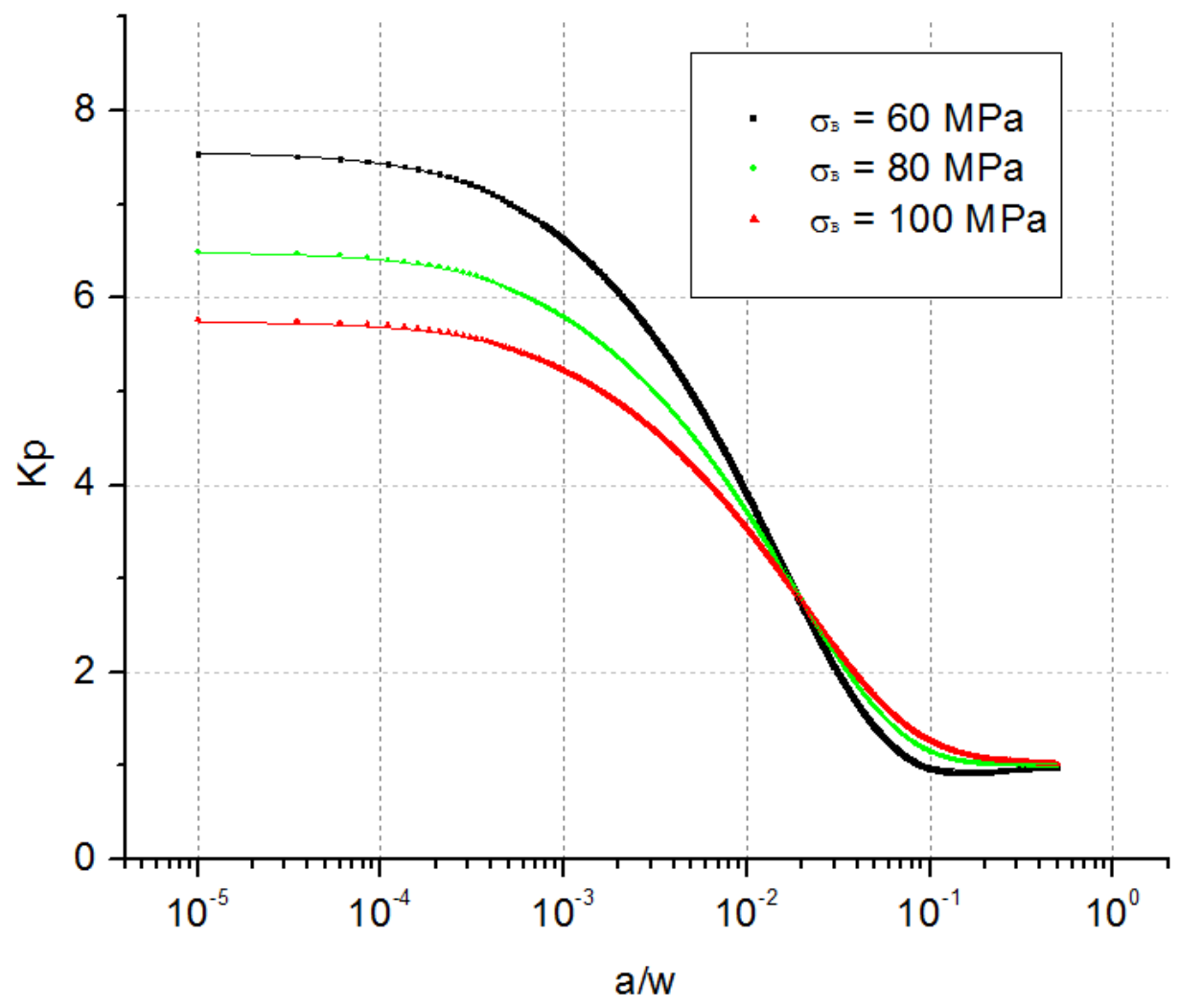

Figura 209 - Alumínio - $\mu$ 0,75 


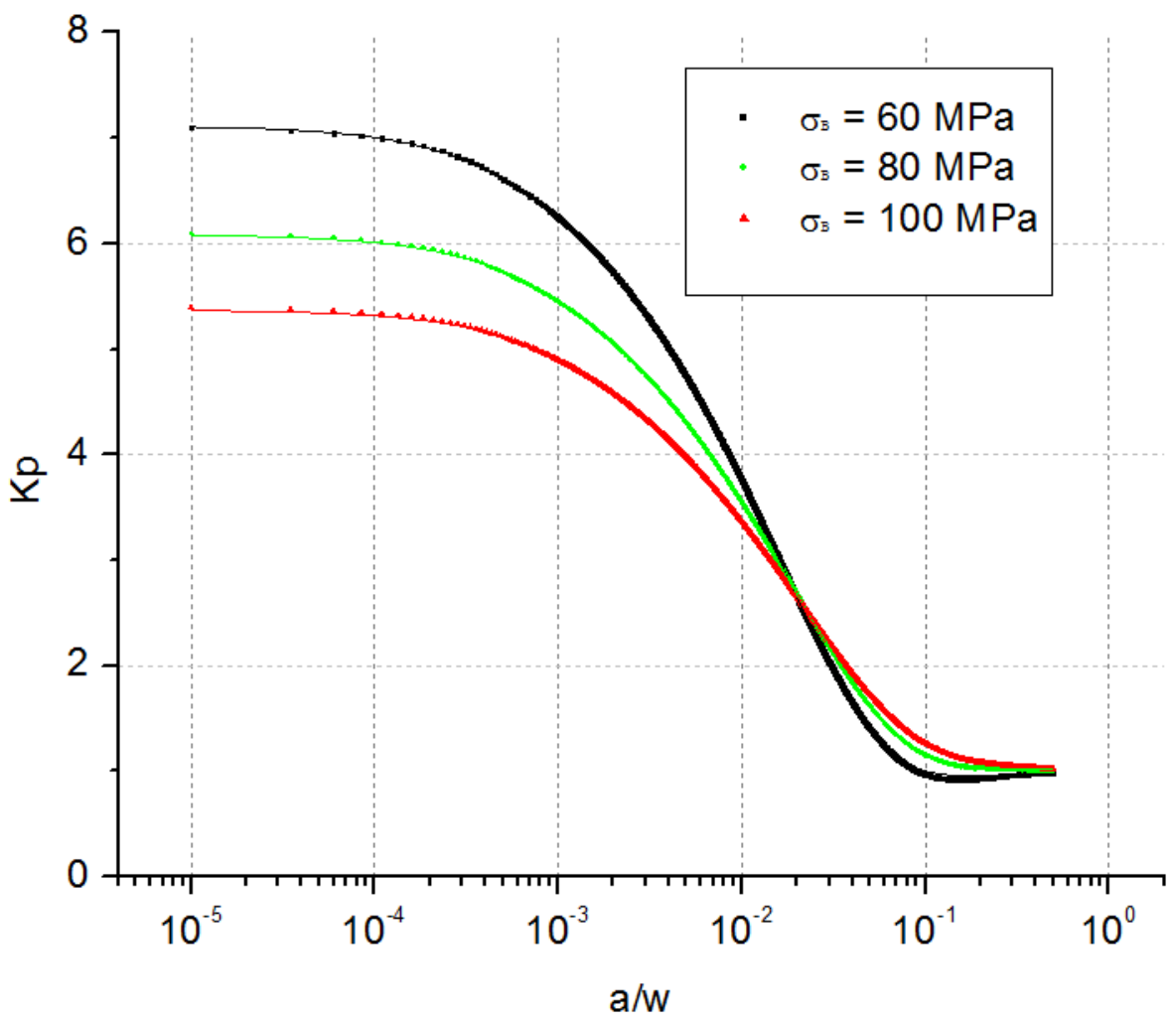

Figura 210 - Alumínio - $\mu$ 0,65

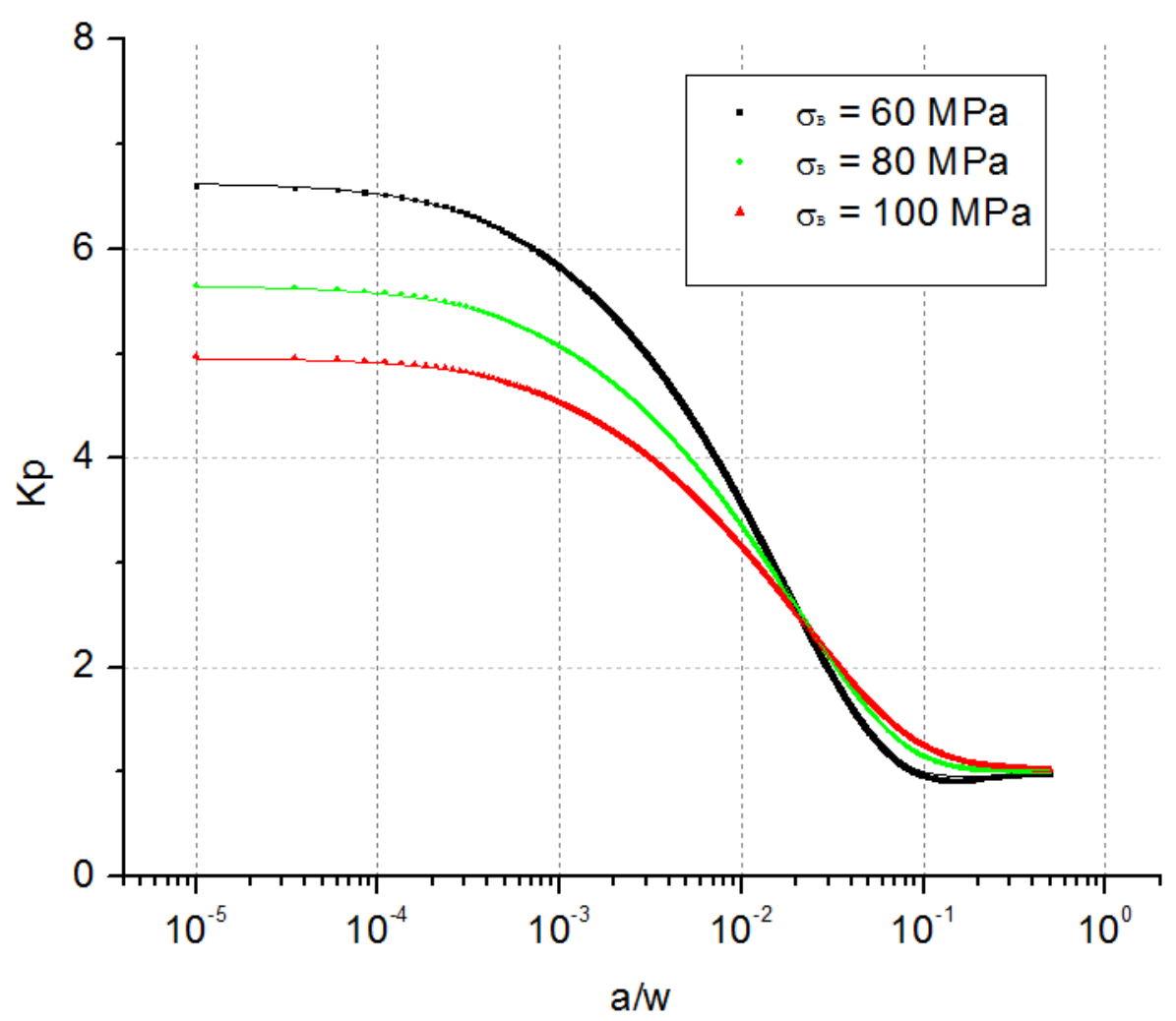

Figura 211 - Alumínio - $\mu$ 0,55 


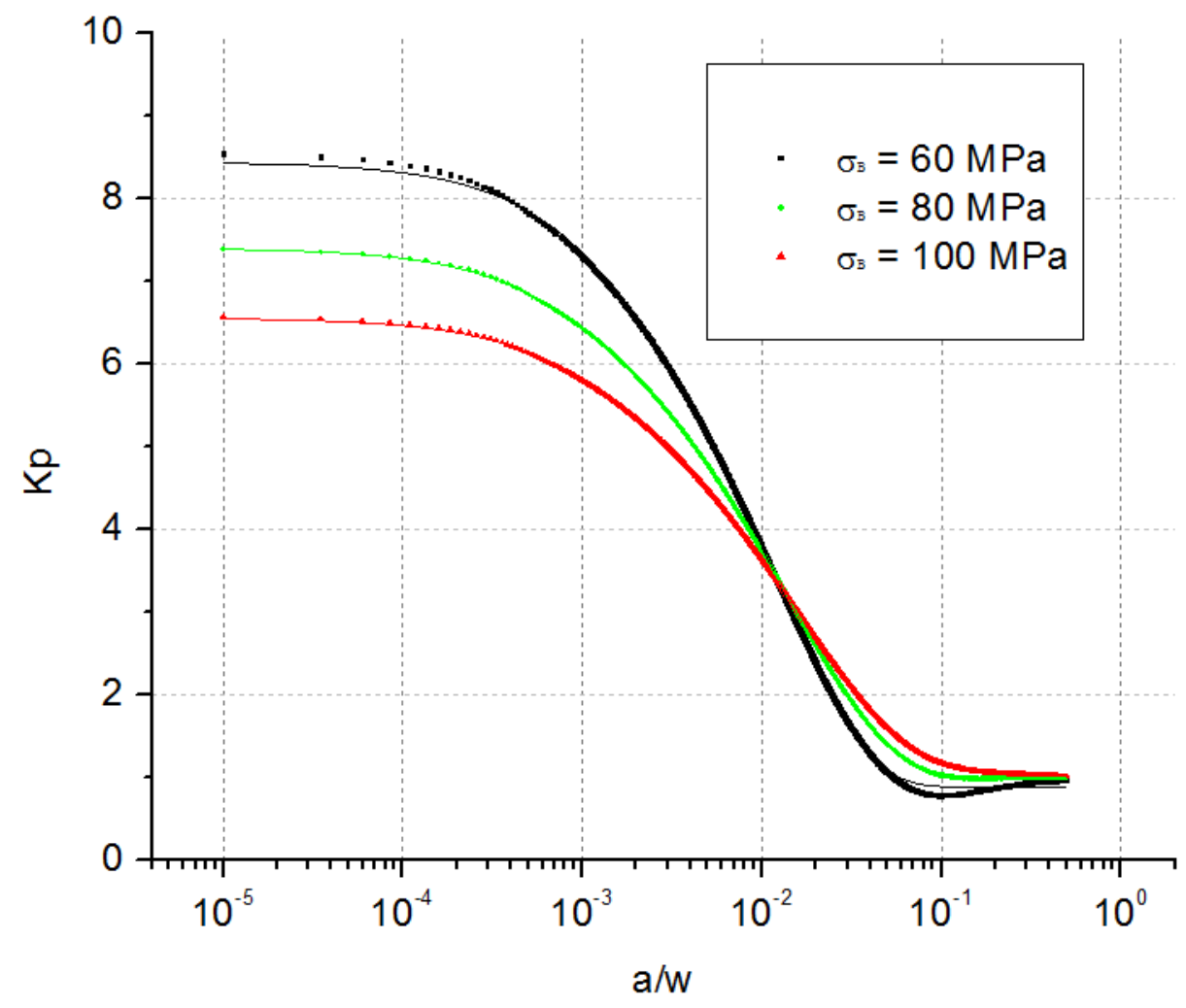

Figura 212 - Titânio $-\sigma_{\text {bulk }}=100 \mathrm{MPa}$

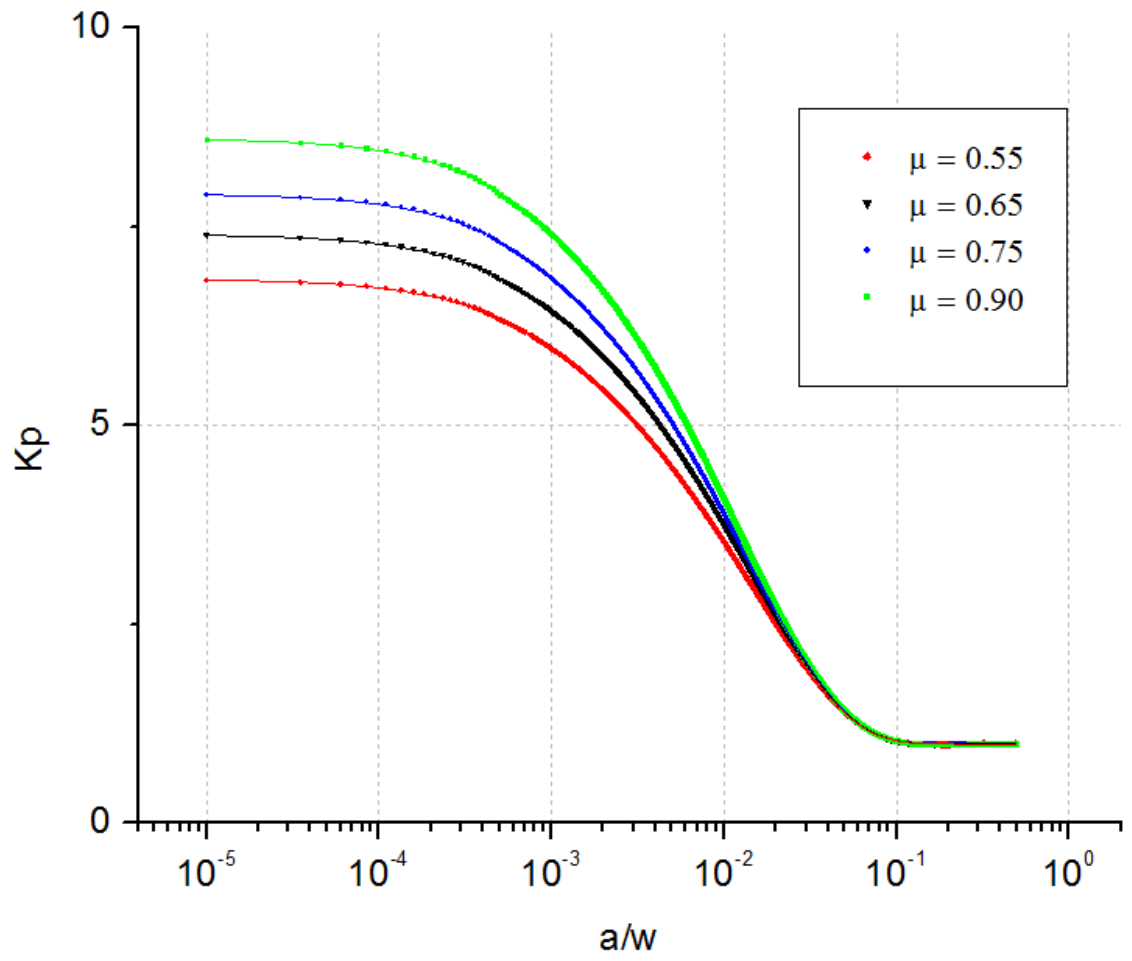

Figura $213-$ Titânio $-\boldsymbol{\sigma}_{\text {bulk }}=80 \mathrm{MPa}$ 


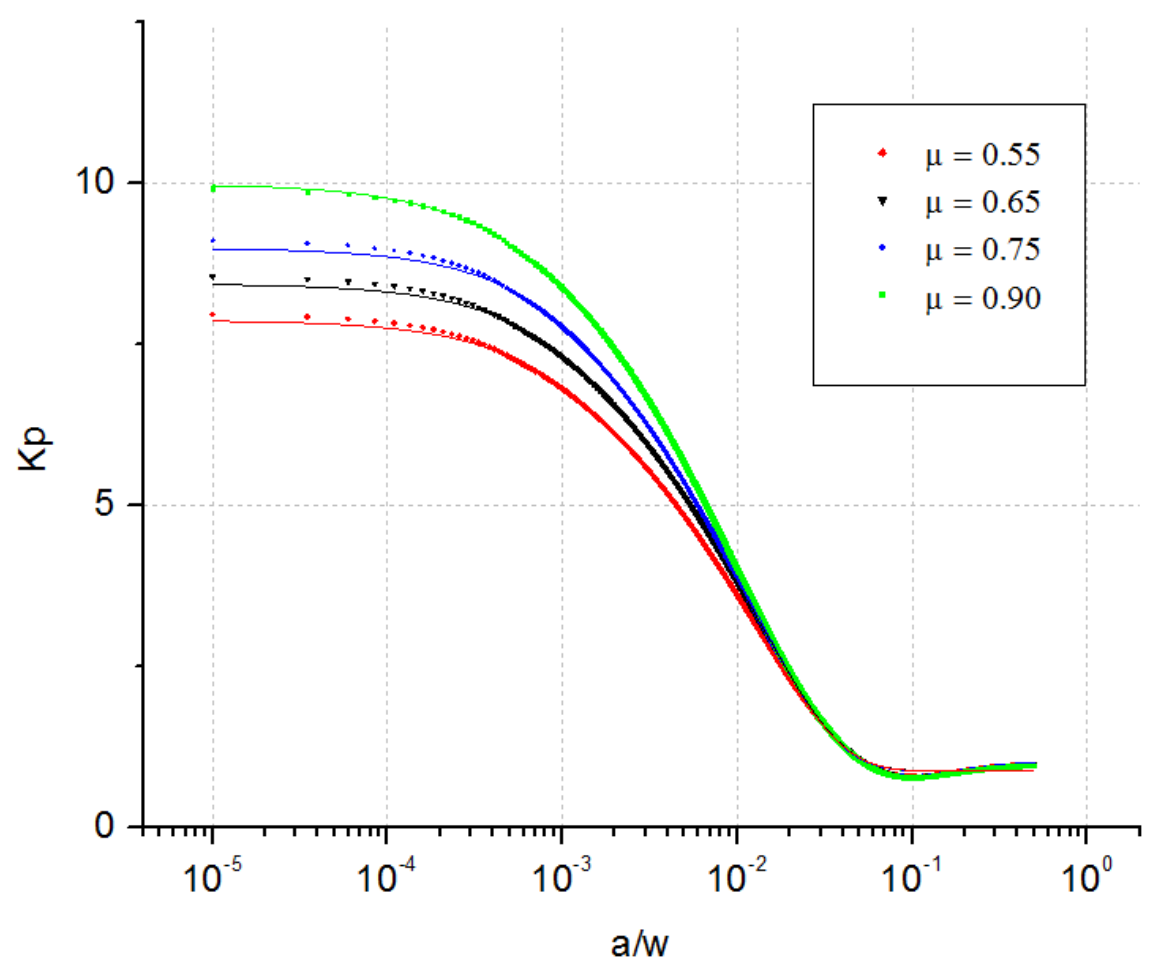

Figura $214-$ Titânio $-\sigma_{\text {bulk }}=60 \mathrm{MPa}$

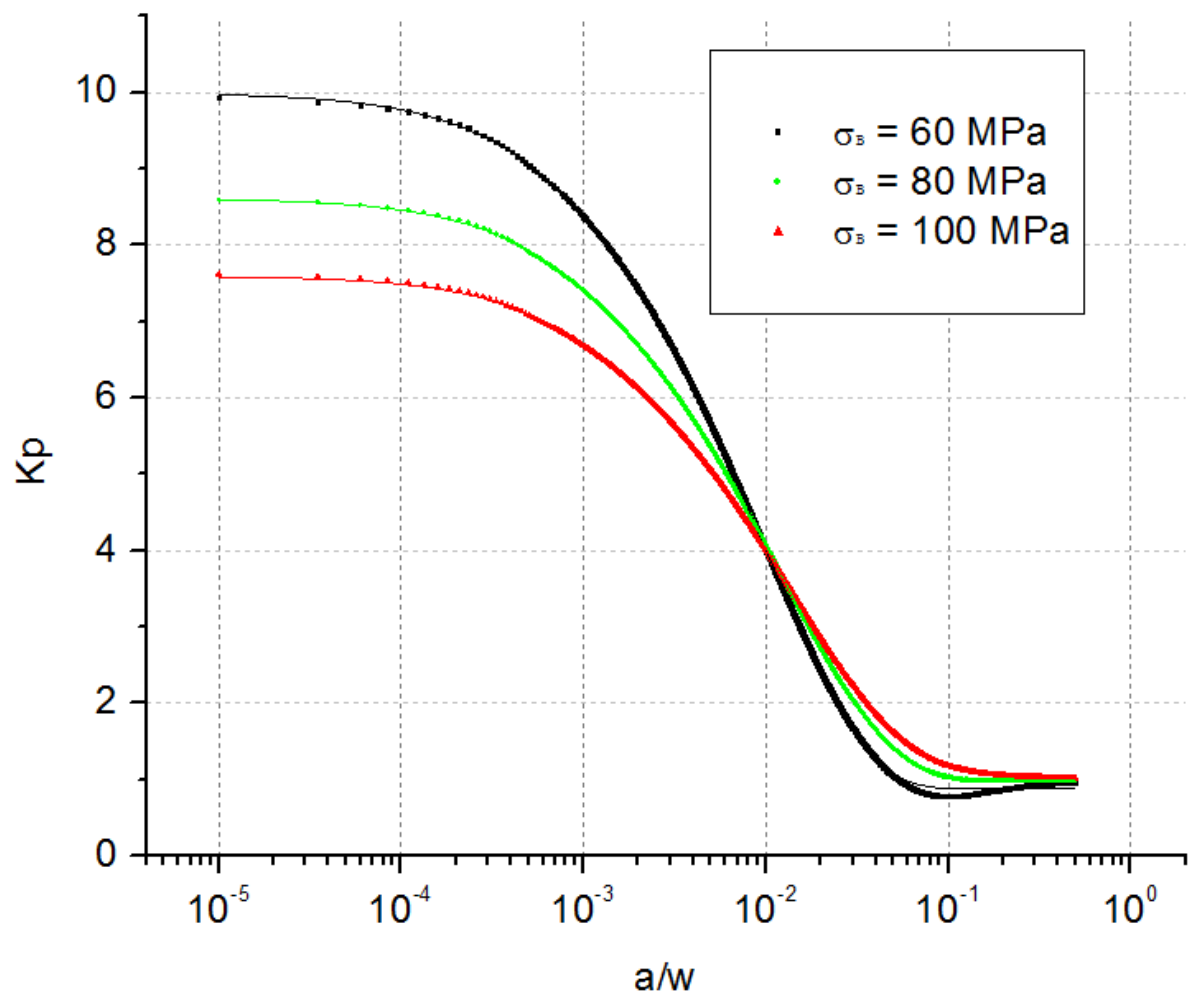

Figura 215 - Titânio - $\mu$ 0,90 


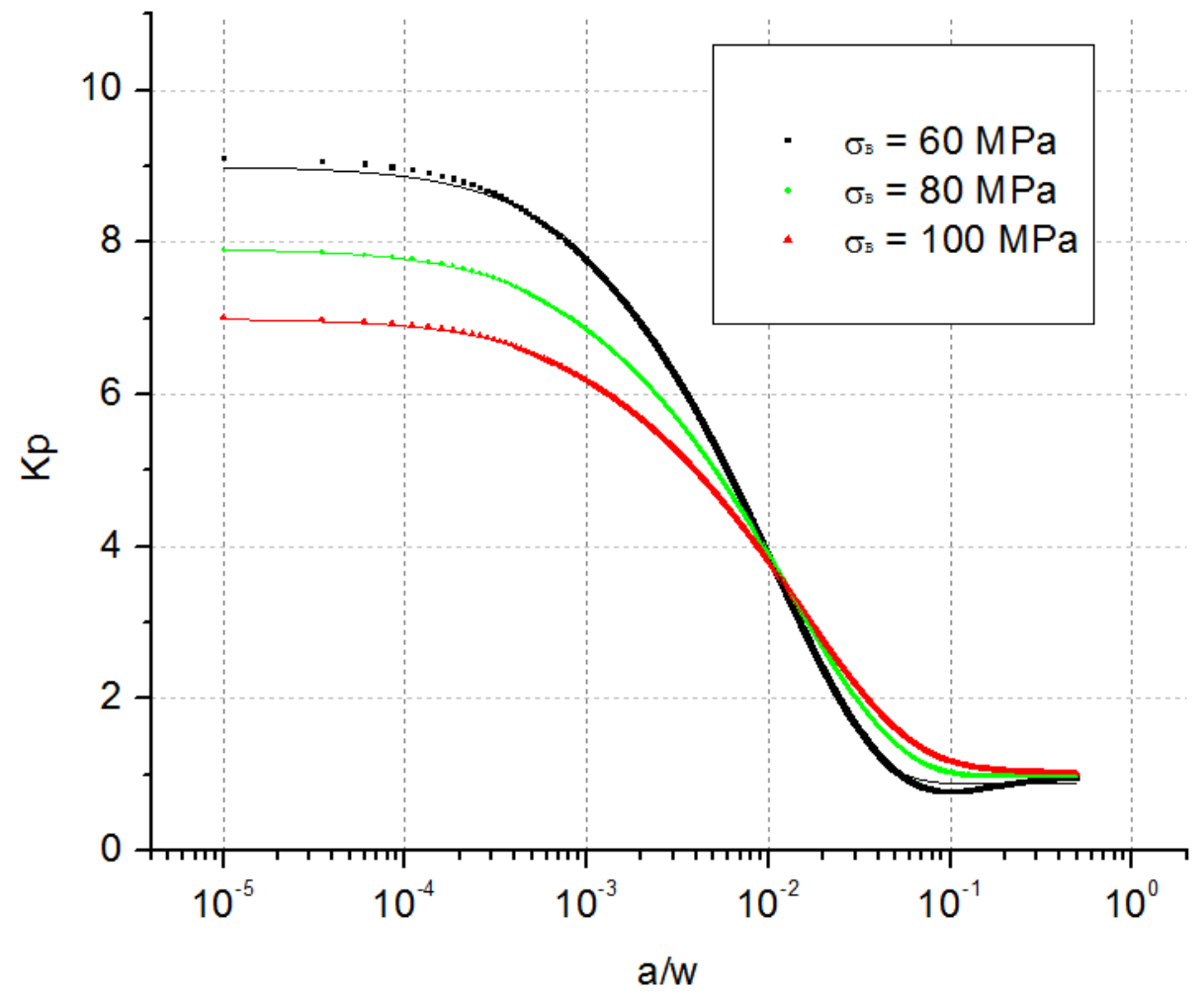

Figura 216 - Titânio - $\mu$ 0,75

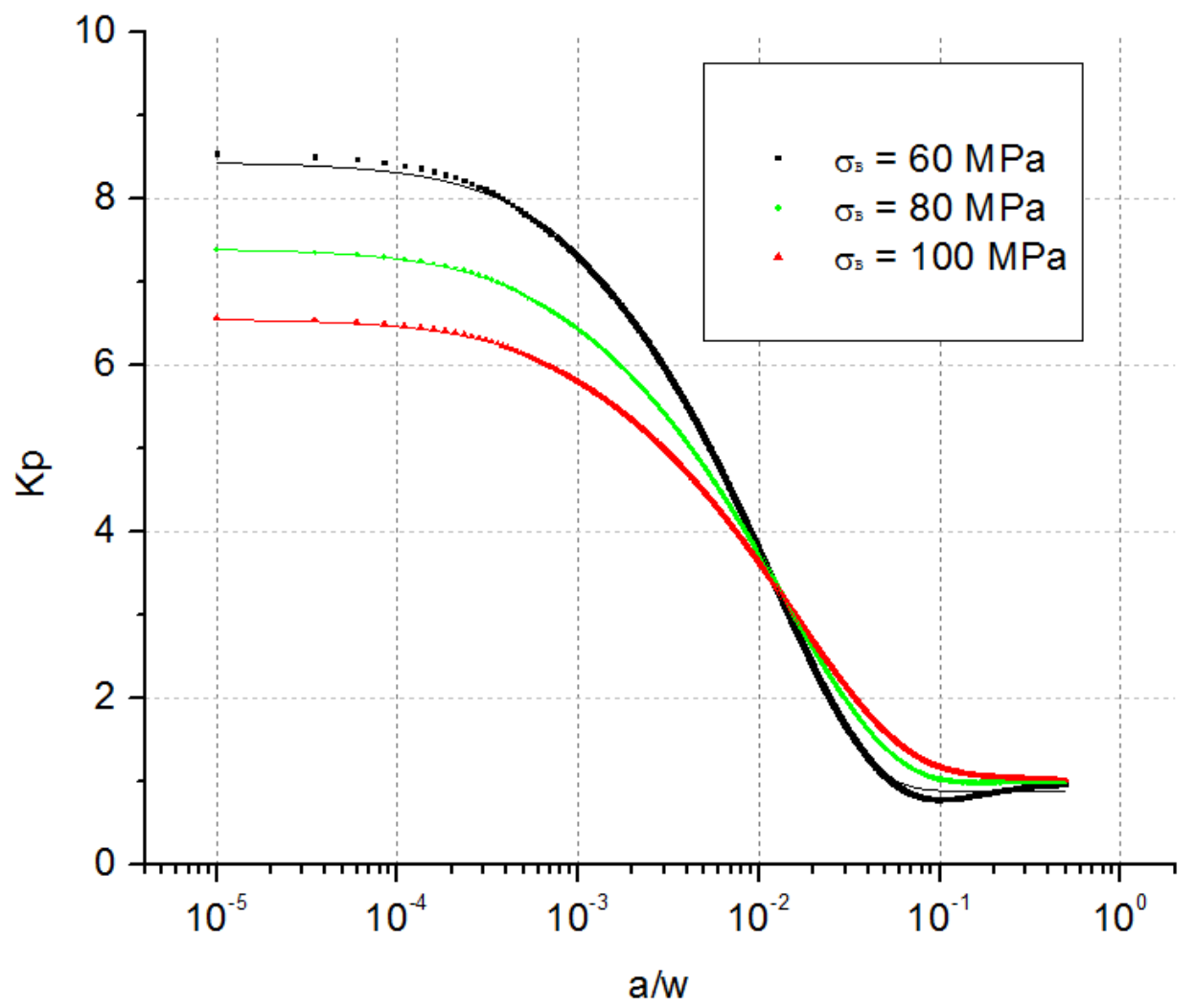

Figura 217 - Titânio - $\mu$ 0,65 


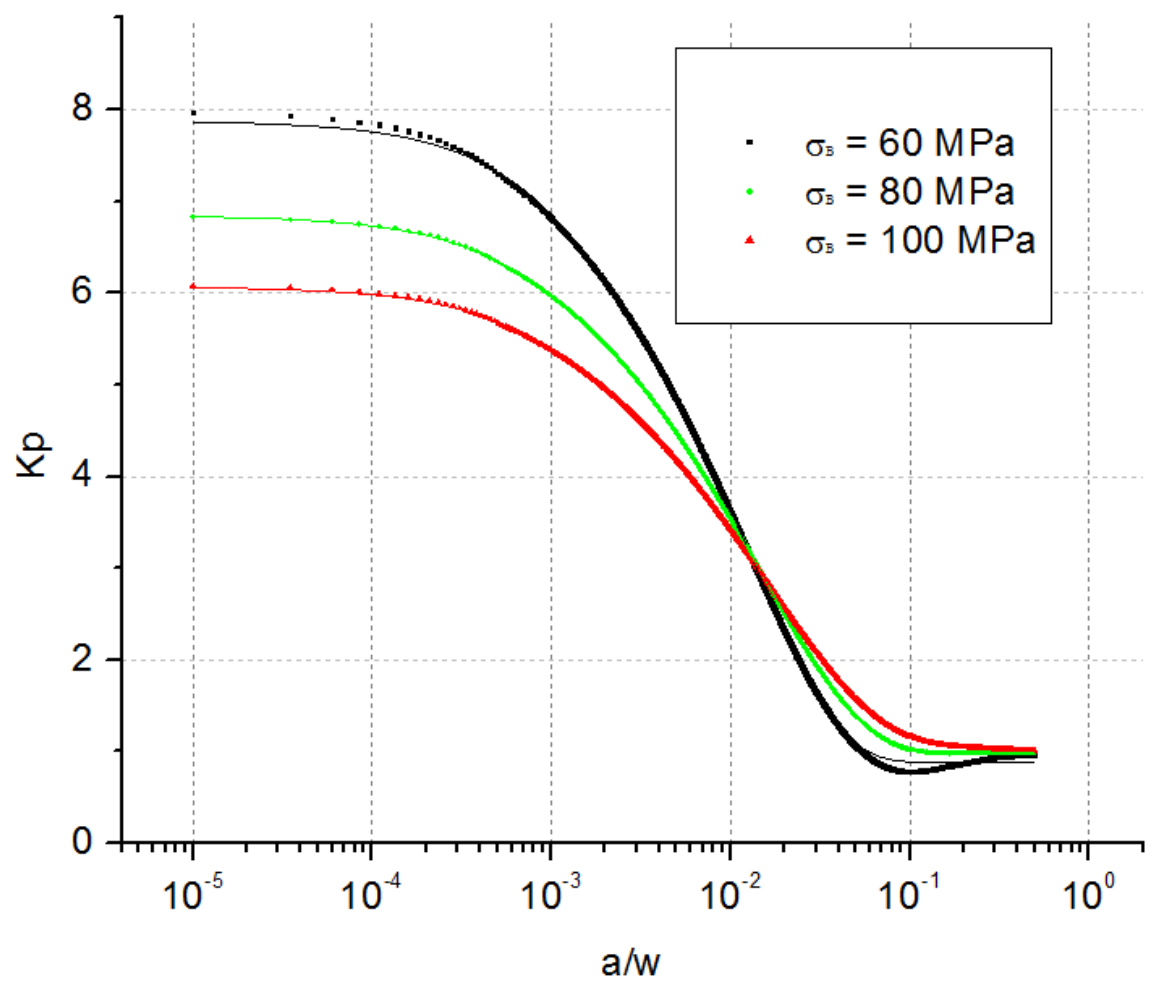

Figura 218 - Titânio - $\mu$ 0,55 


\section{ANEXO II - EQUAÇÕES DE $\boldsymbol{K}_{p}$}

As equações de $K_{p}$ foram ajustadas no software Origin por meio de ajuste não linear de curva, no formato ExpDec3. As equações encontradas foram escritas na forma:

$$
\begin{aligned}
& \mathrm{K}_{\mathrm{p}}=A 1^{-\left(\frac{\left(\frac{a}{w}\right)}{t 1}\right)}+A 2^{-\left(\frac{\left(\frac{a}{w}\right)}{t 2}\right)}+A 3^{-\left(\frac{\left(\frac{a}{w}\right)}{t 3}\right)}+\mathrm{K}_{\mathrm{p} 0} \\
& \text { Aço }-\sigma_{\text {bulk }}=60 \mathrm{MPa}
\end{aligned}
$$

\begin{tabular}{|c|c|c|}
\hline & Variable & Value \\
\hline \multirow[t]{7}{*}{$\mu 0.55$} & $K_{p 0}$ & 0,80057 \\
\hline & A1 & 3,45558 \\
\hline & t1 & 0,01182 \\
\hline & $A 2$ & 2,97827 \\
\hline & t2 & 0,01182 \\
\hline & A3 & 2,05065 \\
\hline & $\mathrm{t} 3$ & 0,00164 \\
\hline \multirow[t]{7}{*}{$\mu 0.65$} & $K_{p 0}$ & 0,80385 \\
\hline & A1 & 2,31799 \\
\hline & $\mathrm{t} 1$ & 0,00169 \\
\hline & $\mathrm{A} 2$ & 3,3582 \\
\hline & $\mathrm{t} 2$ & 0,01154 \\
\hline & A3 & 3,56465 \\
\hline & $\mathrm{t} 3$ & 0,01154 \\
\hline \multirow[t]{7}{*}{$\mu 0.75$} & $K_{p 0}$ & 0,8066 \\
\hline & A1 & 3,67544 \\
\hline & $\mathrm{t} 1$ & 0,01132 \\
\hline & $\mathrm{A} 2$ & 3,6241 \\
\hline & $\mathrm{t} 2$ & 0,01131 \\
\hline & A3 & 2,62644 \\
\hline & $\mathrm{t} 3$ & 0,00176 \\
\hline \multirow[t]{7}{*}{$\mu 0.90$} & $K_{p 0}$ & 0,80968 \\
\hline & $\mathrm{A} 1$ & 3,15418 \\
\hline & $\mathrm{t} 1$ & 0,00186 \\
\hline & $\mathrm{A} 2$ & 2,50623 \\
\hline & $\mathrm{t} 2$ & 0,01108 \\
\hline & A3 & 5,19824 \\
\hline & t3 & 0,01108 \\
\hline
\end{tabular}




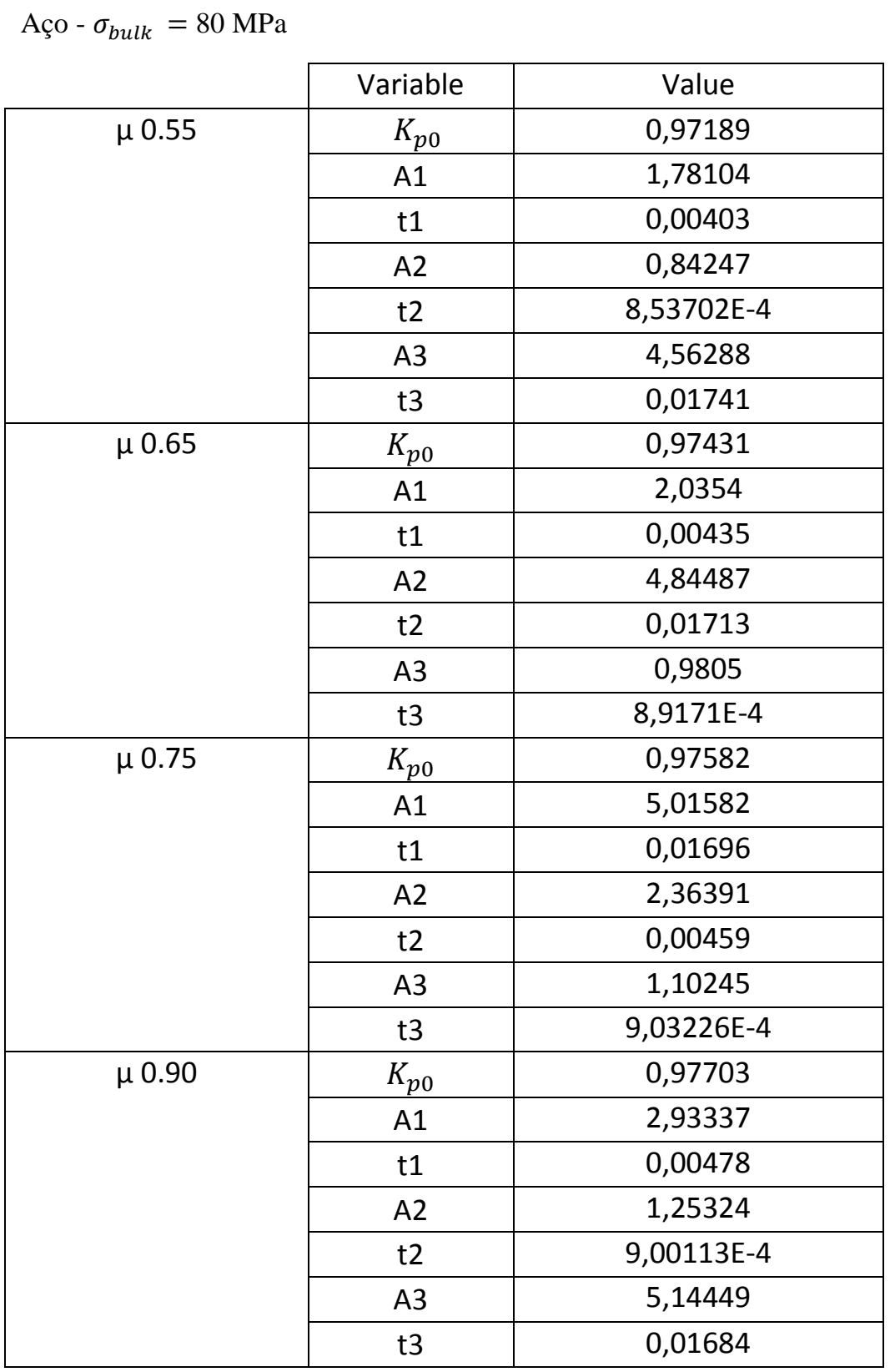




\begin{tabular}{|c|c|c|}
\hline \multicolumn{3}{|l|}{ Aço $-\sigma_{\text {bulk }}=100 \mathrm{MPa}$} \\
\hline & Variable & Value \\
\hline \multirow{7}{*}{$\mu 0.55$} & $K_{p 0}$ & 1,02762 \\
\hline & A1 & 3,04794 \\
\hline & t1 & 0,02666 \\
\hline & $\mathrm{A} 2$ & 2,12894 \\
\hline & t2 & 0,00746 \\
\hline & A3 & 1,04404 \\
\hline & t3 & 0,00127 \\
\hline \multirow{7}{*}{$\mu 0.65$} & $K_{p 0}$ & 1,03035 \\
\hline & A1 & 3,11785 \\
\hline & $\mathrm{t} 1$ & 0,02682 \\
\hline & $\mathrm{A} 2$ & 2,54259 \\
\hline & t2 & 0,00802 \\
\hline & A3 & 1,17054 \\
\hline & t3 & 0,00131 \\
\hline \multirow{7}{*}{$\mu 0.75$} & $K_{p 0}$ & 1,03237 \\
\hline & A1 & 3,15796 \\
\hline & $\mathrm{t} 1$ & 0,02678 \\
\hline & $\mathrm{A} 2$ & 2,95865 \\
\hline & t2 & 0,00819 \\
\hline & A3 & 1,2683 \\
\hline & t3 & 0,0013 \\
\hline \multirow{7}{*}{$\mu 0.90$} & $K_{p 0}$ & 1,03396 \\
\hline & A1 & 1,38952 \\
\hline & $\mathrm{t} 1$ & 0,00127 \\
\hline & $\mathrm{A} 2$ & 3,53281 \\
\hline & t2 & 0,00808 \\
\hline & A3 & 3,2154 \\
\hline & t3 & 0,02664 \\
\hline
\end{tabular}


Alumínio $-\sigma_{\text {bulk }}=60 \mathrm{MPa}$

\begin{tabular}{|c|c|c|}
\hline & Variable & Value \\
\hline \multirow{7}{*}{$\mu 0.55$} & $K_{p 0}$ & 0,95668 \\
\hline & $\mathrm{A} 1$ & 4,36107 \\
\hline & $\mathrm{t} 1$ & 0,02166 \\
\hline & $\mathrm{A} 2$ & 2,06476 \\
\hline & t2 & 0,00553 \\
\hline & A3 & 0,78989 \\
\hline & t3 & 0,00108 \\
\hline \multirow{7}{*}{$\mu 0.65$} & $K_{p 0}$ & 0,95497 \\
\hline & $\mathrm{A} 1$ & 4,20847 \\
\hline & $\mathrm{t} 1$ & 0,02234 \\
\hline & $\mathrm{A} 2$ & 1,66238 \\
\hline & $\mathrm{t} 2$ & 0,00536 \\
\hline & A3 & 0,72815 \\
\hline & $\mathrm{t} 3$ & $9,98 \mathrm{E}-04$ \\
\hline \multirow{7}{*}{$\mu 0.75$} & $K_{p 0}$ & 0,95381 \\
\hline & $\mathrm{A} 1$ & 1,45383 \\
\hline & $\mathrm{t} 1$ & 0,00502 \\
\hline & $\mathrm{A} 2$ & 0,65739 \\
\hline & t2 & $9,65 \mathrm{E}-04$ \\
\hline & A3 & 4,0507 \\
\hline & t3 & 0,02255 \\
\hline \multirow{7}{*}{$\mu 0.90$} & $K_{p 0}$ & 0,95564 \\
\hline & A1 & 1,28087 \\
\hline & $\mathrm{t} 1$ & 0,00454 \\
\hline & $\mathrm{A} 2$ & 0,56646 \\
\hline & $\mathrm{t} 2$ & $8,94 \mathrm{E}-04$ \\
\hline & A3 & 3,82767 \\
\hline & t3 & 0,02267 \\
\hline
\end{tabular}


Alumínio $-\sigma_{\text {bulk }}=80 \mathrm{MPa}$

\begin{tabular}{|c|c|c|}
\hline & Variable & Value \\
\hline \multirow{7}{*}{$\mu 0.55$} & $K_{p 0}$ & 1,02325 \\
\hline & $\mathrm{A} 1$ & 2,12661 \\
\hline & $\mathrm{t} 1$ & 0,0088 \\
\hline & $A 2$ & 0,86358 \\
\hline & $\mathrm{t} 2$ & 0,00137 \\
\hline & $\mathrm{A3}$ & 3,03016 \\
\hline & t3 & 0,03156 \\
\hline \multirow{7}{*}{$\mu 0.65$} & $K_{p 0}$ & 1,02206 \\
\hline & $\mathrm{A} 1$ & 0,77418 \\
\hline & $\mathrm{t} 1$ & 0,00139 \\
\hline & $\mathrm{A} 2$ & 1,75216 \\
\hline & t2 & 0,00861 \\
\hline & A3 & 2,9401 \\
\hline & $\mathrm{t} 3$ & 0,03181 \\
\hline \multirow{7}{*}{$\mu 0.75$} & $K_{p 0}$ & 1,02206 \\
\hline & $\mathrm{A} 1$ & 0,77418 \\
\hline & $\mathrm{t} 1$ & 0,00139 \\
\hline & $\mathrm{A} 2$ & 1,75216 \\
\hline & $\mathrm{t} 2$ & 0,00861 \\
\hline & A3 & 2,9401 \\
\hline & t3 & 0,03181 \\
\hline \multirow{7}{*}{$\mu 0.90$} & $K_{p 0}$ & 1,02086 \\
\hline & $\mathrm{A} 1$ & 1,52008 \\
\hline & $\mathrm{t} 1$ & 0,00829 \\
\hline & $\mathrm{A} 2$ & 2,83924 \\
\hline & $\mathrm{t} 2$ & 0,0321 \\
\hline & A3 & 0,70446 \\
\hline & t3 & 0,00139 \\
\hline
\end{tabular}


Alumínio $-\sigma_{\text {bulk }}=100 \mathrm{MPa}$

\begin{tabular}{|c|c|c|}
\hline & Variable & Value \\
\hline \multirow{7}{*}{$\mu 0.55$} & $K_{p 0}$ & 1,04403 \\
\hline & $\mathrm{A} 1$ & 2,23321 \\
\hline & t1 & 0,04359 \\
\hline & $\mathrm{A} 2$ & 2,14789 \\
\hline & $\mathrm{t} 2$ & 0,01206 \\
\hline & A3 & 0,83533 \\
\hline & t3 & 0,0018 \\
\hline \multirow{7}{*}{$\mu 0.65$} & $K_{p 0}$ & 1,0424 \\
\hline & A1 & 2,15243 \\
\hline & $\mathrm{t} 1$ & 0,04421 \\
\hline & $\mathrm{A} 2$ & 0,7498 \\
\hline & $\mathrm{t} 2$ & 0,00187 \\
\hline & A3 & 1,80042 \\
\hline & $\mathrm{t} 3$ & 0,01213 \\
\hline \multirow{7}{*}{$\mu 0.75$} & $K_{p 0}$ & 1,04387 \\
\hline & $\mathrm{A} 1$ & 2,11648 \\
\hline & $\mathrm{t} 1$ & 0,04384 \\
\hline & $\mathrm{A} 2$ & 0,6744 \\
\hline & t2 & 0,00184 \\
\hline & A3 & 1,5351 \\
\hline & t3 & 0,01155 \\
\hline \multirow{7}{*}{$\mu 0.90$} & $K_{p 0}$ & 1,03815 \\
\hline & A1 & 1,35534 \\
\hline & $\mathrm{t} 1$ & 0,01132 \\
\hline & $\mathrm{A} 2$ & 0,60815 \\
\hline & $\mathrm{t} 2$ & 0,00186 \\
\hline & A3 & 1,95588 \\
\hline & t3 & 0,04519 \\
\hline
\end{tabular}


Titânio- $\sigma_{\text {bulk }}=60 \mathrm{Mpa}$

\begin{tabular}{|c|c|c|}
\hline & Variable & Value \\
\hline \multirow{7}{*}{$\mu 0.55$} & $K_{p 0}$ & 0,87799 \\
\hline & $\mathrm{A} 1$ & 2,39166 \\
\hline & t1 & 0,00343 \\
\hline & $\mathrm{A} 2$ & 5,8945 \\
\hline & $\mathrm{t} 2$ & 0,01486 \\
\hline & A3 & 0,82885 \\
\hline & t3 & $7,13804 \mathrm{E}-4$ \\
\hline \multirow{7}{*}{$\mu 0.65$} & $K_{p 0}$ & 0,88242 \\
\hline & $\mathrm{A} 1$ & 2,18723 \\
\hline & $\mathrm{t} 1$ & 0,00224 \\
\hline & $\mathrm{A} 2$ & 2,99415 \\
\hline & $\mathrm{t} 2$ & 0,01454 \\
\hline & A3 & 2,93809 \\
\hline & t3 & 0,01454 \\
\hline \multirow{7}{*}{$\mu 0.75$} & $K_{p 0}$ & 0,88483 \\
\hline & A1 & 2,81259 \\
\hline & $\mathrm{t} 1$ & 0,01507 \\
\hline & $\mathrm{A} 2$ & 2,81271 \\
\hline & $\mathrm{t} 2$ & 0,01507 \\
\hline & A3 & 1,93458 \\
\hline & $\mathrm{t} 3$ & 0,00211 \\
\hline \multirow{7}{*}{$\mu 0.90$} & $K_{p 0}$ & 0,88159 \\
\hline & $\mathrm{A} 1$ & 1,77328 \\
\hline & $\mathrm{t} 1$ & 0,00204 \\
\hline & $\mathrm{A} 2$ & 2,72187 \\
\hline & $\mathrm{t} 2$ & 0,01543 \\
\hline & A3 & 2,49846 \\
\hline & t3 & 0,01543 \\
\hline
\end{tabular}


Titânio $-\sigma_{\text {bulk }}=80 \mathrm{Mpa}$

\begin{tabular}{|c|c|c|}
\hline & Variable & Value \\
\hline \multirow{7}{*}{$\mu 0.55$} & $K_{p 0}$ & 0,99603 \\
\hline & A1 & 2,51461 \\
\hline & $\mathrm{t} 1$ & 0,00631 \\
\hline & $\mathrm{A} 2$ & 4,03025 \\
\hline & $\mathrm{t} 2$ & 0,02199 \\
\hline & A3 & 1,07097 \\
\hline & t3 & 0,00109 \\
\hline \multirow{7}{*}{$\mu 0.65$} & $K_{p 0}$ & 0,99491 \\
\hline & A1 & 2,0404 \\
\hline & $\mathrm{t} 1$ & 0,00611 \\
\hline & $\mathrm{A} 2$ & 0,95274 \\
\hline & t2 & 0,0011 \\
\hline & A3 & 3,92722 \\
\hline & t3 & 0,02213 \\
\hline \multirow{7}{*}{$\mu 0.75$} & $K_{p 0}$ & 0,99617 \\
\hline & A1 & 3,81197 \\
\hline & $\mathrm{t} 1$ & 0,02223 \\
\hline & $\mathrm{A} 2$ & 1,74468 \\
\hline & t2 & 0,00577 \\
\hline & A3 & 0,85068 \\
\hline & t3 & 0,00109 \\
\hline \multirow{7}{*}{$\mu 0.90$} & $K_{p 0}$ & 0,99162 \\
\hline & A1 & 3,57289 \\
\hline & $\mathrm{t} 1$ & 0,02265 \\
\hline & $\mathrm{A} 2$ & 1,52793 \\
\hline & $\mathrm{t} 2$ & 0,00547 \\
\hline & A3 & 0,7497 \\
\hline & t3 & 0,00106 \\
\hline
\end{tabular}


Titânio $-\sigma_{\text {bulk }}=100 \mathrm{Mpa}$

\begin{tabular}{|c|c|c|}
\hline & \\
\hline & Variable & Value \\
\hline \multirow{7}{*}{$\mu 0.55$} & $K_{p 0}$ & 1,03609 \\
\hline & A1 & 1,05884 \\
\hline & $\mathrm{t} 1$ & 0,00144 \\
\hline & $\mathrm{A} 2$ & 2,76371 \\
\hline & $\mathrm{t} 2$ & 0,00956 \\
\hline & A3 & 2,73935 \\
\hline & t3 & 0,03269 \\
\hline \multirow{7}{*}{$\mu 0.65$} & $K_{p 0}$ & 1,03466 \\
\hline & $\mathrm{A} 1$ & 2,30723 \\
\hline & $\mathrm{t} 1$ & 0,00954 \\
\hline & $\mathrm{A} 2$ & 2,68424 \\
\hline & $\mathrm{t} 2$ & 0,03286 \\
\hline & A3 & 0,9693 \\
\hline & $\mathrm{t} 3$ & 0,00147 \\
\hline \multirow{7}{*}{$\mu 0.75$} & $K_{p 0}$ & 1,03531 \\
\hline & A1 & 0,89272 \\
\hline & $\mathrm{t} 1$ & 0,00144 \\
\hline & $\mathrm{A} 2$ & 1,97717 \\
\hline & $\mathrm{t} 2$ & 0,00915 \\
\hline & A3 & 2,65228 \\
\hline & $\mathrm{t3}$ & 0,03273 \\
\hline \multirow{7}{*}{$\mu 0.90$} & $K_{p 0}$ & 1,03531 \\
\hline & A1 & 1,97717 \\
\hline & $\mathrm{t} 1$ & 0,00915 \\
\hline & $\mathrm{A} 2$ & 2,65228 \\
\hline & $\mathrm{t} 2$ & 0,03273 \\
\hline & A3 & 0,89272 \\
\hline & t3 & 0,00144 \\
\hline
\end{tabular}


Aço $-\sigma_{\text {bulk }}=100 \mathrm{MPa} . \mu=0,75$. Variação de raio do pad

\begin{tabular}{|c|c|c|}
\hline & \multirow[b]{2}{*}{ Variable } & \multirow[b]{2}{*}{ Value } \\
\hline & & \\
\hline \multirow{7}{*}{$\mathrm{r}=20 \mathrm{~mm}$} & $K_{p 0}$ & 1,01237 \\
\hline & A1 & 4,9114 \\
\hline & $\mathrm{t} 1$ & 0,01593 \\
\hline & $\mathrm{A} 2$ & 4,36714 \\
\hline & $\mathrm{t} 2$ & 0,00542 \\
\hline & A3 & 1,94421 \\
\hline & t3 & 0,00102 \\
\hline \multirow{7}{*}{$\mathrm{r}=30 \mathrm{~mm}$} & $K_{p 0}$ & 1,02058 \\
\hline & A1 & 3,74832 \\
\hline & $\mathrm{t} 1$ & 0,00664 \\
\hline & $\mathrm{A} 2$ & 1,63779 \\
\hline & $\mathrm{t} 2$ & 0,00113 \\
\hline & A3 & 3,94756 \\
\hline & t3 & 0,02032 \\
\hline \multirow{7}{*}{$\mathrm{r}=40 \mathrm{~mm}$} & $K_{p 0}$ & 1,02662 \\
\hline & A1 & 3,3405 \\
\hline & t1 & 0,0076 \\
\hline & $\mathrm{A} 2$ & 1,43242 \\
\hline & t2 & 0,00124 \\
\hline & A3 & 3,41195 \\
\hline & t3 & 0,02407 \\
\hline \multirow{7}{*}{$\mathrm{r}=50 \mathrm{~mm}$} & $K_{p 0}$ & 1,03237 \\
\hline & $\mathrm{A} 1$ & 2,95865 \\
\hline & $\mathrm{t} 1$ & 0,00819 \\
\hline & $\mathrm{A} 2$ & 3,15796 \\
\hline & $\mathrm{t} 2$ & 0,02678 \\
\hline & A3 & 1,2683 \\
\hline & t3 & 0,0013 \\
\hline \multirow{7}{*}{$\mathrm{r}=60 \mathrm{~mm}$} & $K_{p 0}$ & 1,03605 \\
\hline & A1 & 2,63522 \\
\hline & $\mathrm{t} 1$ & 0,00864 \\
\hline & $\mathrm{A} 2$ & 3,00311 \\
\hline & $\mathrm{t} 2$ & 0,02932 \\
\hline & A3 & 1,14545 \\
\hline & t3 & 0,00126 \\
\hline \multirow{7}{*}{$\mathrm{r}=70 \mathrm{~mm}$} & $K_{p 0}$ & 1,03455 \\
\hline & A1 & 2,49914 \\
\hline & $\mathrm{t} 1$ & 0,00945 \\
\hline & $A 2$ & 1,04062 \\
\hline & $\mathrm{t} 2$ & 0,00146 \\
\hline & A3 & 2,73988 \\
\hline & t3 & 0,03216 \\
\hline
\end{tabular}


